A Research Report for

Rockwell Hanford Operations

\title{
UNSAT-H Version 1.0: \\ Unsaturated Flow Code \\ Documentation and \\ Applications for the \\ Hanford Site
}

M. J. Fayer
G. W. Gee
T. L. Jones

August 1986

Prepared for the U.S. Department of Energy under Contract DE-AC06-76RLO 1830

Pacific Northwest Laboratory Operated for the U.S. Department of Energy by Battelle Memorial Institute 


\title{
DISCLAIMER
}

This report was prepared as an account of work sponsored by an agency of the United States Government. Neither the United States Government nor any agency thereof, nor any of their employees, makes any warranty, express or implied, or assumes any legal liability or responsibility for the accuracy, completeness, or usefulness of any information, apparatus, product, or process disclosed, or represents that its use would not infringe privately owned rights. Reference herein to any specific commercial product, process, or service by trade name, trademark, manufacturer, or otherwise, does not necessarily constitute or imply its endorsement, recommendation, or favoring by the United States Government or any agency thereof. The views and opinions of authors expressed herein do not necessarily state or reflect those of the United States Government or any agency thereof.

\author{
PACIFIC NORTHWEST LABORATORY \\ operated by \\ BATTELLE \\ for the \\ UNITED STATES DEPARTMENT OF ENERGY \\ under Contract DE-AC06-76RLO 1830
}

\begin{tabular}{|c|c|}
\hline \multicolumn{2}{|c|}{ Printed in the United Srates of America } \\
\hline \multicolumn{2}{|c|}{ Available from } \\
\hline \multirow{4}{*}{\multicolumn{2}{|c|}{$\begin{array}{l}\text { National Technical Information Service } \\
\text { United States Department of Commerce } \\
5285 \text { Port Royal Road } \\
\text { Springfield, Virginia } 22161\end{array}$}} \\
\hline & \\
\hline & \\
\hline & \\
\hline \multicolumn{2}{|c|}{ NTIS Price Codes } \\
\hline \multicolumn{2}{|c|}{ Microfiche A01 } \\
\hline \multicolumn{2}{|c|}{ Printed Copy } \\
\hline & Price \\
\hline Pages & Codes \\
\hline $001-025$ & 102 \\
\hline $026-050$ & $\mathrm{~A} 03$ \\
\hline $051-075$ & $\mathrm{~A} 04$ \\
\hline $976-100$ & $A 05$ \\
\hline $101-125$ & A06 \\
\hline $126-150$ & A07 \\
\hline $151-175$ & A08 \\
\hline $176-200$ & $A 09$ \\
\hline $201-225$ & A010 \\
\hline $226-250$ & $\wedge 011$ \\
\hline $251-275$ & A012 \\
\hline $276-300$ & A013 \\
\hline
\end{tabular}




\author{
A Research Report for \\ Rockwell Hanford Operations \\ UNSAT-H VERSION 1.0 : \\ UNSATURATED FLOW CODE DOCUMENTATION \\ AND APPLICATIONS FOR THE HANFORD SITE
}

M. J. Fayer
G. W. Gee
T. L. Jones

August 1986

Prepared for

the U.S. Department of Energy

under Contract DE-ACO6-7 6RLO 1830

Pacific Northwest Laboratory

Richland, Washington 99352 


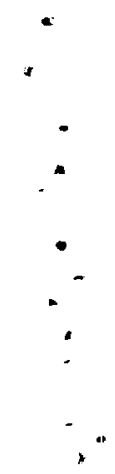

, 


\section{ACKNOWLEDGMENTS}

This work was funded by the U.S. Department of Energy through the Rockwell Hanford Operations Waste Management Program Office and the program "Site Performance Assessment for the Disposal of Hanford Defense Waste." We acknowledge several Rockwell staff, namely C. DeFigh-Price, C. J. Geier, and J. C. Sonnichsen, Jr., who directed the compilation of this document, and R. C. Routson, who provided us with the data set for the 200-E Area lysimeter. We also acknowledge the support of PNL manager, J. A. Stottlemyre, and the assistance of $P$. R. Heller, who provided the soil hydraulic property analysis for the UNSAT-H model testing, and R. L. Skaggs and G. P. Streile, who willingly reviewed portions of this report in detail. We wish to thank $A$. E. Reisenauer of Pacific Northwest Laboratory for the data shown in Figure B.2.

Finally, we thank L. K. Grove and M. E. Strong, who diligently edited this report, and S. E. Kesterson's word processing group. 


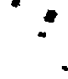

$-$ 
SUMMARY

Waste management practices at the Hanford Site have relied heavily on near-surface burial. Predicting the future performance of any burial site in terms of the migration of buried contaminants requires a model capable of simulating water flow in the unsaturated soils above the buried waste. The model currently being developed to meet this need is UNSAT-H, which was developed at Pacific Northwest Laboratory for assessing the water dynamics of nearsurface waste-disposal sites at the Hanford Site. The code will primarily be used to predict deep drainage (i.e., recharge) as a function of environmental conditions such as climate, soil type, and vegetation. UNSAT-H will also simulate various waste-management practices such as placing surface barriers over waste sites.

UNSAT-H is a one-dimensional model that simulates the dynamic processes of infiltration, drainage, redistribution, surface evaporation, and uptake of water from soil by plants. The mathematical basis of the model is Darcy's Law as extended by Richards (1931). The numerical implementation of UNSAT-H is based on the UNSAT model of Gupta et a1. (1978). UNSAT-H uses a fully implicit, finite difference method for solving the water transport equation. Plant water uptake is introduced as a sink term at each node and is calculated as a function of root density, moisture content, and potential evapotranspiration. The simulated soil profile can be homogeneous or layered. The boundary conditions can be controlled as either constant head or flux conditions to reflect actual conditions at a given site. Features of UNSAT-H that are improvements over earlier codes such as UNSAT include isothermal vapor flow, cheatgrass transpiration function, additional options for describing soil hydraulic properties, and reduction of mass-balance error.

UNSAT-H is designed to utilize two auxiliary codes. These codes are DATAINH, which is used to process the input data, and DATAOUT, which is used to process the UNSAT-H output. Operation of the code requires three separate steps. First, the problem to be simulated must be conceptualized in terms of boundary conditions, available data, and soil properties. Next, the data must 
be correctly formatted for input. Finally, the input data must be processed, UNSAT-H run, and the output data processed for analysis.

This report includes three examples of code use. In the first example, a benchmark test case is run in which the results of UNSAT-H simulations of infiltration are compared with an analytical solution and a numerical solution. The comparisons show excellent agreement for the specific test case, and this agreement provides verification of the infiltration portion of the UNSAT-H code. The other two examples of code use are a simulation of a layered soil and one of plant transpiration.

Development of unsaturated flow models at the Hanford Site was started in the 1960s. Progress has been guided by changes in the flow problems that need to be solved, the need for greater detail in the model solutions, and continual advances in computer software and hardware. The current effort to document UNSAT-H represents a commitment to use this model as the basis for unsaturated flow modeling related to land burial of waste and barrier development. Potential enhancements of the UNSAT-H model that have been identified for future study are the addition of nonisothermal vapor flow, the substitution of mechanistic descriptions of evaporation and transpiration for the empirical expressions currently used, and the inclusion of a snowmelt algorithm.

There is an ongoing effort in model validation for UNSAT-H. This involves testing the code with reliable data sets and independently predicting the past and present recharge and water balance at specific sites. The documentation of the model supplied herein establishes the current status of the model. Validation of the model will demonstrate its degree of credibility and indicate the degree to which the model can be used in a predictive manner to support a variety of performance assessment tasks for waste management at Hanford. 


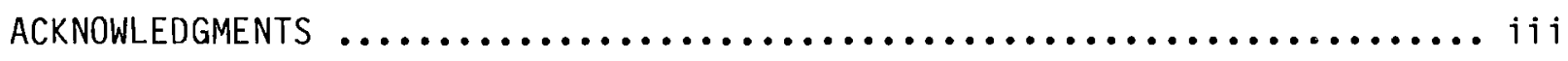

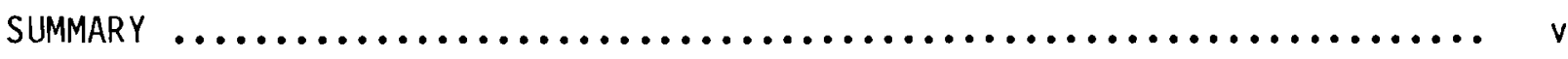

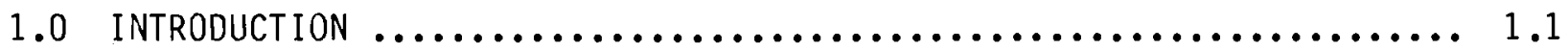

2.0 MODEL OVERVIEW $\ldots \ldots \ldots \ldots \ldots \ldots \ldots \ldots \ldots \ldots \ldots \ldots \ldots \ldots \ldots \ldots \ldots \ldots \ldots \ldots, 2.1$

2.1 OBJECTIVES $\ldots \ldots \ldots \ldots \ldots \ldots \ldots \ldots \ldots \ldots \ldots \ldots \ldots \ldots \ldots \ldots \ldots, 2.1$

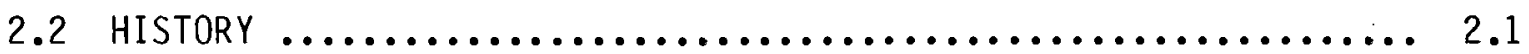

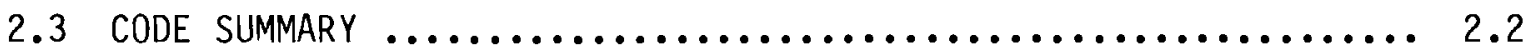

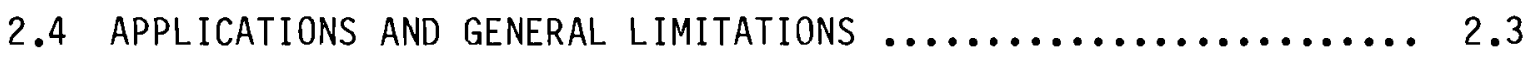

2.5 SYSTEM REQUIREMENTS $\ldots \ldots \ldots \ldots \ldots \ldots \ldots \ldots \ldots \ldots \ldots \ldots \ldots \ldots \ldots \ldots \ldots \ldots \ldots$

3.0 THEORETICAL DEVELOPMENT $\ldots \ldots \ldots \ldots \ldots \ldots \ldots \ldots \ldots \ldots \ldots \ldots \ldots \ldots \ldots \ldots \ldots \ldots \ldots \ldots .1$

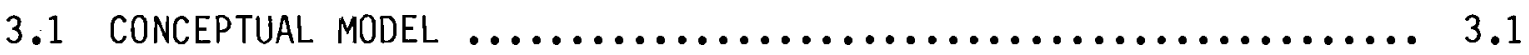

3.1.1 Precipitation $. . \ldots \ldots \ldots \ldots \ldots \ldots \ldots \ldots \ldots \ldots \ldots \ldots \ldots . . .2$

3.1 .2 Evaporation $\ldots \ldots \ldots \ldots \ldots \ldots \ldots \ldots \ldots \ldots \ldots \ldots \ldots \ldots \ldots, 3.3$

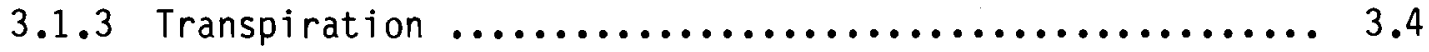

3.1 .4 Drainage $\ldots \ldots \ldots \ldots \ldots \ldots \ldots \ldots \ldots \ldots \ldots \ldots \ldots \ldots \ldots \ldots \ldots \ldots \ldots \ldots, 3.5$

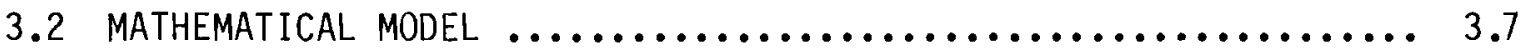

3.2.1 Unsaturated Flow Equation $\ldots \ldots \ldots \ldots \ldots \ldots \ldots \ldots \ldots \ldots \ldots \ldots \ldots \ldots$

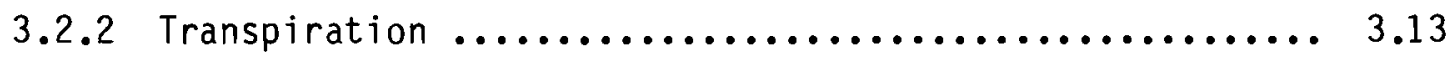

3.2.3 Boundary Conditions $\ldots \ldots \ldots \ldots \ldots \ldots \ldots \ldots \ldots \ldots \ldots \ldots . . .18$

4.0 NUMERICAL IMPLEMENTATION $\ldots \ldots \ldots \ldots \ldots \ldots \ldots \ldots \ldots \ldots \ldots \ldots \ldots \ldots, 4.1$

4.1 Finite DifFERENCE APPROXIMATION $\ldots \ldots \ldots \ldots \ldots \ldots \ldots \ldots \ldots \ldots, 4.1$

4.1 .1 Interior Nodes $\ldots \ldots \ldots \ldots \ldots \ldots \ldots \ldots \ldots \ldots \ldots \ldots, 4.3$

4.1 .2 Surface-Boundary Node $\ldots \ldots \ldots \ldots \ldots \ldots \ldots \ldots \ldots \ldots, 4.4$

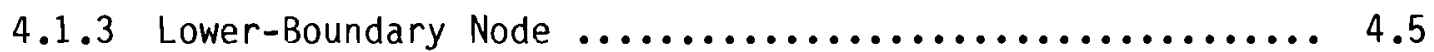

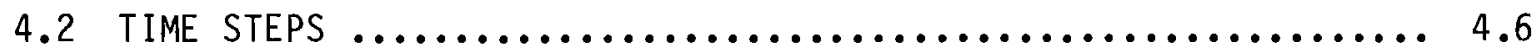




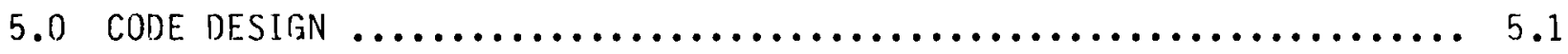

5.1 INPUT PROGRAM DATAINH $\ldots \ldots \ldots \ldots \ldots \ldots \ldots \ldots \ldots \ldots \ldots \ldots \ldots \ldots \ldots \ldots \ldots \ldots \ldots . .1$

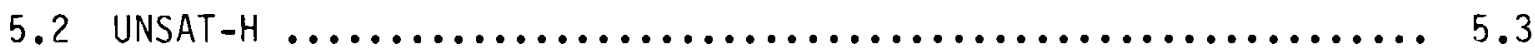

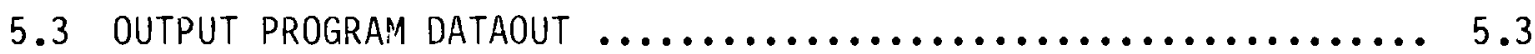

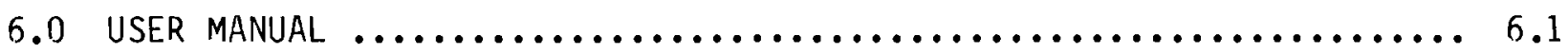

6.1 PROBLEM FORMULATION $\ldots \ldots \ldots \ldots \ldots \ldots \ldots \ldots \ldots \ldots \ldots \ldots \ldots \ldots, 6.1$

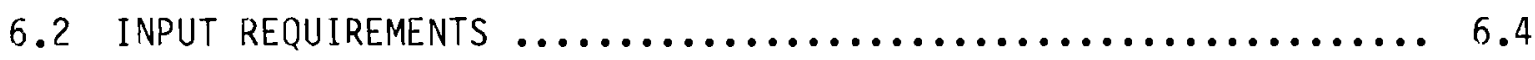

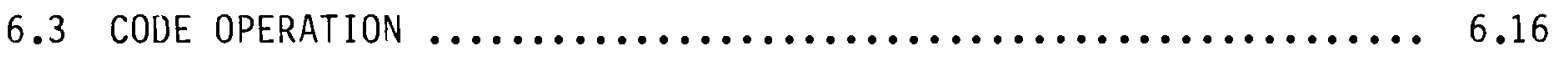

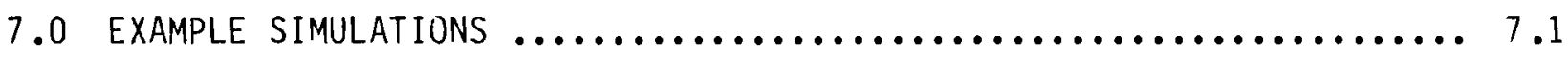

7.1 VERIFICATION OF INFILTRATION $\ldots \ldots \ldots \ldots \ldots \ldots \ldots \ldots \ldots \ldots \ldots \ldots . .1$

7.1 .1 Problem Description $\ldots \ldots \ldots \ldots \ldots \ldots \ldots \ldots \ldots \ldots \ldots \ldots \ldots \ldots . . .1$

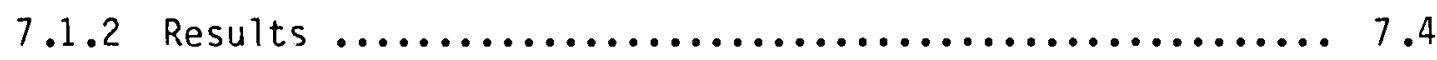

7.2 LAYERED SOIL SIMULATION $\ldots \ldots \ldots \ldots \ldots \ldots \ldots \ldots \ldots \ldots \ldots \ldots \ldots . \ldots \ldots$

7.2.1 Problem Description .......................... 7.11

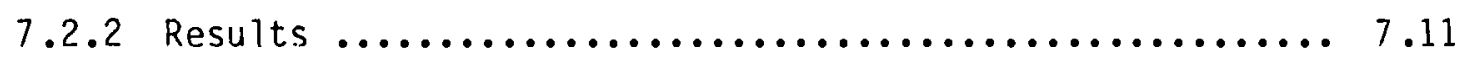

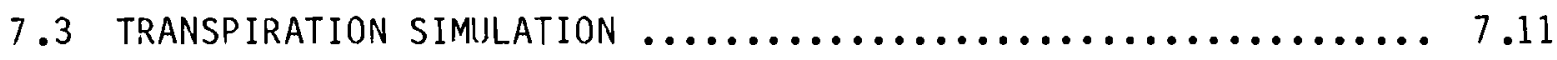

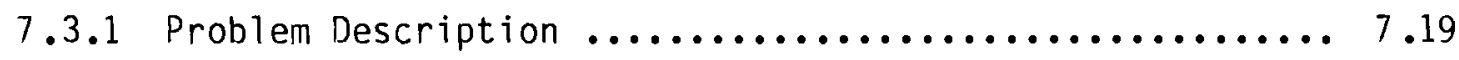

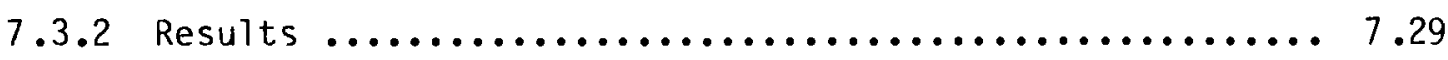

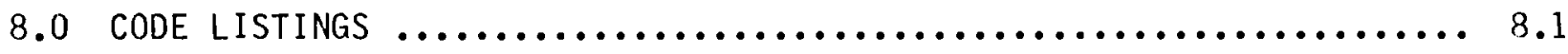

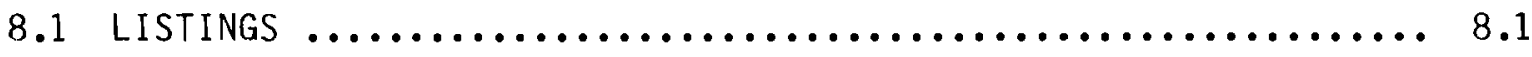

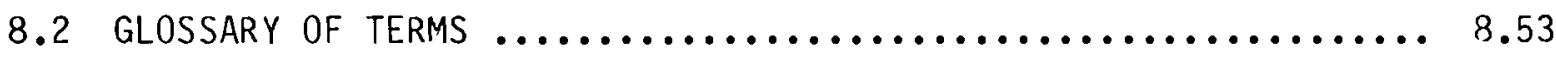

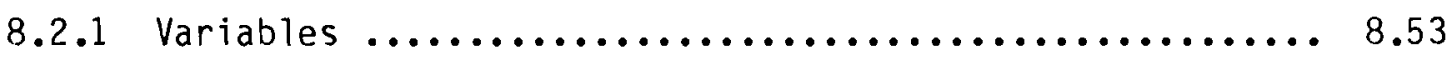

8.2 .2 Arrays $\ldots \ldots \ldots \ldots \ldots \ldots \ldots \ldots \ldots \ldots \ldots \ldots \ldots \ldots \ldots \ldots .6 .60$

8.2.3 Parameter Constants ......................... 8.62

8.2.4 Functions and Subroutines $\ldots \ldots \ldots \ldots \ldots \ldots \ldots \ldots \ldots \ldots . .6 .62$ 
9.0 REFERENCES $\ldots \ldots \ldots \ldots \ldots \ldots \ldots \ldots \ldots \ldots \ldots \ldots \ldots \ldots \ldots \ldots \ldots \ldots \ldots \ldots,{ }^{9} .1$

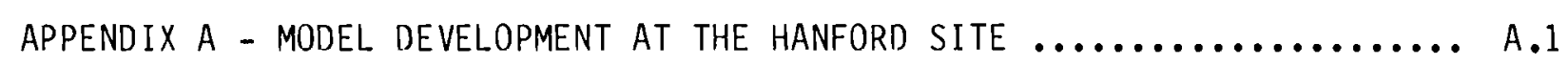
APPENDIX B - MODEL VALIDATION: AN ASSESSMENT OF CREDIBILITY .......... B.1 


\section{FIGURES}

3.1 Relationship Between Transpiration, Net Radiation, and

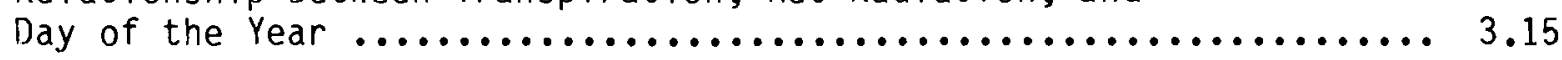

3.2 Root Mass at the End of the 1974 Growing Season in Cheatgrass

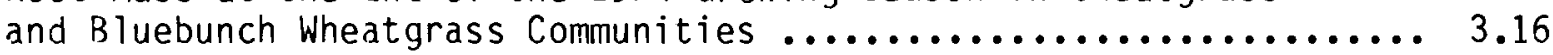

3.3 Actual Sink Term as a Function of the Water Content ........... 3.18

5.1 Format of the *.BIN Input File Created by DATAINH For Input to

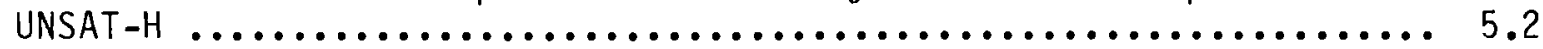

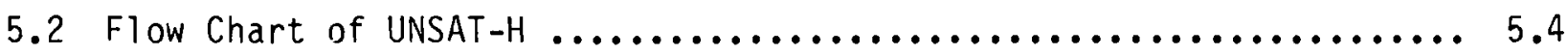

5.3 Flow Chart of DELSUB Loop Within UNSAT $-\mathrm{H} \ldots \ldots \ldots \ldots \ldots \ldots \ldots \ldots \ldots$

5.4 Format of *.RES Output File Created by UNSAT-H $\ldots \ldots \ldots \ldots \ldots \ldots$

6.1 Example Problem Formulation: a) Site Description; b) Model Representation

6.2 Listing of Sample Command File for Running UNSAT-H in the Batch Mode .......................................... 6.18

7.1 Listing of the Input file CLAY.INP $\ldots \ldots \ldots \ldots \ldots \ldots \ldots \ldots \ldots \ldots \ldots . . \ldots \ldots$

7.2 Infiltration Rate and Cumulative Infiltration Versus Time as Determined Using Philip's Solution, the Numerical Code of

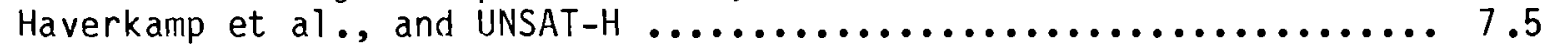

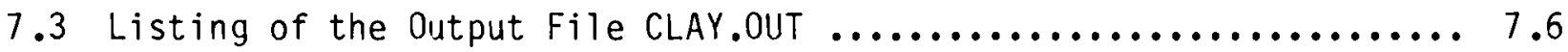

7.4 Conceptual Model of Protective Barrier $\ldots \ldots \ldots \ldots \ldots \ldots \ldots \ldots \ldots \ldots . \ldots . \ldots \ldots$

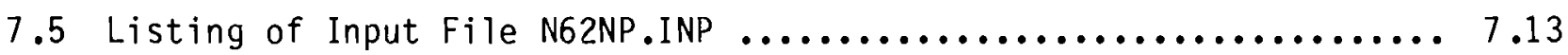

7.6 Listing of Output File N62NP.OUT $\ldots \ldots \ldots \ldots \ldots \ldots \ldots \ldots \ldots \ldots \ldots \ldots \ldots . \ldots \ldots . \ldots \ldots$

7.7 Listing of Input file RHOLYP74.INP $\ldots \ldots \ldots \ldots \ldots \ldots \ldots \ldots \ldots \ldots \ldots \ldots . \ldots \ldots$

7.8 Soil Hydraulic Properties for 200-Area Lysineter .............. 7.27

7.9 Plant Parameters a) Assumed Leaf Area Index b) Assumed Maximum

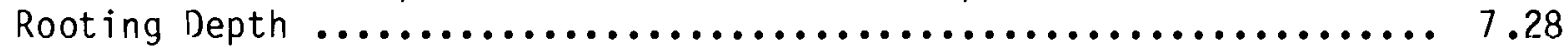

7.10 Listing of Output File RHOLYPT4.OUT ....................... 7.29

A.1 Effect of Surface Conditions on Recharge at Hanford ............ A.2 
B.1 Steps in Constructing and Validating a Model for Performance Assessment

B.2 Estimated Travel Time Through the Unsaturated Zone Beneath the

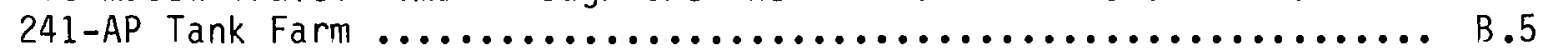

B.3 Simulated Storage Variations in the 200-Area Closed-Bottom

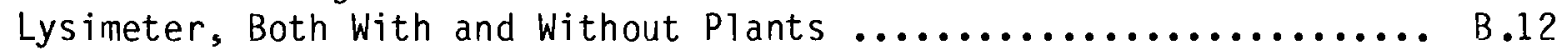

B.4 Simulated and Measured Moisture Profiles for the 200-Area

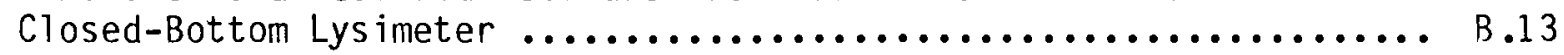




\section{TABLES}

3.1 Cheatgrass Root Biomass Data, Root Length, and Root Density Function

5.1 Data Flow, Program Tasks, and Subroutines

5.2 Subroutines Called by DATAOUT

6.1 Logical Unit Assignments $\ldots \ldots \ldots \ldots \ldots \ldots \ldots \ldots \ldots \ldots \ldots \ldots \ldots \ldots \ldots \ldots$

7.1 Coefficients and Parameters Used in the Infiltration Simulations ... 7.2

A.1 Unsaturated Flow Models Used at Hanford to Assess Recharge ........ A.5

B.1 Annual Bare Soil Fraction Assumed in the Simulation of the

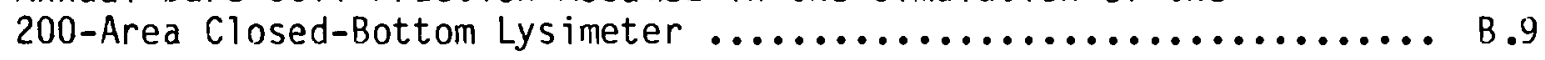

B.2 Summary of Simulations of the 200-Area Closed-Bottom Lysimeter Without Plants on the Surface

B.3 Summary of Simulations of the 200-Area Closed-Bottom Lysimeter With Plants on the Surface 


\subsection{INTRODUCTION}

One of the waste-management practices of the past and present at the Hanford Site is burial of waste in the thick unsaturated soil zone that lies some distance above the water table. This practice is considered acceptable if drainage (i.e., recharge) is negligible at the waste sites. Field experiments, however, indicate that recharge at the Hanford Site is negligible at sone sites but measurable at others and that the quantity of recharge depends heavily on specific site characteristics (see Gee and Heller 1985 for details). If buried waste is contacted by soil water, the potential exists for soluble contaminants to be leached and transported to the underlying ground water. Long-term protection against ground-water contamination requires that a suitable methodology be developed to ensure that recharge rates remain below those that would transport enough contaminants to create an environmental hazard. Because such low rates are extremely difficult to monitor and because the time period involved is so large (thousands of years), it is necessary to estimate the flow rates using numerical model simulations.

Numerical models to describe water flow have been developed at the Hanford Site since the 1960s. One weakness of this effort has been the lack of adequate documentation of the models and their applications. The purpose of this report is to document the present version of the unsaturated flow code UNSAT-H, which was developed at Pacific Northwest Laboratory for assessing the water dynamics of arid sites under consideration for near-surface waste disposal. This report provides a more complete documentation of UNSAT-H than the previous report by Fayer and Gee (1985), including a presentation of the bases for the conceptual model and its numerical implementation as well as example simulations involving layered soils and plants. As UNSAT-H is used and evaluated over the next few years, this documentation will serve as the base upon which evaluations and enhancements will be made.

Section 2.0 provides an overview of the model, including its objectives, history, and applications. Section 3.0 presents the conceptual and mathematical models underlying UNSAT-H. Section 4.0 details the numerical 
implementation of the mathematical model. Section 5.0 outlines the code design, including input/output file structure and model flow charts. Section 6.0 is the user's manual and discusses problem formulation, input requirements, and code use. Section 7.0 contains three example simulations: 1) a verification exercise for the infiltration portion of the code; 2) a simulation of the water balance in a layered soil system (e.g., a protective barrier); and 3) a simulation of the water balance in a field lysimeter located in the 200 Area. Section 8.0 lists the code for the main programs and all subroutines, as well as a glossary of terms used in the UNSAT-H code. The history of model development at the Hanford Site is described in Appendix A. Appendix B presents the current view of model calibration and validation as means for testing conceptual models and establishing a given level of credibility. 


\subsection{MODEL OVERVIEW}

\subsection{OBJECTIVES}

The major objective of UNSAT-H is to estimate recharge rates for use in contaminant transport analyses. For UNSAT-H to accomplish this task, the model must be able to predict the long-term water balance (particularly deep drainage) at waste burial sites under both existing climatic conditions and postulated future climatic conditions.

A second objective of UNSAT-H is to optimize the conceptual design of waste-management strategies for minimizing recharge. For example, a tool like UNSAT-H can be used to narrow the range of design alternatives for protective barriers to a few choices. Limiting the number of design alternatives will result in considerable savings by lessening the need for full-scale experiments to test every design.

\subsection{HISTORY}

The use of numerical models to predict water flow in unsaturated sediments at the Hanford Site began in the early 1960s (e.g., Reisenauer 1963). Since that time, there have been several efforts to develop models suitable for solving contemporary problems. A detailed discussion of model development at the Hanford Site, together with a brief description of the models, is contained in Appendix A.

The model currently being developed and tested for use in predicting soil water balance is UNSAT-H. This model is derived from the UNSAT model of Gupta et. a1. (1978). The objective of the UNSAT model was to predict the water dynamics of agricultural land. The current model, UNSAT-H, is an adaptation of the UNSAT model better suited to the needs of waste management at the Hanford Site. While most of the mathematical and numerical formulation of the UNSAT model has been retained in UNSAT-H, several changes in the model have been made.

Changes already incorporated into UNSAT-H are the addition of isothermal vapor transport, inclusion of an empirical cheatgrass-transpiration option 
based on Hanford Site data, and reduction in mass-balance error. Modifications being considered for the future include a mechanistic transpiration algorithm that includes plant growth and development, and a diffusion-based evaporation algorithm. Two additional enhancements that are being considered are inclusion of soil temperature predictions that would account for nonisothermal effects during evaporation as well as for freezing soils, and changes to precipitation and evaporation algorithms that would account for extended snow cover and snowmelt.

\subsection{CODE SUMMARY}

The UNSAT-H computer code is designed to simulate water flow in unsaturated soils and sediments. It is a mechanistic model in that it is based on Darcy's Law of water flow as extended to unsaturated systems by Richards (1931). UNSAT-H can simulate the isothermal flow of both liquid and water vapor in response to precipitation and irrigation, plant water extraction, and deep drainage. The basic numerical scheme used in UNSAT-H is the fullyimplicit Crank-Nicholson method.

The input data required by UNSAT-H can be divided into five categories: 1) program control variables; 2) soil hydraulic properties; 3) initial conditions; 4) plant data; and 5) boundary conditions. The format for entering the data and running the code are given in Section 6.0 .

The first category of input, the set of program control variables, formulates the problem in terms of options chosen, maximum allowable mass-balance error, time-step control, amount of output data saved, and simulation time. This category also includes specification of elevation and material type for each node.

The soil hydraulic properties required by UNSAT-H include hydraulic conductivity as a function of water potential and water content as a function of water potential (i.e., the soil water characteristic or desorption curve). These properties can be entered as one of several functional relationships and need to be provided for each soil material in the problem description. 
Initial conditions consist of suction head values for each node and the day on which to start the simulation. The plant data necessary include mature root length distribution, either leaf area index through time or germination and harvesting dates, and fraction of surface area that is bare.

The final category of input is the boundary conditions. For the lower boundary, either a constant head or flux values, such as measured drainage from a lysimeter, can be specified. For the upper boundary (the soil surface), a constant head or flux values, such as hourly precipitation and daily potential evapotranspiration, can be added.

The file containing the input data is read using the program DATAINH, which processes the data and creates a binary file that serves as the actual input file to UNSAT-H. There is only one output file from UNSAT-H and it is also in binary form. This output file can be read using the program DATAOUT. The output file contains hourly or daily (as selected by the user) summaries of water content, water potential, flux, and plant water use as a function of depth, as well as cumulative totals of the water balance components (storage, precipitation, evaporation, transpiration, and drainage). The binary output file will serve as input to a solute-transport code that requires estimates of water flux.

\subsection{APPLICATIONS AND GENERAL LIMITATIONS}

In its present state, UNSAT-H can be used to obtain solutions to a number of unsaturated flow problems. Precipitation, evaporation, transpiration, and soil water redistribution at the Hanford Site can all be simulated, thus providing an estimate of the recharge rate to the underlying ground water. With proper accounting for the soil and plant characteristics at a specific site, recharge can be estimated as a function of a variable climate (e.g., the effect of precipitation changes on recharge can be evaluated). The effects of variations in soil type or layering, and the effects of variations in plant cover and type can also be demonstrated with the model by simulating various soil and plant configurations under identical climate conditions. It should be 
noted that UNSAT-H can be applied equally well to other sites, provided the appropriate plant algorithms were used to simulate evapotranspiration.

The UNSAT-H model was developed only recently (Fayer and Gee 1985) and therefore has been used in only one application. Fayer et al. (1985) used UNSAT-H to simulate the water balance of multilayer barriers. These simulations were performed to help illustrate how barrier design (e.g., soil type, layer thickness) could affect recharge to the ground water. Applications of a related code, UNSAT1D (see Appendix A), include the work of Jones, Campbel1, and Gee (1984), who simulated the water balance of a bare-surface soil located in the Hanford Site's 300 Area, and Gee and Kirkham (1984), who simulated the water balance of a cheatgrass-vegetated site, also located in the 300 Area.

General limitations of UNSAT-H include assumptions of one-dimensionality and isothermal flow, use of empirical plant transpiration algorithms, and lack of a snowmelt algorithm. As mentioned above, Fayer et al. (1985) simulated flow through layered barriers, specifically through the central portion of the barriers where flow was assumed to be strictly vertical. The one-dimensional limitation of UNSAT-H precluded its use for describing flow at the lateral boundaries of the barrier. Although the one-dimensional nature of the model presents a well-defined limitation on the types of problems that can be solved, the remaining three limitations listed above do not. The seriousness of each of these limitations has yet to be demonstrated conclusively in a model validation exercise, which is the process by which model predictions are objectively compared to experimental data. A discussion of validation strategy and an assessment of some past model validation efforts at the Hanford Site are provided in Appendix B. Until UNSAT-H is subjected to model validation exercises, the credibility of UNSAT-H predictions cannot be properly evaluated. For this reason, completion of the planned model validation program is essential, in order to establish the model's usefulness for simulating recharge at waste sites. 


\subsection{SYSTEM REOUIREMENTS}

The UNSAT-H code runs under the VAX/VMS Version 4.0 Operating System. (a) The operating system provides the access to the disk storage devices required by UNSAT-H for its input/output options. The UNSAT-H code is written in VAX FORTRAN Version 4.0 , (b) which is based on American National Standard FORTRAN-77 (ANSI X3.9-1978). Although extensions to FORTRAN-77 are available in VAX FORTRAN, we have made limited use of them in order to keep UNSAT-H close to standard FORTRAN-77 form.

During operation, the UNSAT-H code requires 1 million bytes of memory. The source codes listed in Section 8.0 require 130 kilobytes of storage. The executable images require 64 kilobytes of storage.

\footnotetext{
(a) "VAX/VMS DCL Dictionary." 1984. Digital Equipment Corporation, Maynard, Massachusetts.

(b) "Programming in VAX FORTRAN." 1984. AA-D034D-TE. Digital Equipment Corporation, Maynard, Massachusetts.
} 


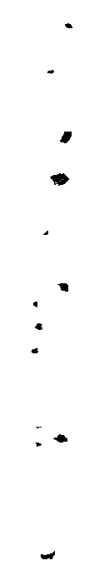




\subsection{THEORETICAL DEVELOPMENT}

The theoretical development of UNSAT-H involves two components, the conceptual model and the mathematical model. The conceptual model identifies which environmental processes are thought to significantly influence soil water flow at the Hanford Site. The mathematical model consists of a set of equations that quantitatively describe the processes outlined in the conceptual model. The numerical implementation of these equations in the UNSAT-H Code is discussed in Section 4.0.

\subsection{CONCEPTUAL MODEL}

The development of a site-specific conceptual model for unsaturated water flow begins with establishing a site-specific water balance equation. Such an equation is a way of partitioning the water at a site into the three categories of input, output, and storage. The water balance equation that forms the basis of the UNSAT-H conceptual model is:

$$
\Delta W=P-E-T-D
$$

The term $\Delta W$, located on the left-hand side of Equation (3.1), represents the change in water storage over an interval of time. Water storage is calculated as the average volumetric water content of the soil times the depth of soil. The water balance equation simply states that the increase or decrease in the amount of water stored in the soil profile is equal to the total precipitation $(P)$, minus the amount of water lost to evaporation (E), transpiration $(T)$, and drainage (D).

The second step in developing the conceptual model is to identify the environmental processes and physical principles controlling each term in Equation (3.1). It is important to understand the interrelationships among terms in this equation. Any attempt to predict one term will be limited by the prediction accuracy of the other terms. 


\subsubsection{Precipitation}

Precipitation at the Hanford Site averages about $16 \mathrm{~cm}$ per year, ranging from less than 8 up to $28 \mathrm{~cm}$ in any given year (Stone et a1. 1983). In addition to low annual rates, precipitation at the Hanford Site is highly seasonal, with an average of 60 percent of the annual total coming between October and February. During these months, a significant percentage of precipitation may occur as snow. In fact, snowfall averages over 25 percent of the annual precipitation total and 38 percent of the winter total.

The seasonal character of precipitation, together with the significant proportion of snowfall, raises two issues that must be addressed at the level of the conceptual model. The first question is whether to explicitly account for snowfall and snowmelt or to treat snow as an equivalent amount of rain. Snow covers the ground at the Hanford Site an average of 19 days per year, with a range from as many as 54 to as few as zero days. The presence of a snowpack may both delay the entry of water into the soil and affect evaporation rates. The present conceptualization supporting UNSAT-H, however, is to view snow as an equivalent amount of water. The UNSAT-H model does not attempt to simulate snowmelt or the effects of snow cover on evaporation nor does it account for snow sublimation effects.

The second issue raised because of winter precipitation is how frozen soil affects infiltration and evaporation. If the climate at the Hanford Site were such that precipitation were negligible during winter months, then the effects of soil freezing and the depth of snow would likely be small. However, the presence of significant precipitation during winter months means that these processes need to be considered. Simulating snowmelt and freezing soil is currently beyond the ability of UNSAT-H, but the possibility of enhancing UNSAT-H in the future to account for these processes is being investigated.

A water balance component that was not included in Equation (3.1) is overland flow (i.e., runoff/runon). When the precipitation rate exceeds the infiltration rate, water begins to pond on the soil surface. Overland flow occurs when the soil's surface detention capacity is exceeded and there is some slope to the ponded water surface. Overland flow is extremely unlikely to occur during a rain event at the Hanford Site because the infiltration capacities of 
most of the soils exceed several centimeters per hour in contrast to the 100and 1000-year storm intensities of less than 2 or 3 centimeters per hour (Stone et al. 1983). However, overland flow may occur when a snowpack melts quickly and the soil beneath is frozen so that infiltration is severely restricted. Overland flow has been observed at the Hanford Site under such conditions.

An overland flow component has not been included in the conceptual model for UNSAT-H, partly because the process occurs so rarely, but mostly because UNSAT-H is a one-dimensional model. When overland flow does occur, it is caused, in part, by variable surface topography. This is a multidimensional process that a one-dimensional model cannot describe. For a one-dimensional model to be applicable, the problem must be formulated as one in which water is applied uniformly over the surface. Therefore, UNSAT-H can only be applied to areas over which local runon/runoff processes can be represented by a uniform precipitation rate over the entire area or to areas in which overland flow is prevented, such as in lysimeters.

\subsubsection{Evaporation}

Evaporation is the process that dominates water loss from the surface of bare (unvegetated) soil. When the soil surface is very wet, as it is just after a heavy rainfall, the evaporation rate will be at a maximum. This maximum rate, termed potential evaporation (PE), is determined largely by atmospheric parameters that control the supply of energy to the surface and the transport of water vapor away from the surface.

At the Hanford Site, the actual evaporation rate from a soil surface will only equal the $P E$ rate for the several hours immediately following a rain event. More often, the evaporation rate is much lower than the PE rate. The reason is that as water evaporates from the soil, the soil profile begins to dry, especially near the surface. Dry soil is a poor conductor of water and so cannot supply water from the moist deeper layers to the evaporating surface fast enough to maintain the PE rate. Thus, drying of the soil limits actual evaporation to a rate that is generally a small fraction of the PE. Because of the soil dryness, an important idea in this conceptual model of evaporation at the Hanford Site is that the evaporation rate is mostly limited by soil conditions rather than atmospheric conditions. 


\subsubsection{Transpiration}

Transpiration is the evaporation of water from plants. When the soil surface is well-vegetated with active plants, transpiration is usually the dominant mode of water loss from the soil profile. Even when the \#urface is only sparsely vegetated, transpiration can rival evaporation as the primary source of water loss from the soil. Exceptions to the above may occur during certain times of the year when plants are dormant or reacting to extreme water stress.

In a review of literature concerning unsaturated flow on the Hanford Site, Gee and Heller (1985) reported that the plant community consists of a mixture of sagebrush and cheatgrass, with lesser amounts of bitterbrush, rabbitbrush, bluegrass, and Russian thistle. Rooting depths range from less than $100 \mathrm{~cm}$ for cheatgrass, to $200 \mathrm{~cm}$ for sagebrush, $220 \mathrm{~cm}$ for rabbitbrush, $240 \mathrm{~cm}$ for Russian thistle, and $300 \mathrm{~cm}$ for bitterbrush. Gee and Heller noted that areas of the Hanford Site disturbed by construction or brush fires tend to become colonized by a mixture of cheatgrass and Russian thistle. The exact composition of this mixture will affect the water balance, because the shallow-rooted cheatgrass will not remove as much water from the soil profile as would the deeper-rooted Russian thistle.

Annual water loss caused by transpiration at the Hanford Site falls short of potential transpiration (PT) just as annual evaporation falls short of PE. The reduction of transpiration below the potential rate is caused by two primary mechanisms. The first mechanism involves a decrease in plant biomass, primarily leaf area.

When plants are stressed by lack of water, they may lose leaves, shoots, and roots. This reduction in plant tissue means that less water is necessary to maintain the remaining biomass. Reduction of plant biomass is a relatively slow mechanism that responds to climatic conditions averaged over weeks or months. On a diurnal or even an hourly basis, water loss can be reduced with the second mechanism for reducing transpiration called stomatal closure. Closing of stomata (small openings in the leaves) reduces plant water loss to near zero. In addition, closure of the stomata reduces carbon dioxide uptake, which limits photosynthesis and reduces growth. 
The UNSAT-H conceptual model of transpiration relies on estimates of a potential evapotranspiration rate (PET) that is calculated from climate data. That potential rate is then modified by a crop coefficient that is a function of either leaf area or time of year. The resulting potential transpiration (PT) rate is applied to depths within the soil profile in proportion to the fraction of roots at the respective depths. UNSAT-H currently allows for a fixed rooting distribution throughout the year and a variable maximum depth of root penetration. This conceptual model of transpiration offers some flexibility to vary transpiration during the simulation, but only in a predetermined way, never solely in response to the conditions of the specific simulation. Some of the plant communities at the Hanford Site are mixed. That is, they include perennial as well as annual species, each with its own life cycle and rooting characteristics that influence the composite annual transpiration distribution. The UNSAT-H model should not be applied to such areas until more information is available on the behavior of mixed communities.

\subsubsection{Drainage}

The final term of Equation (3.1) is drainage, which is the movement of water downward through the soil profile. Of particular interest is drainage of water through the soil to the water table. This specific type of drainage is known as ground-water recharge. As a practical matter, once water drains below the root zone, there is little chance of it being drawn upward again. Therefore, recharge is often defined as drainage below the root zone. Recharge is perhaps the water balance term of most interest for waste management because of its potential to move contaminants out of waste-disposal sites. The primary objective of any waste-treatment facility such as protective barriers is to reduce recharge and thus the drainage of water through the waste material.

Drainage is a result of the process of redistribution, in which the flow of water through a soil system will occur in response to gradients in the energy state of the water. Other mechanisms that might induce water flow, such as geothermal gradients and barometric pressure fluctuations, have been shown to be minor contributors to overall flow in soils under Hanford Site conditions (Reisenauer et a1. 1975; Jones 1978; Gee and Simmons 1979). The energy state of water can be described by its potential energy, which is commonly assumed to 
consist of a gravitational potential, pressure or matric potential, and solute potential. All of these potentials are expressed relative to the energy state of pure, free water at atmospheric pressure and at some reference elevation. Pressure or matric potential describes the water pressure difference from the reference state. When the water pressure is greater than the atmospheric pressure, the soil is saturated and we use the term pressure potential. When the water pressure is less than the atmospheric pressure, the soil is unsaturated and we use the term matric potential. Nearly all applications of UNSAT-H will be for unsaturated problems, so the convention is to speak of matric potential. The solute potential, which is the drop in potential energy caused by the presence of solutes, is only effective in contributing to liquid-water flow when there is a differential restriction of solute movement relative to water. In the absence of a semi-permeable membrane, the solute potential is commonly neglected. In the conceptual model, therefore, the energy state of water is described by the sum of the gravitation and matric potentials; the sum is usually called the hydraulic potential. Water continually redistributes from areas of high water potential to areas of low water potential, regardless of direction.

A final question to be addressed at the conceptual model level is whether to include the flow of water vapor in the redistribution and drainage calculations. The above discussion of water redistribution in response to potential gradients applies mainly to water in the liquid phase. In unsaturated soils, water is also present in the vapor phase. Water vapor moves and redistributes within the soil in response to vapor-pressure gradients. These vapor pressure gradients can arise from either matric potential gradients in the liquid phase or from temperature gradients within the soil. Water-vapor flow induced by matric potential gradients is known as isothermal vapor flow. Vapor flow induced by thermal gradients is known as nonisothermal flow.

Analyses like that of Campbell (1985) imply that isothermal vapor flow can affect the near-surface (top $10 \mathrm{~cm}$ ) water-content profile, although it is unclear how this would affect long-term simulations of the water balance. Nonisothermal vapor flow plays a role during evaporation when the surface soil is dry and steep thermal gradients are present. Hammel, Papendick, and Campbell 
(1981) reported that exclusion of nonisothermal vapor flow resulted in a higher predicted evaporative loss and poorer agreement between measured and predicted moisture profiles in a seed zone. In contrast, Jones, Campbe11, and Gee (1984) reported that an isothermal model predicted water storage in a Hanford soil more accurately than did a nonisothermal model.

In the current UNSAT-H model, vapor flow is considered as an isothermal process. We recognize that isothermal vapor flow is not a dominant process in the overall water balance, but have included it in anticipation of UNSAT-H enhancements that would allow us to model nonisothermal flow. Plans to include nonisothermal vapor flow will be intimately linked with plans to upgrade UNSAT$H$ to a coupled soil-temperature/soil-water flow model that would allow us to include other nonisothermal effects, like soil freezing and snowmelt.

\subsection{MATHEMATICAL MODEL}

The mathematical model consists of a differential equation with a set of boundary conditions that together describe the processes that are listed in Equation (3.1) and have been discussed for the conceptual model. The differential equation, a modified form of Richards' Equation (Richards 1931), describes the change in water storage, redistribution, and plant water uptake at every point in the interior of the soil profile. Flow of water across the boundaries of the profile is represented by specifying a flux (e.g., precipitation, evaporation, or drainage) or by holding the boundary node head value constant and calculating a flux (e.g., ponding, evaporation, water table).

In discussions of soil water flow, hydraulic potential is calculated as the sum of the gravitation and matric potentials. The fundamental expression of potential is as energy per unit mass expressed in units of Joules per kilo$\operatorname{gram}(\mathrm{J} / \mathrm{kg})$. It is much more convenient and common, however, to replace the term potential with head, which is energy per unit weight with units of centimeters $(\mathrm{cm})$. Therefore, we commonly speak of the total potential as the hydraulic head $(H)$, the gravitational potential as the gravitational head $(z)$, and the matric potential as the matric head $(\psi)$. Note that gravitational head and depth below the soil surface (z) are synonymous. 


\subsubsection{Unsaturated Flow Equation}

The development of the modified Richards Equation begins with Darcy's Law. In its original form, Darcy's Law represented an empirical relationship between the rate of flow in saturated sand and the hydraulic head gradient. The differential form of Darcy's Law (Hillel 1980) is

$$
q=-K_{s} \frac{d H}{d z}
$$

where $q$ is the volume flux of water per unit area, $k_{s}$ the constant of proportionality commonly referred to as the saturated hydraulic conductivity, and $\mathrm{dH} / \mathrm{dz}$ the hydraulic head gradient. Darcy's Law can be extended to unsaturated flow by replacing the saturated conductivity term with conductivity as a function of matric head, yielding

$$
q=-K(\psi) \frac{\partial H}{\partial z}
$$

Equation (3.3) must be combined with the continuity equation in order to describe transient flow. The continuity equation states that the change in water content of a volume element of soil must equal the difference between flux into and out of the element. For one-dimensional flow, the continuity equation is

$$
\frac{\partial \theta}{\partial t}=-\frac{\partial q}{\partial z}
$$

Combining Equations (3.3) and (3.4) yields

$$
\frac{\partial \theta}{\partial t}=\frac{\partial}{\partial z}\left[K(\psi) \frac{\partial H}{\partial z}\right]
$$

In UNSAT-H, there are two sign conventions. The first convention concerns gravitational head. With the soil surface as the reference elevation, gravitational head can be equated with depth below the soil surface, $z$, and thus is 
negative. In UNSAT-H, however, depth measured from the surface is considered positive. Therefore, in UNSAT-H, gravitational head is equal to $-z$. The second convention concerns matric head, which is a negative number in unsaturated flow. In UNSAT-H, matric head is replaced with suction head (h), which is the negative of matric head. Thus, a positive suction head represents a matric head, and a negative suction head represents a pressure head. The calculation of hydraulic head then changes from $H=\psi+z$ to the UNSAT-H form

$$
H=-(h+z)
$$

Using the chain rule of differentiation, $\partial \theta / \partial t$ in Equation (3.5) can be replaced by $c(h)(\partial h / \partial t)$, where $c(h)$ represents $\partial \theta / \partial h$ (i.e., the negative of the specific moisture capacity). With this manipulation and the incorporation of the identity $h=-4$, Equation (3.5) becomes

$$
C(h) \frac{\partial h}{\partial t}=\frac{\partial}{\partial z}\left[K(h) \frac{\partial H}{\partial z}\right]
$$

Combining Equations (3.6) and (3.7) and adding a sink term (S) for water uptake by plants gives

$$
c(h) \frac{\partial h}{\partial t}=-\frac{\partial}{\partial z}\left[K(h)\left(\frac{\partial h}{\partial z}+1\right)\right]-S(z, t)
$$

where $S(z, t)$ indicates that the sink term is a function of depth and time. With slight rearrangement, Equation (3.8) is the same as that in Gupta et al. (1978), Gee and Simmons (1979), and Simmons and Gee (1981).

To arrive at Equation (3.8), we assumed that 1) fluid is incompressible, 2) air phase is continuous, 3) air phase is at constant pressure, 4) flow is one-dimensional, 5) flow is isothermal, and 6) vapor flow is negligible. The first three assumptions are routinely made for unsaturated soil water flow modeling and are considered valid for the Hanford Site at this time. The fourth assumption, one-dimensional flow, is considered valid for most nearsurface modeling efforts, provided the surface is uniform and nearly level and there is no overland flow. The fifth assumption, isothermal flow, is 
considered valid for the subsurface. At the surface, however, large temperature fluctuations are common and may induce flow. Attempts to quantify the error caused by neglecting temperature-induced flow have failed. Therefore, at this juncture, we have had to assume isothermal conditions. The final assumption, that vapor flow can be ignored, is not considered valid. Hanford Site soils dry out significantly during the summer and liquid-water conductivities decrease dramatically, to the point where diffusion of water vapor from the profile can be the dominant mode of water loss. For this reason, we have incorporated isothermal vapor flow into our conceptual model.

The approach taken to model vapor flow is identical to that outlined by Simmons and Gee (1981) and by Campbell (1985) and described by Fayer and Gee (1985). The total flux of water $\left(q_{t}\right)$ between two points in the soil is the sum of the liquid and vapor fluxes $\left(q_{1}\right.$ and $q_{v}$, respectively), or

$$
q_{t}=q_{1}+q_{v}
$$

The liquid flux is calculated with Equation (3.3). The vapor flux can be determined with Fick's first law of diffusion (Hillel 1980), which is

$$
q_{v}=\frac{-D v}{\rho_{w}} \frac{\partial \rho_{v}}{\partial z}
$$

$D_{v}$ represents the apparent diffusion coefficient of water vapor through the air space of the soil. The vapor density is $\rho_{v}$. The density of water, $\rho_{w}$, is included here to convert the units of vapor flux into units compatible with those of $q_{1}$. The apparent diffusion coefficient can be expressed as

$$
D_{v}=a(\phi-\theta) D_{a}
$$

(Hillel 1980). The parameter a, an empirical pore-tortuosity factor, is commonly given the value of 0.66 (Penman model). The total soil porosity is $\phi$, which means that the quantity $(\phi-\theta)$ represents the air-filled porosity. The diffusion coefficient of water vapor in bulk air is $D_{a}$. 
The vapor density at a specific point in the soil can be related to the saturated vapor density $\left(\rho_{v s}\right)$ and relative humidity $(R H)$ by

$$
\rho_{v}=\rho_{v s} R H
$$

The saturated vapor density can be calculated from the soil temperature $\left(T_{S}\right)$ with the empirical equation

$$
\rho_{V S}=1000 M \exp \left[54.878919-\left(6790.4985 / T_{S}\right)-5.02808 \ln \left(T_{S}\right)\right] / R T_{S}
$$

(Doorenbos and Pruitt 1977), where $M$ is the molecular weight of water and $R$ the gas constant. From the soil suction head (Campbell 1985), the relative humidity can be determined using

$$
\mathrm{RH}=\exp \left[\frac{\mathrm{hMg}}{\mathrm{RT}}\right]
$$

where $g$ is the gravitational constant. Using the chain rule of differentiation on Equation (3.9), differentiating Equation (3.11), and combining the results yields

$$
q_{v}=\frac{-D_{v}}{\rho_{w}} \frac{\partial \rho_{v}}{\partial h} \frac{\partial h}{\partial z}=\frac{D_{v} \rho_{v s} M g}{\rho_{w} R T} \exp \left[\frac{-h M g}{R T}\right] \frac{\partial h}{\partial z}
$$

Equation (3.12) is similar to the flux equation for liquid flow. As such, most of the parameters can be lumped together to yield a vapor conductivity term, $k_{V}$, where

$$
K_{V}=\frac{D_{v} \rho_{v s} M g}{\rho_{w} R T} \exp \left[\frac{-h M g}{R T}\right]
$$


Equation (3.8) can now be rewritten to include the contribution of vapor flow:

$$
c(h) \frac{\partial h}{\partial t}=\frac{-\partial}{\partial z}\left[K_{T}(h) \frac{\partial h}{\partial z}+K_{L}(h)\right]-S(z, t)
$$

where $K_{T}=K_{L}+K_{V}$. This equation is the modified Richards equation that serves as the primary differential equation solved by UNSAT-H. It describes change in water storage, redistribution of liquid water, isothermal vapor flux, and plant water uptake. This equation is applied at every point in the interior of the soil profile.

To solve the flow equation, UNSAT-H must be supplied with functional relationships for both hydraulic conductivity and water content as functions of suction head. The capacity term can be calculated by UNSAT-H from the soil water retention curve. Together, these two functions form the necessary set of hydraulic properties required by UNSAT-H. The UNSAT-H code contains three options for describing the soils hydraulic properties: polynomials (Bond, Cole, and Gutknecht 1984), Haverkamp functions (Haverkamp et al. 1977), and Campbel1 functions (Campbel1 1974).

The polynomial option allows up to four polynomials of the forms

$$
\begin{aligned}
\theta & =a+b \log (h)+c \log ^{2}(h)+d \log ^{3}(h)+e \log ^{4}(h) \text { and } \\
\log k & =a+b \log (h)+c \log ^{2}(h)+d \log ^{3}(h)+e \log ^{4}(h)
\end{aligned}
$$

to be used to describe each soil property. Bond, Cole, and Gutknecht (1984) developed a computer program that can be used to fit polynomials to measured soil hydraulic data and to ensure that the fit is continuous at each of the matching points. The two major advantages of this option are that the user can easily fit polynomials to any data set and that the user can extend the polynomials into the high suction head range. A disadvantage of the polynomial option is that is consumes slightly more computer time for representing soil properties than the other options. 
In the second option, the soil properties are described by equations of the forms

$$
\begin{aligned}
& \theta=\theta_{r}+\alpha\left(\theta_{s}-\theta_{r}\right) /\left(\alpha+|h|^{\beta}\right) \text { and } \\
& K=K_{s} A /\left(A+|h|^{B}\right)
\end{aligned}
$$

where $\theta_{r}$ is the residual water content, $\theta_{s}$ is the saturated water content, and a, b, A, and B are curve-fitting parameters (Haverkamp et al. 1977). The option exists in UNSAT-H to replace the $h$ term in Equation (3.15) with $\ln (h)$. Mckeon et al. (1983) developed two programs that can be used to fit the Haverkamp functions to measured soil hydraulic data.

In the third soil property option available, the Campbell functions (Campbell 1974), the soil properties are fit with equations of the forms

$$
\begin{aligned}
& \theta=\theta_{s}\left(h_{e} / h\right)^{(1 / b)} \text { and } \\
& K=k_{s}\left(h_{e} / h\right)^{(2+3 / b)}
\end{aligned}
$$

where $h_{e}$ represents the air-entry pressure head (the point at which the soil begins to desaturate) and $b$ is a curve-fitting parameter. A problem arises when this option is used for layered soils, however, because the soil properties are not described for head values below $h_{e}$. If two adjacent materials with different $h_{e}$ values should become nearly saturated, a situation could arise where flow is artificially induced in the wrong direction. Therefore, this option should not be used for layered systems.

\subsubsection{Transpiration}

The loss of water through plant water uptake and transpiration is treated as a sink term in the flow equation. The calculation of the sink term is accomplished in three steps. First, PET is partitioned into potential transpiration (PT) and potential evaporation (PE), subject to the constraint

$$
P E T=P T+P E
$$


In the second step, PT is distributed over the root zone in proportion to the relative root density at each depth. This effectively establishes a potential sink term for each depth. The final step is to modify the potential sink term of each node, based on its moisture content, to arrive at the actual sink term. Calculation of the sink term in this manner was proposed by Feddes, Kowalik, and Zaradny (1978).

There are two methods to partition PET in the UNSAT-H code. In the first method, PT is calculated from the leaf area index (LAI) with the equation

$$
P T=\operatorname{PET}(-0.21+0.70 \mathrm{LAI}) \text { for } 0.1 \leqslant L A I \leqslant 2.7 \text {, }
$$

developed by Ritchie and Burnett (1971) for cotton and grain sorghum. Ritchie (1972) noted that PET in Equation (3.16) was actually net radiation and not PET as calculated with the Penman combination equation (Doorenbos and Pruitt 1977). Seasonal LAI data are not currently available for the plant communities at the Hanford Site, hence this option has not been tested on Hanford data sets.

The second method for partitioning PET uses local cheatgrass data. Hinds (1975) conducted field experiments with cheatgrass growing in small microlysimeters located in a field plot on the Hanford Site's Arid Lands Ecology (ALE) Reserve. During April and May 1972, he measured total and net shortwave radiation, soil heat flux, evaporation, and transpiration, and calculated net longwave radiation with an empirical equation. Hinds then related transpiration to the total net radiation and computed what might be considered a crop coefficient. The relationship is shown in Figure 3.1 , with the shaded portion representing the ratio of transpiration to net radiation over a 2 -month period.

According to Klemmedson and Smith (1964), cheatgrass usually germinates in the fall, remains dormant during the winter, resumes growth in early spring, and flowers and dies of either maturity or lack of soil moisture by early June. To use UNSAT-H to simulate the phenology of cheatgrass, we have extended the transpiration relationship (shown as a cross-hatched area in Figure 3.1) throughout the growing season. The code user can do this by choosing two dates, NSOW and NHRVST. The first, NSOW, is the day when the cheatgrass seeds germinate. The second, NHRVST is the day when the cheatgrass plants cease 


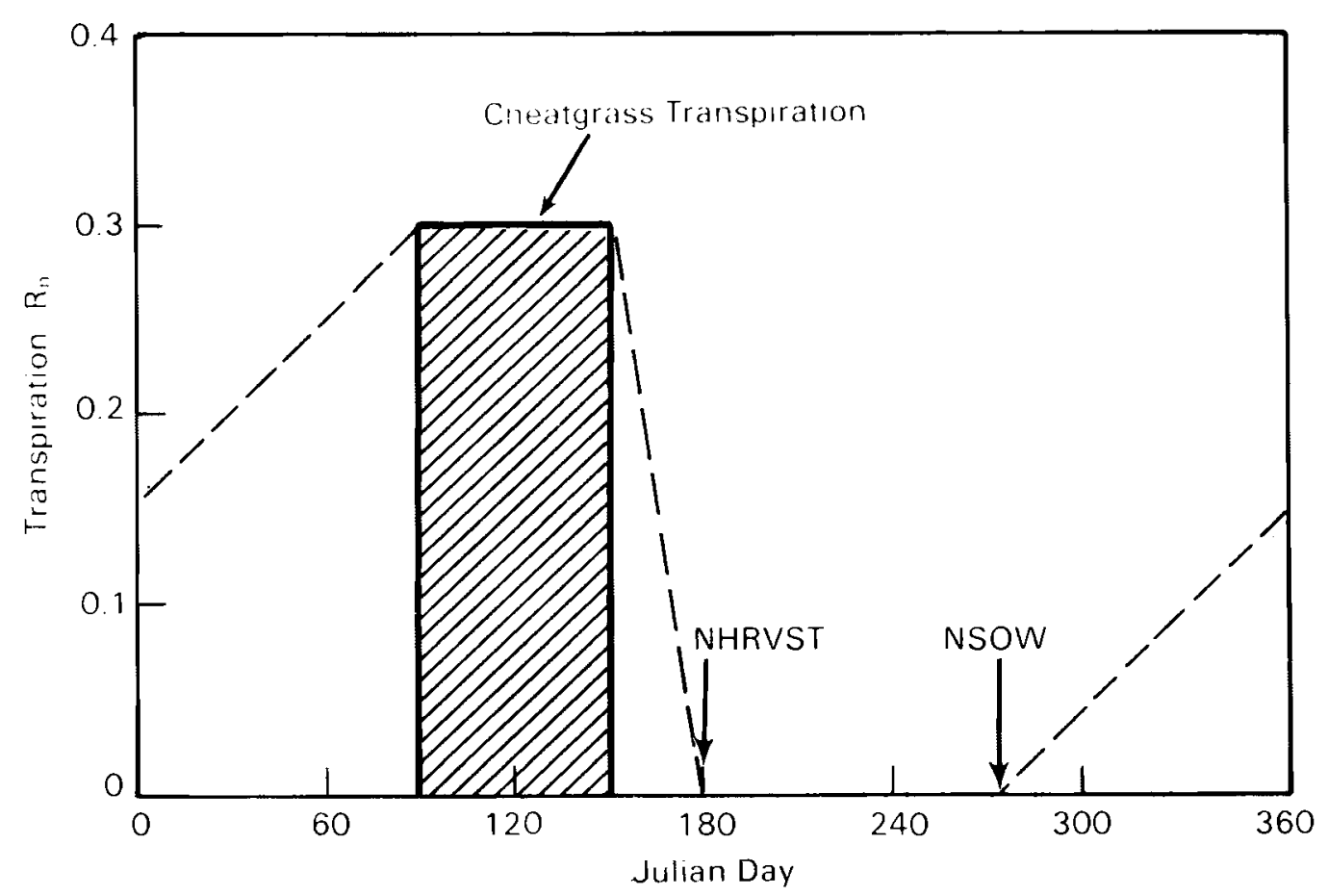

FIGURE 3.1. Relationship Between Transpiration, Net Radiation $\left(R_{n}\right)$, and Day of the Year

transpiring. Because the exact dates for these two parameters are unknown, they are left as variables for the code user. As seen in Figure 3.1, the transpiration/net radiation ratio increases linearly between NSOW and the first day of maximum transpiration (Day of the Year 90), and it decreases linearly from the last day of maximum transpiration (Day of the Year 151) to zero on NHR VST.

From year to year, plant biomass production (and thus transpiration) will vary from that observed during Hinds' experiment because of the weather or possibly nutrient availability. At the present time, the exact relationship between biomass and transpiration has not been established for cheatgrass or other common species at the Hanford Site. Therefore, an empirical relationship is used to estimate the effect of increased biomass on transpiration. Hinds (1975) measured a shoot biomass production of $220 \mathrm{~g} / \mathrm{m}^{2}$ over the course of his experiment. If we assume a direct relationship between shoot biomass and transpiration, we can alter the transpiration ratio within UNSAT-H by specifying a value for shoot biomass other than 220. For example, specifying a shoot 
biomass of $440 \mathrm{~g} / \mathrm{m}^{2}$ will result in doubling the transpiration/net radiation ratio, with the constraint that the ratio must fall between 0.0 and 1.0 .

Once PT is determined, the transpiration demand is applied to the root zone using the volumetric sink term of Equation (3.14). The sink term of each node is assigned a fraction of the transpiration demand, with the fraction calculated as the root-length density of the node divided by the total root length within the soil profile. Cline, Uresk, and Rickard (1977) have measured end-of-the-growing-season distributions of below-ground biomass (both living and dead tissue) in two plant communities on the ALE Reserve. Figure 3.2 shows the total root biomass distributions for an annual grass community (mostly cheatgrass) located at the 1000-ft elevation and for a perennial grass community (mostly bluebunch wheatgrass) located at the 1200-ft elevation. Note that the cheatgrass root biomass was greatest in the top $30 \mathrm{~cm}(0$ to $3 \mathrm{dm})$ of soil.

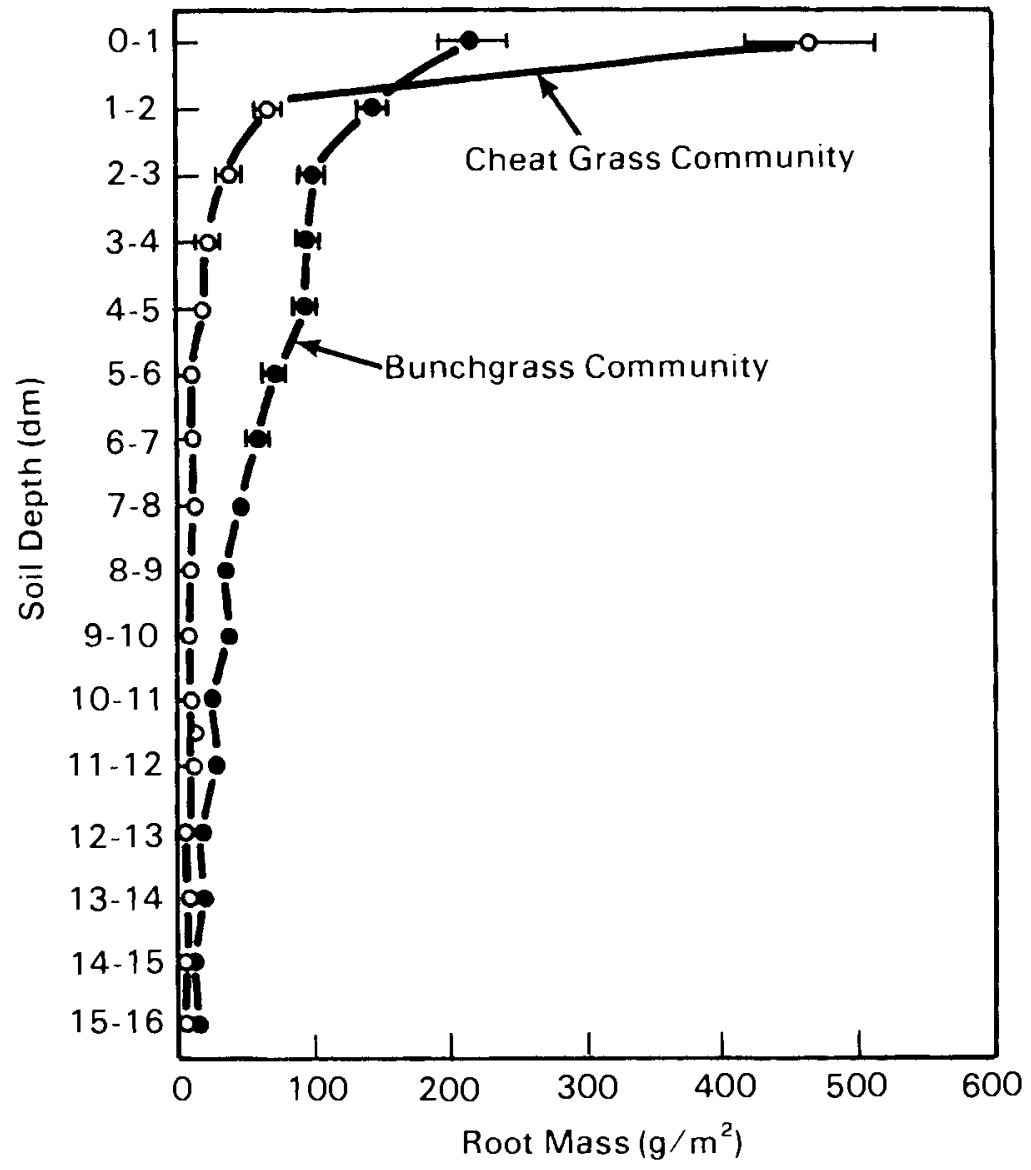

FIGURE 3.2. Root Mass at the End of the 1974 Growing Season in Cheatgrass and Bluebunch Wheatgrass Communities (After Cline, Uresk, and Rickard 1977) 
The cheatgrass root biomass data of Figure 3.2 were normalized (Table 3.1). Assuming that the normalized total root biomass could be directly related to root-length density, the root-length density (RHO) could be related to the depth $(z)$ below the surface by

$$
\mathrm{RHO}=\mathrm{a} \exp (-\mathrm{bz})+c
$$

where $a, b$, and $c$ are coefficients that optimize the fit to the normalized biomass data $(a=1.163, b=0.129$, and $c=0.020)$. The units of RHO are $\mathrm{cm}$ roots/cm soil. To calculate the root-density function (RDF), the values of RHO are multiplied by their respective depth intervals to obtain the total root length. Each RHO value is then divided by the total root length to obtain the RDF value for each depth. Table 3.1 contains the RDF values calculated for two depths of root penetration.

After PT is distributed throughout the root zone, the final step is to calculate the actual transpiration or sink term at each depth. This is done by multiplying the potential sink term $\left(S_{\text {pot }}\right)$ of each node by $\alpha_{f}$, a factor that is less than or equal to 1.0 and is a function of the soil water content of the respective node. The factor $\alpha_{f}$ relates the transpiration rate to the moisture status in the root zone. An example function is shown in Figure 3.3. When the

TABLE 3.1. Cheatgrass Root Biomass Data, Root-Length Density (RHO), and Root-Density Function (RDF)

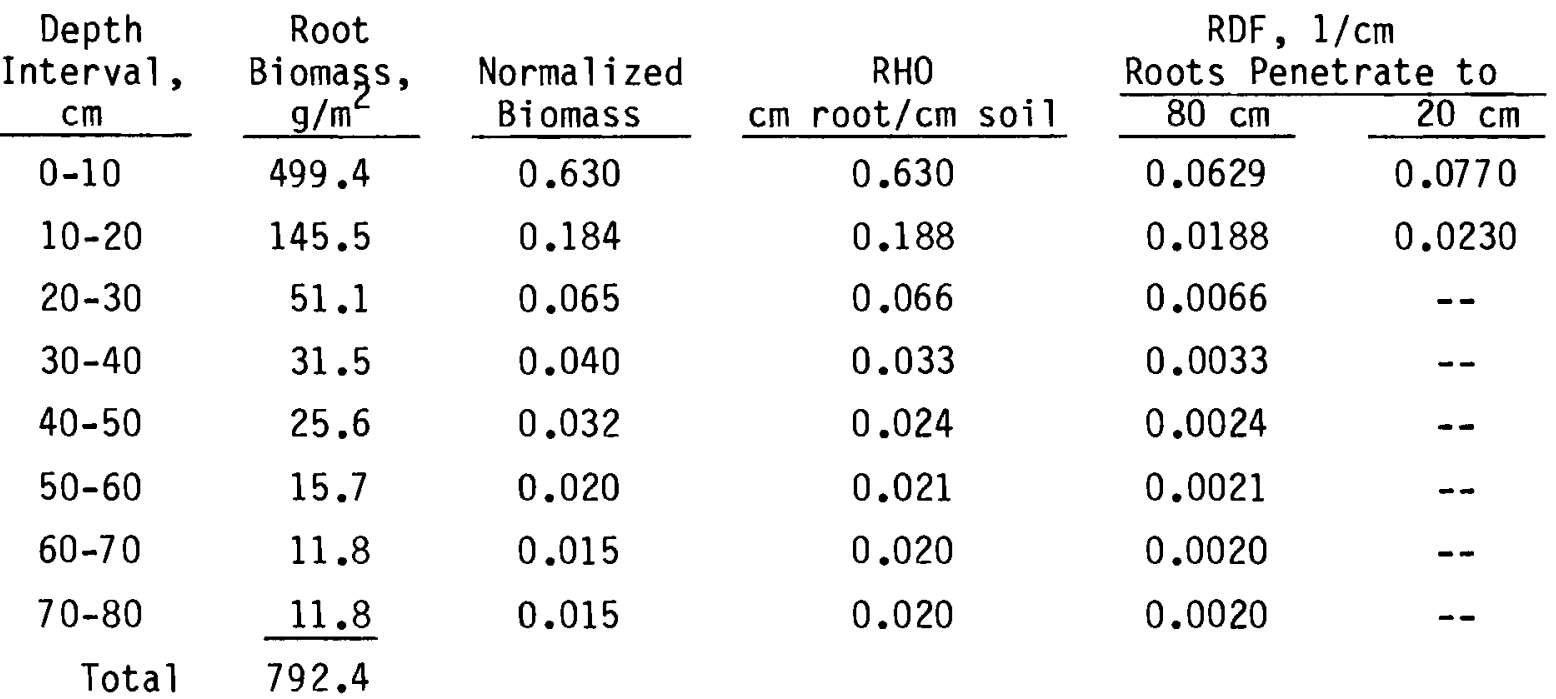




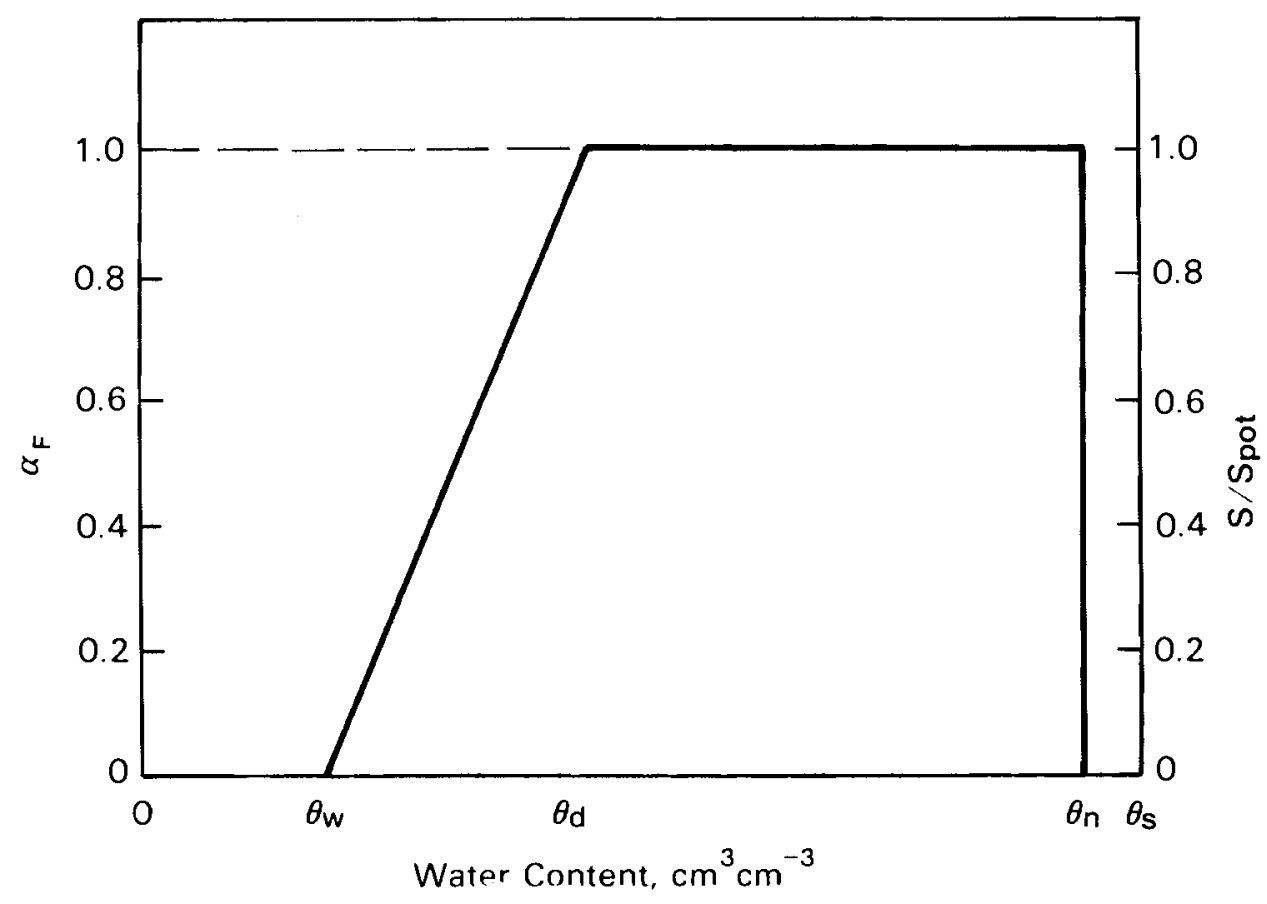

FIGURE 3.3. Actual Sink Term as a Function of the Water Content

soil moisture content of a node is greater than $\theta_{n}, \alpha_{f}$ equals zero because the soil is so wet that it is anaerobic, and the plant ceases water withdrawal from that node. When the soil moisture content is between $\theta_{d}$ and $\theta_{n}, \alpha_{f}$ is 1.0 and the rate of withdrawal is equal to $S_{\text {pot }}$. If the soil moisture content is between $\theta_{w}$ and $\theta_{d}$, the rate of withdrawal is reduced by the appropriate amount (see the variation in $\alpha_{f}$ in Figure 3.3). When the soil moisture content is less than $\theta_{w}, \alpha_{f}$ equals zero to indicate that the plant has stopped withdrawing water from that node. Currently, choices for moisture content values of $\theta_{W}$, $\theta_{d}$, and $\theta_{n}$ are left to the code user because data are lacking.

\subsubsection{Boundary Conditions}

The above discussion of the flow equation and the plant sink term apply to points in the interior of the soil profile. The flow of water across the surface and lower boundary of the soil is determined by boundary condition specifications.

During precipitation events, the upper boundary (i.e., the infiltration rate) is specified as a flux that is equivalent to the precipitation rate. If 
the head of the surface node should decrease below the minimum suction head, the upper boundary becornes a constant head equivalent to the minimum suction head. While the surface boundary is a constant head, infiltration is calculated as the sum of the change in storage of the surface node and the flux between the surface node and the one below it. The problem continues as one of constant head until the precipitation rate falls below the potential infiltration rate and the head of the top node increases above the minimum suction head. At that point, the upper boundary reverts to being a flux.

During evaporation, the surface boundary condition is either a flux or a constant head. The boundary condition will be a flux equivalent to the potential evaporation rate $(P E)$ as long as the suction head of the surface node does not exceed the maximum suction head, a value that corresponds to air-dry soil. When the maximum head is exceeded, the problem is continued with a constant head boundary in which the surface node head is held equal to the maximum head value. Under such conditions, the evaporation rate is always less than PE and is calculated as the sum of the change in storage of the surface node and the flux between the surface node and the one below it.

The second boundary to be specified is the lower boundary. Four options are available. The lower boundary can be set to a fixed-head, a unit-gradient, a flux, or an impermeable boundary (i.e., zero flux). The fixed-head option is most often chosen when the soil profile being simulated extends to a static water table, in which case the fixed-head value would be zero. The unitgradient option corresponds to gravity-induced drainage and is most appropriate when applied to soil profiles that extend at least out of the root zone and in which drainage is not impeded. With the unit-gradient lower boundary, the drainage flux that is calculated depends on the conductivity of the bottom node. Whenever drainage fluxes are known, they can be input directly using the flux option. Finally, the impermeable-bottom boundary condition can be used for situations in which drainage is restricted (e.g., in closed-bottom lysimeters). 

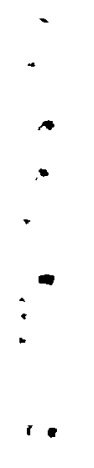


\subsection{NUMERICAL IMPLEMENTATION}

The equations used to represent our conceptual model are solved numerically with a Crank-Nicholson finite difference scheme. In this scheme, the mathematical equations are approximated with finite difference equations in which a finite grid represents both the space and time derivatives. There is some error associated with this approximation, but the error can be minimized by increasing the number of space and/or time grid intervals. The finite difference equations can be formed into a matrix that is amenable to an iterative solution scheme.

\subsection{FINITE DIFFERENCE APPROXIMATION}

In the Crank-Nicholson method, the time derivatives are evaluated at the grid midpoints. Thus, Equation (3.14) is approximated in the computer code as

$$
c_{i}^{j-1 / 2}\left(\frac{h_{i}^{j}-h_{i}^{j-1}}{t^{j}-t^{j-1}}\right)=\frac{-2}{z_{i+1}^{-z} i-1}\left[q_{j+1 / 2}^{j-1 / 2}-q_{i-1 / 2}^{j-1 / 2}\right]-s_{i}^{j-1 / 2}
$$

where

$$
\begin{aligned}
& c_{i}^{j-1 / 2}=\frac{c_{i}^{j}+c_{i}^{j-1}}{2} \\
& q_{i \pm 1 / 2}^{j-1 / 2}=\frac{q_{i \pm 1 / 2}^{j}+q_{i \pm 1 / 2}^{j-1}}{2}
\end{aligned}
$$

The subscript $i$ denotes the node at depth $z_{j}$. The superscript $j$ denotes the time step $t^{j}$. The sink term, $S_{j}$, is directly calculated in the code as a function of the time of day and the water content, $\theta_{j}^{j-1 / 2}$. 
The flux terms at the space node midpoints are approximated by

$$
\begin{aligned}
& q_{i+1 / 2}^{j}=k_{T}^{j}{ }_{i+1 / 2}\left(\frac{h_{i+1}^{j}-h_{i}^{j}}{z_{i+1}^{-z}}\right)+G k_{L}^{j}{ }_{j+1 / 2} \\
& q_{i-1 / 2}^{j}=k_{T}^{j}{ }_{i-1 / 2}\left(\frac{h_{i}^{j}-h_{i-1}^{j}}{z_{i}^{-z} i-1}\right)+G k_{L}^{j}{ }_{i-1 / 2}^{j}
\end{aligned}
$$

The $G$ term is the gravity flow factor. When $G$ has a value of 0 , the gravity contribution to flow is neglected, thus allowing for simulation of horizontal problems. When $G$ is 1 , the gravity contribution to flow is included.

The conductivity between nodes can be calculated as either the arithmetic mean, with an option for weighting the arithmetic mean to the upstream or downstream flow direction, or the geometric mean. The appropriate equations are

and

$$
\begin{aligned}
& K_{T}^{j}=\frac{\operatorname{UP}\left(K_{L}{ }_{i}^{j}+K_{V}^{j}\right)+\operatorname{DOWN}\left(K_{L_{i+1}}^{j}+K_{V}^{j}\right)}{2} \\
& K_{T+1 / 2}^{j}=\left[\left(K_{L_{i}}^{j}+K_{V}{ }_{i}^{j}\right)\left(K_{L_{i+1}}^{j}+K_{V}{ }_{i+1}^{j}\right)\right]^{1 / 2}
\end{aligned}
$$

for the arithmetic (where UP+DOWN = 1) and geometric means, respectively. values of $K_{L}$ are calculated from the input soil properties based on the head value of the corresponding node. The value of $K_{V}$ is calculated from

$$
k_{V_{i}}^{j}=\operatorname{VAPCOE}\left(\phi-\theta_{i}^{j}\right) \operatorname{EXP}\left[\frac{-h_{i}^{j} M g}{R T}\right]
$$

where VAPCOE is a collection of the constant terms in Equations (3.10) and $(3.13)$. 


\subsubsection{Interior Nodes}

Equation (4.1) is rearranged to solve for the head values at the end of a particular time step, with the general form of the rearranged equation being

$$
A_{i}^{*} h_{i-1}^{j}+B_{i}^{*} h_{i}^{j}+C_{i}^{*} h_{i+1}^{j}=D_{i}^{*}
$$

For the boundary nodes, the exact form of the coefficients in Equation (4.2) will depend on the boundary conditions chosen. For all interior nodes, however, the coefficients for nodes $I=2, n-1$ will be

$$
\begin{aligned}
& A_{i}^{*}=K_{T}^{j}{ }_{i-1 / 2}^{j}\left[\left(z_{i+1}-z_{i-1}\right)\left(z_{i}-z_{i-1}\right)\right] \\
& B_{i}^{*}=\frac{C_{i}^{j-1 / 2}}{t^{j}-t^{j-1}}-\left[K_{T_{i+1 / 2}^{j}}^{j} /\left(z_{i+1}-z_{i}\right)+k_{T_{i-1 / 2}^{j}}^{j} /\left(z_{i}-z_{i-1}\right)\right] /\left(z_{i+1}-z_{i-1}\right) \\
& c_{i}^{*}=k_{T}^{j} /\left[\left(z_{i+1}-z_{i-1}\right)\left(z_{i+1}-z_{i}\right)\right] \\
& D_{i}^{*}=\frac{C_{i}^{j-1 / 2} h_{i}^{j-1}}{t^{j}-t^{j-1}}-S_{i}^{j-1 / 2}-\frac{G}{z_{j+1}-z_{j-1}}\left(K_{L_{j+1 / 2}^{j}}^{j}-K_{L_{i-1 / 2}^{j}}^{j}\right) \\
& -\frac{1}{z_{i+1}-z_{i-1}}\left[k_{T_{i+1 / 2}^{j-1}}\left(\frac{n_{i+1}^{j-1}-n_{i}^{j-1}}{z_{i+1}-z_{i}}\right)-k_{T}^{j-1}\left(\frac{h_{i}^{j-1}-n_{i-1}^{j-1}}{z_{i}-z_{i-1}}\right)\right. \\
& \left.+G\left(K_{L_{i+1 / 2}^{j-1}}-K_{L_{i-1 / 2}}^{j-1}\right)\right]
\end{aligned}
$$




\subsubsection{Surface-Boundary Node}

The coefficients for node 1 will depend on the surface-boundary condition chosen. One option in UNSAT-H is to specify a constant head for node 1 . The resulting solution equation for node 2 is

$$
B_{2}^{*} h_{2}^{j}+C_{2}^{*} h_{3}^{j}=D_{2}^{*}-A_{2}^{*} h_{1}^{j}
$$

In this case, the number of equations in the solution matrix is reduced by one because $h_{1}$ is al ready known.

Another surface-boundary option in UNSAT-H is to specify a surface flux, either evaporation or precipitation. The special form of Equation (4.2) for this case looks like

$$
B_{1}^{*} h_{j}^{j}+C_{1}^{*} h_{2}^{j}=D_{1}^{*}
$$

where $A_{1}^{\star}=0$

$$
\begin{aligned}
& B_{1}^{*}=C_{i}^{j-1 / 2} /\left(t^{j}-t^{j-1}\right)-k_{T / 2}^{j} /\left(z_{2}-z_{1}\right)^{2} \\
& c_{1}^{*}=k_{T_{3 / 2}}^{j} /\left(z_{2}-z_{1}\right)^{2} \\
& D_{1}^{*}=\frac{c_{i}^{j-1 / 2} h_{i}^{j-1}}{t^{j}-t^{j-1}}-s_{i}^{j-1 / 2}-\frac{1}{z_{2}-z_{1}}\left[-2 q_{1 / 2}^{j-1 / 2}+G k_{L}^{j}\right. \\
& \left.+k_{T / 2}^{j-1}\left(\frac{h_{2}^{j-1}-h_{1}^{j-1}}{z_{2}-z_{1}}\right)+G K_{L_{3 / 2}^{j-1}}^{j}\right]
\end{aligned}
$$


Note that the time-averaged flux $q_{1 / 2}^{j-1 / 2}$ is specified by the user. If, during a time step, the surface head value should fall outside the range of values permitted (being either too wet or dry), then the surface head is set to the appropriate limit and the problem is re-solved for that time step for the remaining nodes. At the start of the next time step, the program will again assume a flux surface condition.

\subsubsection{Lower-Boundary Node}

Of the four options for determining the lower-boundary condition, one is a fixed-head option. In this option, the user specifies in the initial conditions what the head value of the node will be. The solution equation for node $n-1$ changes to

$$
A_{n-1}^{*} h_{n-2}^{j}+B_{n-1}^{\star} h_{n-1}^{j}=D_{n-1}^{\star}-C_{n-1}^{\star} h_{n}^{j}
$$

and the number of equations to be solved is reduced by one. The user can specify a constant water-table condition by using this fixed-head option and setting $h_{n}$ to zero.

The three remaining options are flux options. The general form of Equation (4.2) pertinent to all three options is

where

$$
A_{n}^{\star} h_{n-1}^{j}+B_{n}^{*} h_{n}^{j}=D_{n}^{*}
$$

$$
\begin{aligned}
& A_{n}^{\star}=K_{T-1 / 2}^{j} /\left(z_{n}-z_{n-1}\right)^{2} \\
& B_{n}^{\star}=\frac{C_{n}^{j-1 / 2}}{t^{j}-t^{j-1}}-k_{T}^{j}{ }_{n-1 / 2}^{j} /\left(z_{n}-z_{n-1}\right)^{2} \\
& C_{n}^{\star}=0
\end{aligned}
$$




$$
\begin{aligned}
& D_{n}^{\star}=\frac{C_{n}^{j-1 / 2} h_{n}^{j-1}}{t^{j}-t^{j-1}}-\frac{1}{z_{n}-z_{n-1}}\left[2 q_{n+1 / 2}^{j-1 / 2}-k_{T-1 / 2}^{j-1}\left(\frac{h_{n}^{j-1}-h_{n-1}^{j-1}}{z_{n}-z_{n-1}}\right)\right. \\
& \left.-G K_{L-1 / 2}^{j-1}-G K_{L}^{j}{ }_{n-1 / 2}^{j}\right]
\end{aligned}
$$

For the impermeable-boundary option, $q_{n}$ is set to zero. For the specified-flux boundary, $q_{n}$ is set to values entered by the code user. For the unit-gradient boundary condition, the flux is calculated as

$$
q_{n+1 / 2}^{j-1 / 2}=\frac{1}{2}\left(K_{L_{n}}^{j}+K_{L_{n}}^{j-1}\right)
$$

\subsection{TIME STEPS}

To solve the system of non-linear equations with a minimum of the error associated with the time discretization, the time steps must be kept smal1. Optimally, the time-step size would be infinitesimal. Practically, however, the time-step size must be finite to ensure that a solution can be reached in a reasonable amount of real time. In UNSAT-H, the time step is allowed to vary between specified minimum and maximum values. The actual size of a particular time step will depend on the assessment of the mass-balance error. The only other controls on the time step are that the sizes of the initial time step and the time step at the start of an infiltration event are specified by the code user.

During simulations, time-step adjustments are carried out in the following manner. At the end of each time step, an error calculation is performed and that error term is compared to the allowable limit. If the limit is exceeded, the present time-step calculations are rejected, the time step is reduced, and the solution matrix is recalculated and solved. This process will continue to occur until either the error term is within the allowable level or the time step is reduced below the minimum time-step value. At that point, the program will accept the solution and its error and proceed with the simulation using the prescribed minimum time step. 
When the error is within the allowable limit, the next time step will be increased relative to the one just completed. Each successive time-step size can be increased until the maximum allowable time step, as defined by the user, is reached. From then on, as long as the error criteria are satisfied, the time-step size will be set to the maximum value.

There are two options for calculating an error term in UNSAT-H. The first, which is identical to that used by Gupta et al. (1978), is to monitor the nodes for the largest fractional change in $\theta$ over each time step. The largest fractional change is calculated as

$$
\text { Error }=\operatorname{MAx}\left|\frac{\theta_{i}^{j}-\theta_{i}^{j-1}}{\theta_{i}^{j-1}}\right|
$$

Although this is not exactly an error term, it does allow the user to monitor the system for the node with the fastest-changing moisture content. Generally, that node is likely to be the point of the greatest simulation error.

The second option in UNSAT-H is to calculate an actual mass-balance error. First, soil-water storage at the end of a time step is calculated using

$$
w^{j}=\theta_{1}^{j} \frac{\left(z_{2}-z_{1}\right)}{2}+\theta_{n}^{j} \frac{\left(z_{n}-z_{n-1}\right)}{2}+\sum_{i=2}^{n-1}\left[\theta_{i}^{j} \frac{\left(z_{i+1}-z_{i-1}\right)}{2}\right]
$$

Then the mass balance error for the time step can be obtained using

$$
\text { Error }=\Delta I^{j}-\Delta E^{j}-\Delta T^{j}-\Delta D^{j}-\Delta W^{j}
$$

where the terms $\Delta I^{j}, \Delta E^{j}, \Delta T^{j}, \Delta D^{j}$, and $\Delta W^{j}$ refer to the amounts of infiltration, evaporation, transpiration, drainage, and change in storage, 
respectively, that have taken place over the time step. As with the first time-step option, this error term can be compared with the maximum allowable error to determine if the time-step size should be increased or decreased. 


\subsection{CODE DESIGN}

The UNSAT $-H$ model consists of three main programs: DATAINH, UNSATH, and DATAOUT. The interconnections among these three programs, as well as the file specifications and subroutine calls, are illustrated in Table 5.1. The "*" in the file names is a "wildcard character" that can be replaced by any problem name. For example, the input file for a drainage problem might be called DRAIN.INP. The three-character ending of the filenames (e.g., BIN, RES) is called the "filename extension". There is a convention in the UNSAT-H model that BIN indicates a binary input file, INP an ASCII input file, RES a binary results file, and LIS and OUT are ASCII results files.

\subsection{INPUT PROGRAM DATAINH}

The purpose of DATAINH is to process the input data that is destined for the UNSAT-H program. Having DATAINH preprocess the data lessens the likelihood that UNSAT-H will fail to run because of input errors. Thus jobs (program runs) submitted to run overnight have a greater likelihood of running successfully given that the input data have already been checked by DATAINH.

The DATAINH program, which is run interactively, reads the data contained in the specified *. INP file, checks for errors, performs calculations, and then writes the data in binary form to a file with the same name as the input file but with the extension BIN. The error checking done by DATAINH mostly involves

TABLE 5.1 Data Flow, Program Tasks, and Subroutines

\begin{tabular}{|c|c|c|c|c|}
\hline $\begin{array}{l}\text { Input } \\
\text { Files }\end{array}$ & Program & Purpose & $\begin{array}{l}\text { Output Files } \\
\text { or Device }\end{array}$ & $\begin{array}{l}\text { Subroutines } \\
\text { and Functions }\end{array}$ \\
\hline $\begin{array}{l}\text { *. INP } \\
\text { (ASCI I } \\
\text { format) }\end{array}$ & DATAINH & $\begin{array}{l}\text { Process Input } \\
\text { Data }\end{array}$ & $\begin{array}{l}\text { *.BIN (binary } \\
\text { format) }\end{array}$ & $\begin{array}{l}\text { MYHRLY,POLYCH, } \\
\text { POLYKH, POLYTH, RHO }\end{array}$ \\
\hline $\begin{array}{l}\text { *. BIN } \\
\text { (binary } \\
\text { format) }\end{array}$ & UNSATH & Model Calculations & $\begin{array}{l}\text { *.RES (binary } \\
\text { format) }\end{array}$ & $\begin{array}{l}\text { DELCHK ,POL YCH, POLYKH, } \\
\text { POLYTH, RHO, TRIDAG }\end{array}$ \\
\hline $\begin{array}{l}\text { *.RES } \\
\text { (binary } \\
\text { format) }\end{array}$ & DATAOUT & $\begin{array}{l}\text { Process Output } \\
\text { Data }\end{array}$ & $\begin{array}{l}\text { screen, printer, } \\
\text { *.OUT, *. LIS, } \\
\text { TOSS.OUT (ASCII } \\
\text { format) }\end{array}$ & $\begin{array}{l}\text { HARDCOPY, LISTDATA, } \\
\text { READREC, REINIT, SCAN, } \\
\text { SUMMARY }\end{array}$ \\
\hline
\end{tabular}


checking whether the choices for various options exist. (e.g., if an option 3 was chosen although only options 1 and 2 exist), whether array dimensions are exceeded, and whether rainfall dates are listed in ascending order.

Besides error checking, DATAINH also calculates 1) water contents, conductivities, and capacities at both the upper and lower head limits 2) a vapor transport coefficient; 3) leaf area index for each day of the simulation;

4) the maximum depth of root penetration for the simulation period; 5) $\theta w, \theta d$, and $\theta$ for each soil material; 6) hourly factors for distributing the daily PET; 7) the daily bottom flux (if chosen as an option); and 8) potential transpiration and evaporation, the sum of which is PET.

Whenever estimates of soil hydraulic properties are required, DATAINH calls the subroutines POLYCH, POLYKH, and POLYTH to calculate capacity, conductivity, and water content, respectively. Plant rooting distribution is calculated with a call to the function RHO. Note that UNSAT-H uses the identical function. Hourly factors to distribute daily PET are calculated by the subroutine MYHRLY.

All of the data required by UNSAT-H are output to a *.BIN file in the arrangement shown in Figure 5.1. Dimensions and variable type for each parameter are shown in the code listings located in Section 8.1 .

\subsection{UNSAT-H}

The UNSAT-H program is the heart of the model. The *.BIN file created by DATAINH serves as the input file for UNSAT-H. The major steps executed within

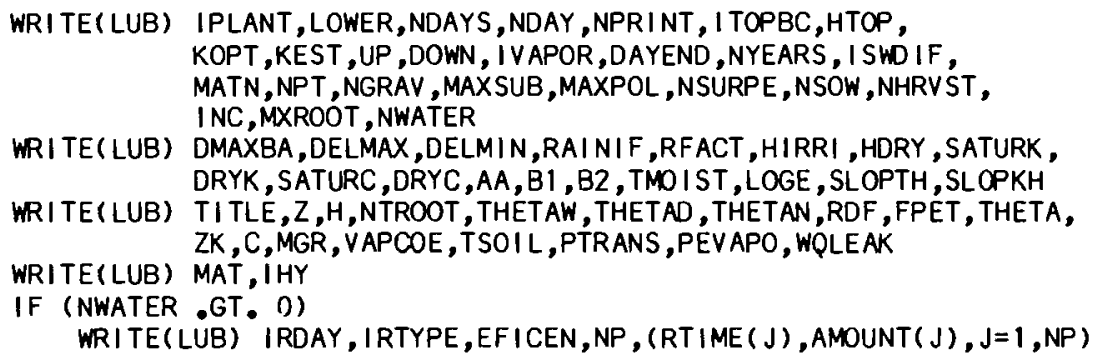

FIGURE 5.1. Format of the *.BIN File Created by DATAINH For Input to UNSAT-H. LUB is a logical name for the binary output file. 
UNSAT-H are illustrated in Figures 5.2 and 5.3. The steps start with data input and end with the final simulation summary output to file *.RES.

While executing, UNSAT-H calls the subroutines POLYCH, POLYKH, and POLYTH whenever soil hydraulic property information is needed. When plants are being simulated, function $\mathrm{RHO}$ is called to calculate the rooting density. Subroutine DELCHK is called at the end of every time step. If the solution for a particular time step is judged to be unsuccessful (e.g., mass-balance error too large), the solution is rejected, DELCHK decreases the time-step size and the problem is resolved. Conversely, if the solution is acceptable, DELCHK projects an increased time-step size to the next step. The projected time-step size is bounded by user-determined maximum and minimum limits. The final subroutine called hy UNSAT-H is TRIDAG, which is the matrix solver.

A certain amount of simulation data is output to the *. RES file, including initial conditions, DELSUB and day-end values for head, moisture content, fluxes, sinks, water balance terms, and, at the end of the file, the simulation-end results. The *.RES format is shown in Figure 5.4 while the dimensions and variable type for each parameter are shown in the code listings in Section 8.1 .

\subsection{OUTPUT PROGRAM DATAOUT}

The purpose of DATAOUT is to process the UNSAT-H output data. Specifically, DATAOUT converts the binary output data into ASCII format so that the results can be sent to a screen for viewing or to either a printer or a file for a permanent record. The program DATAOUT, which is run interactively, reads the first record of the data file and uses subroutine READREC to read the DELSUB and daily summaries and subroutine SUMMARY to read the simulation-end summary. The main program, DATAOUT, uses the four subroutines described in Table 5.2 to output the data. 


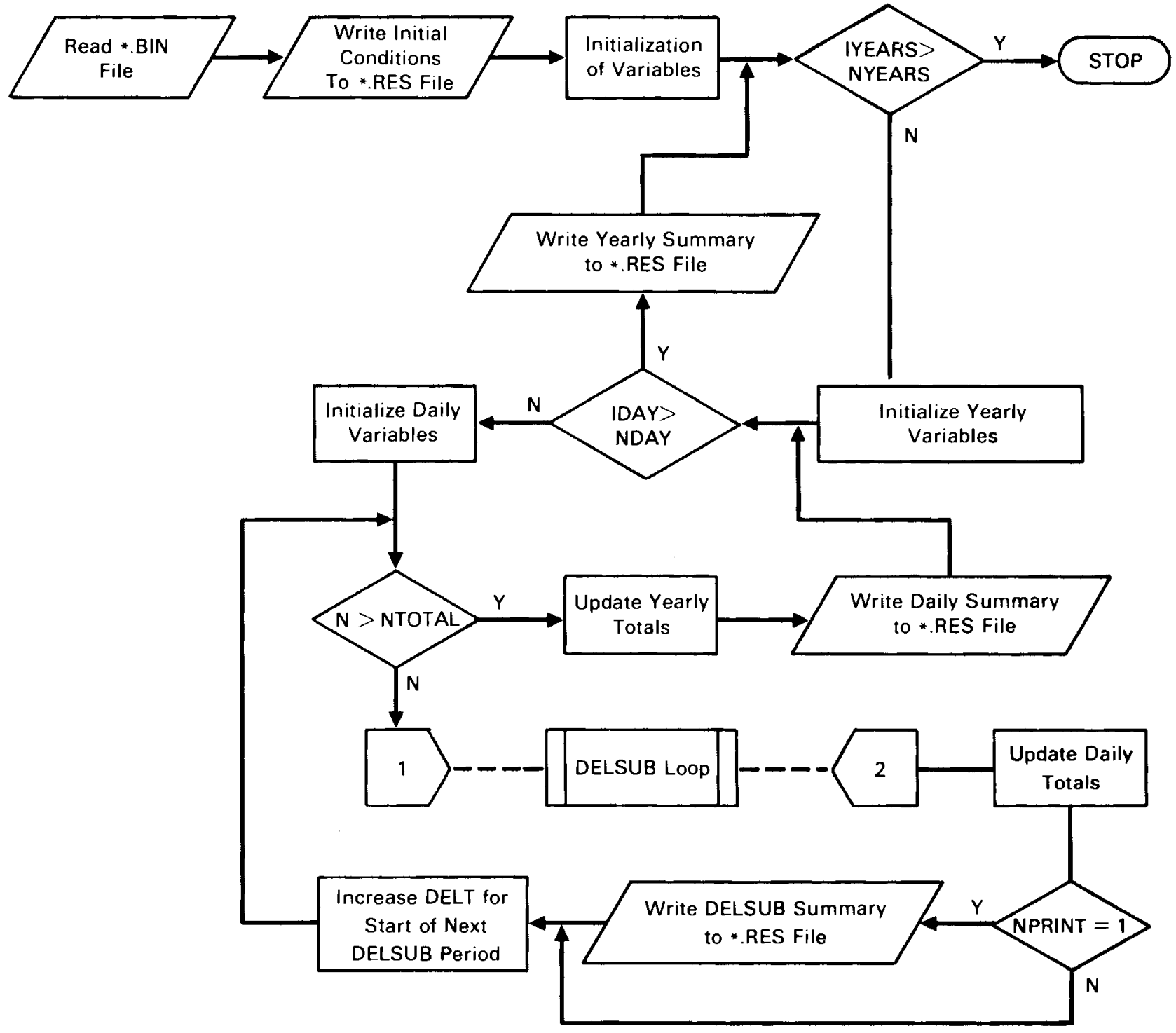

FIGURE 5.2. Flow Chart of UNSAT-H 


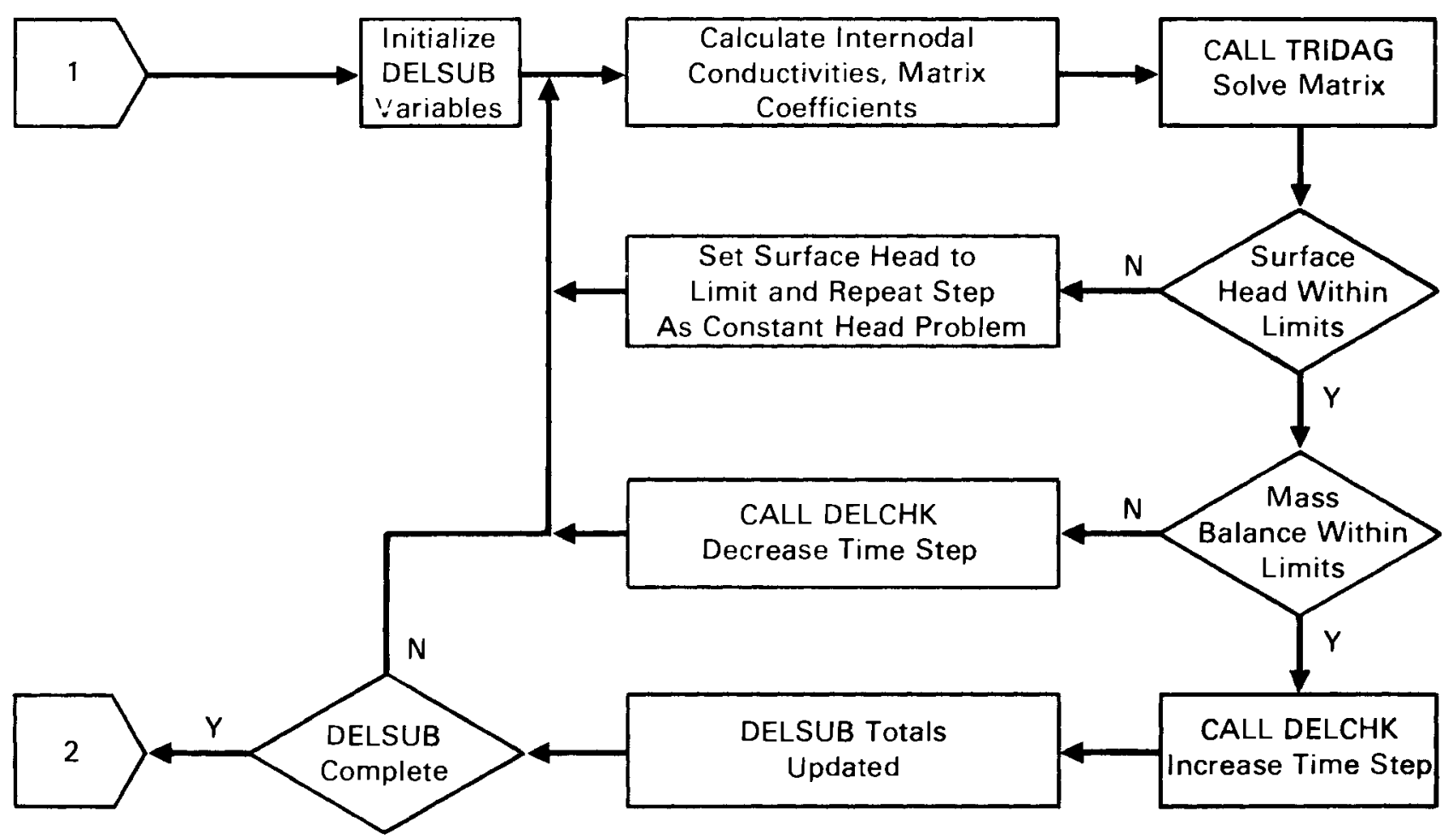

FIGURE 5.3. Flow Chart of DELSUB Loop Within UNSAT-H

C Output of simulation parameters to first record of *.RES fille

WRITE (LUB, REC $=1)$ NPT, IPLANT, $(Z(1), 1=1$, ,NPT ), DAYEND, NPRINT, NSURPE, NTOTAL, I FILE, SDATE, STIME

C Output of daily totals at the end of each simulated day

C (format for DELSUB totals is identical)

IF (IPLANT .EQ. O) THEN

WRI TE (LUB, REC $=$ (REC) IDAY, HOUR, $(H(J), \operatorname{THETA}(J), D A Y Q(J)$,

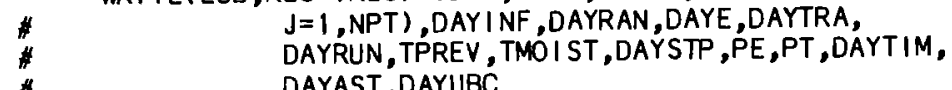

\# DAYAST, DAYUBC

ELSE

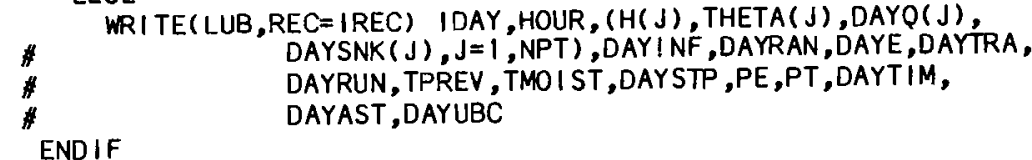

C Output of simulation totals at the conclusion of the simulation

WRITE(LUB, REC=IREC) IDAY,G, IPLANT, TPET, TPT, TTRA, TPE ,TE, TETRAN,

\# TRUNOF, TINF, TTIM, TRAIN,APLIED, TTIRRI, TMO IST, TERR,

\# $\quad$ TSTP, $(T Q(1), 1=1, N P T), T A S T, T U B C$

FIGURE 5.4. Format of the *.RES Output File Created by UNSAT-H. LUB is a logical name for the binary output file. 
TABLE 5.2. Subroutines Called by DATAOUT

Subroutine

REINIT

SCAN

HARDCOPY

LISTDATA
Function

Creates an output file (called TOSS.OUT) containing the final simulation head values in a format ready for inclusion in a *. INP file. The TOSS.OUT file can serve as the initial condition for simulating the next year. This option performs the same function as the program REINITIAL does for UNSATID (Bond, Cole, and Gutknecht 1984).

Allows the user to see on the screen a summary of the initial conditions, any day of the simulation, or the final simulation results. No hardcopy listings are created here.

Creates $a *$.OUT file. There are two choices for what goes into the file: a summary of the first and last simulation days and the simulation summary, or a summary of every DELSUB period and day as well as the simulation summary. The *.OUT file generated with the second choice is very similar to the *.OUT file created by UNSATID (Bond, Cole, and Gutknecht 1984).

Generates data files for plotting purposes. Variables that can be listed as a function of time include head, water content, infiltration, fluxes, and storage. 


\subsection{USER MANUAL}

There are three basic steps to using the UNSAT-H model to solve a flow problem. First, the problem must be formulated in terms of the conceptual model and available site characterization data. Second, the data necessary to describe the formulated problem must be assembled in a form that can be used by the model. Finally, the model is run and the results processed for eventual analysis.

\subsection{PROBLEM FORMULATION}

Application of the model to a particular problem requires that the problem be formulated in terms understood by the model. Problem formulation entails constructing the space grid, assigning soil and plant properties, defining the boundary conditions, and specifying program control options.

As an example, suppose that the water dynamics of the site illustrated in Figure 6.1 a are to be simulated. The first action would be to note that the problem is one of vertical flow and therefore requiring a grid of nodes arranged in the vertical direction, as in Figure 6.1b. The nodal spacing should be very small near the surface and get progressively larger moving downward through the profile. The smaller node spacing near the surface is necessary for a correct solution because very large and sudden changes in suction head are expected as the surface dries and wets up because of evaporation and precipitation. Therefore, node spacing of $0.1 \mathrm{~cm}$ near the surface is commonly used. In situations where head changes at the surface are less dramatic, such as under constant ponding, the node spacing can be increased. By convention, the first node is located at the soil surface and the last node at the bottom of the simulated soil profile.

There is a definite trade-off between the number of nodes simulated and computer time. Other things being equal, a greater number of nodes will provide a more accurate solution but will require more computer time. If you are uncertain whether a sufficient number of nodes was used for a particular problem, repeat the simulation with more nodes and see if the solution changes. If the solution remains nearly the same, then the extra nodes were not necessary. 


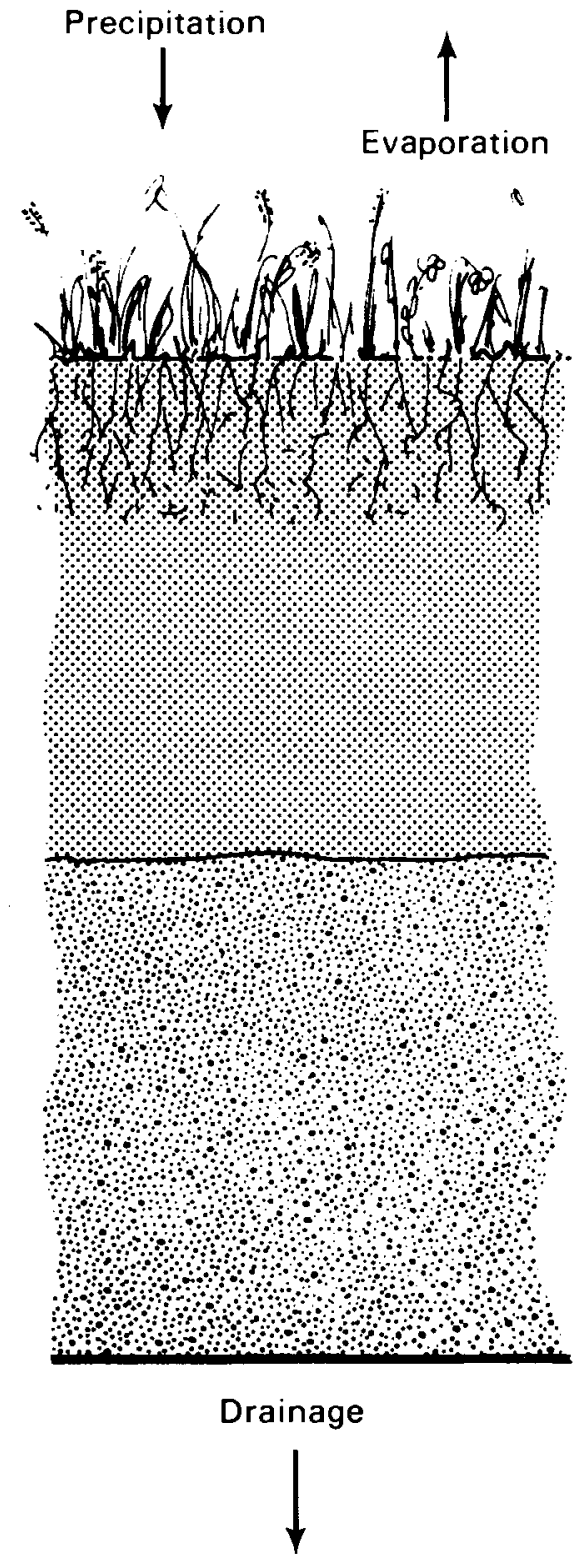

(a)
Hourly Rainfall

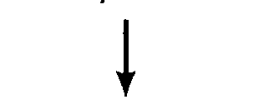

$\uparrow_{E T=f(P E T)}$
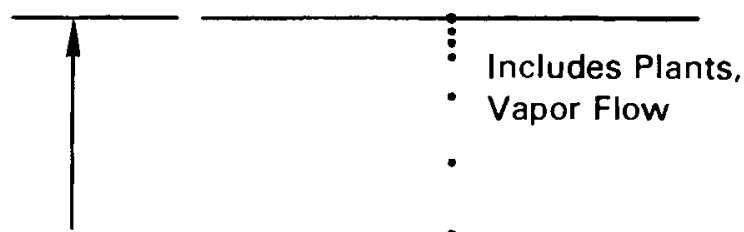

- Vapor Flow

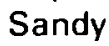

Loam

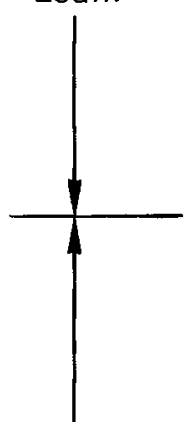

Loamy

Sand
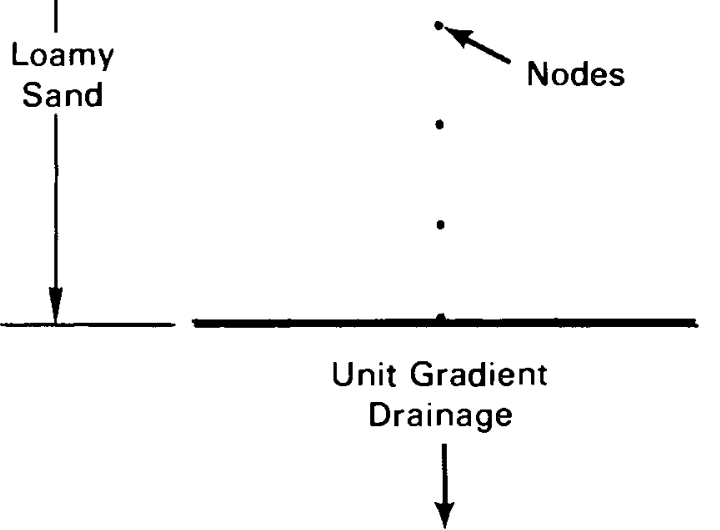

(b)

FIGURE 6.1. Example Problem Formulation: a) Site Description; b) Mode1 Representation 
If the solution does change, then the original number of nodes was too small, ie., the node spacing was too large. In that case, repeat the simulation with smaller node spacings until the solution does not change measurably.

In the particular example shown in Figure 6.1, the soil type changes at the midpoint of the profile. This kind of change may present some difficulty. Therefore, decrease the node spacing near the interface of two materials so that there are more nodes in that vicinity. Again, the number of nodes should be increased (i.e., nodal spacing decreased) until the solution does not change.

After constructing the space grid, the next step is to assign soil properties. In the example in Figure 6.1, there are two soil types. Nodes located in the zone of each soil would be assigned the soil hydraulic properties of that soil. In many situations, soil layering is less clearly defined. In those cases, decide which soil types are dominant, perhaps averaging soil properties for the whole soil. For example, the hydraulic properties of two soils may be sufficiently alike that they can be considered as one soil.

Once soil properties have been assigned, decide on initial conditions, i.e., specify the head values at the start of the simulation period. In most instances, soil characterization data will consist of moisture content measurements taken with a neutron probe at several depths within the profile. From these measurements, moisture contents must be assigned to each node. Unfortunately, the depths of measurement are unlikely to coincide with the nodal depths. Therefore, the nodal moisture content values must be interpolated between the moisture content measurements. The nodal moisture contents must then be converted to head values (the initial conditions required by UNSAT-H) according to the soil hydraulic properties assigned to the respective node.

The next stage in problem formulation is to describe any plants present. The plant data required include fractional cover, dates of germination and death, rooting depths, and plant responses to moisture stress.

Boundary conditions must be identified next. The lower boundary in Figure 6.1 is unknown. We know that it is not impermeable, that we do not have measurements of the drainage rate, and that the head of the lowest node is not 
likely to remain constant for long periods of time. As an approximation, a unit gradient can be assumed to exist at the lower boundary because the boundary is well below the root zone. For the surface boundary, potential evapotranspiration (PET) and precipitation rates must be supplied. Daily PET can be calculated from meteorological data using programs such as FAOPET (Doorenbos and Pruitt 1977). Precipitation rates can be entered directly.

The program control variables to be decided include length of time to be simulated, whether hourly or daily data are to be output, maximum and minimum time-step size, and mass-balance error limit. Some of these choices will affect the amount of computer time necessary to solve the problem. For instance, limiting the maximum time step or using very small mass-balance error limits will increase the computer time. However, such choices will probably yield a more accurate solution. Because there is such a tradeoff between benefits and their costs, the parameters should be chosen carefully. Several trial runs should be made to optimize both solution accuracy and computer time. (See Section 4.2 for a discussion of time steps.)

\subsection{INPUT REQUIREMENTS}

Once a problem has been formulated, the data must be collected into a *.INP file with the format expected by the program DATAINH. That format is specified below. Note that the words "card," "line," and "record" are considered interchangeable, although the word "record" is used here exclusively.

OPTIONS, CONSTANTS, AND LIMITS

$$
\begin{aligned}
& \begin{array}{l}
\text { Record 1: Format (A80) } \\
\text { Column } \\
\text { No. } \\
\text { 1-80 }
\end{array} \frac{\text { Variable }}{\text { TITLE }}
\end{aligned}
$$

Description

Problem description or identifier. This variable is passed through to the output file. 
Record 2: Format (4I5)

Column

$\frac{\text { No. }}{1-5} \quad \frac{\text { Variable }}{\text { IPLANT }}$

Description

6-10 LOWER

11-15 NGRAV

Plant option

(0) No plants

(1) Plants

Lower boundary condition option

(1) Unit gradient

(2) Constant head (e.g., a value of zero would correspond to a static water table)

(4) Specified bottom flux

(5) Impermeable boundary

Orientation of the profile

(0) Horizontal

(1) Vertical

16-20 ISWDIF 0ption for time step control

(0) Check all nodes to see if the fractional change in THETA of every node is less than DMAXBA

(1) Reduce the time step if the mass balance for the whole profile exceeds DMAXBA

Record 3: Format (4I5)

Column

$\frac{\text { No. }}{1-5} \quad \frac{\text { Variable }}{\text { NPRINT }}$

6-10

NDAYS

DAYEND

$16-20$

NYEARS

Description

Option for level of output

(0) Daily summaries and end-of-simulation summary

(1) DELSUB and daily summaries and end-of-simulation summary. Limited to 15 days because of the amount of output

Number of days for which data is provided

Ending day of the simulation. DAYEND cannot exceed 365 days

Number of years for the simulation to be run. A value of 1 will result in a single-year simulation 


\begin{tabular}{|c|c|c|}
\hline No. & Variable & Description \\
\hline $1-5$ & NSURPE & $\begin{array}{l}\text { Option to allow evaporation when there are no plants } \\
\text { (0) No evaporation } \\
\text { (1) Evaporation }\end{array}$ \\
\hline $6-10$ & NFHOUR & $\begin{array}{l}\text { Option to distribute the daily potential evapotranspira- } \\
\text { tion (PET) value over the } 24 \mathrm{~h} \text { of the day } \\
\text { (1) User supplies } 24 \text { hourly factors } \\
\text { (2) Hourly factors are generated with a sine wave } \\
\text { function for the hours between } 0600 \text { and } 1800 \text {, } \\
\text { while the remaining hourly factors are set } \\
\text { equal to } 0.01\end{array}$ \\
\hline $11-15$ & I TOPBC & $\begin{array}{l}\text { Option for the surface boundary condition } \\
\text { (0) Flux } \\
\text { (1) Constant head. If this option is chosen, } \\
\text { specify the constant surface head value, HTOP }\end{array}$ \\
\hline
\end{tabular}

Record 5: Format (315)

Column

No. Variable

$1-5 \quad$ KOPT

6-10 KEST

(3) Geometric mean

11-15 IVAPOR Option to allow vapor flow. If chosen, values must be supplied for TORT, TSOILC, and VAPDIF (Record 28) 
Record 6: Format (3F10.0)

Column

No. $\frac{\text { Variable }}{1-10} \quad \frac{\text { HIRRI }}{11-20}$

Description

11-20 HDRY

21-30 HTOP

Minimum head to which the soil can wet up (units: $\mathrm{cm}$ )

Maximum head to which the soil can dry out

(units: $\mathrm{cm}$ )

Constant head value of the surface node when the ITOPBC = 1 option is chosen (units: $\mathrm{cm}$ )

Record 7: Format (3F10.0)

Column

$\frac{\text { No. }}{1-10} \quad \frac{\text { Variable }}{\text { DMAXBA }}$

Description

Time step control parameter. If ISWDIF $=0$, DMAXBA

is the maximum allowable fractional change in the water content of any node [suggested value is 0.01 (no units)].

If ISWDIF $=1$, DMAXBA is the maximum allowable mass balance error (units: $\mathrm{cm}$ )

11-20 DELMAX Maximum allowable time step, normally $1 \mathrm{~h}$ (units: $h$ )

21-30 DELMIN Minimum allowable time step

(units: $h$ )

Record 8: Format (3F10.0)

Column

$\frac{\text { No. }}{1-10} \quad \frac{\text { Variable }}{\text { WTF }}$

Description

Weighting factor (from 0.0 to 1.0 ) used to weight the conductivity of the upstream node in the calculation of midnode conductivities. A value of 0.5 weights the nodes equally

11-20 RFACT Maximum time step factor. The time step can be potentially increased by this factor following the completion of a successful time step

21-30 RAINIF Rainfall initiation factor. At the start of any water application event, the time step will be reduced by the RAINIF factor

NODE INFORMATION

Record 9: Format (2I5)

Column

$\frac{\text { No. }}{1-5} \quad \frac{\text { Variable }}{\text { MATN }}$

Description

Number of different soil materials

Number of nodes 


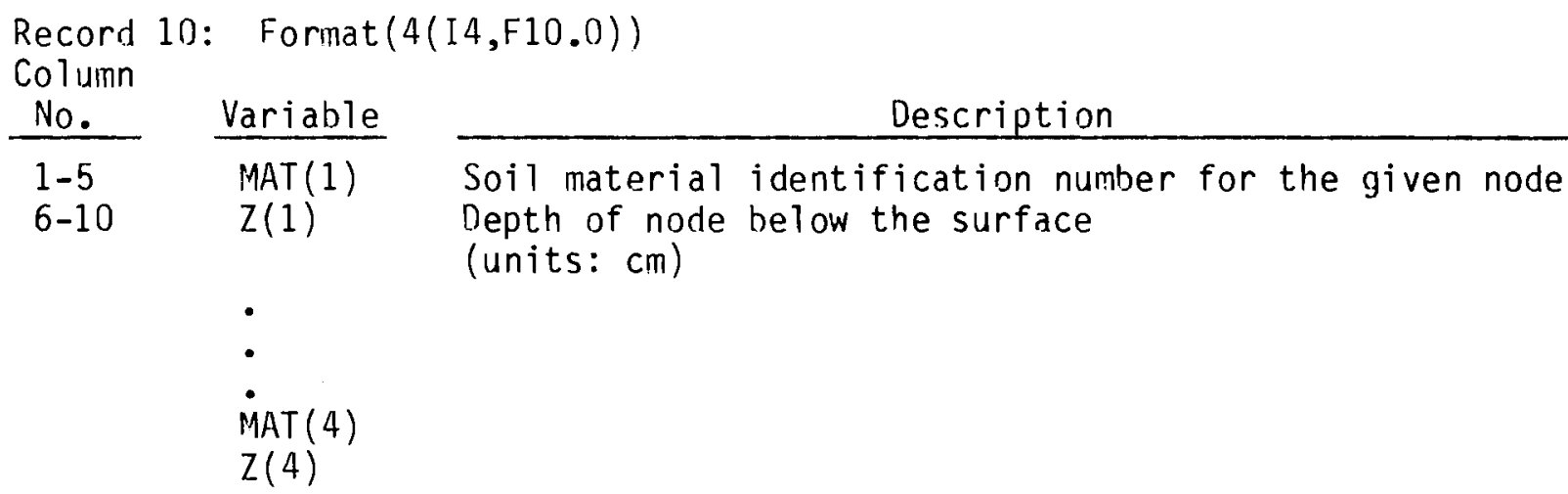

Note: Repeat Record 10 until all data have been entered

SOIL PROPERTY DESCRIPTION Note: Records 11-19 are entered only if KOPT $=1$

Record 11: Format (2I5)

Column

$\frac{\text { No. }}{1-5} \quad \frac{\text { Variable }}{\text { MAXSUB }}$

Maximum number of subdivisions of any given soil property description (1imit is 4)

6-10 MAXPOL Maximum degree of soil property polynomials (1imit is 5)

Record 12: Format (A60)

Column

$\frac{\text { No. }}{1-60} \quad \frac{\text { Variable }}{\text { DUMMY }}$

Description

Title describing the soil type and indicating that what follows is moisture characteristic data

Record 13: Format (1X,I5,2F15.0)

Column

$\frac{\text { No. }}{2-6} \quad \frac{\text { Variable }}{\text { NSUBTH }}$

Description

$7-21 \quad$ AIRINT

Number of subdivisions of the moisture characteristic for that particular material

22-36 THET

Air entry head (units: $\mathrm{cm}$ )

Saturated water content (units: $\mathrm{cm}^{3} / \mathrm{cm}^{3}$ ) 
Record 14: Format (1X,2I5,2F 15.0)

Col umn

$\begin{array}{ll}\text { No. } & \text { Variable } \\ 2-6 & \text { II } \\ 7-11 & \text { NDEGTH }\end{array}$

$\frac{\text { Description }}{\text { Index of the moisture characteristic polynomial }}$

degree +1

$12-26 \quad x x$

Minimum head for which the given polynomial applies (units: $\mathrm{cm}$ )

27-41 XDIVTH

Maximum head for which the given polynomial applies

(units: $\mathrm{cm}$ )

Record 15: Format (5F15.0)

Column

$\frac{\text { No. }}{1-15} \quad \frac{\text { Variable }}{\text { CREGTH }}$

Description

Moisture characteristic coefficients

Note: Enter NDEGTH values of CREGTH

Note: Repeat the sequence of Records 14-15 NSUBTH times

Record 16: Format (A60)

Column

$\frac{\text { No. }}{1-60} \frac{\text { Variable }}{\text { DUMMY }}$

Description

Title describing the soil type and indicating that what follows is conductivity data

Record 17: Format (1X,I5,2F15.0)

Column

$\frac{\text { No. }}{2-6} \quad \frac{\text { Variable }}{\text { NSUBKH }}$

Description

7-21 AIRINK Air entry head (units

22-36 SK Saturated hydraulic conductivity (units: $\mathrm{cm} / \mathrm{h}$ )

Record 18: Format (1X,2I5,2F15.0)

Column

\begin{tabular}{|c|c|}
\hline No. & Variable \\
\hline $\begin{array}{l}2-6 \\
7-11\end{array}$ & $\begin{array}{l}\text { I I } \\
\text { NDEGKH }\end{array}$ \\
\hline
\end{tabular}

Description

Index of the conductivity polynomial

Number of polynomial coefficients, or polynomial degree +1

$12-26 \quad x X$

27-41 XDIVKH

Minimum head for which the given polynomial applies

Maximum head for which the given polynomial applies 
Record 19: Format (5F15.0)

Column

No. Variable

Description

1-15 CREGKH Polynomial coefficients for describing conductivity

Note: Enter NDEGKH values of CREGKH

Note: Repeat the sequence of Records 18-19 NSUBK times

Records 20-23 are entered only if KOPT $=2$ or 4

Record 20: Format (A60)

Column

$\frac{\text { No. }}{1-60} \quad \frac{\text { Variable }}{\text { DUMMY }}$

Description

Title describing the soil type and indicating that what follows is moisture characteristic data

Record 21: Format (5F15.0)

Column

No. Variable

Description

1-15 AIRINT Air entry head (units: $\mathrm{cm}$ )

16-30 THET Saturated water content (units: $\mathrm{cm}^{3} / \mathrm{cm}^{3}$ )

31-45 THTR Residual water content (units: $\mathrm{cm}^{3} / \mathrm{cm}^{3}$ )

46-60 ALPHA Coefficient of Haverkamp function (Haverkamp et al. 1977)

61-75 BETA Coefficient of Haverkamp function

Record 22: Format (A60)

Column

$\frac{\text { No. }}{1-60} \frac{\text { Variable }}{\text { DUMMY }}$

Description

Title describing the soil type and indicating that what follows is conductivity data

Record 23: Format (4F15.0)

Column

No. Variable

1-15 AIRINK

16-30 SK

$31-45 \quad A$

Sk Saturated hydraulic conductivity (units: $\mathrm{cm} / \mathrm{h}$ )

$46-60 \quad B$

Coefficient of Haverkamp function

Coefficient of Haverkamp function

Enter Records 24-27 if KOPT $=3$ 
$\begin{aligned} & \text { Record 24: Format }(A 60) \\ & \text { Column } \\ & \text { No. } \\ & \text { 1-60 }\end{aligned} \frac{\text { Variable }}{\text { DUMMY }}$

Description

Title describing the soil type and indicating that what follows is moisture characteristic data

Record 25: Format (3F15.0)

Column

No. Variable

1-15 AIRINT

Air entry head (units: $\mathrm{cm}$ )

$16-30$

THET

Saturated water content (units: $\mathrm{cm}^{3} / \mathrm{cm}^{3}$ )

$31-45$

B

Coefficient of Campbell function (Campbel1 1974)

Record 26: Format (A60)

Column

$\frac{\text { No. }}{1-60} \quad \frac{\text { Variable }}{\text { DUMMY }}$

Description

Title describing the soil type and indicating that what follows is conductivity data

Record 27: Format (3F15.0)

Column

$\begin{array}{ll}\frac{\text { No. }}{1-15} & \quad \text { Variable } \\ 16-30 & \text { SIRINK } \\ 31-45 & \text { B }\end{array}$

Description

Air entry head (units: $\mathrm{cm}$ )

Saturated hydraulic conductivity (units: $\mathrm{cm} / \mathrm{h}$ )

Coefficient of Campbell function (Campbell 1974)

Note: Repeat the appropriate soil property descriptions MATN times

Enter Record 28 if IVAPOR $=1$

Record 28: Format (3F15.0)

Column

No. Variable

$1-15$

TORT

TSOILC

31-45 VAPDIF Diffusion coefficient of vapor in air (units: $\mathrm{cm}^{2} / \mathrm{s}$ )

Description

$16-30$

INITIAL CONDITIONS

Record 29: Format (I5)

Column

$\frac{\text { No. }}{1-5} \quad \frac{\text { Variable }}{\text { NDAY }}$

Description

Simulation starting day; ranges from zero to NDAYS 
Record 30: Format (4F14.0)

Column

$\begin{array}{cc}\text { No. } & \frac{\text { Variable }}{1-14} \\ \begin{array}{c}\text { - } \\ \text { - }\end{array} & \\ & H(4)\end{array}$

Description

Initial head (units: $\mathrm{cm}$ )

Note: Repeat Record 30 until NPT values of $H$ have been entered

PLANT INFORMATION

Enter Record 31 if IPLANT $=1$

Record 31: Format (6I5)

Column

$\frac{\text { No. }}{1-5} \quad \frac{\text { Variable }}{\text { LEAF }}$

Description

Option for leaf area index (LAI)

(0) LAI values not needed (i.e., NFPET = 2)

(1) User supplies LAI values for the year (Records 32-33)

(2) User supplies a subroutine (inoperative)

6-10 NFRO0T Option for root growth

(1) Exponential relationship

(2) User supplies a subroutine (inoperative)

11-15 NUPTAK Option for plant water uptake

(1) Sink term approximation proposed by Feddes, Kowalik, and Zaradny (1978). Requires entry of $H W, H D$, and HN values (Record 36 )

(2) User supplies a subroutine (inoperative)

16-20 NFPET Option for partitioning PET into transpiration and evaporation (PE) components

(1) User supplies daily PET values and program partitions it into PT and PE based on LAI and equation by Ritchie and Burnett (1971)

(2) User supplies daily PET values and program partitions it into PT and PE based on the cheatgrass data of Hinds (1975)

21-25 NSOW Day of the year on which seeds are planted

26-30 NHRVST Day of the year on which plants cease transpiring

Enter Record 32 if LEAF $=1$ 
Record 32: Format (I5,F5.0)

Column

\begin{tabular}{|c|c|c|}
\hline No. & Variable & Description \\
\hline $1-5$ & NPOINT & $\begin{array}{l}\text { Number of changes in the LAI relationship when } \\
\mathrm{LEAF}=1\end{array}$ \\
\hline $6-10$ & BARE & Fraction of soil surface that is bare of plants \\
\hline
\end{tabular}

Record 33: Format $(5(I 5, F 5.0))$

Column

$\frac{\text { No. }}{1-5} \quad \frac{\text { Variable }}{\text { NGROW(1) }}$

Description

corresponding FLAI value

6-10 FLAI(1) Leaf area index on the corresponding NGROW day

-

-

41-45 NGROW(5)

46-50 FLAI (5)

Note: Repeat Record 33 until NPOINT pairs of NGROW, FLAI values have been entered

Enter Records 34-35 if NFROOT $=1$

Record 34: Format (3F10.0)

Column

$\frac{\text { No. }}{1-10} \quad \frac{\text { Variable }}{\text { AA }}$

$11-20 \quad B 1$

B2

Description

Coefficient a in the root growth equation (Equation 3.17)

Coefficient $b$ in the root growth equation (Equation 3.17 )

Coefficient $c$ in the root growth equation (Equation 3.17 )

Record 35: Format(10I5)

Column

$\frac{\text { No. }}{1-5} \quad \frac{\text { Variable }}{\text { NTROOT(1) }}$

Description

Growth day on which roots reach the corresponding node

46-50

NTROOT (10)

Note: Repeat Record 35 until NPT values of NTRO0T have been entered 


Enter Record 36 if N
Record 36: Format
Column
$\begin{aligned} & \text { No. } \\ & 1-10\end{aligned}$ Variable
$11-20$

Description

Head corresponding to moisture content below which plants wilt and stop transpiring (units: $\mathrm{cm}$ ) Head corresponding to moisture content below which plant transpiration starts to decrease (units: $\mathrm{cm}$ ) Head corresponding to moisture content above which plants do not transpire because of anaerobic conditions (units: $\mathrm{cm}$ )
Enter Record 37 if N
Record 37: Format
Column
No.
$\begin{aligned} & \text { 1-10 } \\ & \text { BIOMAable }\end{aligned}$

11-20 BARE

\section{Description}

Plant shoot biomass scaling factor used in adjusting the transpiration component of PET. The base value is $220 \mathrm{~g} / \mathrm{m}^{2}$. A lower value will result in lower transpiration and higher evaporation, while a higher value will result in higher transpiration and lower evaporation (units: $\mathrm{g} / \mathrm{m}^{2}$ )

Fraction of soil surface that is bare of plants

BOUNDARY CONDITIONS

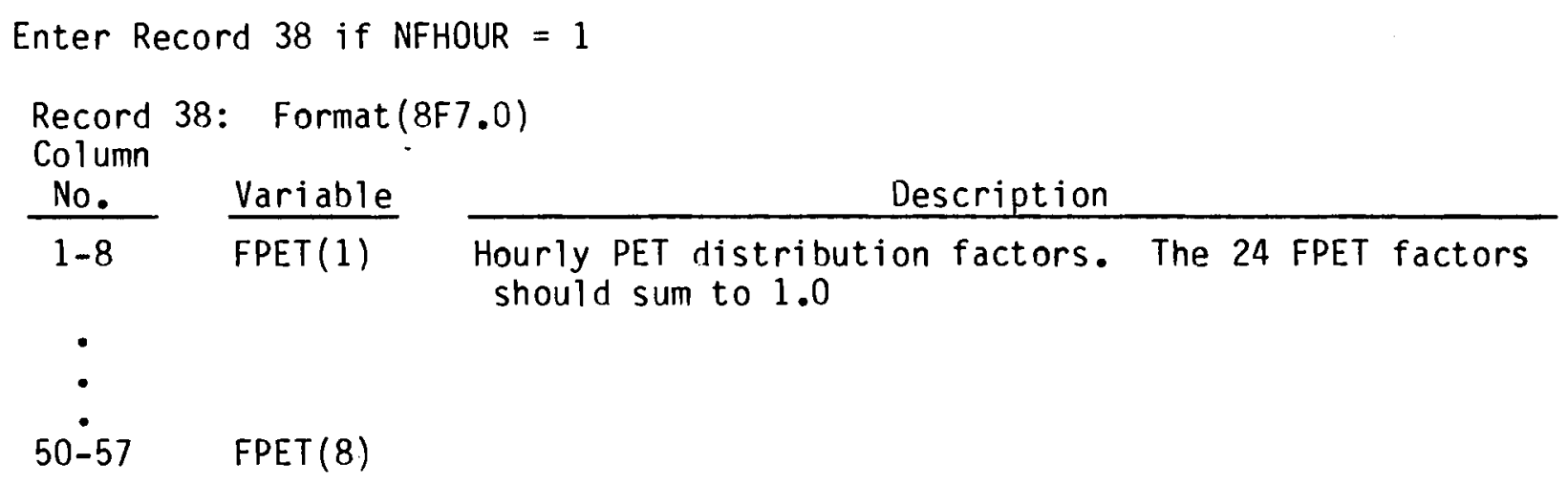

Note: Repeat Record 38 until 24 FPET values have been added 


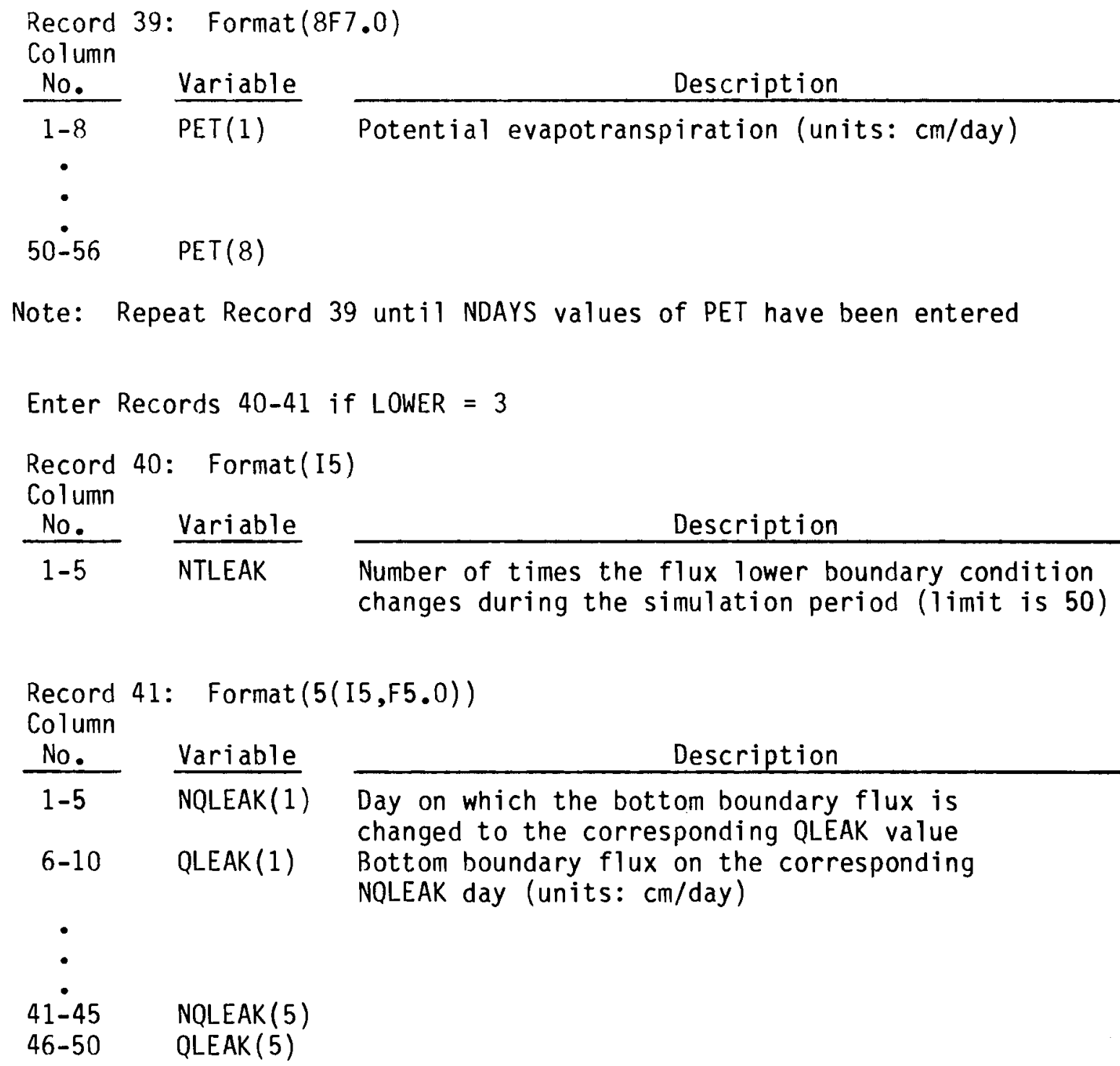

Note: Repeat Record 41 until NTLEAK pairs of data have been entered

Record 42: Format (I5)

Column

$\frac{\text { No. }}{1-5} \quad \frac{\text { Variable }}{\text { NWATER }}$

Description

Total number of days during which there is water application 
Record 43: Format (3I5,F6.0)

Column

$\frac{\text { No. }}{1-5} \quad \frac{\text { Variable }}{\text { IRDAY }}$

6-10 IRTYPE

Day on which a water application event occurs

Option for type of water application

(1) rainfall

(2) irrigation

(3) constant ponding depth less than 1 day

(4) constant ponding depth greater than 1 day

$11-15 \quad N P$

Number of times during the day that the

water application rate changes

16-20 EFICEN

Efficiency of the irrigation scheme (i.e., how much of the water actually gets onto the soil surface)

Record 44: Format (2F7.0)

Column

$\frac{\text { No. }}{1-7} \quad \frac{\text { Variable }}{\text { RTIME (1) }}$

Description

Time of day when the water application rate changes (units: $h$ ). The exception is when IRTYPE $=4$, and then the units are days. If IRTYPE $=4$ and $\operatorname{RTIME}(N P)=0$, ponding is continued for the remainder simulation (until DAYEND)

8-14 AMOUNT(1) Rainfall/irrigation amount that falls until the next rate change, RTIME $(I+1)$, or when

IRTYPE $=3$ or 4 , it is the height of water ponded on the surface (units: $\mathrm{cm}$ )

Note: Repeat Record 44 NP times

Note: Repeat the sequence of Records 43 and 44 NWATER times

\subsection{CODE OPERATION}

The UNSAT-H code is run on a VAX 11/780 computer. (a) The discussion of code operation that follows pertains to that computer. Code operation on another computer will likely be different.

There are a number of points at which DATAINH, UNSAT-H, and DATAOUT read and write data. These operations involve particular logical units as specified

(a) The VAX $11 / 780$ is a product of the Digital Equipment Corporation, Maynard, Massachusetts. References to a VAX computer should not be regarded as an endorsement. 
in BVAR.INC and DATAOUT. The current assignments are listed in Table 6.1. Before running the model, ensure that these logical units have not been redefined.

The first step in running UNSAT-H is building the executable images for DATAINH, UNSAT-H, and DATAOUT. The images can be built by compiling the main programs and their subroutines and functions (1isted in Table 5.1) and then linking the appropriate object files. The result should be three images, DATAINH.EXE, UNSATH.EXE, and DATAOUT.EXE. When compiling DATAINH and UNSAT-H, ensure that the files BARRAY.INC, BSOIL.INC, BTIME.INC, and BVAR.INC are present in the default directory. These *.INC files contain the variable and array declaration statements and are included in the codes by using the FORTRAN "INCLUDE" statement. To redimension UNSAT-H, modify the statements in the appropriate *.INC file and recompile both programs. DATAOUT and its subroutines all use a single *.INC file, called BOUT.INC. If DATAINH and UNSAT-H are redimensioned, ensure that DATAOUT is also redimensioned (within BOUT.INC).

The next step in running the UNSAT-H code is to process the input data (located in a *.INP file) by typing the command RUN DATAINH (assuming DATAINH.EXE is in the default directory). The user will then be queried for the input filename and the desired level of output (for data-checking purposes).

The UNSAT-H code is designed to be run in the batch mode, by a command file that instructs the system on file location and provides answers to program queries. Figure 6.2 is a listing of a typical command file. (This file was used to run the example simulation described in Section 7.1.) The default

TABLE 6.1 Logical Unit Assignments

$\begin{array}{ccc}\frac{\text { Unit }}{1} & & \text { Variable } \\ 2 & & \text { LUI } \\ 5 & & \text { LUB } \\ 6 & & \text { LUR } \\ 7 & & \text { LUW }\end{array}$

Description

Binary input file unit (input to UNSAT-H and DATAOUT)

Binary output file unit from DATAINH and UNSAT-H

Read (interactive input)

Screen (interactive output)

ASCII output file from DATAOUT 
directory is established on the first line of the command file. Unless instructed otherwise, the system assumes that the input file (*.BIN) is located in the default directory and that the results file (*.RES) is to go there also.

The next two lines are optional but their use is strongly recommended. They cause copies of the command and ASCII input files to be inserted into the *.LOG file for this simulation. These copies serve as a record of the files used.

The RUN UNSATH command on the fourth line actually starts the code running. If the code is not in the default directory, the RUN UNSATH command must be altered to indicate the directory in which the code is located. For example, the command RUN DISKO:[TRIAL]UNSATH indicates that the executable image of the code is in in the main directory TRIAL, which is located on DISKO. Having only one copy of the code on the computer at a given time saves storage space and ensures that all code users are utilizing the same version.

The fifth line of the command file serves as an answer to an UNSAT-H query for the name of the binary input file (*.BIN, with BIN indicating binary form). There is no dollar sign at the start of this line because the line is not a system command but rather a response to a program query.

The sixth line causes a cost summary of the simulation run to be written to the *.LOG file.

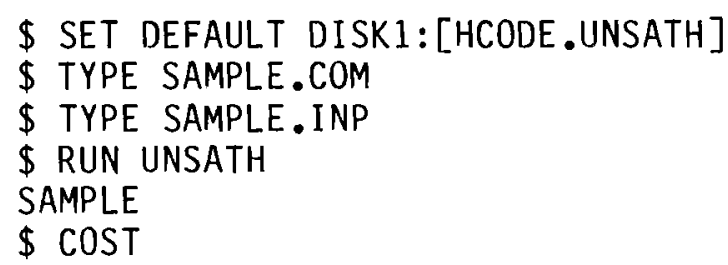

FIGURE 6.2. Listing of Sample Command File (SAMPLE.COM) for Running UNSAT $-H$ in the Batch Mode 
To run the code in the batch mode, the appropriate command file must be submitted to the batch queue. Assuming that the command file SAMPLE.COM (Figure 6.2) is in the current directory, typing the command

\section{SUBMIT/NOPRINTER/LOG $=[]$ SAMPLE}

will send the command file to the SYS\$BATCH queue to be processed. Batch jobs normally generate a *.LOG file that contains program output and a summary of the run characteristics (e.g., total time spent in the queue and computer run time), all destined for the SYS\$PRINT logical unit of the VAX computer. The *.LOG file is automatically printed once the job has finished. With the NOPRINTER option, however, the *.LOG file remains in the user's main directory with the command file name and a*.LOG extension. With the LOG=[] option, the *.LOG file goes to the default directory specified in the command file (Figure 6.2).

The command file set up in Figure 6.2 will generate two files: the binary output file (SAMPLE.RES) from UNSAT-H, and the program *.LOG file, SAMPLE.LOG. The *.LOG file is in ASCII format and can easily be read, but the *.RES file is binary and therefore can only be read after being converted by DATAOUT. To run DATAOUT, type the command RUN DATAOUT (assuming the file DATAOUT.EXE is located in the default directory). The user will be asked for the name of the results file to be processed, followed by questions regarding the form of output desired. 


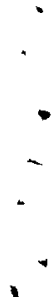

1

,

$\checkmark$

.

. 


\subsection{EXAMPLE SIMULATIONS}

Three examples are provided here to illustrate how various UNSAT-H options work. They are a verification test of the infiltration portion of the UNSAT-H code, a simulation of a layered soil system, and a simulation that includes plant transpiration.

\subsection{VERIFICATION OF INFILTRATION}

Haverkamp et a1. (1977) performed a number of infiltration simulations using different models of the nonlinear flow equation. One of those models, the head-based implicit model (No. 4 in the Haverkamp paper), is the same as that used in UNSAT-H. To verify the infiltration component of UNSAT-H and at the same time provide an example of how UNSAT-H works, the Haverkamp et al. (1977) infiltration problem was simulated with UNSAT-H (see Appendix B for a distinction between verification and validation). The UNSAT-H results are compared with the Haverkamp results and with an approximate analytical solution available in Philip (1969).

\subsubsection{Problem Description}

The two soil types were a sand and a clay (Yolo light clay) used by Haverkamp et al. (1977). In UNSAT-H, the sand and clay were described setting KOPT equal to 2 and 4 , respectively, which indicates the type of soil property descriptions. The various coefficients and input parameters used are listed in Table 7.1.

The soil profile depths were 90 and $250 \mathrm{~cm}$ for the sand and clay, respectively. Depth increments were $1.0 \mathrm{~cm}$. The bottom boundary was assumed to be impervious. For the upper boundary, the head of the surface node was held constant at $20.73 \mathrm{~cm}$ for the sand and $1.0 \mathrm{~cm}$ for the clay. The minimum and maximum time steps were 40 and $500 \mathrm{~s}$, respectively, like those used by Haverkamp et al. (1977). The complete input file for the clay simulation is shown in Figure 7.1 . 
TABLE 7.1. Coefficients and Parameters Used in the Infiltration Simulations

\begin{tabular}{|c|c|c|c|}
\hline $\begin{array}{l}\text { UNSAT-H } \\
\text { Symbols }\end{array}$ & Sand & Clay & $\begin{array}{l}\text { Haverrkamp } \\
\text { Symbols }\end{array}$ \\
\hline THET & 0.287 & 0.495 & $\theta_{s}$ \\
\hline THTR & 0.075 & 0.124 & $\theta_{r}$ \\
\hline$A$ & $1.611 \times 10^{6}$ & 739 & $\alpha$ \\
\hline B & 3.96 & 4.00 & $\beta$ \\
\hline AIRINT & 1.0 & 1.0 & -- \\
\hline SK & 34 & $4.42810^{-2}$ & $k_{s}$ \\
\hline ALPHA & $1.175 \times 10^{6}$ & 124.6 & $A^{3}$ \\
\hline BETA & 4.74 & 1.77 & B \\
\hline AIRINK & 1.0 & 1.0 & $\ldots$ \\
\hline
\end{tabular}

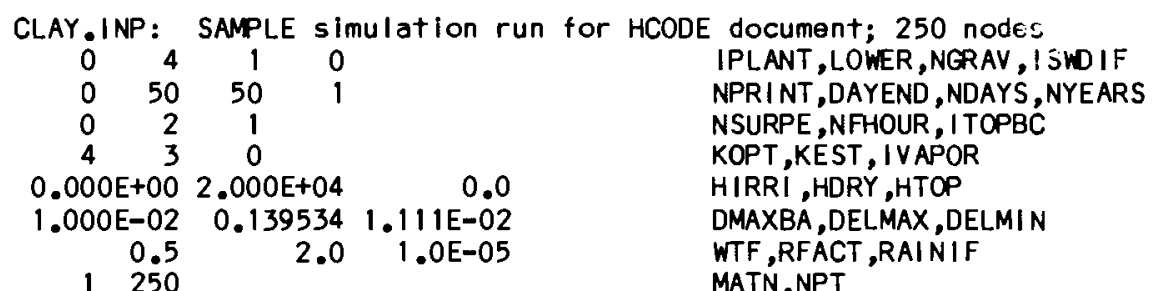

$\begin{array}{lrrrr}1 & 0.000 & 1 & 1.000 & 1 \\ 1 & 4.000 & 1 & 5.000 & 1 \\ 1 & 8.000 & 1 & 9.000 & 1 \\ 1 & 12.000 & 1 & 13.000 & 1 \\ 1 & 16.000 & 1 & 17.000 & 1 \\ 1 & 20.000 & 1 & 21.000 & 1 \\ 1 & 24.000 & 1 & 25.000 & 1 \\ 1 & 28.000 & 1 & 29.000 & 1 \\ 1 & 32.000 & 1 & 33.000 & 1 \\ 1 & 36.000 & 1 & 37.000 & 1 \\ 1 & 40.000 & 1 & 41.000 & 1 \\ 1 & 44.000 & 1 & 45.000 & 1 \\ 1 & 48.000 & 1 & 49.000 & 1 \\ 1 & 52.000 & 1 & 53.000 & 1 \\ 1 & 56.000 & 1 & 57.000 & 1 \\ 1 & 60.000 & 1 & 61.000 & 1 \\ 1 & 64.000 & 1 & 65.000 & 1 \\ 1 & 68.000 & 1 & 69.000 & 1 \\ 1 & 72.000 & 1 & 73.000 & 1 \\ 1 & 76.000 & 1 & 77.000 & 1 \\ 1 & 80.000 & 1 & 81.000 & 1 \\ 1 & 84.000 & 1 & 85.000 & 1 \\ 1 & 88.000 & 1 & 89.000 & 1 \\ 1 & 92.000 & 1 & 93.000 & 1 \\ 1 & 96.000 & 1 & 97.000 & 1\end{array}$

2.000
6.000
10.000
14.000
18.000
22.000
26.000
30.000
34.000
38.000
42.000
46.000
50.000
54.000
58.000
62.000
66.000
70.000
74.000
78.000
82.000
86.000
90.000
94.000
98.000

3.000
7.000
11.000
15.000
19.000
23.000
27.000
31.000
35.000
39.000
43.000
47.000
51.000
55.000
59.000
63.000
67.000
71.000
75.000
79.000
83.000
87.000
91.000
95.000
99.000

MAT, $Z$

MAT,Z

MAT, $Z$

MAT, $Z$

MAT,Z

MAT, $Z$

MAT,Z

MAT,Z

MAT,Z

MAT,Z

MAT,Z

MAT,Z

MAT,Z

MAT, Z

MAT,Z

MAT, $Z$

MAT, $Z$

MAT,Z

MAT, Z

MAT, $Z$

MAT,Z

MAT, $Z$

MAT,Z

MAT,Z

MAT,Z

FIGURE 7.1. Listing of Input File CLAY.INP 


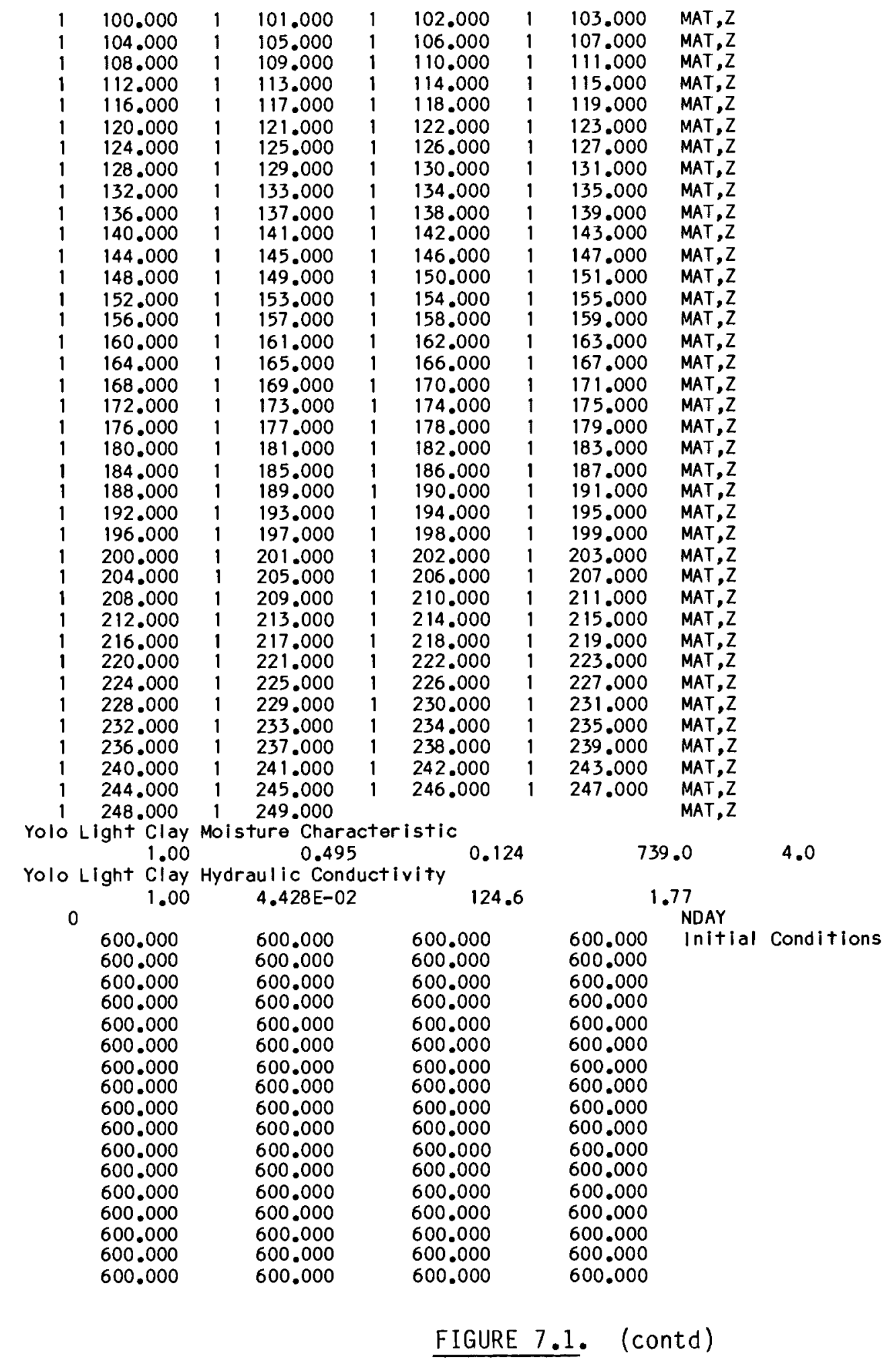




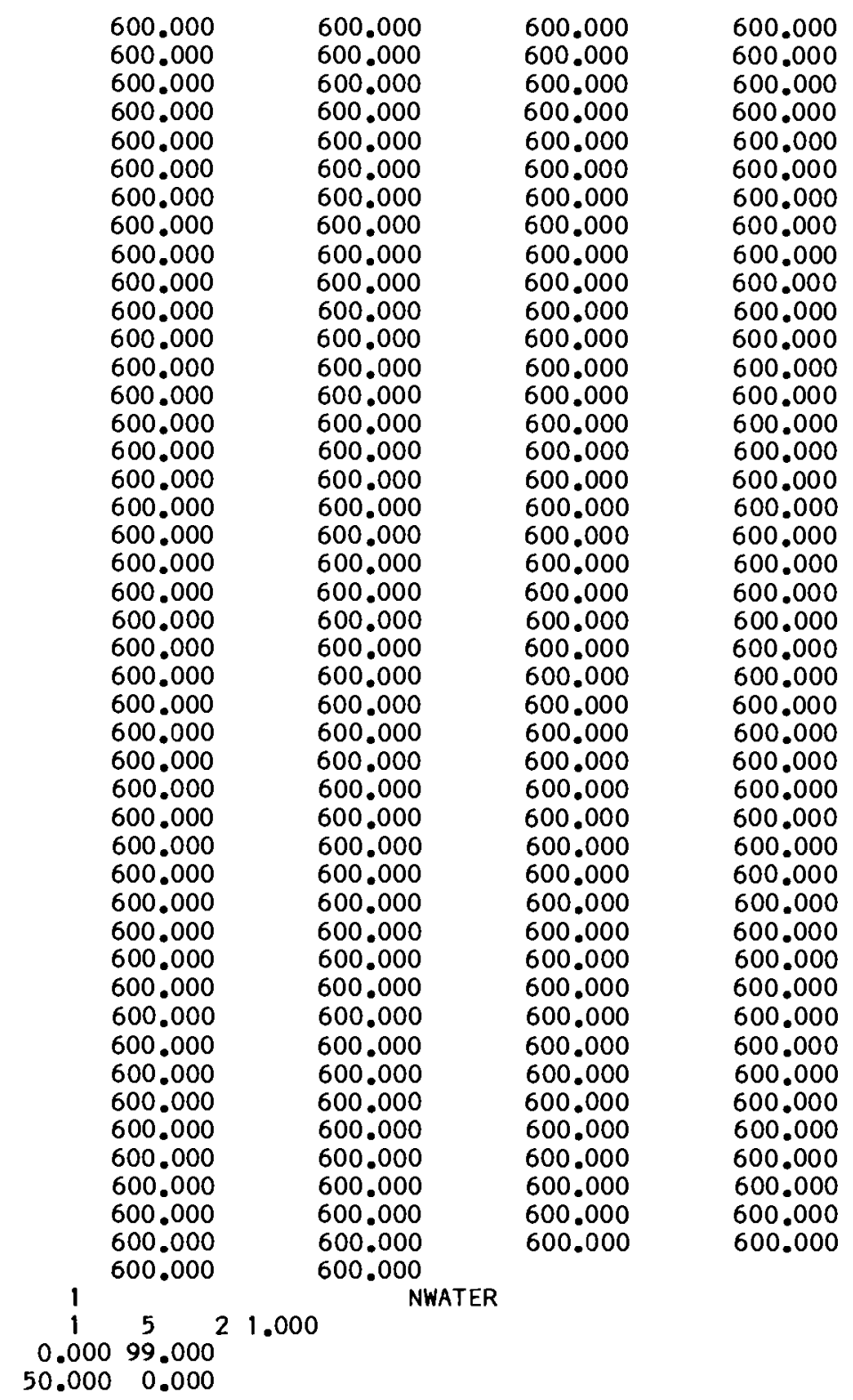

FIGURE 7.1. (contd)

\subsubsection{RESULTS}

Figure 7.2 illustrates the results obtained by Haverkamp et al. (1977: Figure 6). Also plotted is Philip's (1969) quasianalytical series solution. Note that the series solution is only valid for times less than $600 \mathrm{~h}$ for the clay and $0.29 \mathrm{~h}$ for the sand. The UNSAT-H results are shown as dotted lines in Figure 7.2. The UNSAT-H output file is shown in Figure 7.3. For both soils, 

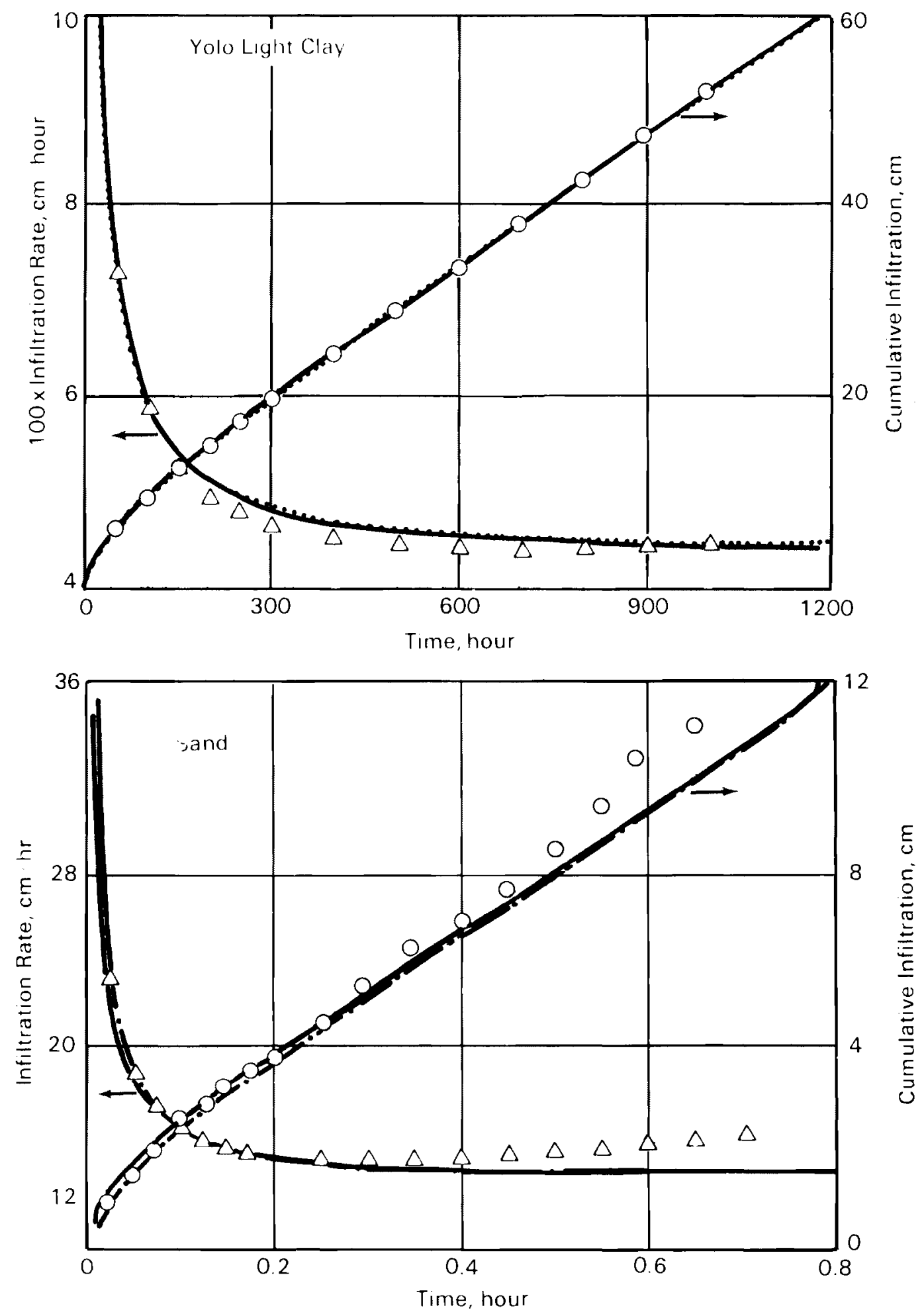

Figure 7.2. Infiltration Rate and Cumulative Infiltration Versus Time as Determined Using Philip's (1969) Solution (symbols), the Numerical Code of Haverkamp et al. (1977) (solid line), and UNSAT-H (dashed line) 
UNSAT-H SIMULATION RESULTS

Input FIlename: CLAY.BIN Date: 27-JUL-86

Time: $17: 55: 07$

INITIAL CONDITIONS

\begin{tabular}{|c|c|c|c|c|c|c|c|}
\hline NODE & DEPTH & HEAD & THETA & NODE & DEPTH & HEAD & THETA \\
\hline $\begin{array}{l}1 \\
3\end{array}$ & $\begin{array}{l}0.000 \\
2.000\end{array}$ & $\begin{array}{l}600.0 \\
600.0\end{array}$ & $\begin{array}{l}0.2376 \\
0.2376\end{array}$ & $\begin{array}{l}2 \\
4\end{array}$ & $\begin{array}{l}1.000 \\
3.000\end{array}$ & $\begin{array}{l}600.0 \\
600.0\end{array}$ & $\begin{array}{l}0.2376 \\
0.2376\end{array}$ \\
\hline 5 & 4.000 & 600.0 & 0.2376 & 6 & 5.000 & 600.0 & 0.2376 \\
\hline 7 & 6.000 & 600.0 & 0.2376 & 8 & 7.000 & 600.0 & 0.2376 \\
\hline 9 & $\begin{array}{r}8.000 \\
10.000\end{array}$ & 600.0 & $\begin{array}{l}0.2376 \\
0.2376\end{array}$ & $\begin{array}{l}10 \\
12\end{array}$ & $\begin{array}{r}9.000 \\
.000\end{array}$ & $\begin{array}{l}600.0 \\
600.0\end{array}$ & $\begin{array}{l}0.2376 \\
0.2376\end{array}$ \\
\hline $\begin{array}{l}11 \\
13\end{array}$ & $\begin{array}{l}10.000 \\
12.000\end{array}$ & $\begin{array}{l}600.0 \\
600.0\end{array}$ & $\begin{array}{l}0.2310 \\
0.2376\end{array}$ & $\begin{array}{l}12 \\
14\end{array}$ & 13.000 & $\begin{array}{l}600.0 \\
600.0\end{array}$ & $\begin{array}{l}0.2376 \\
0.2376\end{array}$ \\
\hline 15 & 14.000 & 600.0 & 0.2376 & 16 & 15.000 & 600.0 & 0.2376 \\
\hline 17 & 16.000 & 600.0 & 0.2376 & 18 & 17.000 & 600.0 & 0.2376 \\
\hline 19 & 18.000 & 600.0 & 0.2376 & 20 & 19.000 & 600.0 & 0.2376 \\
\hline 21 & 20.000 & 600.0 & 0.2376 & 22 & 21.000 & 600.0 & 0.2376 \\
\hline 23 & 22.000 & 600.0 & 0.2376 & 24 & 23.000 & 600.0 & 0.2376 \\
\hline 25 & 24.000 & 600.0 & 0.2376 & 26 & 25.000 & 600.0 & 0.2376 \\
\hline 27 & 26.000 & 600.0 & 0.2376 & 28 & 27.000 & 600.0 & 0.2376 \\
\hline 29 & 28.000 & 600.0 & 0.2376 & 30 & 29.000 & 600.0 & 0.2376 \\
\hline 31 & 30.000 & 600.0 & 0.2376 & 32 & 31.000 & 600.0 & 0.2376 \\
\hline 33 & 32.000 & 600.0 & 0.2376 & 34 & 33.000 & 600.0 & 0.2376 \\
\hline 35 & 34.000 & 600.0 & 0.2376 & 36 & 35.000 & 600.0 & 0.2376 \\
\hline 37 & 36.000 & 600.0 & 0.2376 & 38 & 37.000 & 600.0 & 0.2376 \\
\hline 39 & 38.000 & 600.0 & 0.2376 & 40 & 39.000 & 600.0 & 0.2376 \\
\hline 41 & 40.000 & 600.0 & 0.2376 & 42 & 41.000 & 600.0 & 0.2376 \\
\hline 43 & 42.000 & 600.0 & 0.2376 & 44 & 43.000 & 600.0 & 0.2376 \\
\hline 45 & 44.000 & 600.0 & 0.2376 & 46 & 45.000 & 600.0 & 0.2376 \\
\hline 47 & 46.000 & 600.0 & 0.2376 & 48 & 47.000 & 600.0 & 0.2376 \\
\hline 49 & 48.000 & 600.0 & 0.2376 & 50 & 49.000 & 600.0 & 0.2376 \\
\hline 51 & 50.000 & 600.0 & 0.2376 & 52 & 51.000 & 600.0 & 0.2376 \\
\hline 53 & 52.000 & 600.0 & 0.2376 & 54 & 53.000 & 600.0 & 0.2376 \\
\hline 55 & 54.000 & 600.0 & 0.2376 & 56 & 55.000 & 600.0 & 0.2376 \\
\hline 57 & 56.000 & 600.0 & 0.2376 & 58 & 57.000 & 600.0 & 0.2376 \\
\hline 59 & 58.000 & 600.0 & 0.2376 & 60 & 59.000 & 600.0 & 0.2376 \\
\hline 61 & 60.000 & 600.0 & 0.2376 & 62 & 61.000 & 600.0 & 0.2376 \\
\hline 63 & 62.000 & 600.0 & 0.2376 & 64 & 63.000 & 600.0 & 0.2376 \\
\hline 65 & 64.000 & 600.0 & 0.2376 & 66 & 65.000 & 600.0 & 0.2376 \\
\hline 67 & 66.000 & 600.0 & 0.2376 & 68 & 67.000 & 600.0 & 0.2376 \\
\hline 69 & 68.000 & 600.0 & 0.2376 & 70 & 69.000 & 600.0 & 0.2376 \\
\hline 71 & 000 & 600.0 & 0.2376 & 72 & 71.000 & 600.0 & 0.2376 \\
\hline 73 & 72.000 & 600.0 & 0.2376 & 74 & 73.000 & 600.0 & 0.2376 \\
\hline 75 & .000 & 600.0 & 0.2376 & 76 & 75.000 & 600.0 & 0.2376 \\
\hline 77 & 000 & 600.0 & 0.2376 & 78 & 77.000 & 600.0 & 0.2376 \\
\hline 79 & & 600.0 & 0.2376 & 80 & 79.000 & 600.0 & 0.2376 \\
\hline 81 & 80.000 & 600.0 & 0.2376 & 82 & 81.000 & 600.0 & 0.2376 \\
\hline 83 & 000 & 600.0 & 0.2376 & 84 & .000 & 600.0 & 0.2376 \\
\hline 85 & 000 & 600.0 & 0.2376 & 86 & 85.000 & 600.0 & 0.2376 \\
\hline 87 & 000 & 600.0 & 0.2376 & 88 & 87.000 & 600.0 & 0.2376 \\
\hline 89 & 000 & 600.0 & 0.2376 & 90 & .000 & 600.0 & 0.2376 \\
\hline 91 & & & 0.2376 & 92 & & & 0.2376 \\
\hline 93 & 92.000 & 600.0 & 0.2376 & 94 & 93.000 & 600.0 & 0.2376 \\
\hline 95 & 00 & 600.0 & 0.2376 & 96 & 000 & 600.0 & 0.2376 \\
\hline 97 & 000 & 600.0 & 0.2376 & 98 & 97.000 & 600.0 & 0.2376 \\
\hline 99 & 000 & 600.0 & 0.2376 & 100 & 99.000 & 600.0 & 0.2376 \\
\hline 101 & 100.000 & 600.0 & 0.2376 & 102 & 101.000 & 600.0 & 0.2376 \\
\hline
\end{tabular}

Figure 7.3. Listing of Output File CLAY.OUT

(used 48 minutes of computer time) 


\begin{tabular}{|c|c|c|c|c|c|c|c|}
\hline 103 & 102.000 & 600.0 & 0.2376 & 104 & 103.000 & 600.0 & 0.2376 \\
\hline 105 & 104.000 & 600.0 & 0.2376 & 106 & 105.000 & 600.0 & 0.2376 \\
\hline 107 & 106.000 & 600.0 & 0.2376 & 108 & 107.000 & 600.0 & 0.2376 \\
\hline 109 & 108.000 & 600.0 & 0.2376 & 110 & 109.000 & 600.0 & 0.2376 \\
\hline 111 & 110.000 & 600.0 & 0.2376 & 112 & 111.000 & 600.0 & 0.2376 \\
\hline 113 & 112.000 & 600.0 & 0.2376 & 114 & 113.000 & 600.0 & 0.2376 \\
\hline 115 & 114.000 & 600.0 & 0.2376 & 116 & 115.000 & 600.0 & 0.2376 \\
\hline 117 & 116.000 & 600.0 & 0.2376 & 118 & 117.000 & 600.0 & 0.2376 \\
\hline 119 & 118.000 & 600.0 & 0.2376 & 120 & 119.000 & 600.0 & 0.2376 \\
\hline 121 & 120.000 & 600.0 & 0.2376 & 122 & 121.000 & 600.0 & 0.2376 \\
\hline 123 & 122.000 & 600.0 & 0.2376 & 124 & 123.000 & 600.0 & 0.2376 \\
\hline 125 & 124.000 & 600.0 & 0.2376 & 126 & 125.000 & 600.0 & 0.2376 \\
\hline 127 & 126.000 & 600.0 & 0.2376 & 128 & 127.000 & 600.0 & 0.2376 \\
\hline 129 & 128.000 & 600.0 & 0.2376 & 130 & 129.000 & 600.0 & 0.2376 \\
\hline 131 & 130.000 & 600.0 & 0.2376 & 132 & 131.000 & 600.0 & 0.2376 \\
\hline 133 & 132.000 & 600.0 & 0.2376 & 134 & 133.000 & 600.0 & 0.2376 \\
\hline 135 & 134.000 & 600.0 & 0.2376 & 136 & 135.000 & 600.0 & 0.2376 \\
\hline 137 & 136.000 & 600.0 & 0.2376 & 138 & 137.000 & 600.0 & 0.2376 \\
\hline 139 & 138.000 & 600.0 & 0.2376 & 140 & 139.000 & 600.0 & 0.2376 \\
\hline 141 & 140.000 & 600.0 & 0.2376 & 142 & 141.000 & 600.0 & 0.2376 \\
\hline 143 & 142.000 & 600.0 & 0.2376 & 144 & 143.000 & 600.0 & 0.2376 \\
\hline 145 & 144.000 & 600.0 & 0.2376 & 146 & 145.000 & 600.0 & 0.2376 \\
\hline 147 & 146.000 & 600.0 & 0.2376 & 148 & 147.000 & 600.0 & 0.2376 \\
\hline 149 & 148.000 & 600.0 & 0.2376 & 150 & 149.000 & 600.0 & 0.2376 \\
\hline 151 & 150.000 & 600.0 & 0.2376 & 152 & 151.000 & 600.0 & 0.2376 \\
\hline 153 & 152.000 & 600.0 & 0.2376 & 154 & 153.000 & 600.0 & 0.2376 \\
\hline 155 & 154.000 & 600.0 & 0.2376 & 156 & 155.000 & 600.0 & 0.2376 \\
\hline 157 & 156.000 & 600.0 & 0.2376 & 158 & 157.000 & 600.0 & 0.2376 \\
\hline 159 & 158.000 & 600.0 & 0.2376 & 160 & 159.000 & 600.0 & 0.2376 \\
\hline 161 & 160.000 & 600.0 & 0.2376 & 162 & 161.000 & 600.0 & 0.2376 \\
\hline 163 & 162.000 & 600.0 & 0.2376 & 164 & 163.000 & 600.0 & 0.2376 \\
\hline 165 & 164.000 & 600.0 & 0.2376 & 166 & 165.000 & 600.0 & 0.2376 \\
\hline 167 & 166.000 & 600.0 & 0.2376 & 168 & .000 & 600.0 & 0.2376 \\
\hline 169 & 168.000 & 600.0 & 0.2376 & 170 & 169.000 & 600.0 & 0.2376 \\
\hline 171 & 170.000 & 600.0 & 0.2376 & 172 & 171.000 & 600.0 & 0.2376 \\
\hline 173 & 172.000 & 600.0 & 0.2376 & 174 & 173.000 & 600.0 & 0.2376 \\
\hline 175 & 174.000 & 600.0 & 0.2376 & 176 & 175.000 & 600.0 & 0.2376 \\
\hline 177 & 176.000 & 600.0 & 0.2376 & 178 & 177.000 & 600.0 & 0.2376 \\
\hline 179 & 178.000 & 600.0 & 0.2376 & 180 & 179.000 & 600.0 & 0.2376 \\
\hline 181 & .000 & 600.0 & 0.2376 & 182 & 181.000 & 600.0 & 0.2376 \\
\hline 183 & 182.000 & 600.0 & 0.2376 & 184 & 183.000 & 600.0 & 0.2376 \\
\hline 185 & 184.000 & 600.0 & 0.2376 & 186 & 185.000 & 600.0 & 0.2376 \\
\hline 187 & 186.000 & 600.0 & 0.2376 & 188 & 187.000 & 600.0 & 0.2376 \\
\hline 189 & 188.000 & 600.0 & 0.2376 & 190 & 189.000 & 600.0 & 0.2376 \\
\hline 191 & 000 & 600.0 & 0.2376 & 192 & 191.000 & 600.0 & 0.2376 \\
\hline 193 & .000 & 600.0 & 0.2376 & 194 & 193.000 & 600.0 & 0.2376 \\
\hline 195 & 194.000 & 600.0 & 0.2376 & 196 & 195.000 & 600.0 & 0.2376 \\
\hline 197 & 196.000 & 600.0 & 0.2376 & 198 & 197.000 & 600.0 & 0.2376 \\
\hline 199 & 198.000 & 600.0 & 0.2376 & 200 & 199.000 & 600.0 & 0.2376 \\
\hline 201 & & 600.0 & 0.2376 & 202 & 201.000 & 600.0 & 0.2376 \\
\hline 203 & 202.000 & 600.0 & 0.2376 & 204 & 203.000 & 600.0 & 0.2376 \\
\hline 205 & 204.000 & 600.0 & 0.2376 & 206 & 205.000 & 600.0 & 0.2376 \\
\hline 207 & 206.000 & 600.0 & 0.2376 & 208 & 207.000 & 600.0 & 0.2376 \\
\hline 209 & 208.000 & 600.0 & 0.2376 & 210 & 209.000 & 600.0 & 0.2376 \\
\hline 211 & 210.000 & 600.0 & 0.2376 & 212 & 211.000 & 600.0 & 0.2376 \\
\hline 213 & 212.000 & 600.0 & 0.2376 & 214 & 213.000 & 600.0 & 0.2376 \\
\hline & 214.000 & 600.0 & 0.2376 & 216 & 215.000 & 600.0 & 0.2376 \\
\hline 217 & 216.000 & 600.0 & 0.2376 & 218 & 217.000 & 600.0 & 0.2376 \\
\hline 219 & 218.000 & 600.0 & 0.2376 & 220 & 219.000 & 600.0 & 0.2376 \\
\hline 221 & 220.000 & 600.0 & 0.2376 & 222 & 221.000 & 600.0 & 0.2376 \\
\hline
\end{tabular}

FIGURE 7.3. (contd) 


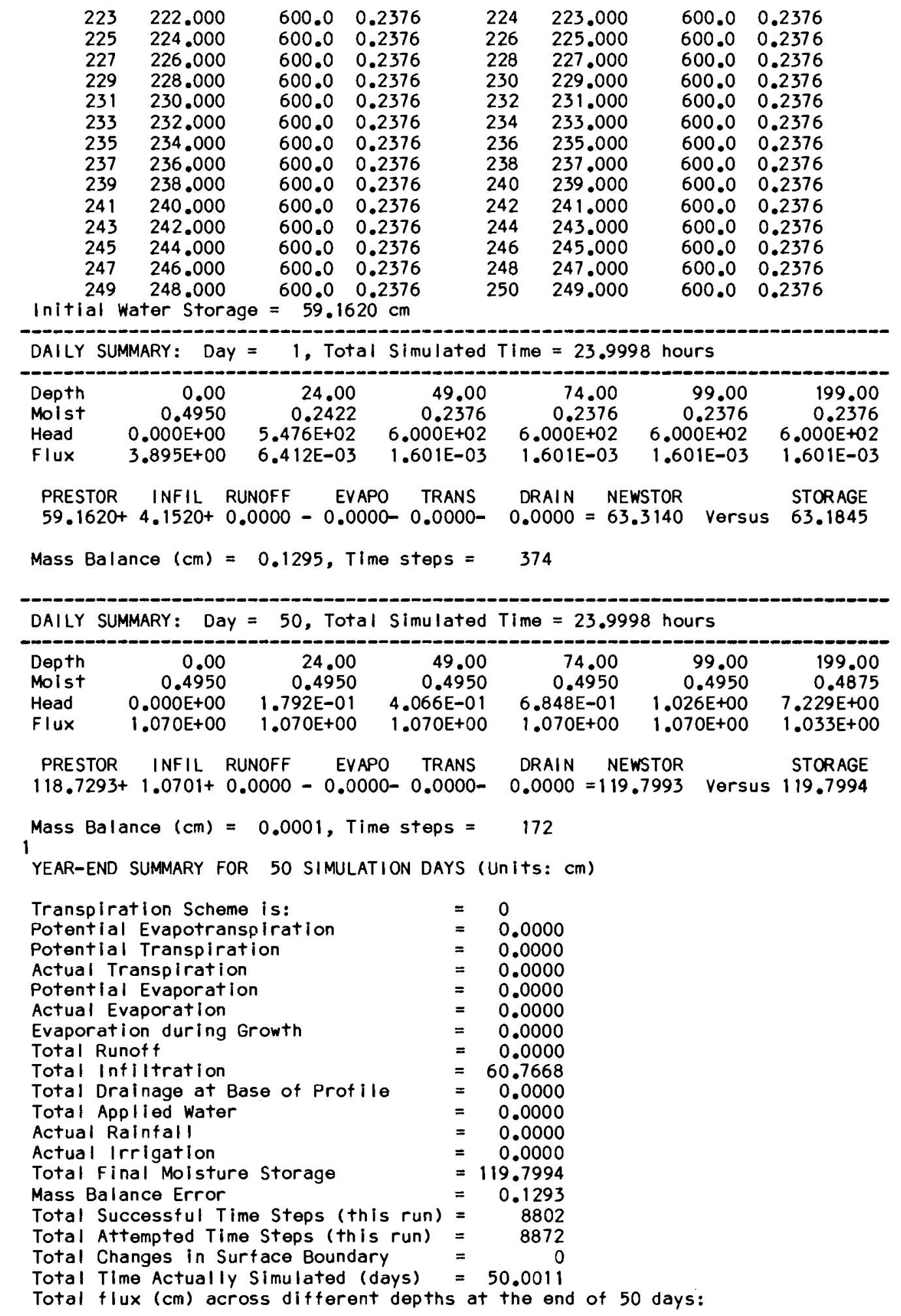

Figure 7.3. (contd) 


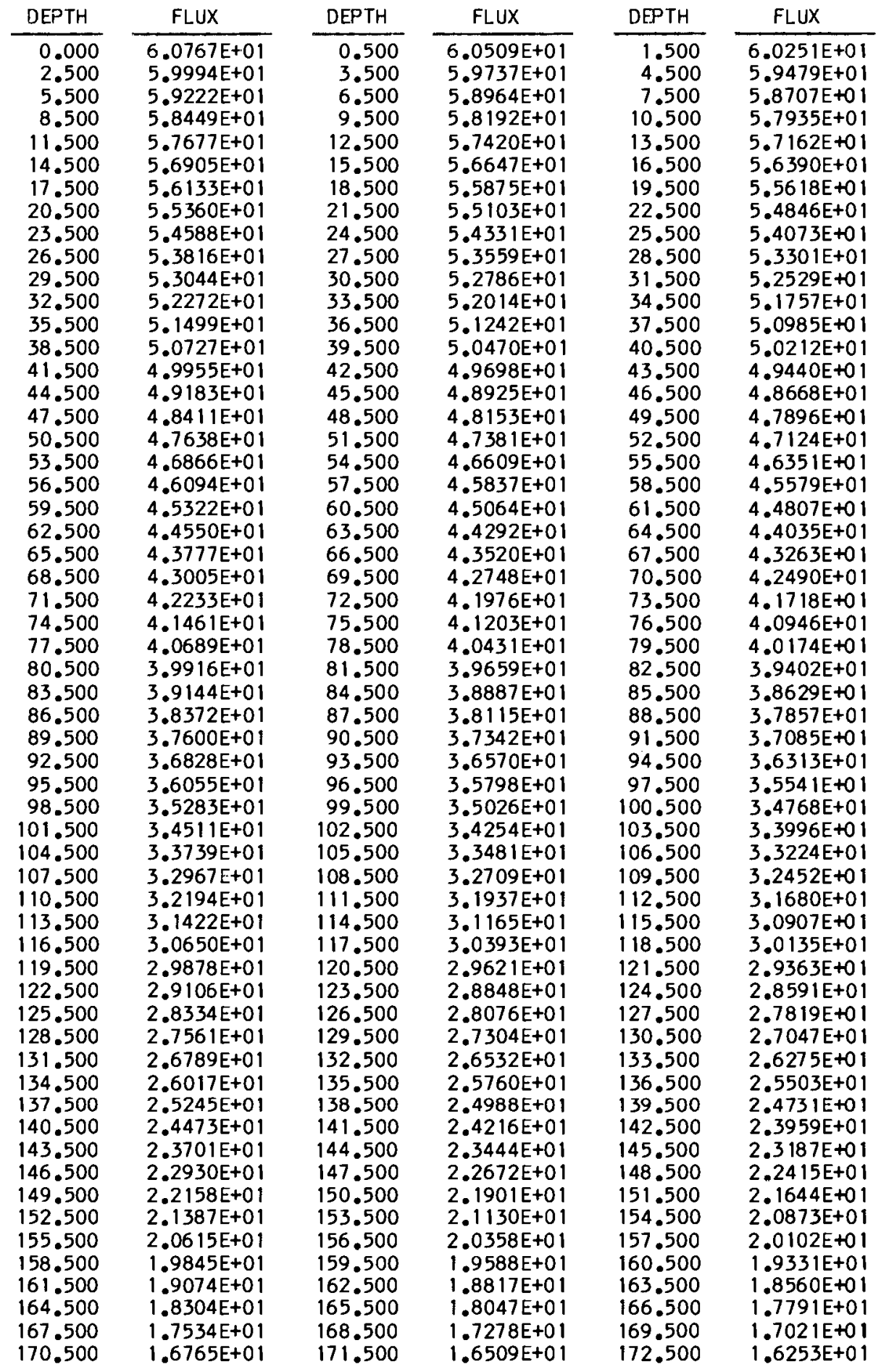

Figure 7.3. (contd) 


\begin{tabular}{|c|c|c|c|c|c|}
\hline $\begin{array}{l}173.500 \\
176.500 \\
179.500 \\
182.500 \\
185.500 \\
188.500 \\
191.500 \\
194.500 \\
197.500 \\
200.500 \\
203.500 \\
206.500 \\
209.500 \\
212.500 \\
215.500 \\
218.500 \\
221.500 \\
224.500 \\
227.500 \\
230.500 \\
233.500 \\
236.500 \\
239.500 \\
242.500 \\
245.500 \\
248.500\end{array}$ & $\begin{array}{l}1.5997 E+01 \\
1.5229 E+01 \\
1.4463 E+01 \\
1.3698 E+01 \\
1.2934 E+01 \\
1.2172 E+01 \\
1.1413 E+01 \\
1.0656 E+01 \\
9.9021 E+00 \\
9.1525 E+00 \\
8.4078 E+00 \\
7.6692 E+00 \\
6.9381 E+00 \\
6.2163 E+00 \\
5.5062 E+00 \\
4.8110 E+00 \\
4.1347 E+00 \\
3.4826 E+00 \\
2.8616 E+00 \\
2.2802 E+00 \\
1.7486 E+00 \\
1.2775 E+00 \\
8.7523 E-01 \\
5.4350 E-01 \\
2.7232 E-01 \\
3.7875 E-02\end{array}$ & $\begin{array}{l}174.500 \\
177.500 \\
180.500 \\
183.500 \\
186.500 \\
189.500 \\
192.500 \\
195.500 \\
198.500 \\
201.500 \\
204.500 \\
207.500 \\
210.500 \\
213.500 \\
216.500 \\
219.500 \\
222.500 \\
225.500 \\
228.500 \\
231.500 \\
234.500 \\
237.500 \\
240.500 \\
243.500 \\
246.500 \\
249.000\end{array}$ & $\begin{array}{l}1.5741 \mathrm{E}+01 \\
1.4974 \mathrm{E}+01 \\
1.4208 \mathrm{E}+01 \\
1.3443 \mathrm{E}+01 \\
1.2680 \mathrm{E}+01 \\
1.1919 \mathrm{E}+01 \\
1.1160 \mathrm{E}+01 \\
1.0404 \mathrm{E}+01 \\
9.6517 \mathrm{E}+00 \\
8.9037 \mathrm{E}+00 \\
8.1609 \mathrm{E}+00 \\
7.4246 \mathrm{E}+00 \\
6.6963 \mathrm{E}+00 \\
5.9781 \mathrm{E}+00 \\
5.2726 \mathrm{E}+00 \\
4.5832 \mathrm{E}+00 \\
3.9143 \mathrm{E}+00 \\
3.2718 \mathrm{E}+00 \\
2.6629 \mathrm{E}+00 \\
2.0969 \mathrm{E}+00 \\
1.5844 \mathrm{E}+00 \\
1.1355 \mathrm{E}+00 \\
7.5703 \mathrm{E}-01 \\
4.4728 \mathrm{E}-01 \\
1.9163 \mathrm{E}-01 \\
0.0000 \mathrm{E}+00\end{array}$ & $\begin{array}{l}175.500 \\
178.500 \\
181.500 \\
184.500 \\
187.500 \\
190.500 \\
193.500 \\
196.500 \\
199.500 \\
202.500 \\
205.500 \\
208.500 \\
211.500 \\
214.500 \\
217.500 \\
220.500 \\
223.500 \\
226.500 \\
229.500 \\
232.500 \\
235.500 \\
238.500 \\
241.500 \\
244.500 \\
247.500\end{array}$ & $\begin{array}{l}1.5485 E+01 \\
1.4718 E+01 \\
1.3952 E+01 \\
1.3188 E+01 \\
1.2426 E+01 \\
1.1665 E+01 \\
1.0908 E+01 \\
1.0153 E+01 \\
9.4019 E+00 \\
8.6554 E+00 \\
7.9147 E+00 \\
7.1808 E+00 \\
6.4557 E+00 \\
5.7414 E+00 \\
5.0409 E+00 \\
4.3577 E+00 \\
3.6969 E+00 \\
3.0647 E+00 \\
2.4690 E+00 \\
1.9196 E+00 \\
1.4272 E+00 \\
1.0014 E+00 \\
6.4658 E-01 \\
3.5718 E-01 \\
1.1392 E-01\end{array}$ \\
\hline
\end{tabular}

FIGURE 7.3. (contd)

the agreement between the UNSAT-H results, the results of Haverkamp et al., and Philip's solutions is excellent. This agreement indicates that the infiltration component of UNSAT-H performs satisfactorily for this type of problem. Currently, work being planned for the Hanford Site for next several years will provide opportunities to more fully test all components of the model.

The final actual mass-balance error was $0.0006 \mathrm{~cm}$ and not the value of $0.1293 \mathrm{~cm}$ reported in Figure 7.3. The discrepancy is caused by UNSAT-H's failure to account for the change in moisture content of the top node as its head value goes from 600 to $1 \mathrm{~cm}$ after time zero. This problem occurs only when the constant-head surface-boundary condition is used (i.e., when ITOPBC $=1$ ), and then only if the initial surface-node head differs from the constant-head value.

\subsection{LAYERED SOIL SIMULATION}

The UNSAT-H model will be used to simulate the water balance of various protective barrier designs. In this example, a particular barrier design was simulated for the weather conditions of the year 1962 . 


\subsubsection{Problem Description}

The concept supporting protective barrier design is illustrated in Figure 7.4. The top $30 \mathrm{~cm}$ of material is composed of the Composite soil reported in Fayer et a1. (1985) and gravel $0.5-1.0 \mathrm{~cm}$ in diameter $(15 \%$ by weight). The material between the 30 and 150-cm depths is Composite soil. Below the $150-\mathrm{cm}$ depth is gravel $0.6-1.3 \mathrm{~cm}$ in diameter. The soil hydraulic properties for all three materials were represented with polynomials by Fayer et al. (1985). Those same polynomials were used in this simulation and can be found in Figure 7.5. Vapor flow was included. Initial head values for each node came from the output from a previous simulation of the year 1961 .

A unit hydraulic gradient was chosen as the lower boundary condition. This was considered a reasonable choice because the lower boundary was located more than $5 \mathrm{~m}$ from the surface, well below the zone of possible upward water movement. For the upper boundary condition, hourly values of precipitation and daily values of PET were supplied. The precipitation data came from the Hanford Meteorological Station (HMS). The PET values were calculated using the Penman Equation given by Doorenbos and Pruitt (1977) and meteorological data from the HMS. The upper and lower head limits for the boundary nodes were 100,000 and $1 \mathrm{~cm}$, respectively.

\subsubsection{Results}

Output from this simulation is shown in Figure 7.6. For the given barrier design and 1952 weather conditions, there was $1.6 \mathrm{~cm}$ of drainage through the barrier. Note that annual actual evaporation was $13.3 \mathrm{~cm}$, which is only $8 \%$ of the annual potential evaporation of $165.2 \mathrm{~cm}$. This result is in accord with the conceptual model as discussed in Section 3.1, where it was indicated that the rate of evaporation from dry soil will be much less than the potential rate. Clearly potential evaporation rates should not be used as indicators of actual evaporation.

\subsection{TRANSPIRATION SIMULATION}

As an example of how UNSAT- $H$ might be used to model transpiration, a simulation of the 200-Area closed-bottom lysimeter was conducted for the year 1974. Gee and Heller (1985) documented that Russian thistle plants were 
growing on the lysimeter during that year. Unfortunately, there was no quantitative characterization of the plant community, so various assumptions were made to provide the model with plant parameters. The data that are available for simulation purposes are soil hydraulic properties and hourly precipitation and meteorological data.

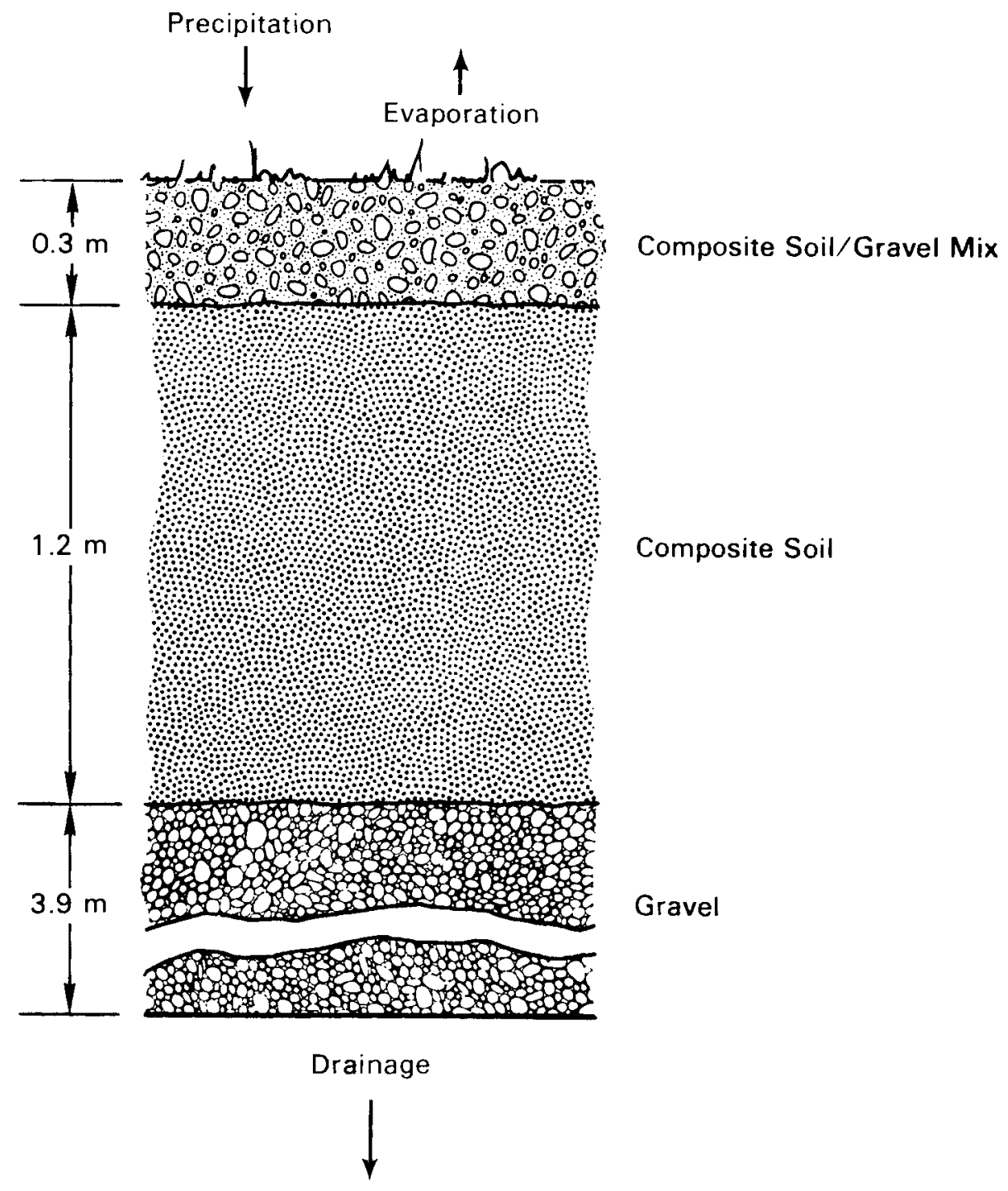

FIGURE 7.4. Conceptual Model of Protective Barrier 
N62NP: FY1986 EBS Study - Composite soil with gravel mix, 1962 data

$$
\begin{array}{rrr}
0 & 1 & 1 \\
0 & 365 & 365 \\
1 & 2 & 0 \\
1 & 3 & 1
\end{array}
$$

$1.000 \mathrm{E}+00 \quad 1.000 \mathrm{E}+05$

$1.000 \mathrm{E}-041.000 \mathrm{E}+00 \quad 1.000 \mathrm{E}-07$

$\begin{array}{llll}0.5 & 2.0 & 1.000 E-05\end{array}$

$3 \quad 37$

$$
\begin{array}{lr}
1 & 37 \\
1 & 0.000 \\
1 & 16.000 \\
2 & 36.000 \\
2 & 70.000 \\
2 & 110.000 \\
2 & 143.000 \\
3 & 153.000 \\
3 & 220.000 \\
3 & 540.000 \\
4 & 5
\end{array}
$$

$$
\begin{aligned}
& \text { IPLANT, LOWER, NGRAV, I SWDIF } \\
& \text { NPRI NT, DAYEND, NDAYS, NYEARS } \\
& \text { NSURPE, NFHOUR, I TOPBC }
\end{aligned}
$$

KOPT, KEST, I I APOR

HIRRI, HDRY, HTOP

DMAXBA,DELMAX,DELMIN

WTF, RFACT , RAININ

MATN, NPT

$0.200 \quad 1 \quad 0.500 \quad$ MAT, $Z$

$\begin{array}{llll}4.000 & 1 & 8.000 & \text { MAT, } Z\end{array}$

$28.000 \quad 2 \quad 32.000 \quad$ MAT, $Z$

$\begin{array}{lll}52.000 & 2 & 60.000 \\ 9 A T, Z\end{array}$

$90.000 \quad 2 \quad 100.000 \quad$ MAT,Z

$130.000 \quad 2 \quad 138.000 \quad$ MAT, $Z$

$149.0003 \quad 151.000$ MAT, $Z$

$165.000 \quad 3 \quad 181.000$ MAT, $Z$

$\begin{array}{lll}340.000 & 3 & 440.000 \\ \text { MAT, } Z\end{array}$

MAT,Z

MAXSUB, MAXPOL

Material No. 1, COMPGRAV.TH1: Composite soil with $15 \%$ gravel by weight

$41.0000000 \mathrm{E}+00 \quad 4.2200000 \mathrm{E}-01$

$1 \quad 4 \quad 1.0000000 E+00 \quad 1.2650003 E+01$

$4.2199999 \mathrm{E}-01-2.7573731 \mathrm{E}-02-2.3653656 \mathrm{E}-0$

$2 \quad 5 \quad 1.2650003 E+01 \quad 2.4420016 E+02$

$-1.3883400 E-011.5021513 E+00-1.4785267 E+$

$3 \quad 5 \quad 2.4420016 \mathrm{E}+02 \quad 7.1970044 \mathrm{E}+03$

$-1.7569752 E+00 \quad 2.7017555 E+00-1.3545368 E+$

$4 \quad 5 \quad 7.1970044 E+03 \quad 8.6326599 E+06$

$-3.4936512 \mathrm{E}-013.1459510 \mathrm{E}-01$-8.4237993E-02

COMPGRAV.KH1

$21.0000000 \mathrm{E}+00 \quad 3.6000000 \mathrm{E}-01$

$14 \quad 4 \quad 1.0000000 E+00 \quad 4.4980000 E+01$

$-4.4369757 E-01-5.8029747 E-01-2.8344643 E-01-2.1685658 E-01$

$23 \quad 4.4980000 E+018.6326599 E+06$

$2.4089615 E+00-3.4391944 E+00 \quad 4.3601289 E-02 \quad 0.0000000 E-01$

Material No. 2, COMPOS1.TH1: Composite soll

$41.0000000 \mathrm{E}+00 \quad 4.2200000 \mathrm{E}-01$

$1331.0000000 E+00 \quad 5.4290004 E+00$

$4.2199999 \mathrm{E}-01-7.3107332 \mathrm{E}-03-3.5250444 \mathrm{E}-02 \quad 0.0000000 \mathrm{E}-01$ $235.4290004 \mathrm{E}+00 \quad 5.6900012 \mathrm{E}+02$

$4.2632636 \mathrm{E}-01-1.9087702 \mathrm{E}-02-2.7235843 \mathrm{E}-02 \quad 0.0000000 \mathrm{E}-01$ $\begin{array}{llll}3 & 4 & 5.6900012 E+02 & 1.6770025 E+04\end{array}$

$2.4613359 E+00-1.7952768 E+00 \quad 4.5785773 E-01-3.9381173 E-02$

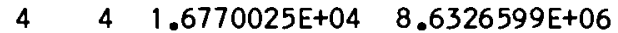

$3.6377275 \mathrm{E}-01-1.0580593 \mathrm{E}-01 \quad 1.0616908 \mathrm{E}-02-3.5810552 \mathrm{E}-04$ COMPOS1.KH1

$31.0000000 E+00 \quad 1.0800020 E-01$

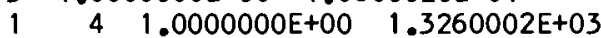

$-9.6657562 \mathrm{E}-0 \mathrm{i}-1.0965506 \mathrm{E}+00 \quad 5.8941185 \mathrm{E}-02-1.2111266 \mathrm{E}-01$

$24 \quad 1.3260002 E+03 \quad 7.1970044 E+03$

$\begin{array}{lll}-6.3407219 E+01 & 6.0421951 E+01-2.0131914 E+01 & 2.0865219 E+00\end{array}$ $3 \quad 4 \quad 7.1970044 \mathrm{E}+03 \quad 8.6326599 \mathrm{E}+06$

$-9.5900745 E+00 \quad 1.8411379 E+00-6.0871047 E-01 \quad 2.4653060 E-02$ Material No. 3, GRAVEL1.TH1: Gravel $0.6-1.3 \mathrm{~cm}$ diameter $4 \quad 9.9999998 \mathrm{E}-03 \quad 4.1900000 \mathrm{E}-01$

$1339.9999998 \mathrm{E}-03 \quad 7.7430010 \mathrm{E}-02$

$2.9529411 \mathrm{E}-01-9.5835656 \mathrm{E}-02-1.6991356 \mathrm{E}-02 \quad 0.0000000 \mathrm{E}-01$

$23 \quad 7.7430010 \mathrm{E}-02 \quad 2.7829993 \mathrm{E}-01$

$-2.0774645 E-01-1.0013254 E+00-4.2446923 E-01 \quad 0.0000000 E-01$

$\begin{array}{llll}5 & 5 & 2.7829993 \mathrm{E}-01 & 1.2920002 \mathrm{E}+01\end{array}$

$5.8681458 \mathrm{E}-02-1.1252354 \mathrm{E}-01^{2} 2.0134400 \mathrm{E}-01-1.705484 \mathrm{IE}-0$

$\begin{array}{llll}4 & 5 & 1.2920002 E+01 & 8.7777891 E+06\end{array}$
NPOLY, $X(1), Y(1)$

$1, \operatorname{NDEG}(1)+1, X X 1, X \times 2$

$0.0000000 E-01$ COEFFICIENTS

$1, \operatorname{NDEG}(1)+1, X \times 1, X \times 2$

COEFFICIENTS

$1, \operatorname{NDEG}(1)+1, X \times 1, X \times 2$

COEFFICIENTS

$1, \operatorname{NDEG}(1)+1, X \times 1, X \times 2$

NPOLY, $X(1), Y(1)$

$1, \operatorname{NDEG}(1)+1, X X 1, X X 2$

0.0000000E-01 COEFFICIENTS

$1, \operatorname{NDEG}(1)+1, x \times 1, x \times 2$

COEFFICIENTS

NPOLY, $X(1), Y(1)$

$1, \operatorname{NDEG}(1)+1, X \times 1, X \times 2$ COEFFICIENTS

$1, \operatorname{NDEG}(1)+1, x \times 1, x \times 2$ COEFFICIENTS

1, $\operatorname{NDEG}(1)+1, x \times 1, x \times 2$ COEFFICIENTS

$1, \operatorname{NDEG}(1)+1, x \times 1, x \times 2$ COEFFICIENTS

NPOLY, $X(1), Y(1)$

$1, \operatorname{NDEG}(1)+1, X X 1, X X 2$

$0.0000000 E-01$ COEFFICIENTŚ

1, $\operatorname{NDEG}(1)+1, x \times 1, x \times 2$

0.0000000E-01 COEFFICIENTS

$1, \operatorname{NDEG}(1)+1, x \times 1, x \times 2$

$0.0000000 E-01$ COEFFICIENTS

\author{
NPOLY, $X(1), Y(1)$ \\ 1, $\operatorname{NOEG}(1)+1, X X 1, X \times 2$ \\ COEFFICI ENTS \\ $1, \operatorname{NDEG}(1)+1, X \times 1, X \times 2$ \\ COEFFICIENTS \\ $1, \operatorname{NDEG}(1)+1, x \times 1, x \times 2$ \\ 5.2016903E-02 COEFFICIENTS \\ $1, \operatorname{NDEG}(1)+1, X X 1, X \times 2$
}

FIGURE 7.5. Listing of Input File N62NP. INP 


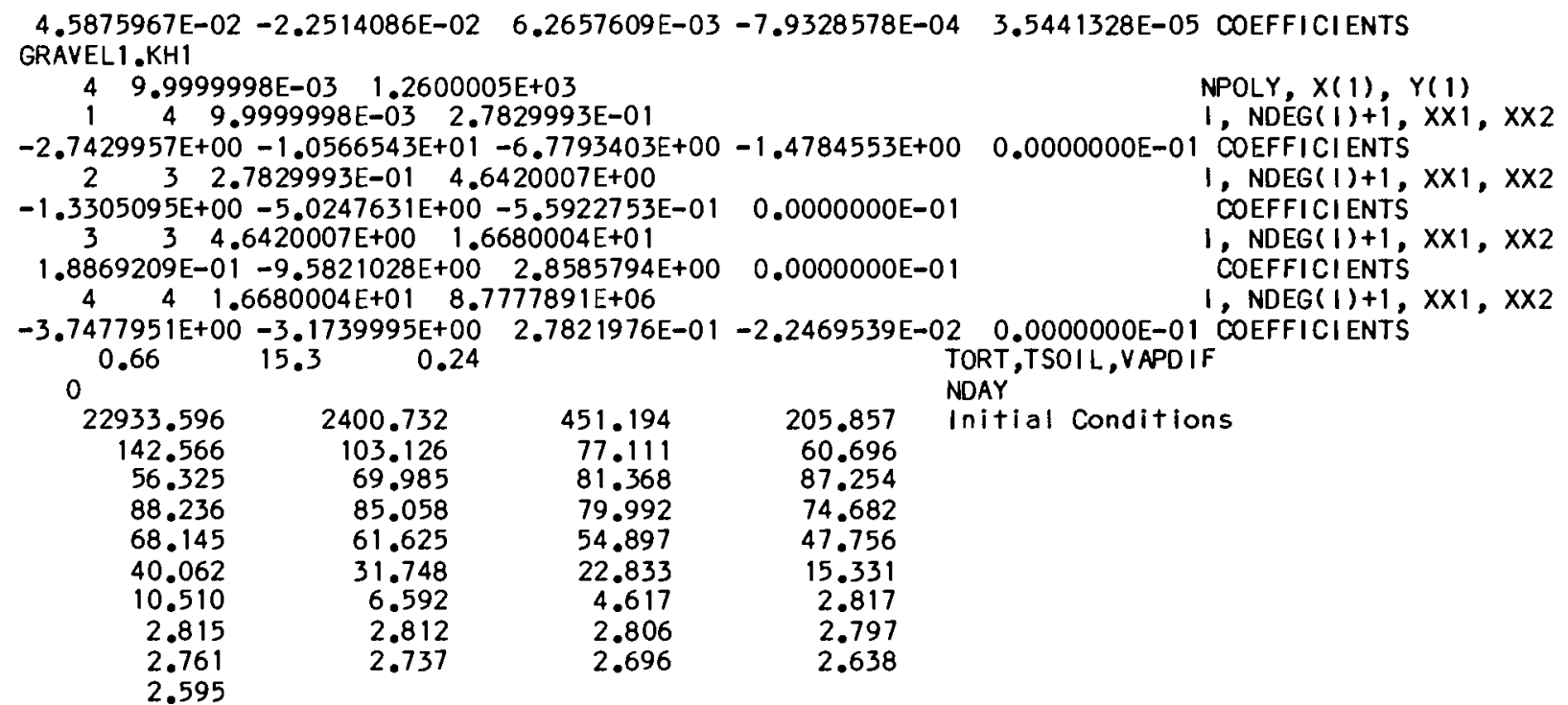

$\begin{array}{lllllllll}0.0000 & 0.0149 & 0.1101 & 0.1104 & 0.0237 & 0.0368 & 0.2147 & 0.1408\end{array}$ $\begin{array}{lllllllllll}0.1915 & 0.0964 & 0.1357 & 0.0578 & 0.0157 & 0.1426 & 0.1050 & 0.0885\end{array}$ $\begin{array}{lllllllllll}0.1158 & 0.0982 & 0.1097 & 0.2216 & 0.0713 & 0.0694 & 0.0774 & 0.1050\end{array}$ $\begin{array}{llllllllllll}0.2072 & 0.2813 & 0.2281 & 0.0883 & 0.0703 & 0.0777 & 0.0937 & 0.0676\end{array}$ $\begin{array}{llllllllll}0.0875 & 0.1119 & 0.1926 & 0.2615 & 0.1271 & 0.0284 & 0.0583 & 0.0089\end{array}$ $\begin{array}{llllllllll}0.1231 & 0.1001 & 0.1161 & 0.0274 & 0.3457 & 0.1219 & 0.1181 & 0.1176\end{array}$ $\begin{array}{lllllllll}0.1168 & 0.2071 & 0.3266 & 0.2582 & 0.2563 & 0.3259 & 0.1955 & 0.2929\end{array}$ $\begin{array}{llllllllll}0.2193 & 0.1765 & 0.0724 & 0.1118 & 0.2551 & 0.1957 & 0.1195 & 0.1159\end{array}$ $\begin{array}{lllllllll}0.2007 & 0.2761 & 0.3615 & 0.1914 & 0.2216 & 0.1846 & 0.2643 & 0.3002\end{array}$ $\begin{array}{llllllllll}0.3615 & 0.3849 & 0.3791 & 0.4040 & 0.4152 & 0.3621 & 0.5266 & 0.2655\end{array}$ $\begin{array}{llllllllll}0.4425 & 0.6560 & 0.4471 & 0.4120 & 0.2278 & 0.4747 & 0.3830 & 0.4169\end{array}$ $\begin{array}{llllllllll}0.4170 & 0.4045 & 0.4545 & 0.4664 & 0.3911 & 0.4639 & 0.5044 & 0.6427\end{array}$ $\begin{array}{lllllllllll}0.6853 & 0.3469 & 0.6483 & 0.6142 & 0.5437 & 0.6405 & 0.5206 & 0.8800\end{array}$ $\begin{array}{llllllllll}0.7259 & 0.5357 & 0.6966 & 0.6924 & 0.7958 & 0.9584 & 0.5604 & 0.6518\end{array}$ $\begin{array}{llllllllll}0.6831 & 0.8087 & 0.5017 & 0.5967 & 0.5787 & 0.5999 & 0.5117 & 0.5277\end{array}$ $\begin{array}{llllllllll}0.7238 & 0.7173 & 0.4897 & 0.5890 & 0.6439 & 0.2533 & 0.5358 & 0.1300\end{array}$ $\begin{array}{llllllllll}0.4096 & 0.6331 & 0.8403 & 0.4804 & 0.7181 & 0.7279 & 0.6675 & 0.8353\end{array}$ $\begin{array}{llllllllll}0.7888 & 0.7619 & 0.3187 & 0.7143 & 0.8767 & 0.6251 & 0.2532 & 0.0643\end{array}$ $\begin{array}{llllllllll}0.3957 & 0.4917 & 0.8598 & 1.0391 & 0.8635 & 0.6780 & 0.7340 & 0.8315\end{array}$ $\begin{array}{llllllllll}0.4906 & 0.5166 & 0.6893 & 0.7208 & 0.7571 & 0.7391 & 0.9491 & 1.0695\end{array}$ $\begin{array}{llllllll}0.9866 & 0.8248 & 0.7786 & 0.5669 & 0.6501 & 0.9943 & 1.1633 & 1.1370\end{array}$ $\begin{array}{lllllllll}0.8122 & 0.9582 & 1.0942 & 1.1848 & 1.0316 & 0.6964 & 1.0351 & 1.1713\end{array}$ $\begin{array}{lllllllll}0.9744 & 0.9160 & 0.8831 & 1.2127 & 1.1724 & 0.9278 & 0.7709 & 0.9986\end{array}$ $\begin{array}{lllllllll}0.4196 & 0.8182 & 0.7055 & 0.8515 & 0.8996 & 1.0218 & 1.0568 & 0.9518\end{array}$ $\begin{array}{lllllllll}1.3675 & 1.1932 & 0.8858 & 1.0623 & 1.0033 & 1.1433 & 0.8163 & 0.7959\end{array}$ $\begin{array}{lllllllll}1.0455 & 0.9644 & 1.0085 & 1.0274 & 0.9932 & 1.2366 & 0.9919 & 0.8420\end{array}$ $\begin{array}{llllllllll}1.1587 & 0.8938 & 0.9756 & 0.9788 & 1.0386 & 0.8886 & 0.4534 & 0.7529\end{array}$ $\begin{array}{llllllllll}0.6019 & 0.6347 & 0.2835 & 0.2899 & 0.6071 & 0.8467 & 0.7368 & 0.8920\end{array}$ $\begin{array}{lllllllllll}0.7038 & 0.7292 & 0.8045 & 1.0671 & 0.8073 & 0.8256 & 0.6993 & 0.7871\end{array}$ $\begin{array}{llllllllll}1.2396 & 0.8158 & 0.6938 & 0.6519 & 1.1046 & 0.8166 & 0.7989 & 0.7260\end{array}$ $\begin{array}{llllllllll}0.6089 & 0.6279 & 0.6779 & 0.7519 & 0.9463 & 0.6887 & 0.7373 & 0.6531\end{array}$ $\begin{array}{lllllllll}0.8436 & 0.8117 & 0.4965 & 0.5639 & 0.3982 & 0.7173 & 0.4295 & 0.3861\end{array}$ $\begin{array}{lllllllll}0.7089 & 0.5258 & 0.4655 & 0.6501 & 0.7985 & 0.5096 & 0.7010 & 0.6194\end{array}$ $\begin{array}{lllllllll}0.5424 & 0.4535 & 0.5146 & 0.5989 & 0.5805 & 0.5624 & 0.1684 & 0.4033\end{array}$ $\begin{array}{llllllllll}0.3929 & 0.3779 & 0.4480 & 0.4206 & 0.4443 & 0.3248 & 0.3529 & 0.0326\end{array}$ $\begin{array}{lllllllll}0.3590 & 0.4006 & 0.0764 & 0.0237 & 0.1594 & 0.3569 & 0.1901 & 0.2897\end{array}$ $\begin{array}{lllllllll}0.2281 & 0.2014 & 0.1490 & 0.1647 & 0.2158 & 0.3026 & 0.2456 & 0.1458\end{array}$ $\begin{array}{lllllllll}0.1899 & 0.1318 & 0.1504 & 0.1372 & 0.1367 & 0.1345 & 0.0127 & 0.0422\end{array}$

FIGURE 7.5. (contd) 


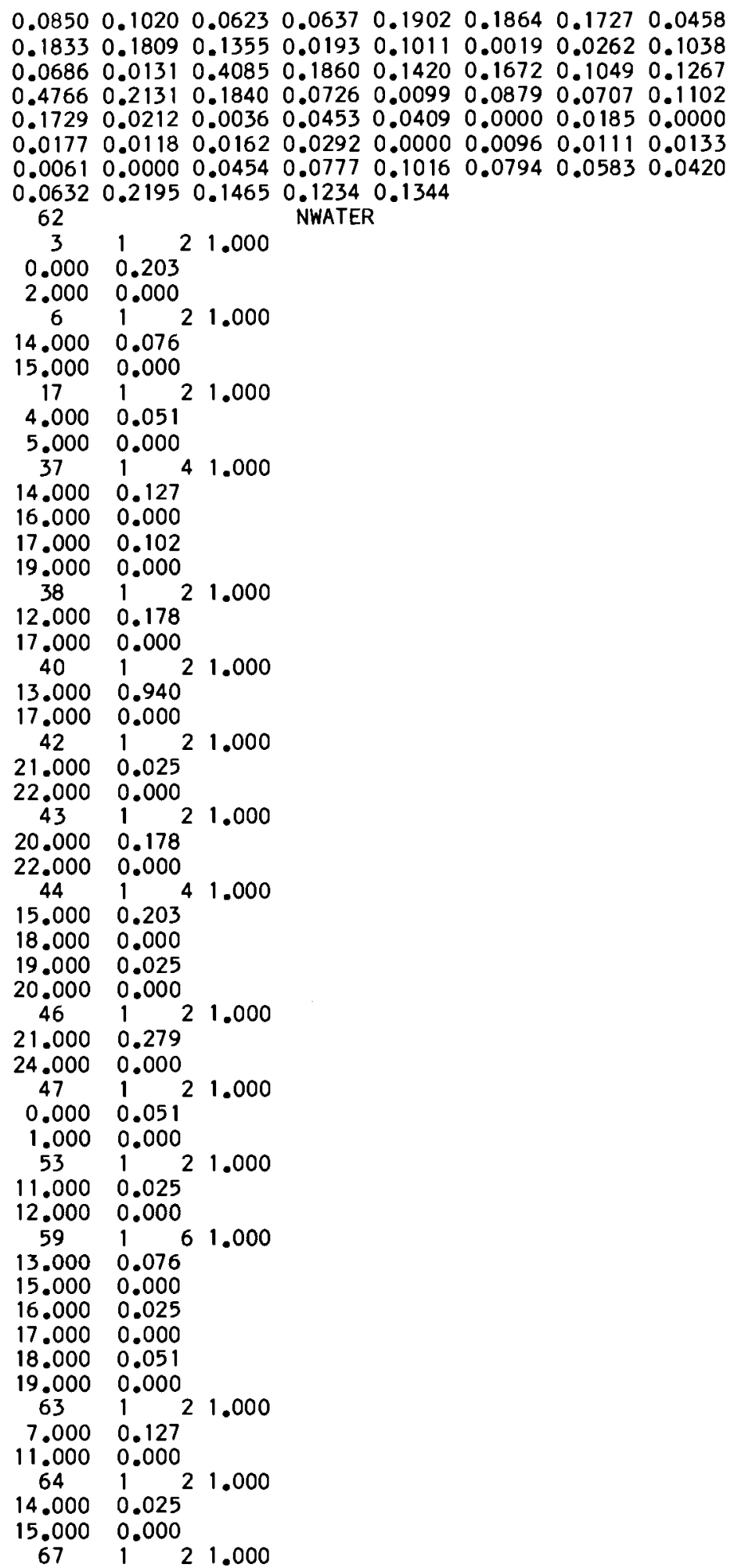

FIGURE 7.5. (contd) 


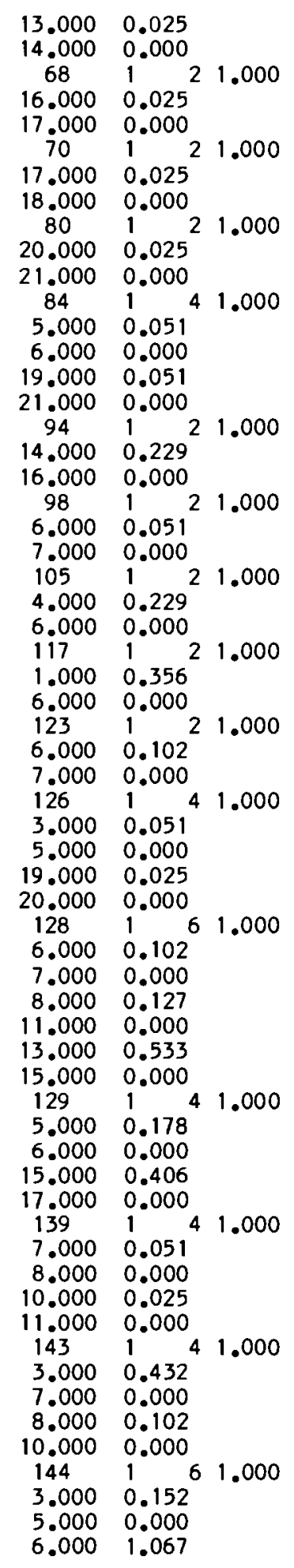

FIGURE 7.5. (contd) 


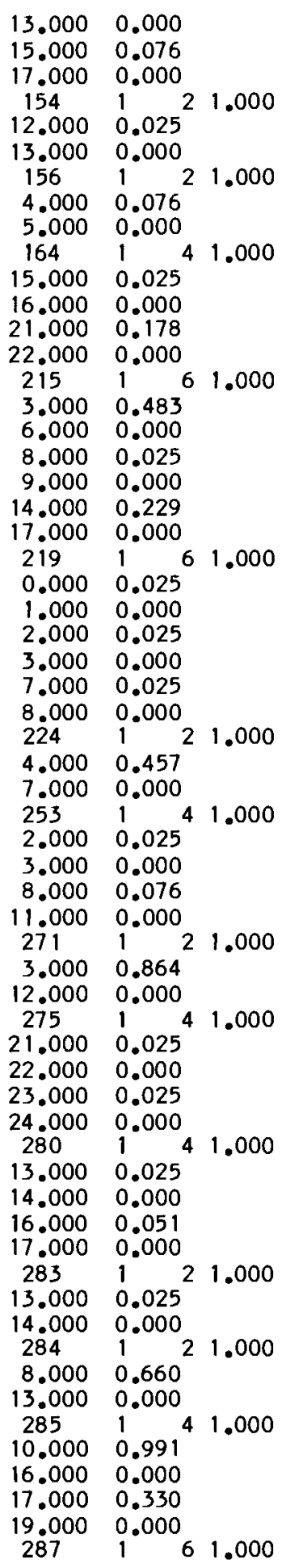

FIGURE 7.5. (contd) 


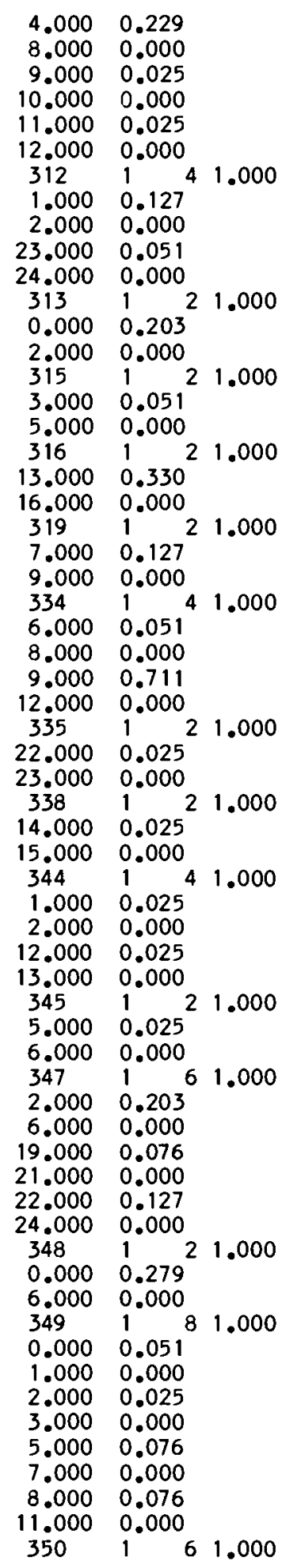

FIGURE 7.5 . (contd) 


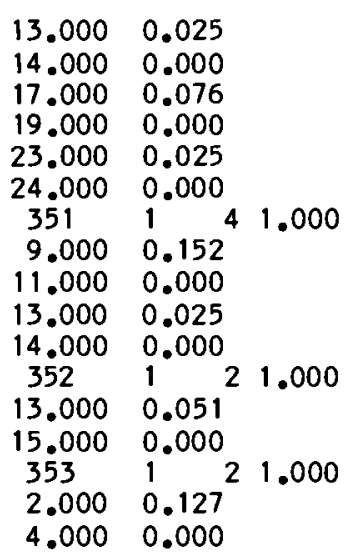

FIGURE 7.5. (contd)

\subsubsection{Problem Description}

The lysimeter, which is $1829 \mathrm{~cm}(60 \mathrm{ft})$ deep, was represented with 43 nodes. The depths of those nodes can be found in the input file RHOLYP74.INP, listed in Figure 7.7.

Laboratory data for the soil water retention curve and saturated conductivity were taken from Finlayson, Nelson, and Baca (1978). The Campbell hydraulic property functions were fit to the data and both the laboratory data and the functions are illustrated in Figure 7.8 .

Initial conditions (i.e., initial head values) were obtained from the results file of a previous simulation of the year 1973. These values are shown in Figure 7.7 .

UNSAT-H SIMULATION RESULTS

\begin{tabular}{|c|c|c|c|c|c|c|c|}
\hline \multirow[b]{3}{*}{ NODE } & $n \theta: N 6$ & . BIN & Date & -50 & & Time: & $13: 46$ \\
\hline & \multirow[b]{2}{*}{ DEPTH } & \multicolumn{3}{|c|}{ INITIAL CONDITIONS } & \multirow[b]{2}{*}{ DEPTH } & \multirow[b]{2}{*}{ HEAD } & \multirow[b]{2}{*}{ THETA } \\
\hline & & HEAD & THETA & NODE & & & \\
\hline $\begin{array}{r}1 \\
3 \\
5 \\
7 \\
9 \\
11 \\
13 \\
15\end{array}$ & $\begin{array}{r}0.000 \\
0.200 \\
1.000 \\
4.000 \\
16.000 \\
28.000 \\
36.000 \\
52.000\end{array}$ & $\begin{array}{r}22933.6 \\
451.2 \\
142.6 \\
77.1 \\
56.3 \\
81.4 \\
88.2 \\
80.0\end{array}$ & $\begin{array}{l}0.0533 \\
0.1203 \\
0.1633 \\
0.1969 \\
0.2196 \\
0.1934 \\
0.2861 \\
0.2914\end{array}$ & $\begin{array}{r}2 \\
4 \\
6 \\
8 \\
10 \\
12 \\
14 \\
16\end{array}$ & $\begin{array}{r}0.100 \\
0.500 \\
2.000 \\
8.000 \\
24.000 \\
32.000 \\
44.000 \\
60.000\end{array}$ & $\begin{array}{r}2400.7 \\
205.9 \\
103.1 \\
60.7 \\
70.0 \\
87.3 \\
85.1 \\
74.7\end{array}$ & $\begin{array}{l}0.0685 \\
0.1490 \\
0.1793 \\
0.2138 \\
0.2035 \\
0.2867 \\
0.2881 \\
0.2950\end{array}$ \\
\hline
\end{tabular}

Figure 7.6. Listing of Output File N62NP.OUT (used 17 minutes of computer time) 


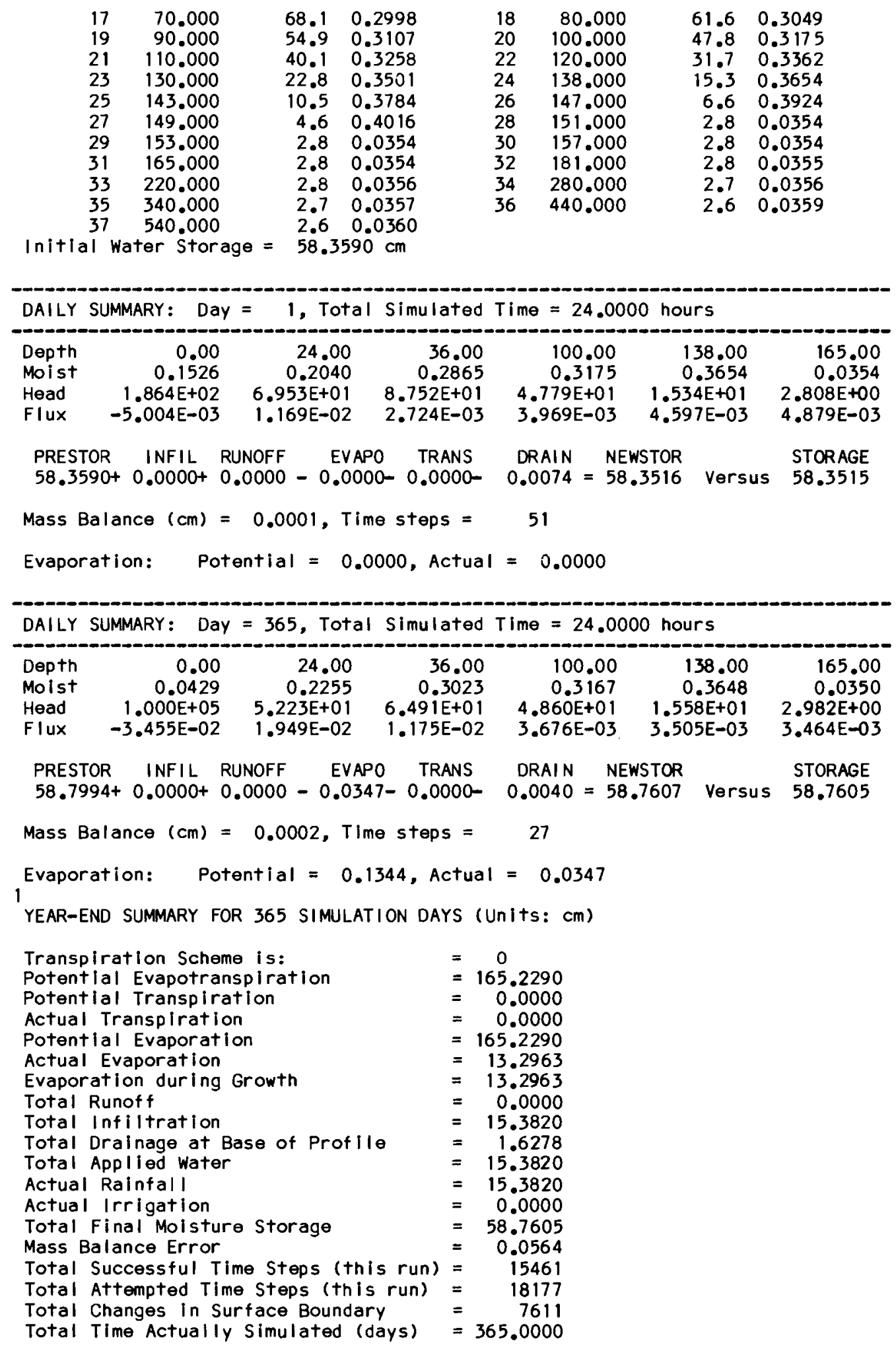

Figure 7.6. (contd) 


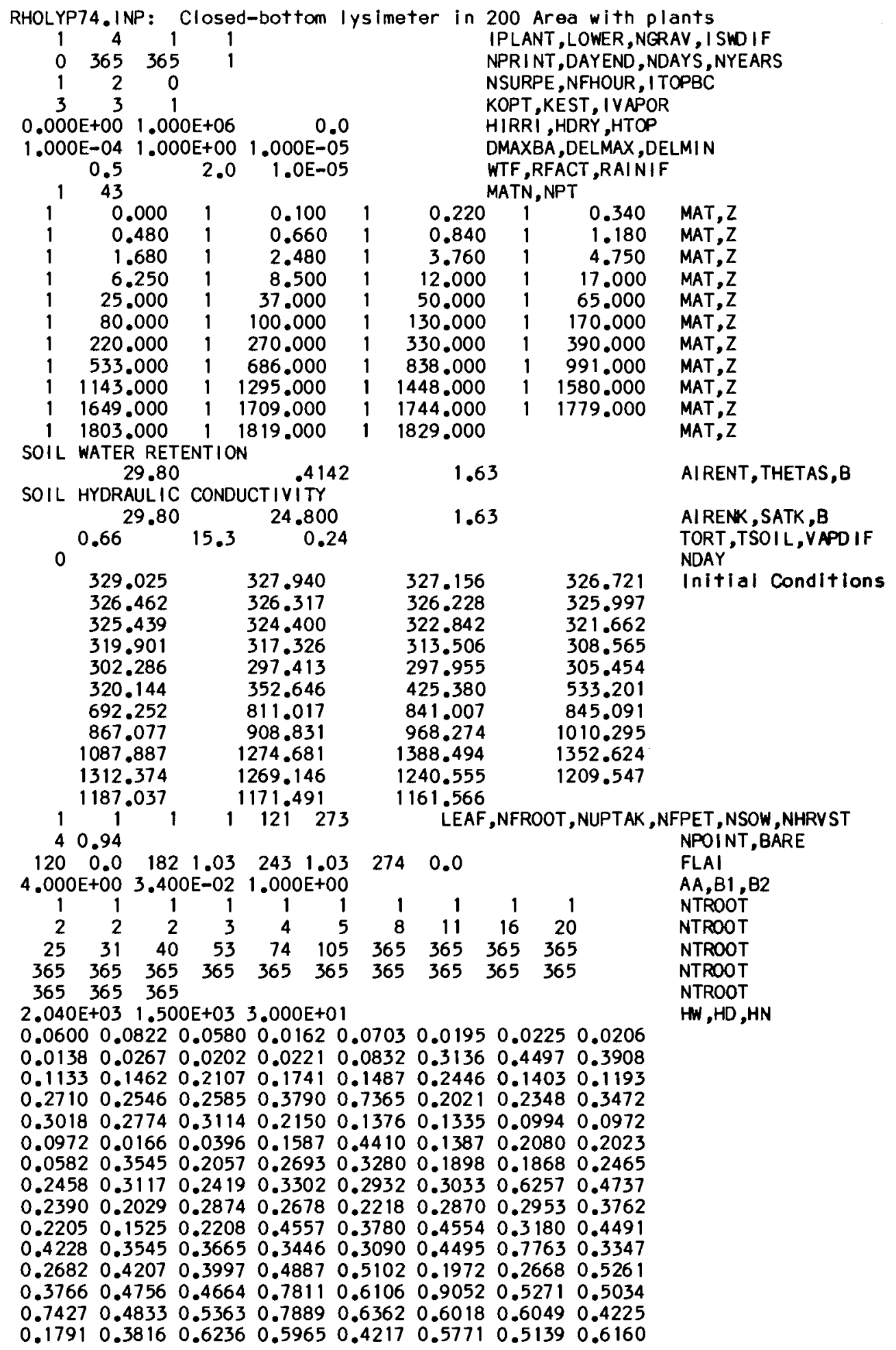

FIGURE 7.7. Listing of Input File RHOLYP74.INP 


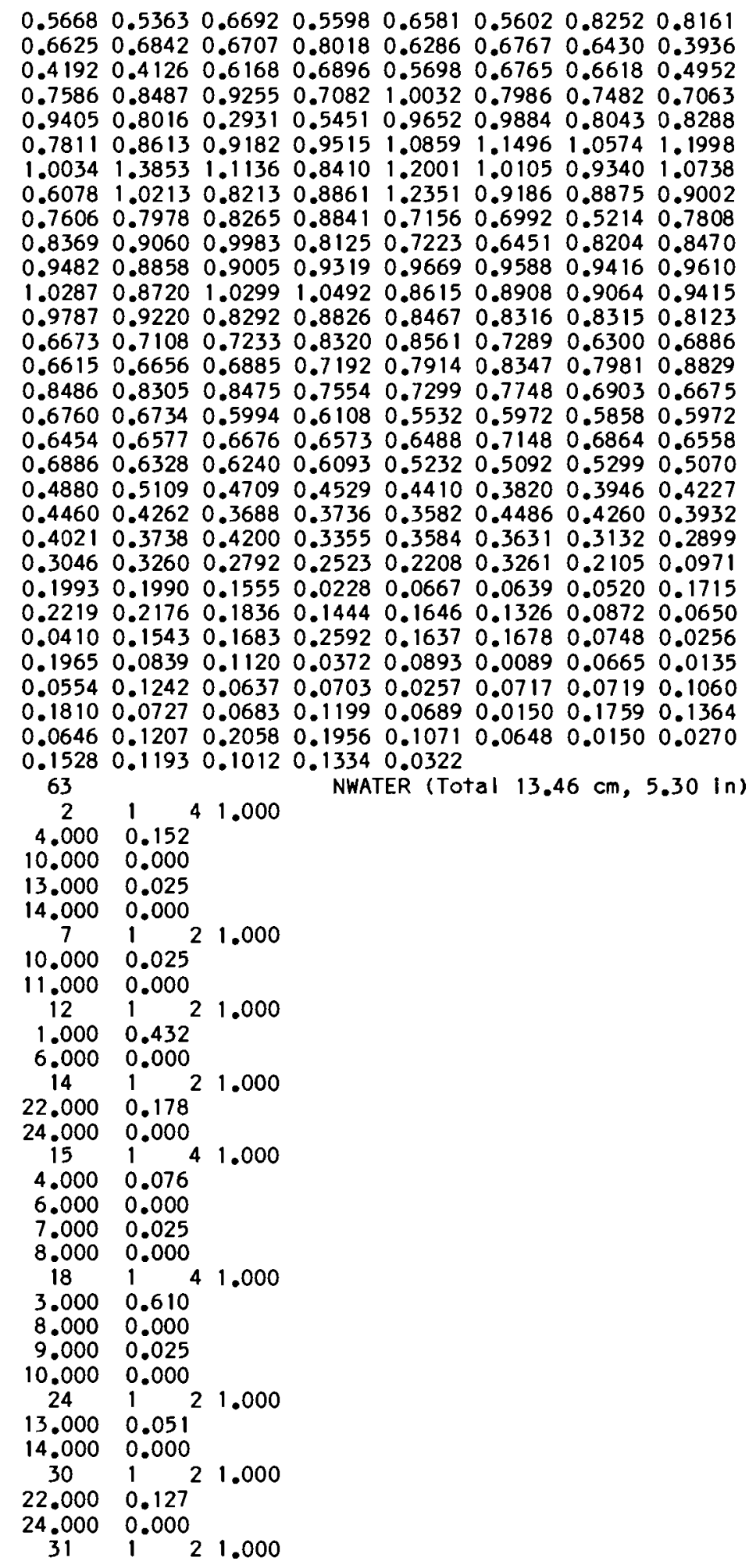

FIGURE 7.7. (contd) 


$$
\begin{aligned}
& 0.000 \quad 0.559 \\
& 7.000 \quad 0.000 \\
& \begin{array}{lll}
44 & 1 & 2 \\
1.000
\end{array} \\
& 24.0000 .000 \\
& 24.000 \quad 0.000 \\
& \begin{array}{llll}
46 & i & 2 & 1.000
\end{array} \\
& 20.000 \quad 0.051 \\
& 22.000 \quad 0.000 \\
& \begin{array}{llll}
49 & 1 & 4 & 1.000
\end{array} \\
& 1.000 \quad 0.076 \\
& 3.000 \quad 0.000 \\
& 13.000 \quad 0.737 \\
& 21.000 \quad 0.000 \\
& \begin{array}{llll}
58 & 1 & 2 & 1.000
\end{array} \\
& 20.000 \quad 0.152 \\
& 24.000 \quad 0.000 \\
& \begin{array}{llll}
60 & 1 & 2 & 1.000
\end{array} \\
& 10.000 \quad 0.076 \\
& 12.000 \quad 0.000 \\
& \begin{array}{llll}
69 & 1 & 2 & 1.000
\end{array} \\
& 21.000 \quad 0.076 \\
& 22.000 \quad 0.000 \\
& \begin{array}{llll}
70 & 1 & 8 & 1.000
\end{array} \\
& 4.000 \quad 0.025 \\
& 5.000 \quad 0.000 \\
& 16.000 \quad 0.102 \\
& 19.000 \quad 0.000 \\
& 20.000 \quad 0.025 \\
& 21.000 \quad 0.000 \\
& 23.000 \quad 0.102 \\
& 24.000 \quad 0.000 \\
& \begin{array}{llll}
71 & 1 & 2 & 1.000
\end{array} \\
& 9.000 \quad 0.076 \\
& 11.000 \quad 0.000 \\
& \begin{array}{llll}
74 & 1 & 2 & 1.000
\end{array} \\
& 7.000 \quad 0.025 \\
& 8.000 \quad 0.000 \\
& \begin{array}{llll}
75 & 1 & 2 & 1.000
\end{array} \\
& 8.000 \quad 0.051 \\
& 9.000 \quad 0.000 \\
& \begin{array}{llll}
86 & 1 & 2 & 1.000
\end{array} \\
& 14.000 \quad 0.051 \\
& 15.000 \quad 0.000 \\
& \begin{array}{llll}
88 & 1 & 2 & 1.000
\end{array} \\
& 7.000 \quad 0.127 \\
& 10.000 \quad 0.000 \\
& \begin{array}{llll}
89 & 1 & 6 & 1.000
\end{array} \\
& 3.000 \quad 0.483 \\
& 9.000 \quad 0.000 \\
& 10.000 \quad 0.025 \\
& 11.000 \quad 0.000 \\
& 13.000 \quad 0.076 \\
& 14.000 \quad 0.000 \\
& \begin{array}{llll}
94 & 1 & 2 & 1.000
\end{array} \\
& 14.000 \quad 0.127 \\
& 17.000 \quad 0.000 \\
& \begin{array}{llll}
112 & 1 & 4 & 1.000
\end{array} \\
& 16.000 \quad 0.076 \\
& 19.000 \quad 0.000 \\
& 21.000 \quad 0.229 \\
& 24.000 \quad 0.000 \\
& 113 \quad 1 \quad 81.000
\end{aligned}
$$

FIGURE 7.7. (contd) 


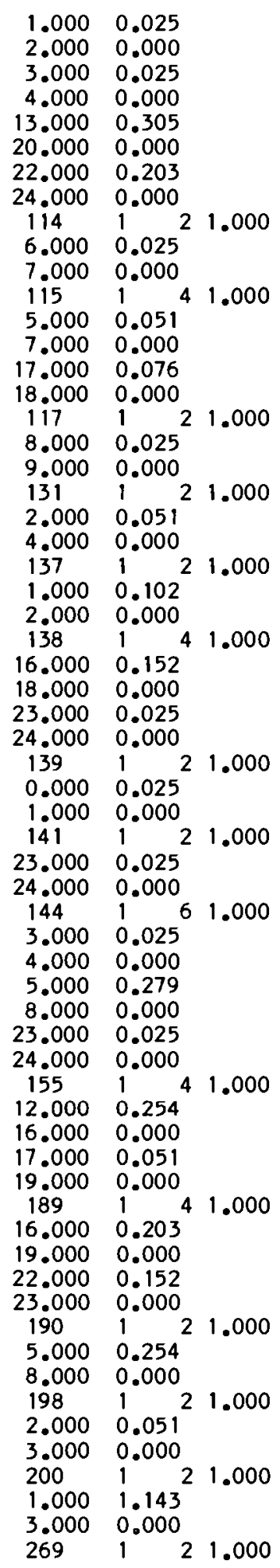

FIGURE 7.7 . (contd) 


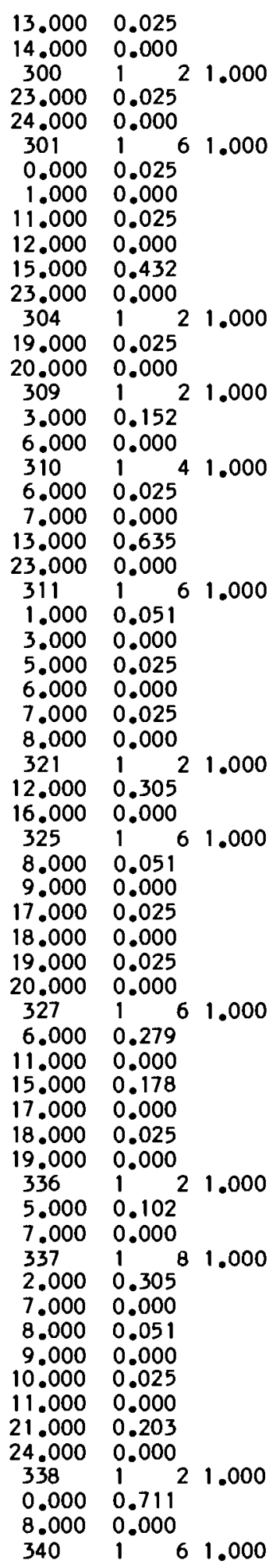

FIGURE 7.7. (contd) 


\begin{tabular}{|c|c|}
\hline $\begin{array}{l}344 \\
16.000 \\
17.000 \\
346 \\
13.000 \\
16.000 \\
348 \\
3.000 \\
4.000 \\
349 \\
2.000 \\
3.000 \\
350 \\
20.000 \\
21.000 \\
353 \\
11.000 \\
13.000 \\
354 \\
11.000 \\
13.000 \\
355 \\
5.000 \\
6.000 \\
359 \\
0.000 \\
1.000 \\
360 \\
15.000 \\
1.00\end{array}$ & 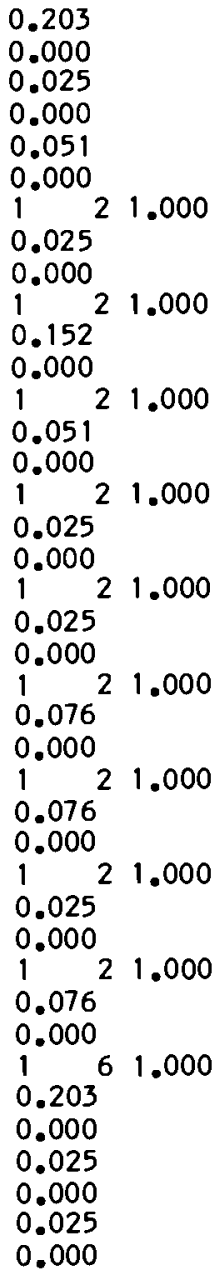 \\
\hline
\end{tabular}

FIGURE 7.7. (contd)

The plant data needed for the simulation include leaf area index (LAI), fraction of the soil surface that is bare, rooting density and depth, and plant response to water content (the sink function). The leaf area index and the maximum rooting depth are shown in Figure 7.9 . Note that growth was started on day 121 and stopped on day 274 of the simulation. In addition, the roots were allowed to penetrate to the 3-m depth by day 244. The bare fraction of soil surface was 0.94 . Rooting density was calculated with Equation (3.17) such that $a=4.0, b=0.034$, and $c=1.0$. Finally, the sink function (Figure 3.3) was approximated with $\theta_{w}=0.031, \theta_{d}=0.0374$, and $\theta_{n}=0.4125$. 

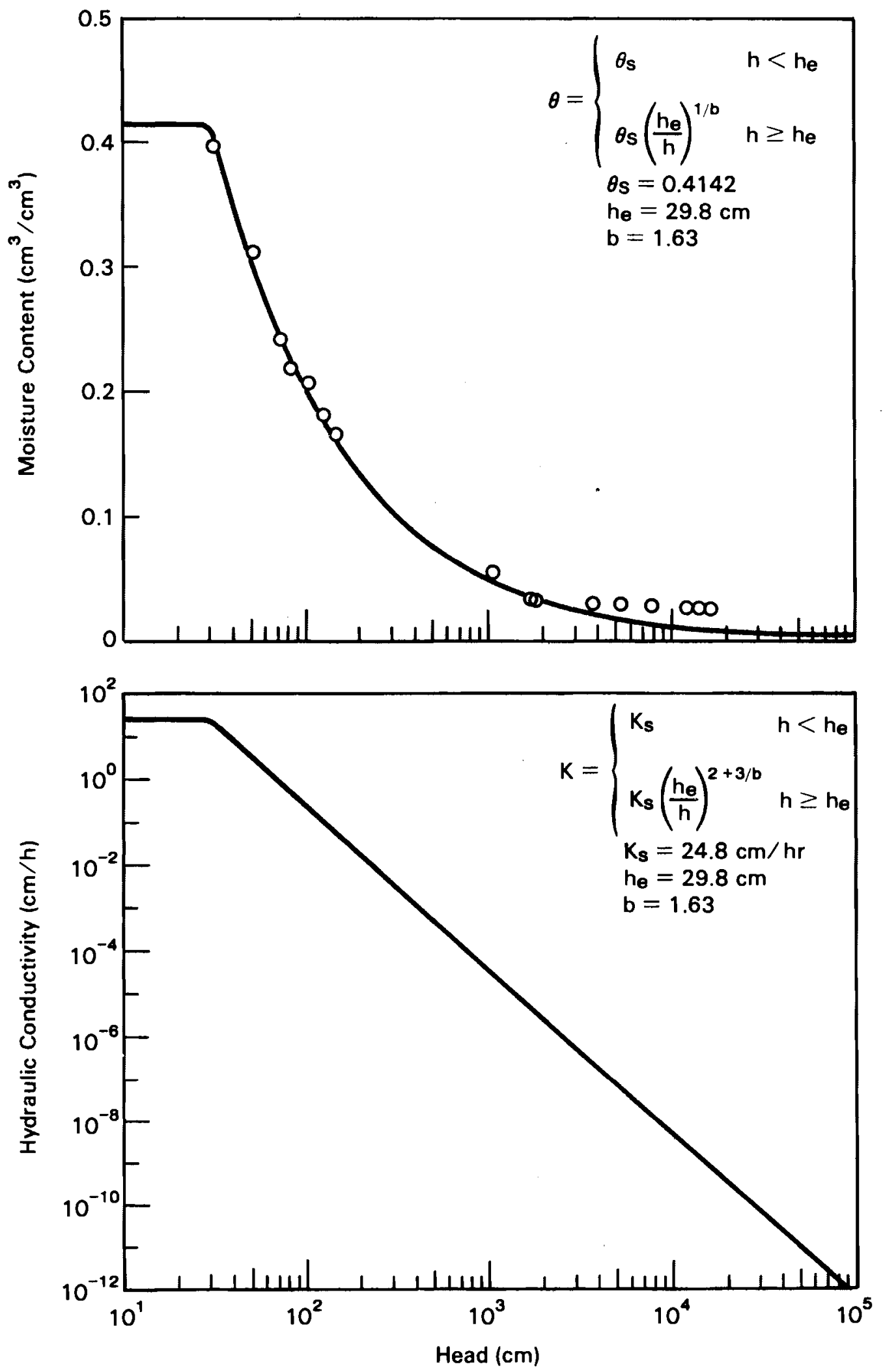

FIGURE 7.8. Soil Hydraulic Properties for 200-Area Lysimeter a) Moisture Retention b) Hydraulic Conductivity 

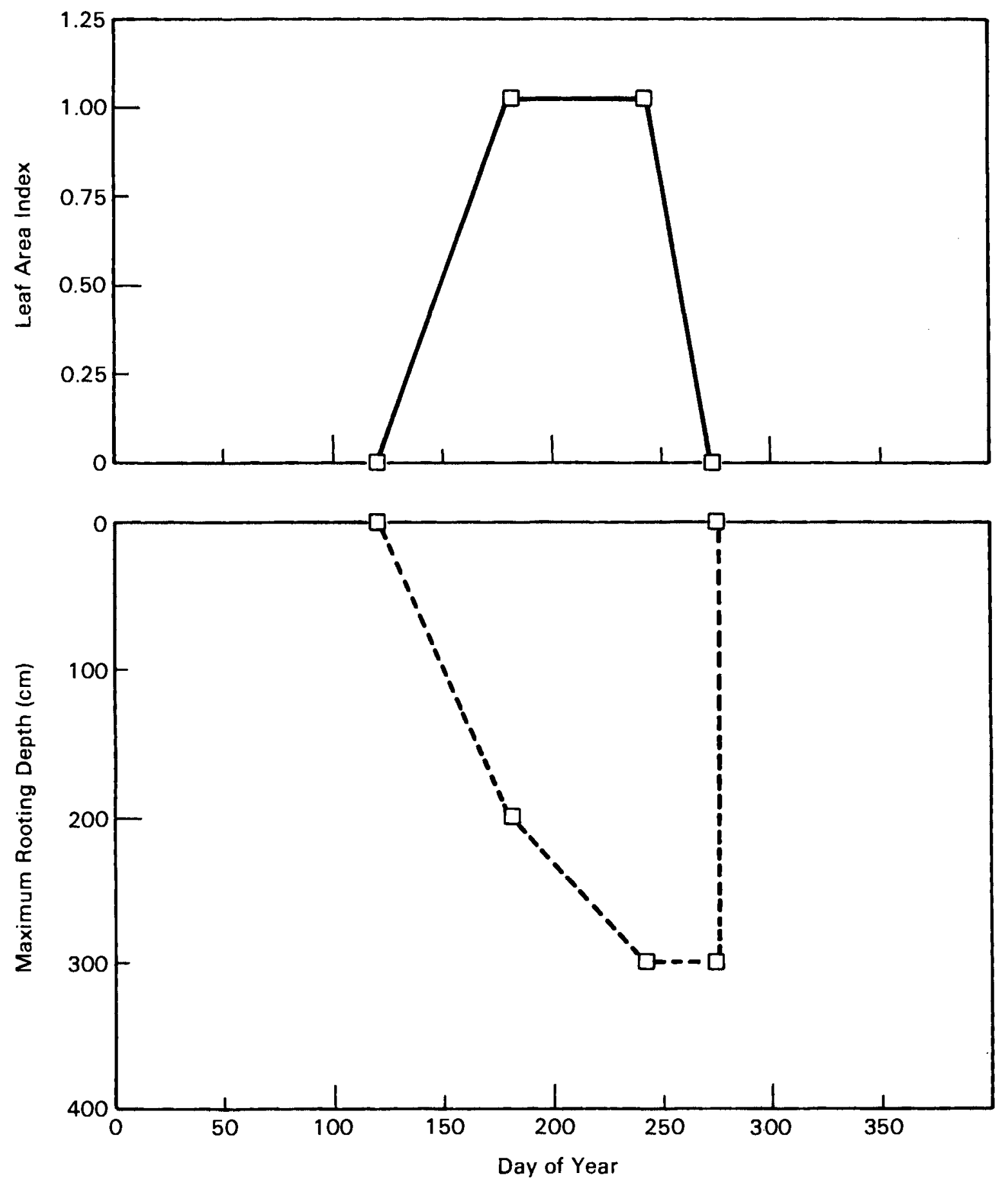

FIGURE 7.9. Plant Parameters a) Assumed Leaf Area Index b) Assumed Maximum Rooting Depth 
7.3.2 Results

A year-end summary of the simulation is provided in Figure 7.10. Note that even though they covered only $6 \%$ of the lysimeter surface, the simulated plants were able to remove $2.3 \mathrm{~cm}$ of water from the lysimeter. This transpired water represented $17 \%$ of the precipitation for the year. Evaporation removed $16 \mathrm{~cm}$ of water, so that the total annual water loss was $18.3 \mathrm{~cm}$. In other words, storage in the lysimeter decreased by $4.9 \mathrm{~cm}$ during the year, a condition that would not support long-term deep drainage or recharge.

UNSAT-H SIMULATION RESULTS

Input Filiename: RHOLYYP74.BIN Date: 27-JUL-86

Time: 12:53:40

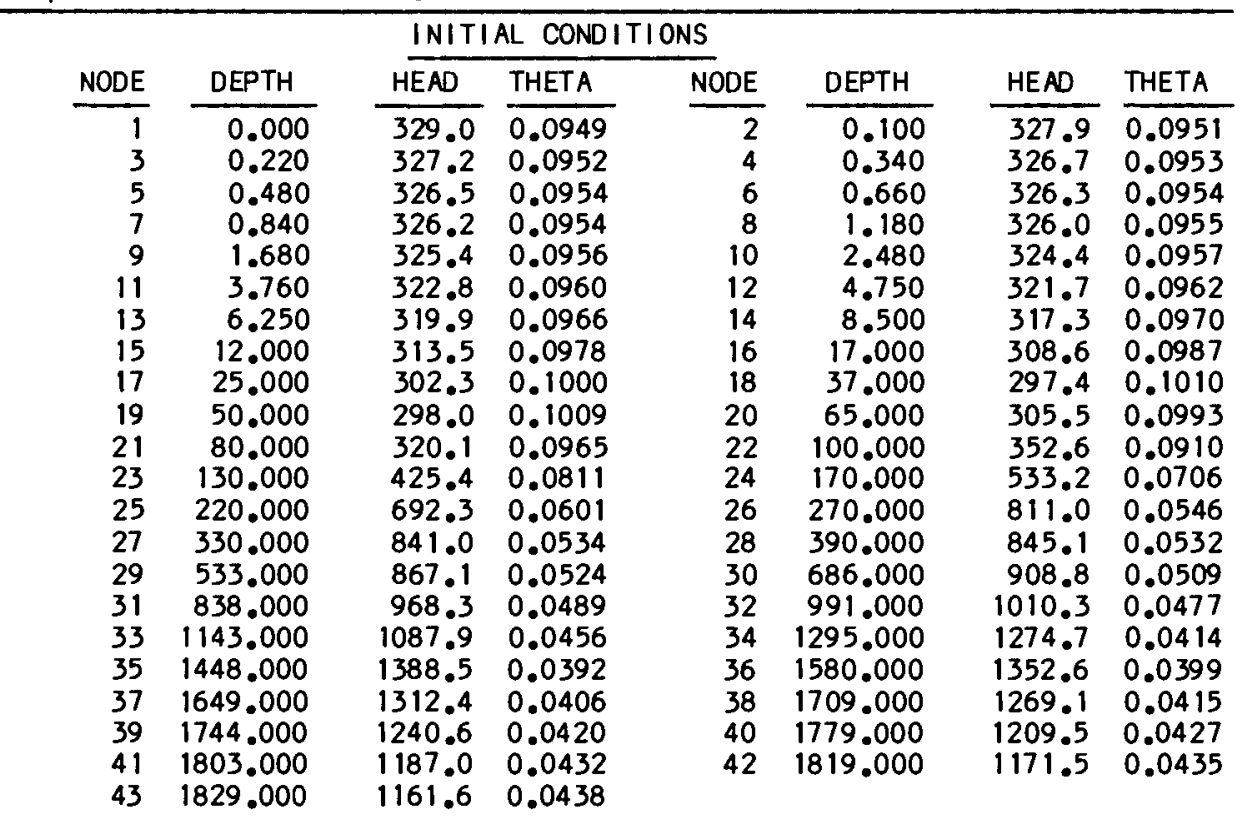

Initial Water Storage $=93.8470 \mathrm{~cm}$

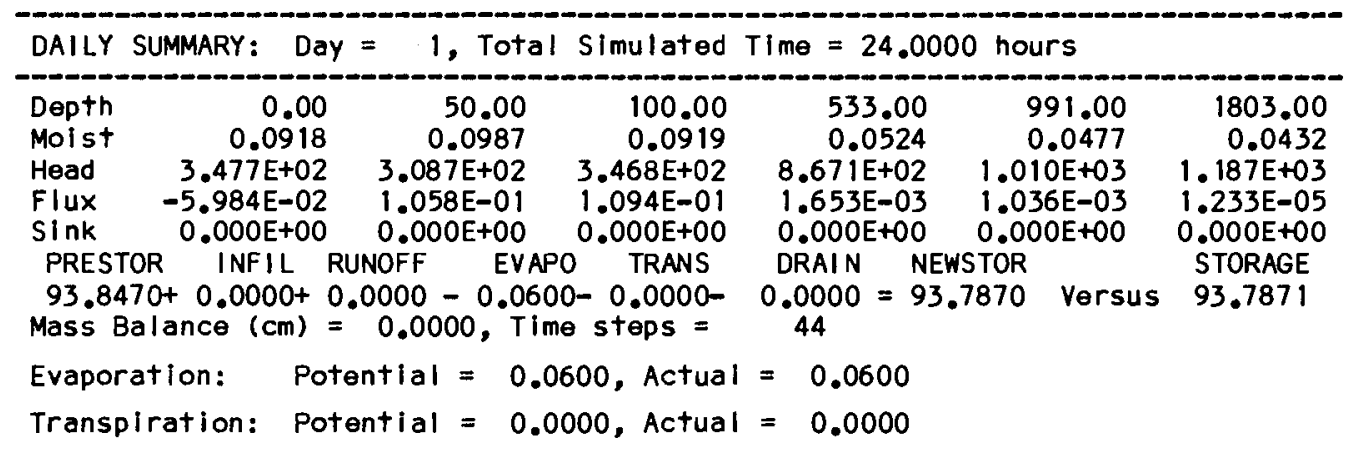

FIGURE 7.10. Listing of Output File RHOLYP74.OUT

(used 25 minutes of computer time) 


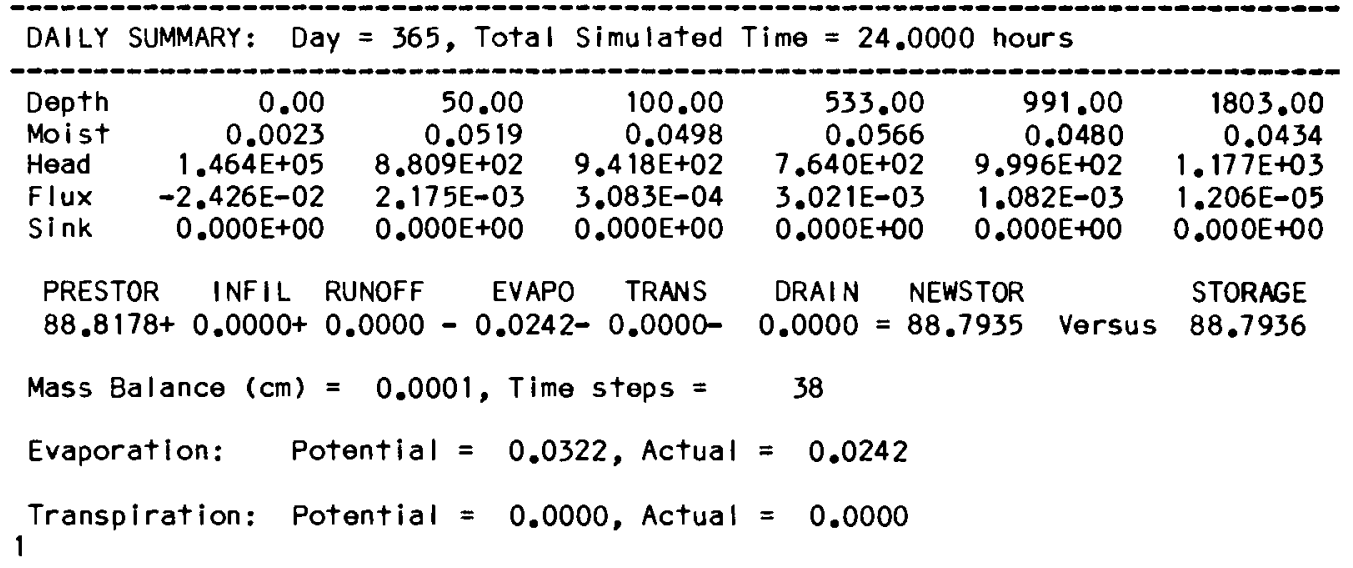

YEAR-END SUMMARY FOR 365 SIMULATION DAYS (Units: $\mathrm{cm}$ )

$\begin{array}{llr}\text { Transpiration Scheme is: } & =1 \\ \text { Potential Evapotranspiration } & =174.9388 \\ \text { Potential Transpiration } & =2.7426 \\ \text { Actual Transpiration } & =2.3401 \\ \text { Potential Evaporation } & =172.1962 \\ \text { Actual Evaporation } & =15.9724 \\ \text { Evaporation during Growth } & =15.9724 \\ \text { Total Runoff } & =0.0000 \\ \text { Total Infiltration } & =13.4480 \\ \text { Total Drainage at Base of Proflle } & =0.0000 \\ \text { Total Applied Water } & =13.4480 \\ \text { Actual Rainfal I } & =13.4480 \\ \text { Actual Irrigation } & =0.0000 \\ \text { Total Final Moisture Storage } & =88.7936 \\ \text { Mass Balance Error } & =0.1889 \\ \text { Total Successful Time Steps (this run) } & =18008 \\ \text { Total Attempted Time Steps (this run) } & =22778 \\ \text { Total Changes in Surface Boundary } & =10142 \\ \text { Total Time Actually Simulated (days) } & =365.0000\end{array}$

Total flux $(\mathrm{cm})$ across different depths at the end of 365 days:

\begin{tabular}{rrrrrr}
\multicolumn{1}{c}{ DEPTH } & \multicolumn{1}{c}{ FLUX } & \multicolumn{1}{c}{ DEPTH } & \multicolumn{1}{c}{ FLUX } & \multicolumn{1}{c}{ DEPTH } & FLUX \\
\hline 0.000 & $-2.5244 \mathrm{E}+00$ & 0.050 & $-2.5136 \mathrm{E}+00$ & 0.160 & $-2.4883 \mathrm{E}+00$ \\
0.280 & $-2.5018 \mathrm{E}+00$ & 0.410 & $-2.5236 \mathrm{E}+00$ & 0.570 & $-2.5438 \mathrm{E}+00$ \\
0.750 & $-2.5641 \mathrm{E}+00$ & 1.010 & $-2.5733 \mathrm{E}+00$ & 1.430 & $-2.5728 \mathrm{E}+00$ \\
2.080 & $-2.5452 \mathrm{E}+00$ & 3.120 & $-2.4874 \mathrm{E}+00$ & 4.255 & $-2.4252 \mathrm{E}+00$ \\
5.500 & $-2.3597 \mathrm{E}+00$ & 7.375 & $-2.2703 \mathrm{E}+00$ & 10.250 & $-2.1492 \mathrm{E}+00$ \\
14.500 & $-2.0014 \mathrm{E}+00$ & 21.000 & $-1.8099 \mathrm{E}+00$ & 31.000 & $-1.5243 \mathrm{E}+00$ \\
43.500 & $-1.1227 \mathrm{E}+00$ & 57.500 & $-6.3125 \mathrm{E}-01$ & 72.500 & $-8.4562 \mathrm{E}-02$ \\
90.000 & $5.4604 \mathrm{E}-01$ & 115.000 & $1.3655 \mathrm{E}+00$ & 150.000 & $2.1820 \mathrm{E}+00$ \\
195.000 & $2.7027 \mathrm{E}+00$ & 245.000 & $2.6980 \mathrm{E}+00$ & 300.000 & $2.4316 \mathrm{E}+00$ \\
360.000 & $2.0959 \mathrm{E}+00$ & 461.500 & $1.4387 \mathrm{E}+00$ & 609.500 & $8.1261 \mathrm{E}-01$ \\
762.000 & $5.7133 \mathrm{E}-01$ & 914.500 & $4.3239 \mathrm{E}-01$ & 1067.000 & $3.8467 \mathrm{E}-01$ \\
1219.000 & $3.4909 \mathrm{E}-01$ & 1371.500 & $1.9108 \mathrm{E}-01$ & 1514.000 & $7.8261 \mathrm{E}-02$ \\
1614.500 & $4.6444 \mathrm{E}-02$ & 1679.000 & $3.2492 \mathrm{E}-02$ & 1726.500 & $2.2872 \mathrm{E}-02$ \\
1761.500 & $1.5388 \mathrm{E}-02$ & 1791.000 & $9.0664 \mathrm{E}-03$ & 1811.000 & $4.3345 \mathrm{E}-03$ \\
1824.000 & $1.2087 \mathrm{E}-03$ & 1829.000 & $0.0000 \mathrm{E}+00$ & &
\end{tabular}

FIGURE 7.10 . (contd) 


\subsection{CODE LISTINGS}

This section contains a listing of the programs, subroutines, and functions that comprise the UNSAT-H model, as well as a glossary of terms. The UNSAT-H code is written in VAX FORTRAN Version 4.0 , which is based on American National Standard FORTRAN-77 (ANSI X3.9-1978). Extensions to FORTRAN-77 are available in VAX FORTRAN, although limited use is made of them. The extensions include the system subroutines DATE and TIME and the FORTRAN statements INCLUDE and PRINT/DELETE as well as certain format specifiers and variable names longer than six characters. Calls to the system subroutines DATE and TIME return the date and time, respectively. The "INCLUDE" statement, when embedded within a program, will "include" a designated external file within the program when it is compiled. The "PRINT/DELETE" statement is used within subroutine HARDCOPY to send the output file to the printer and then delete it. Finally, the format specifiers "\$", "<", and ">" are used to facilitate program input and output.

\subsection{LISTINGS}

The first codes to be listed are the *.INC files: BARRAY. INC, BOUT.INC, BSOIL.INC, BTIME.INC, and BVAR.INC. These *.INC files contain the variable type declarations, array dimensions, data statements, and common blocks that are shared by different programs and subroutines.

After the *.INC files, each program, subroutine, and function is listed separately. The listing starts with DATAINH followed by each of its subroutines, then UNSAT-H followed by each of its subroutines, and finally DATAOUT followed by each of its subroutines. Although some subroutines or functions may be used by more than one main program, they are only listed once.

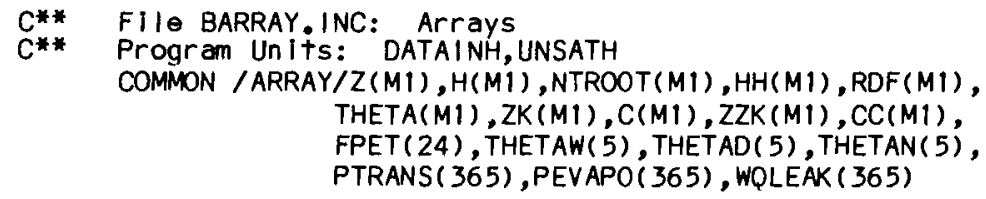

C** File BOUT.INC: Variables, Arrays, and Common Blocks $C^{* *}$ Program Units:
$C^{* *}$ 
CHARACTER*80 IFILE,OFILE, RFILE,STIME* 8, SDATE*9

INTEGER DAYEND,DAYSTP, TSTP, DAYAST, TAST, DAYUBC , TUBC

PARAMETER $(M 1=250)$

DIMENSION DAYQ(M1),DAYSNK (M1),H(M1), THETA(M1),Z(M1),TQ(M1), NODE(6)

COMMON /INTEG/ DAYEND,DAYSTP, TSTP, LUI, LUR, LUS, LUW, NPT, IPLANT NPR INT, NSURPE, NTOTAL, MAXREC, IREC, I ERROR, NCHR, IDAY, DAYAST, TAST, DAYUBC, TUBC

COMMON /REAL/ HOUR,DAYINF,DAYRAN,DAYE, DAYTRA,DAYRUN, TPREV,TMOIST, PE,PT,DAYTIM

COMMON / ARRAY/ DAYQ,DAYSNK,H,THETA,Z,TQ, NOOE

COMMON /CHAR/ IFILE,OFILE,RFILE,STIME, SDATE

DATA LUI,LUR,LUS,LUW/1,5,6,7/

C** File BSOIL.INC: Soll parameters

$C^{* *}$ Program Units: DATAINH,POLYCH,POLYKH, POLYTH,UNSATH

COMMON / IHY/MAT(M1), IHY(320)

DIMENSION NSUBTH( 5 ), AIRINT( 5 ), THET( 5 ), NDEGTH( 20), XDIVTH(20), CREGTH( 100),

NSUBKH (5), AIRINK (5), SK(5),

NDEGKH(20), XD IVKH (20),CREGKH( 100),

AMOUNT (24), SLOPTH(5), SLOPKH( 5)

EQUIVALENCE (I HY (1), NSUBTH), (I HY(6), AIRINT), (IHY(11), THET), ( I HY( 16), NDEGTH), (IHY (36), XDIVTH), ( IHY (56), CREGTH), (IHY(156), NSUBKH), (I HY(161), AIRINK), (IHY( 166), SK), (1HY(171), NDEGKH), (IHY(191), XDIVKH), (IHY (211),CREGKH), $($ IHY $(311)$, SLOPTH $),(1 H Y(316)$, SLOPKH $)$

File BTIME.INC: Time parameters

Program Units: DELCHK,UNSATH

COMMON /TIME/DELT, DI FMAX,DELSAV, D I FFMA, I SWDIF,DELSUB, TSUB, TEND, NRATES, TDONE, IDAY, $N$, SUBEND, I GOI50, RFACT, TSTART, RTIME (24)

C** File BVAR.INC: Real, Integer, and Logical Unit parameters

C* Program Units: DATAINH,DELCHK,POLYCH,POLYKH,POLYTH,UNSATH REAL LOGE INTEGER DAYEND

COMMON /RPARA/DMAXBA,DELMAX,DELMIN,HIRRI, HDRY, TMOIST, LOGE, SATURK, DRYK, SATURC, DRYC, AA, B1, B2

COMMON / IPARA/IPLANT, LOWER, NDAYS, NDAY, KOPT, I VAPOR, MATN, NPT , NGRAV, MAXSUB, MAXPOL, NSURPE, I NC, MXROOT, NWATER, NPRINT

$C^{* *} \quad$ Logical unit assignments

LUI = binary input file unit (input to UNSATH)

LUB = binary output flle unit from DATAINH;

binary output file unit from UNSATH

LUR = read (interactive input unit)

LUS = screen (interactive and additional output unit)

PARAMETER ( LUI $=1$,

LUB $=2$

LUR $=5$

LUS $=6$ )

C** Maximum dimension for nodal arrays

PARAMETER $(M 1=250)$ 


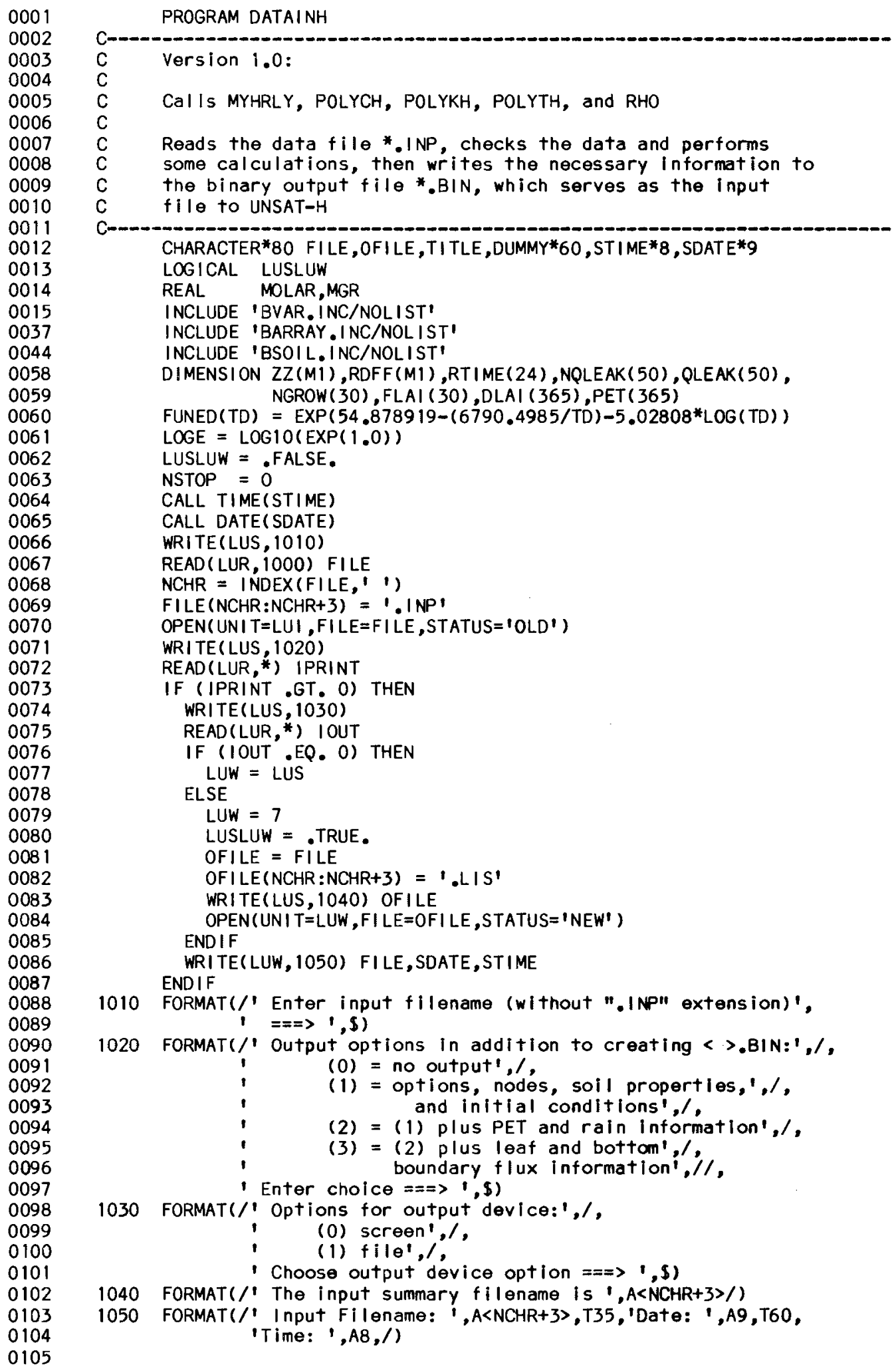




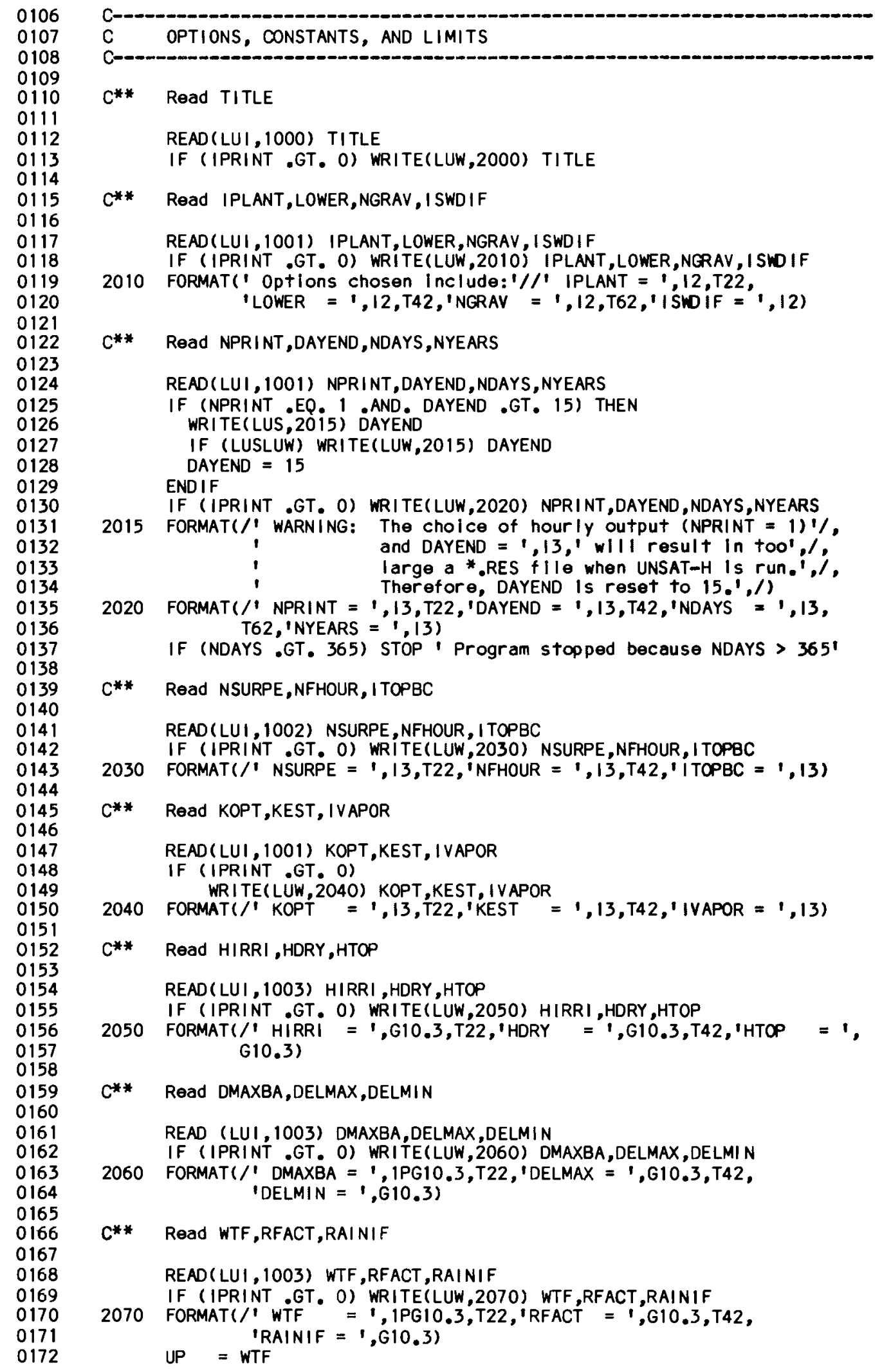




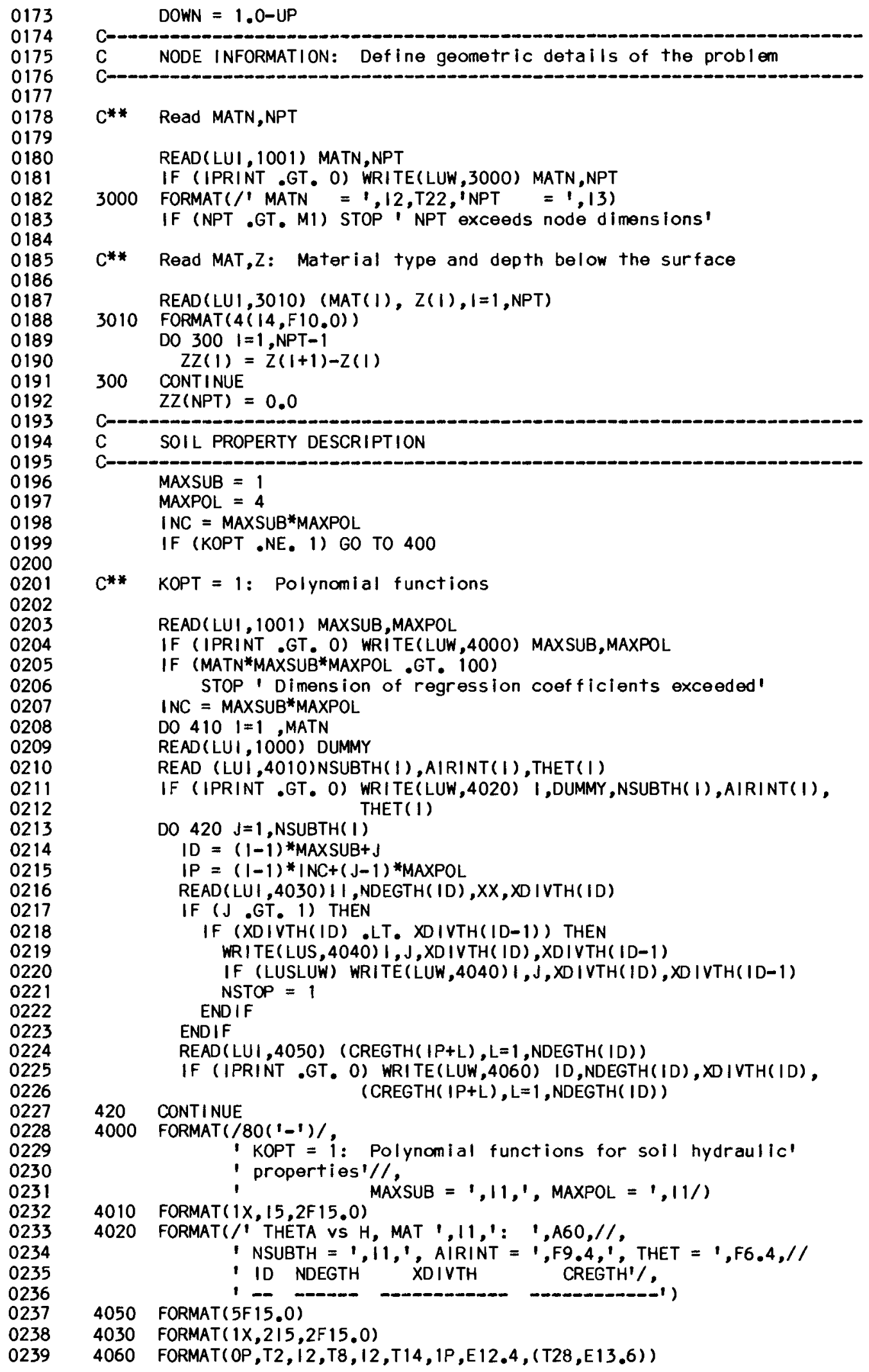




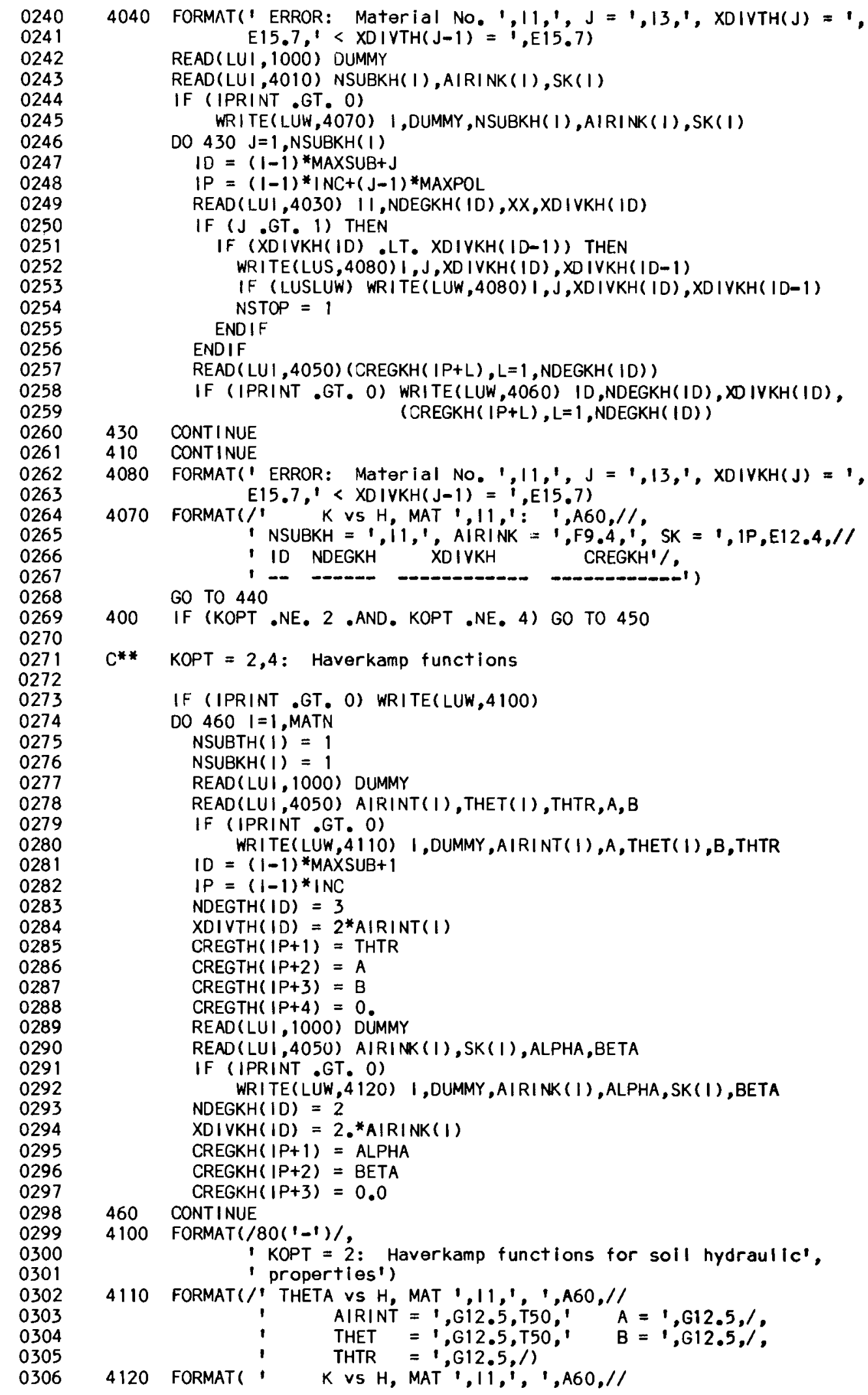




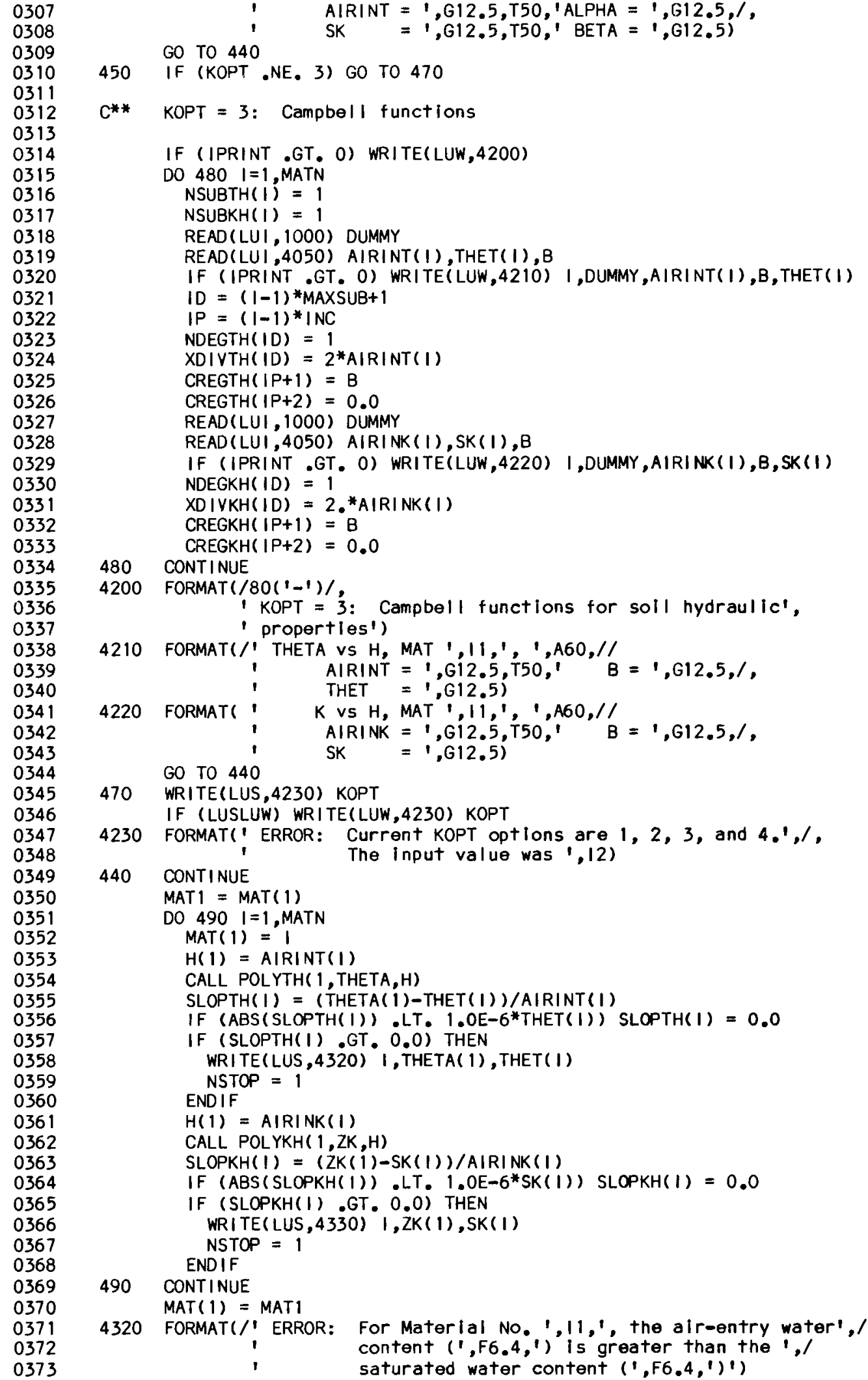




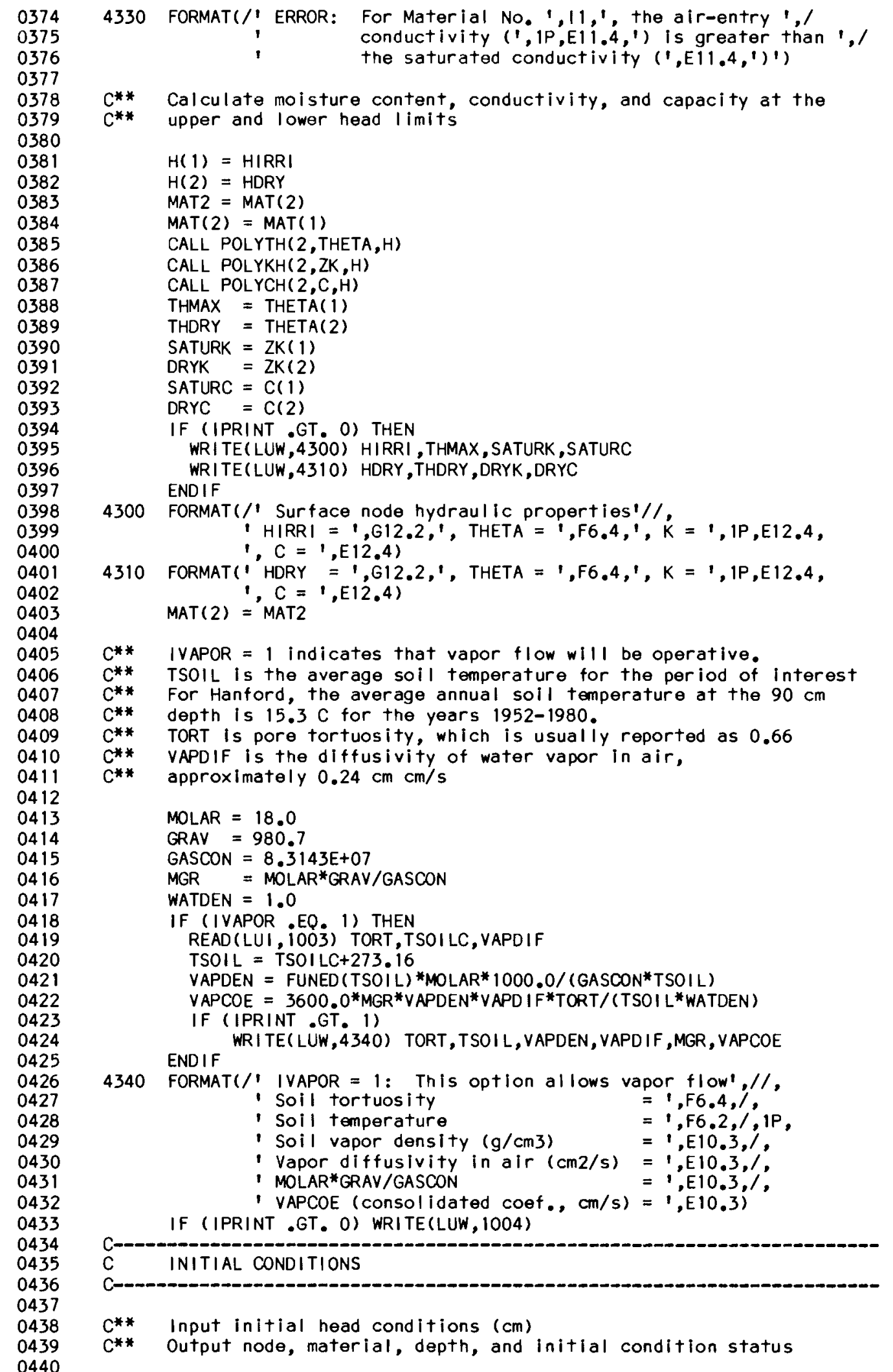




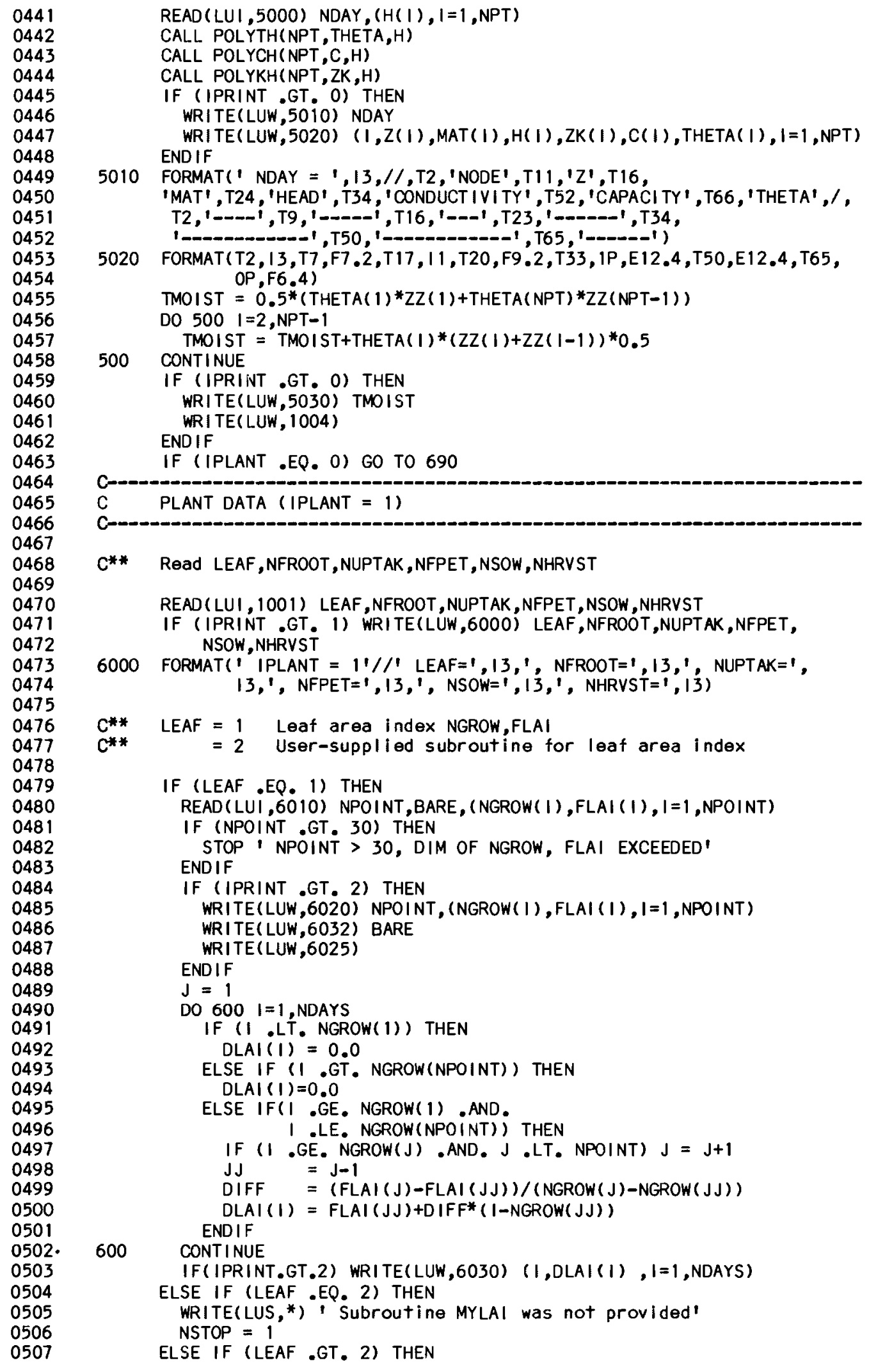




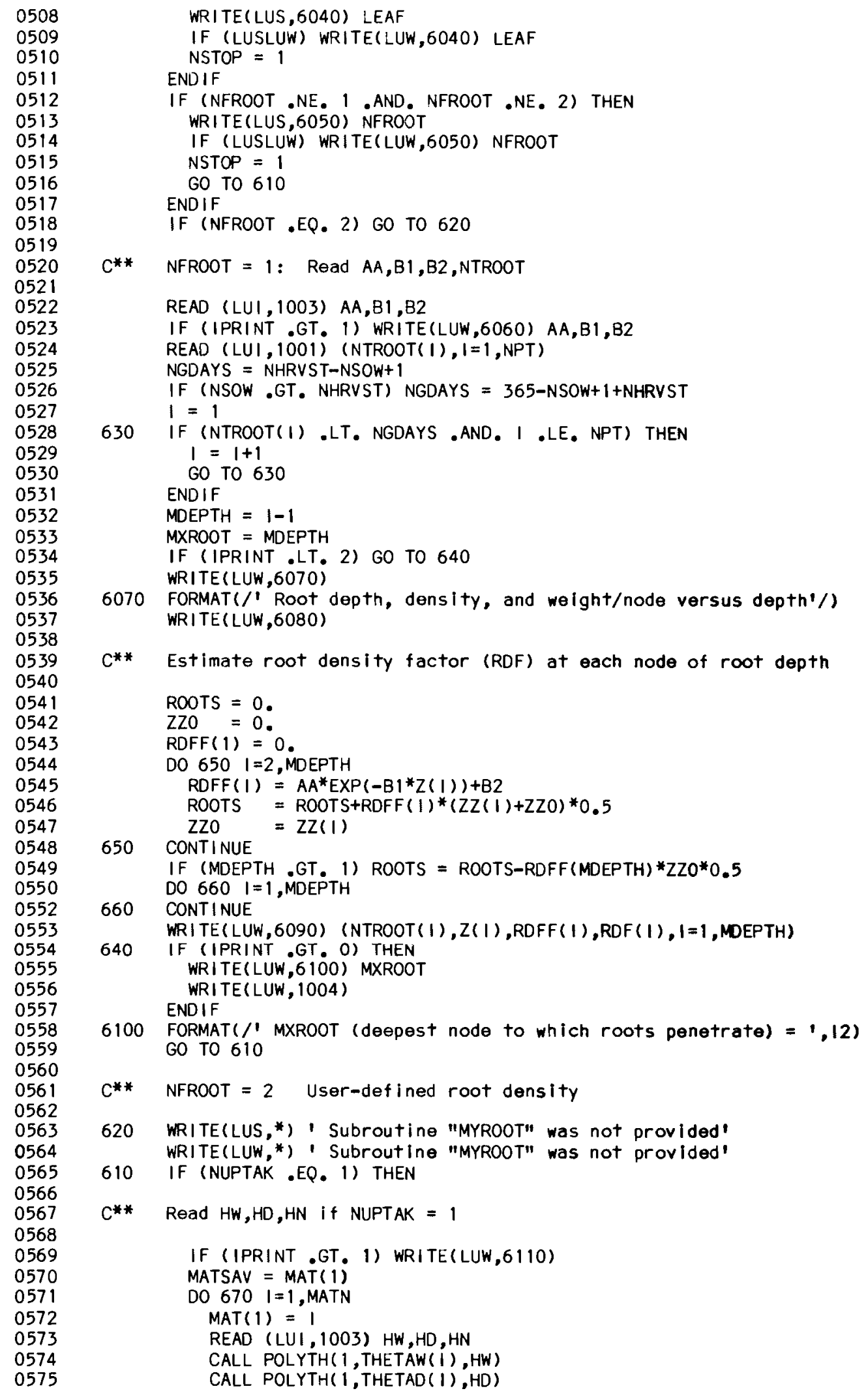




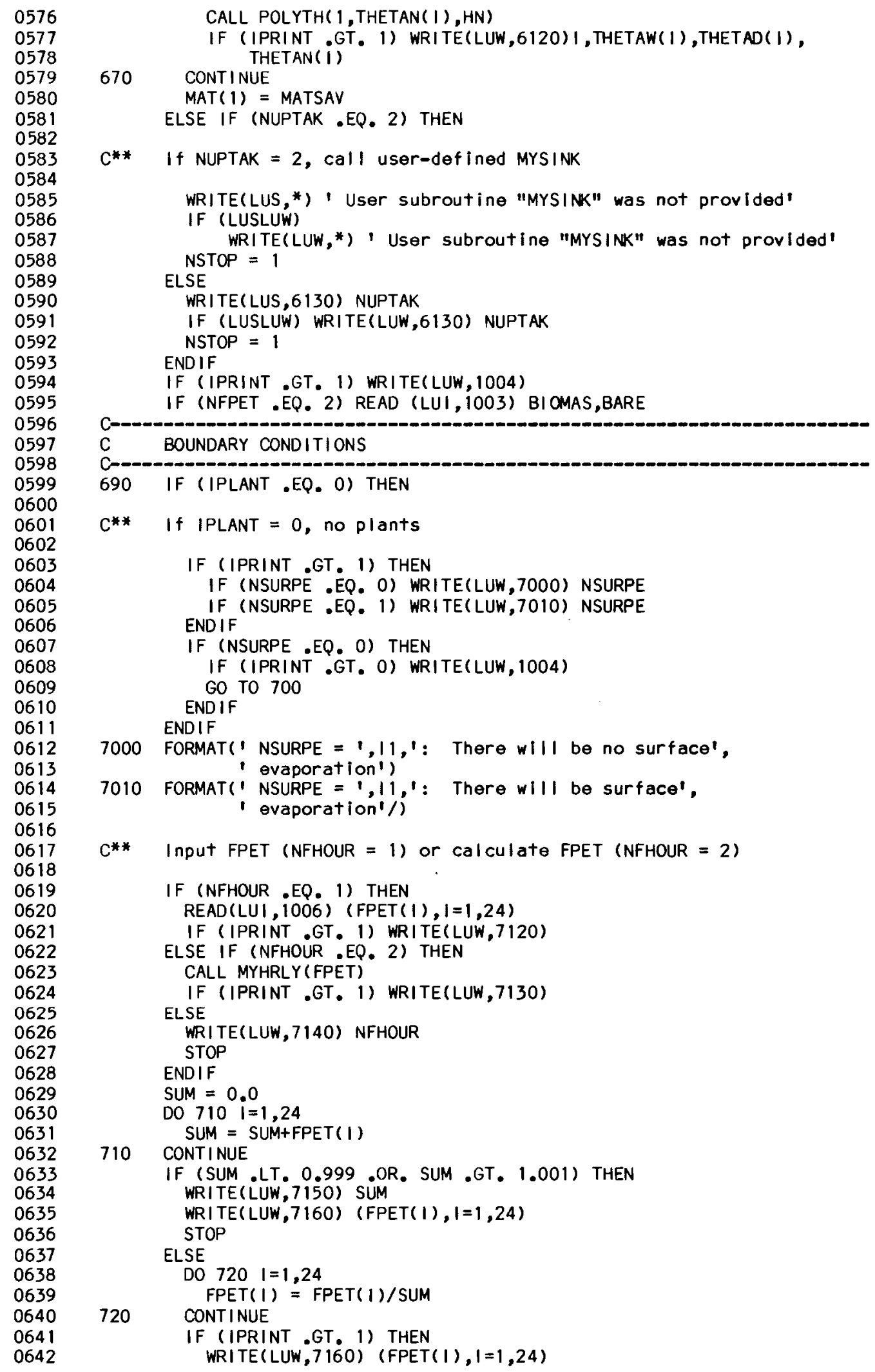




$$
\text { END IF }
$$

FORMAT $5(1$ DAY PEVAPO

FORMAT $(5(14, F 8.4,3 X))$

PEVAPO $=1, F 8,4$ )

IF (NFPET.EQ. 1) THEN

C** If NFPET $=1$, Ritchie method of partitioning PET

READ (LUI, 1006) (PET( 1$), 1=1$, NDAYS)

IF (IPRINT .GT, 1) THEN

WRITE(LUW, 7200)

WRITE(LUW, 7210)

END IF

DO $730 \quad i=1$, NDAYS

$A L A I=D L A I(I)$

PETT = PET (I)

PTRANS $(1)=$ PETT $^{*}(-.21+0.70 * \operatorname{SQRT}(A L A I))$

IF (ALAI .LT. 0.1) PTRANS (I) $=0.0$

IF (ALAI .GT. 2.7) PTRANS(1) = PETT

PTRANS $(1)=(1.0-B A R E) * P T R A N S(1)$

PEVAPO (I) $=$ PETT-PTRANS $(1)$

TOTPET $=$ TOTPET+PETT

TOTPTR = TOTPTR+PTRANS $(1)$

TOTPEV $=$ TOTPEV+PEVAPO $(1)$

730

CONTINUE

IF (IPRINT,GT, O) THEN

IF (IPRINT.GT. 1) WRITE(LUW, 7220) (IDAY,PET(IDAY),

WRITE(LUW, 7230) TOTPET, TOTPTR, TOTPEY

PTRANS (IDAY), PEVAPO (IDAY), IDAY $=1, N D A Y S)$ WRITE (LUW, 1004)

ENDIF

ELSE IF (NFPET.EQ. 2) THEN

NFPET $=2$ Daily PET and Hinds transpiration function to define PT and PE from PET (relation found by Ted Hinds). In addition, the user can scale the data according to biomass (BIOMAS). The base biomass is $220 \mathrm{~g} / \mathrm{m}^{* * 2}$

IF (NSOW .GT. 90 .AND. NSOW . LT. 274) THEN

IF (NSOW .LT. 152) THEN

NSOW $=90$

ELSE

NSOW $=274$

ENDIF

WRITE(LUS, 7235) NSOW 


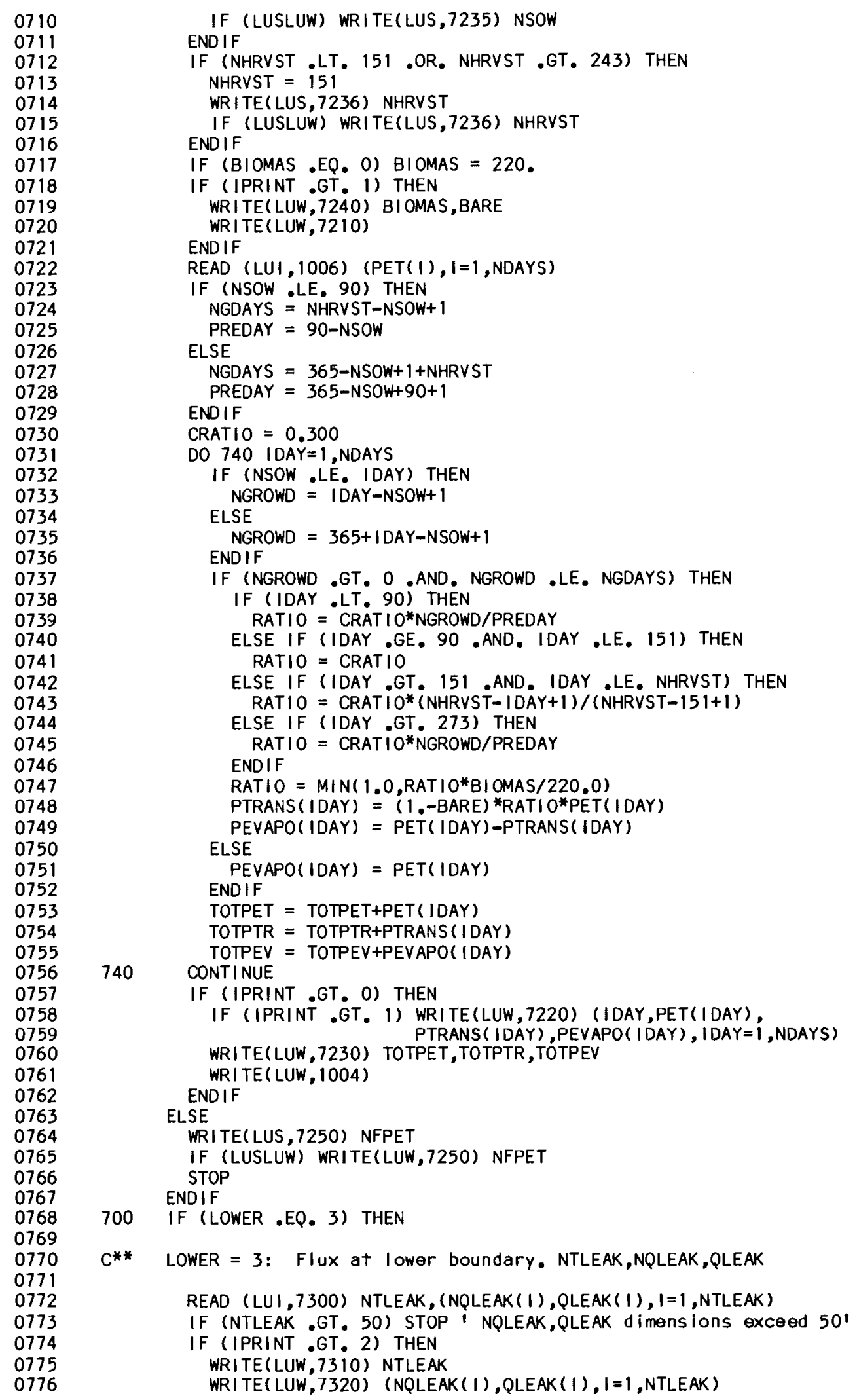




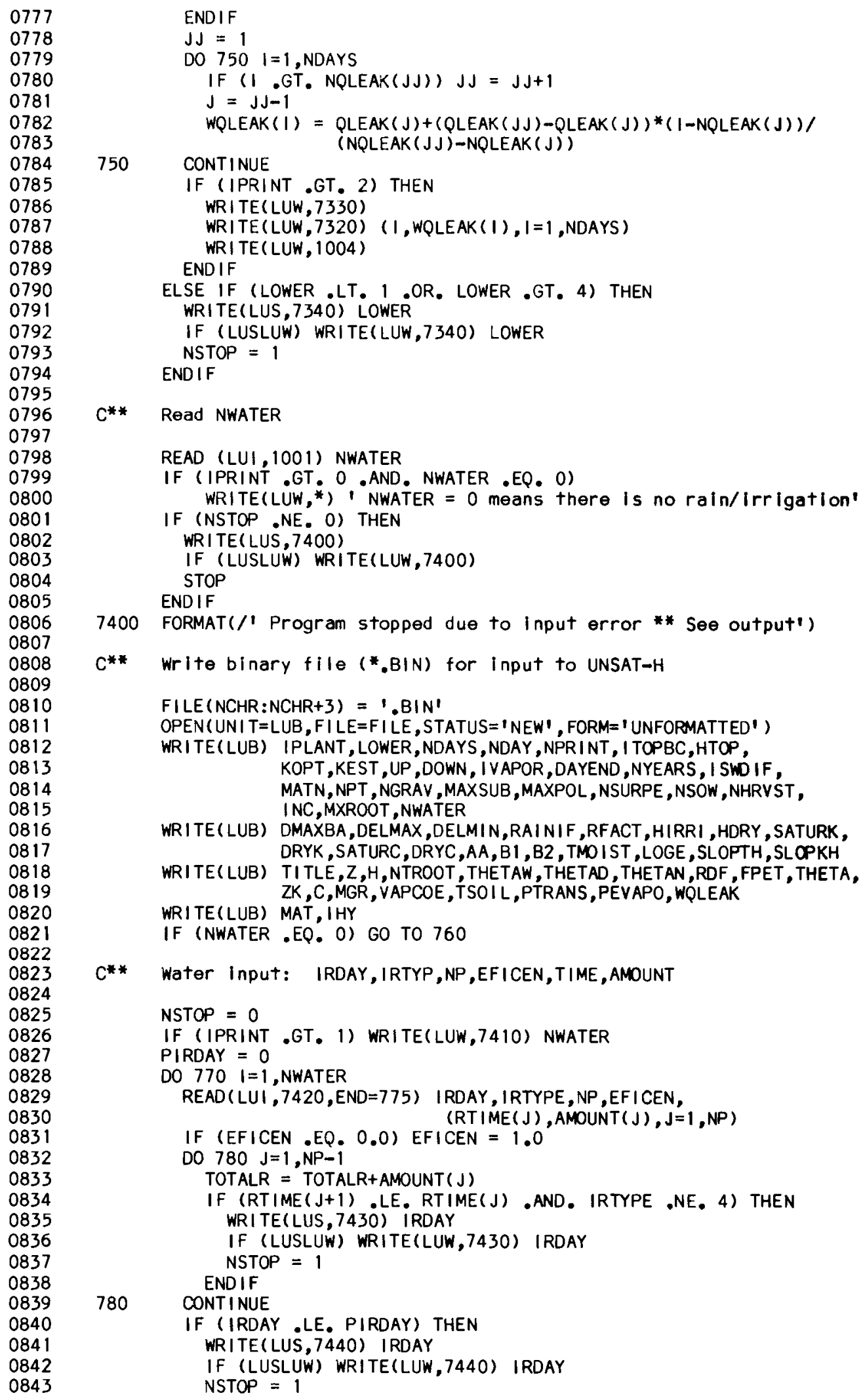

C** Water input: IRDAY, IRTYP, NP, EFICEN, TIME, AMOUNT

NSTOP $=0$

IF (IPRINT .GT, 1) WRITE(LUW,7410) NWATER

PIRDAY $=0$

DO $770 \quad I=1$, NWATER

READ (LUI, 7420,END=775) IRDAY, IRTYPE, NP, EFICEN,

IF (EFICEN .EQ. 0.0) EFICEN $=1.0$ $(R T I M E(J), A M O U N T(J), J=1, N P$ )

DO $780 \mathrm{~J}=1, \mathrm{NP}-1$

TOTALR $=$ TOTALR+AMOUNT $(\mathrm{J})$

IF (RTIME $(J+1)$.LE. RTIME(J) .AND. IRTYPE ,NE, 4) THEN WRI TE(LUS, 7430) IRDAY IF (LUSLUW) WRITE(LUW, 7430) IRDAY NSTOP $=1$ 


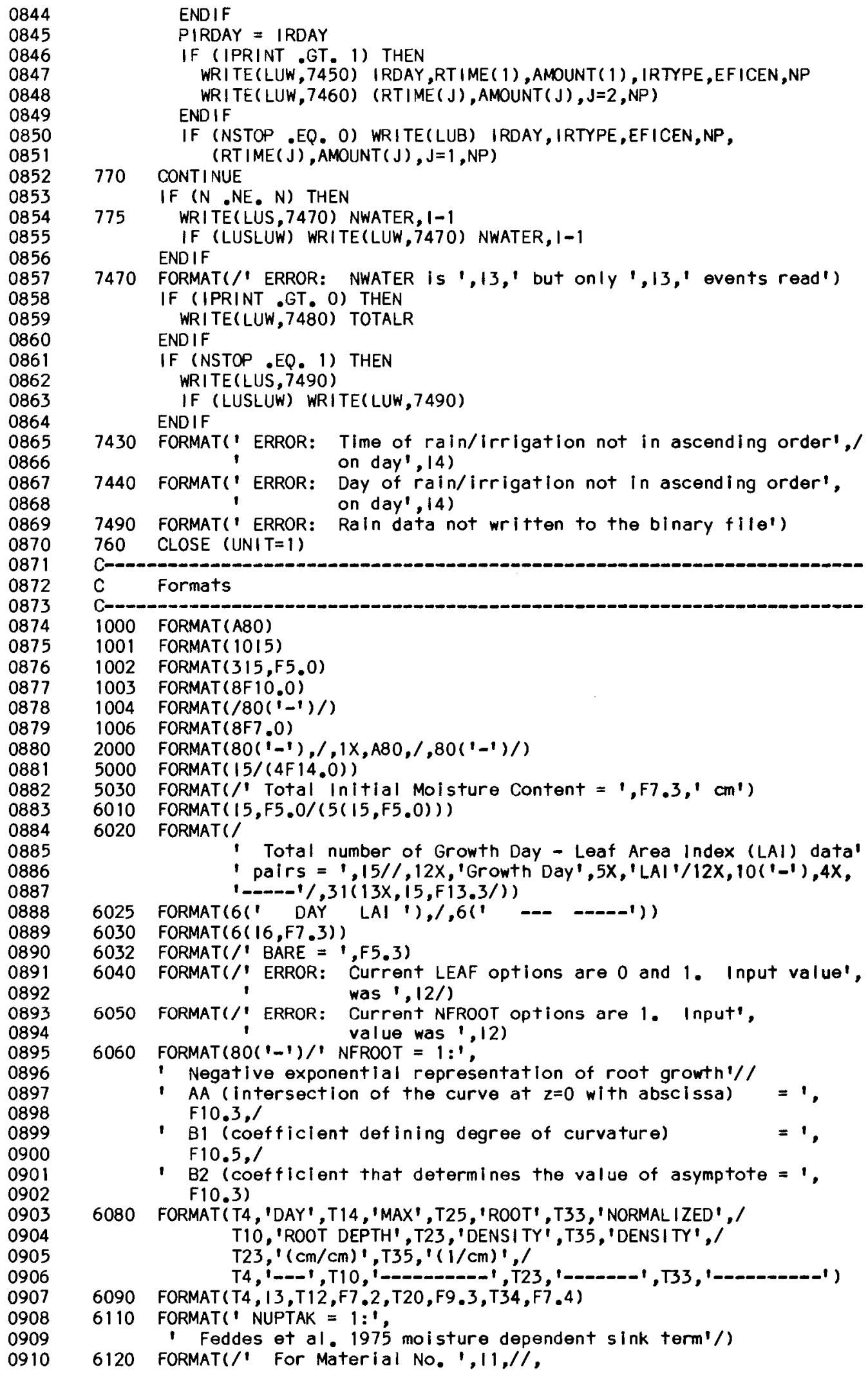




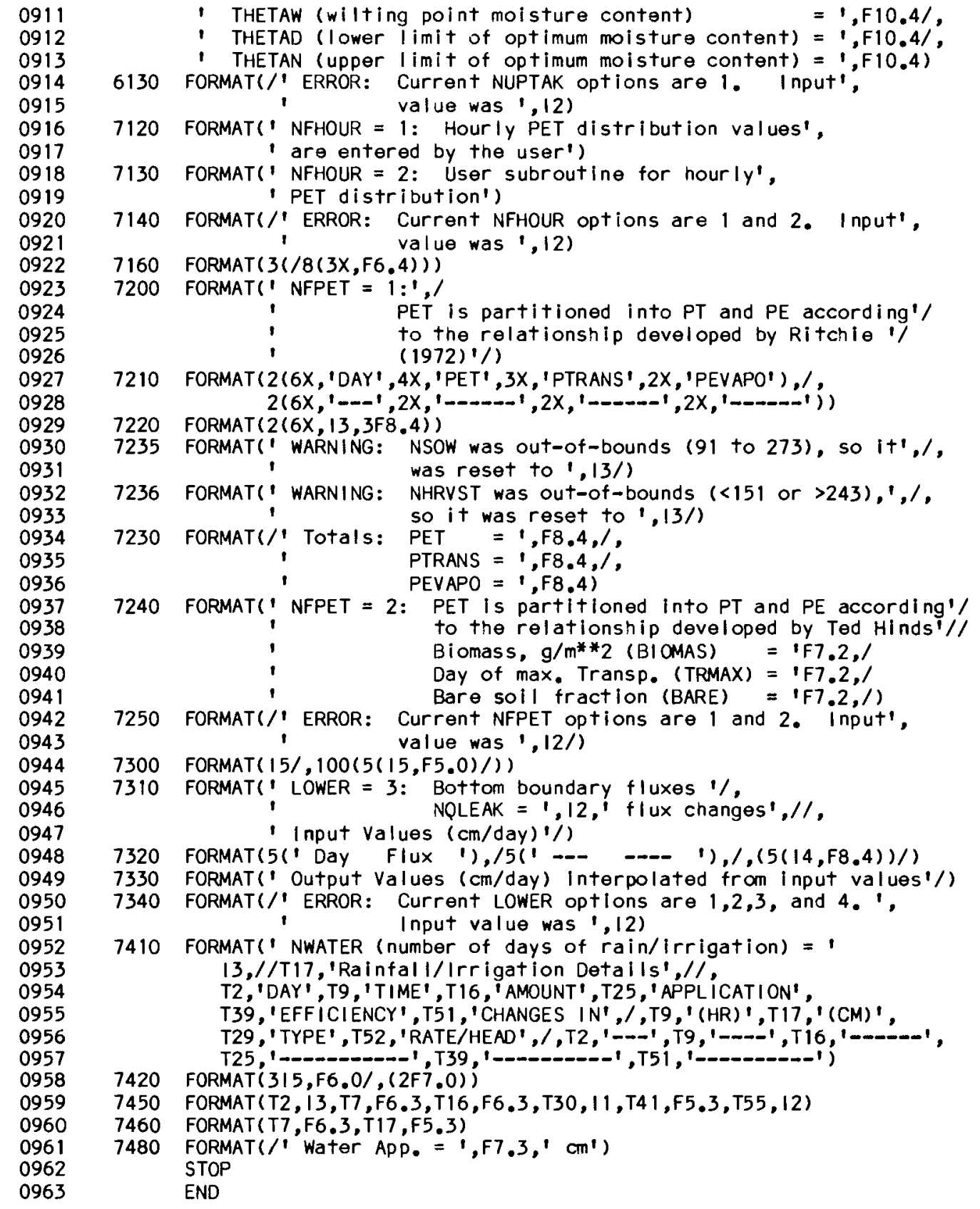




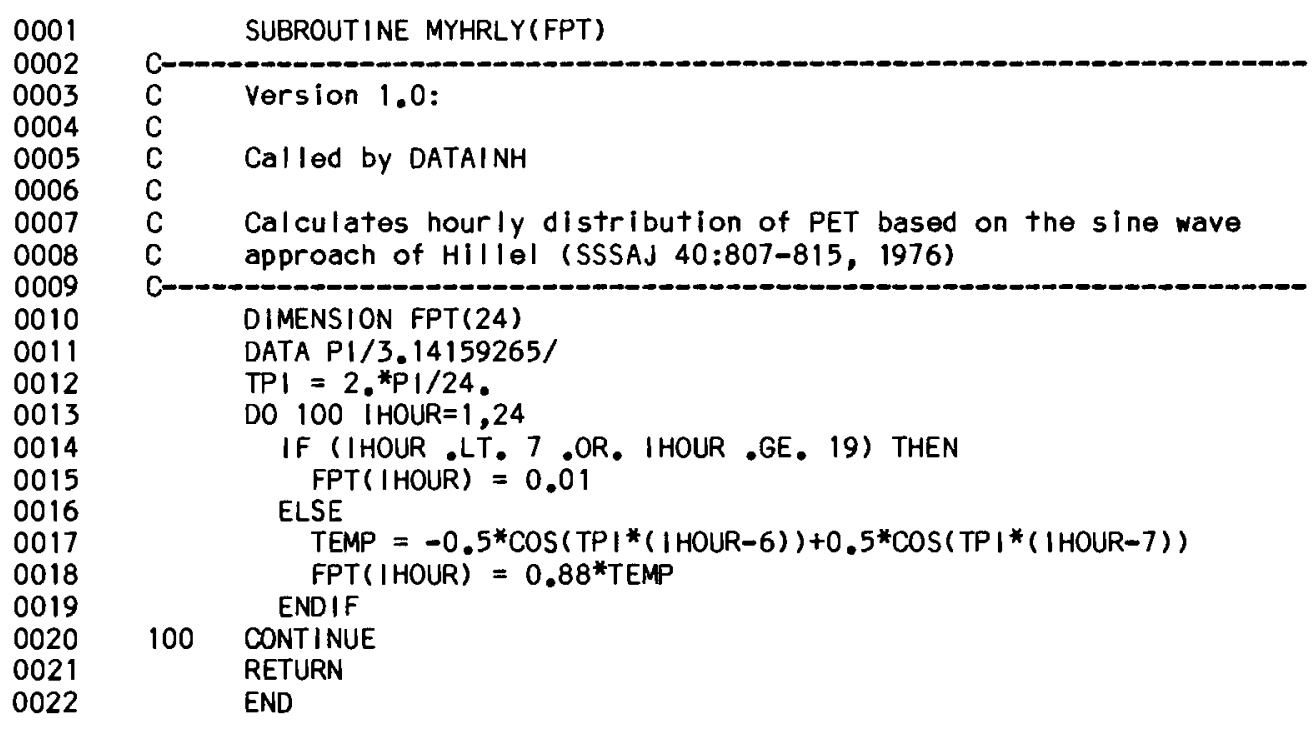




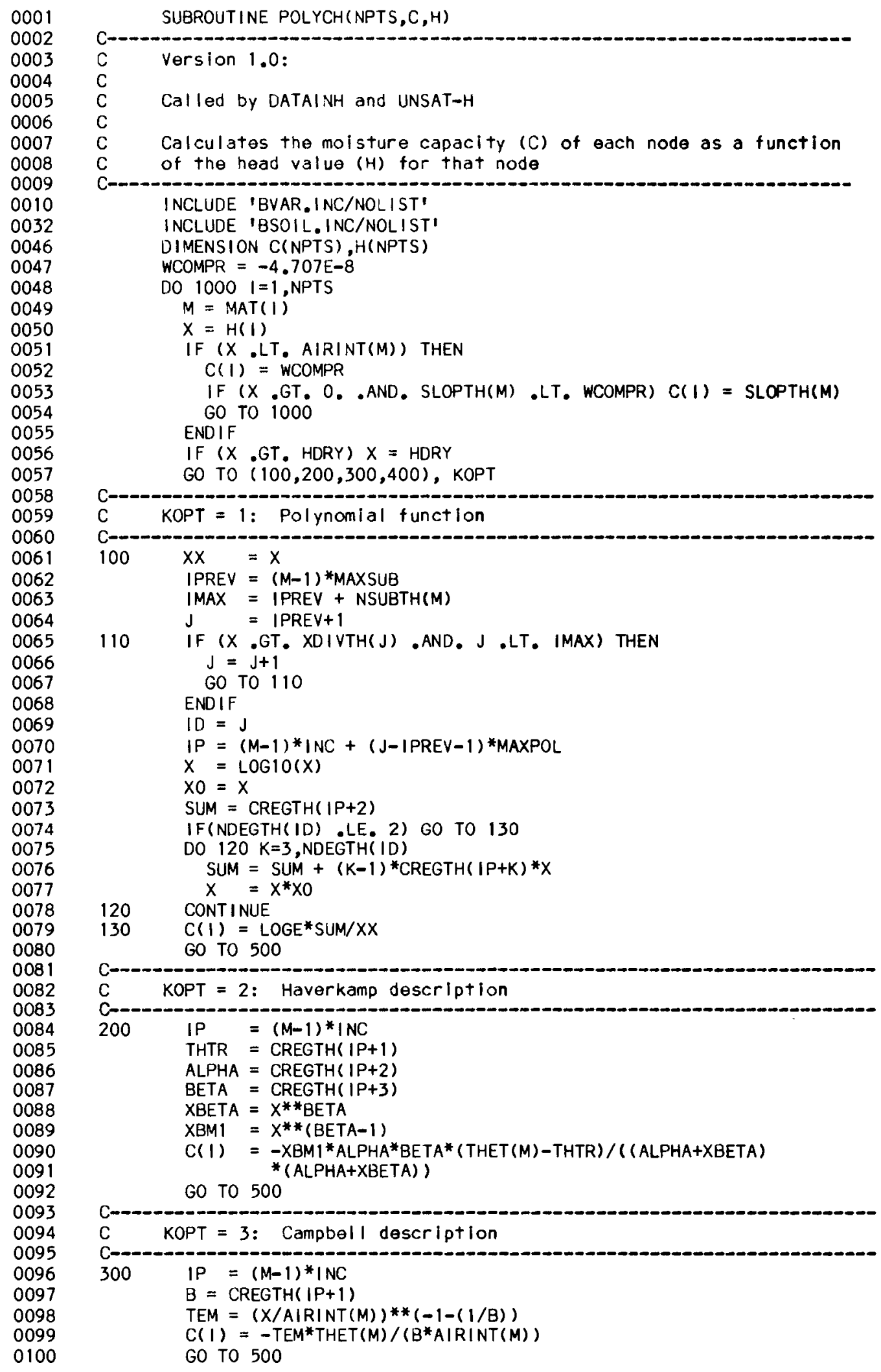




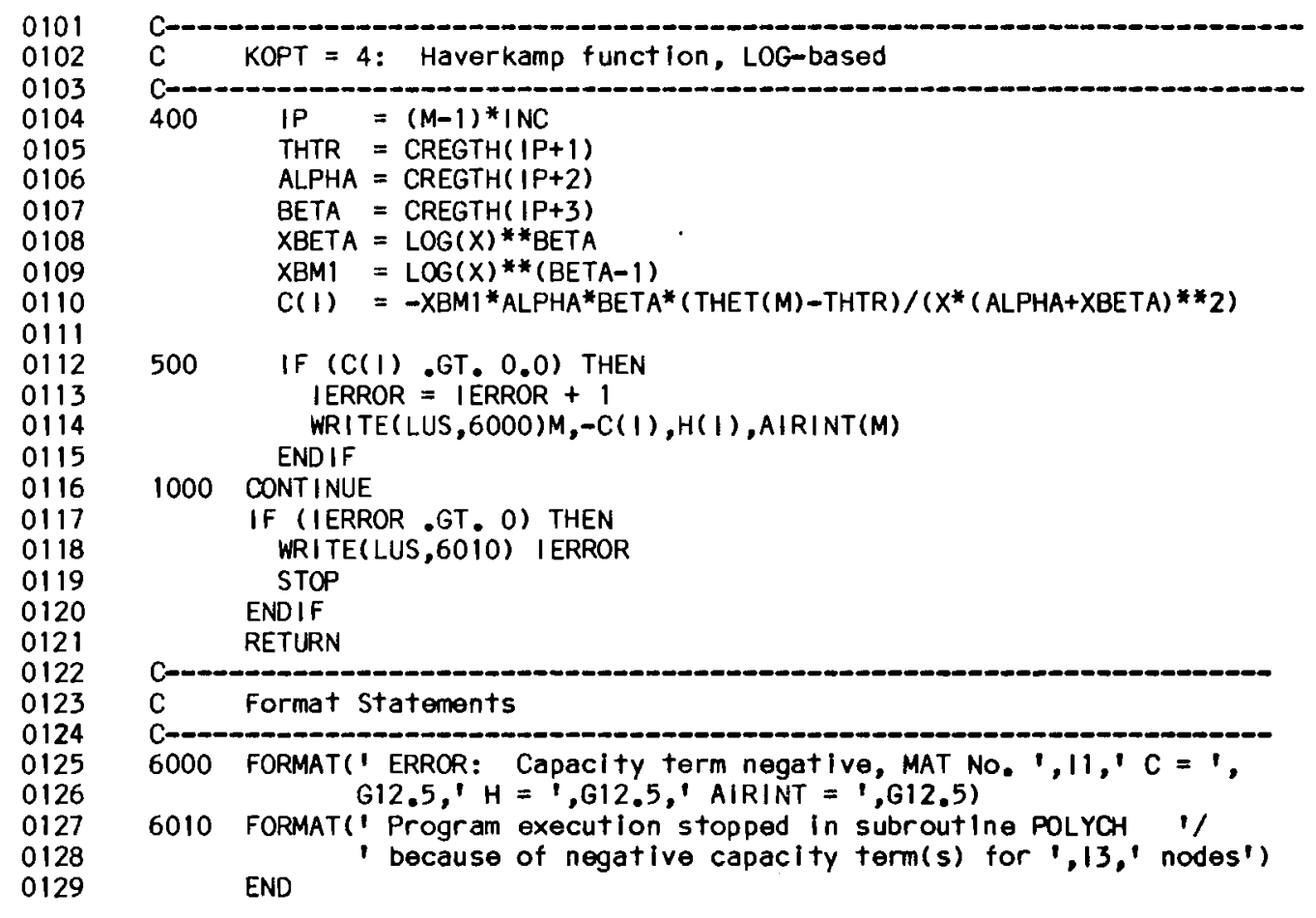




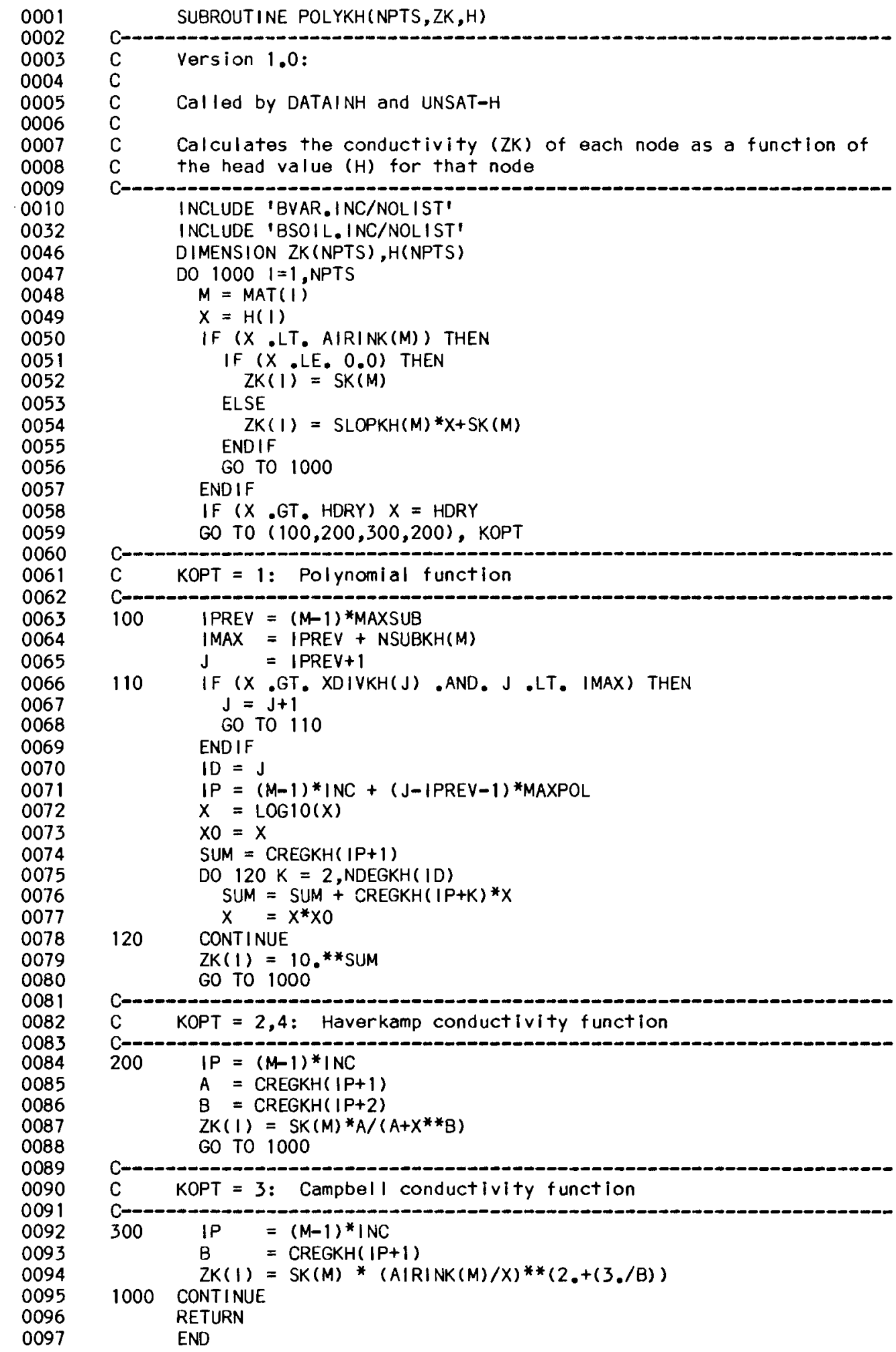




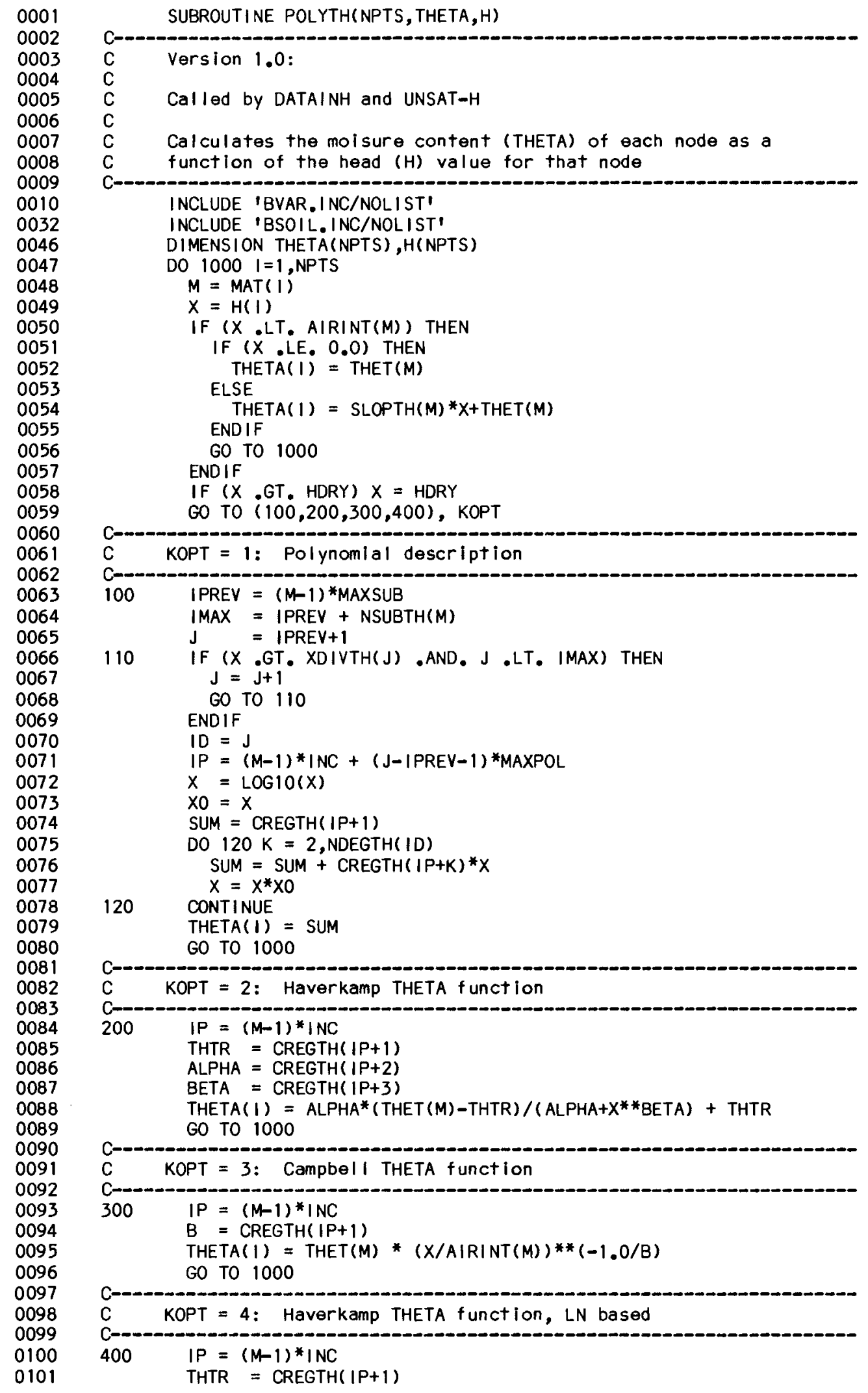


ALPHA $=$ CREGTH $(I P+2)$

BETA = CREGTH $(I P+3)$

1000 CONTINIJE

$\operatorname{THETA}(1)=\operatorname{ALPHA} *(\operatorname{THET}(M)-T H T R) /\left(\operatorname{ALPHA}+\left(\operatorname{LOG}(X) *{ }^{*} B E T A\right)\right)+T H T R$ RETURN

END 
0001

0002

0003

0004

0005

0006

0007

0008

0009

0010

0011

0012

FUNCTION RHO(Z,AA, B1, B2)

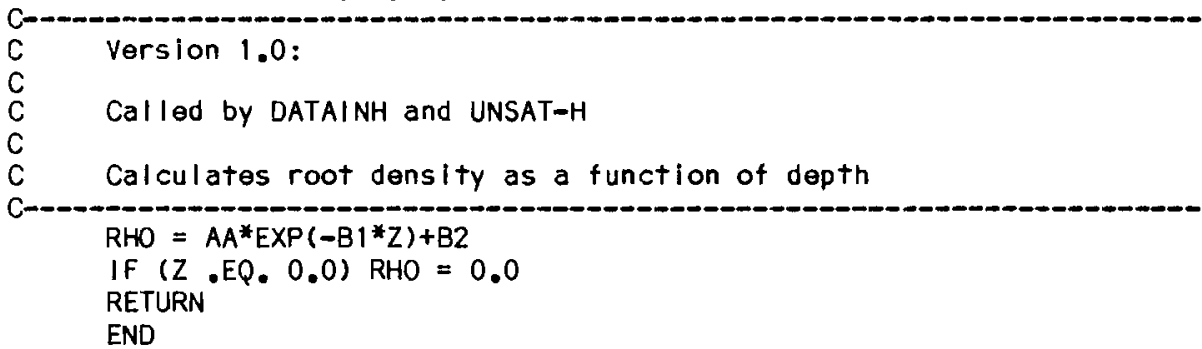




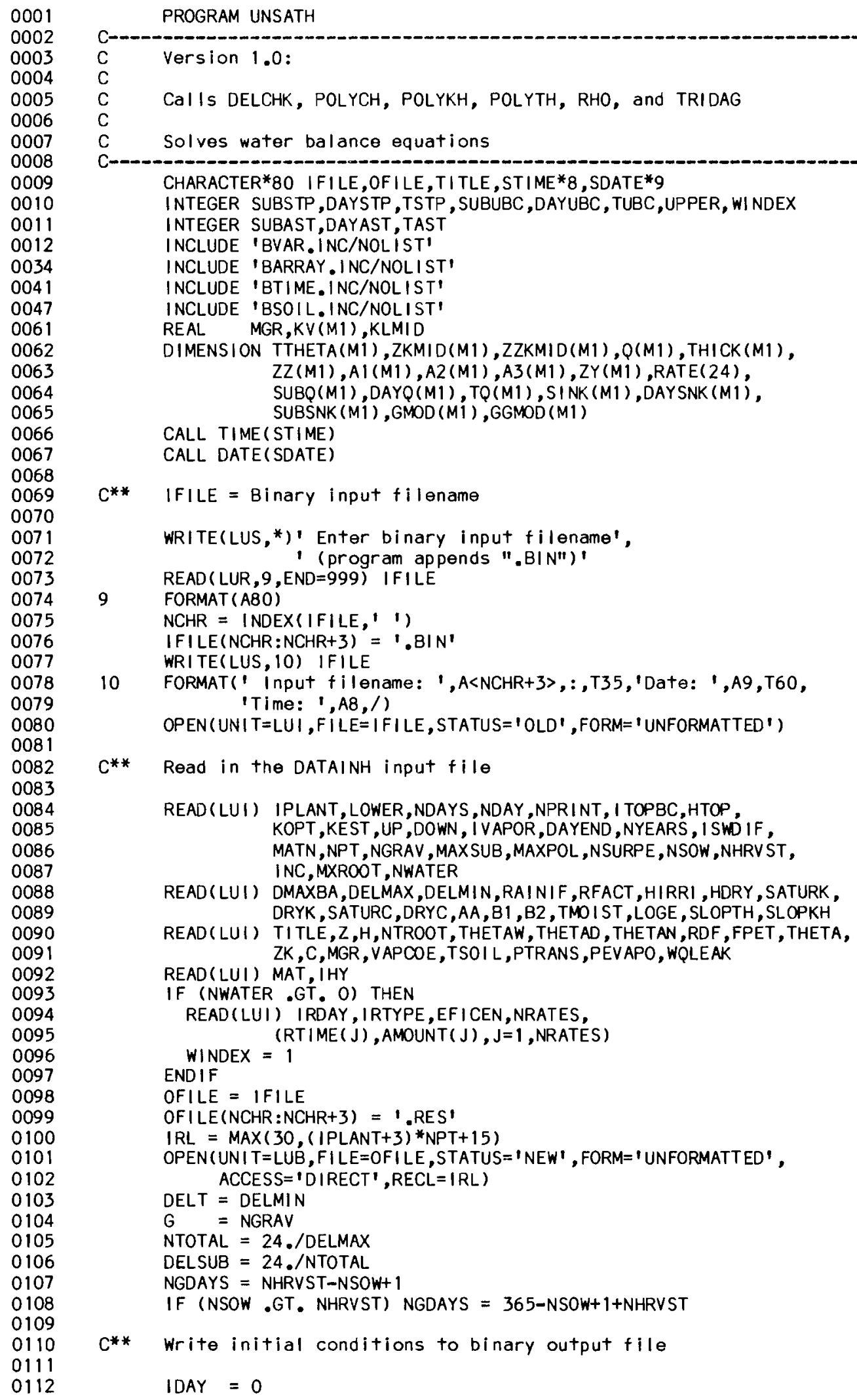




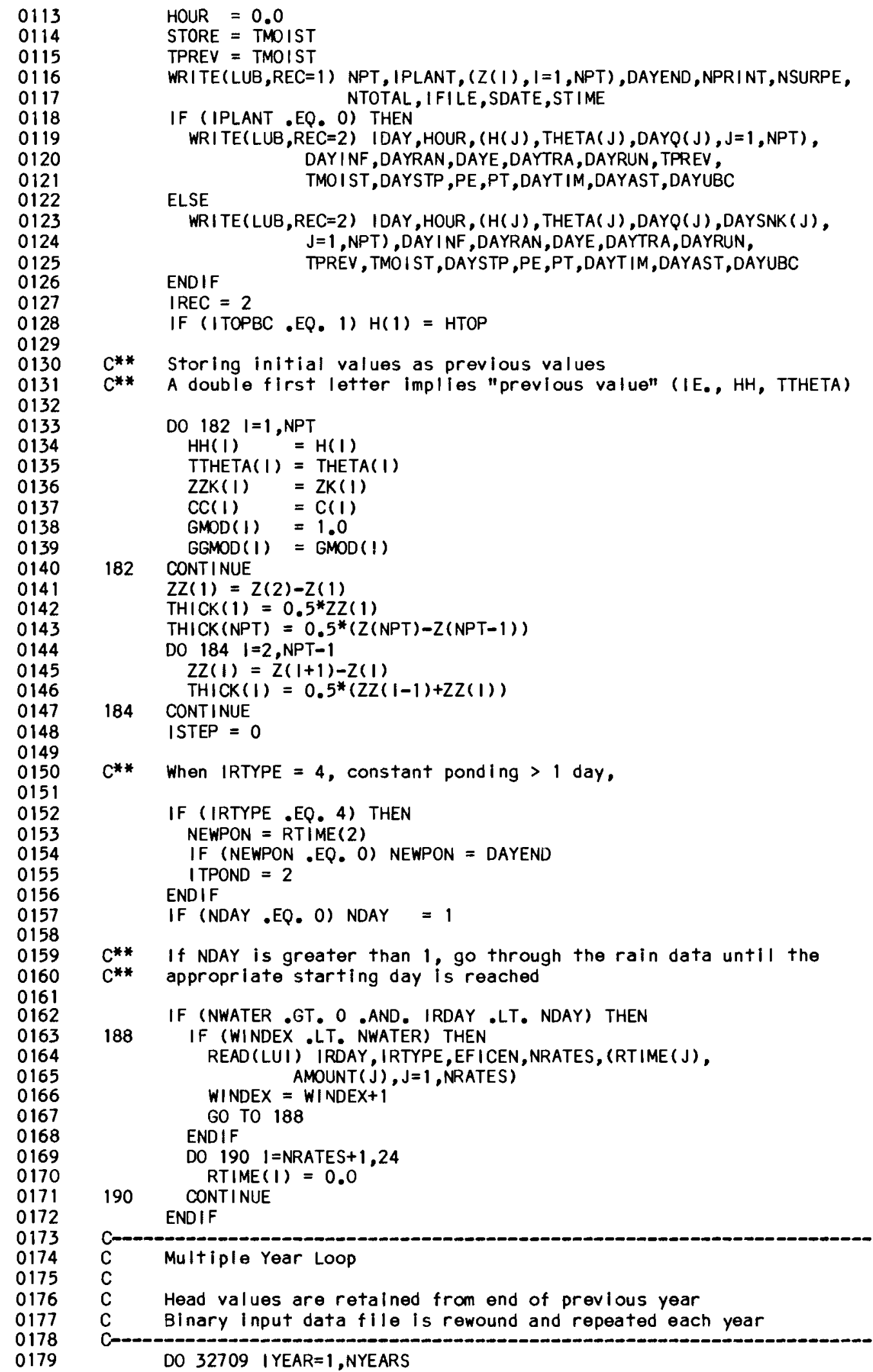




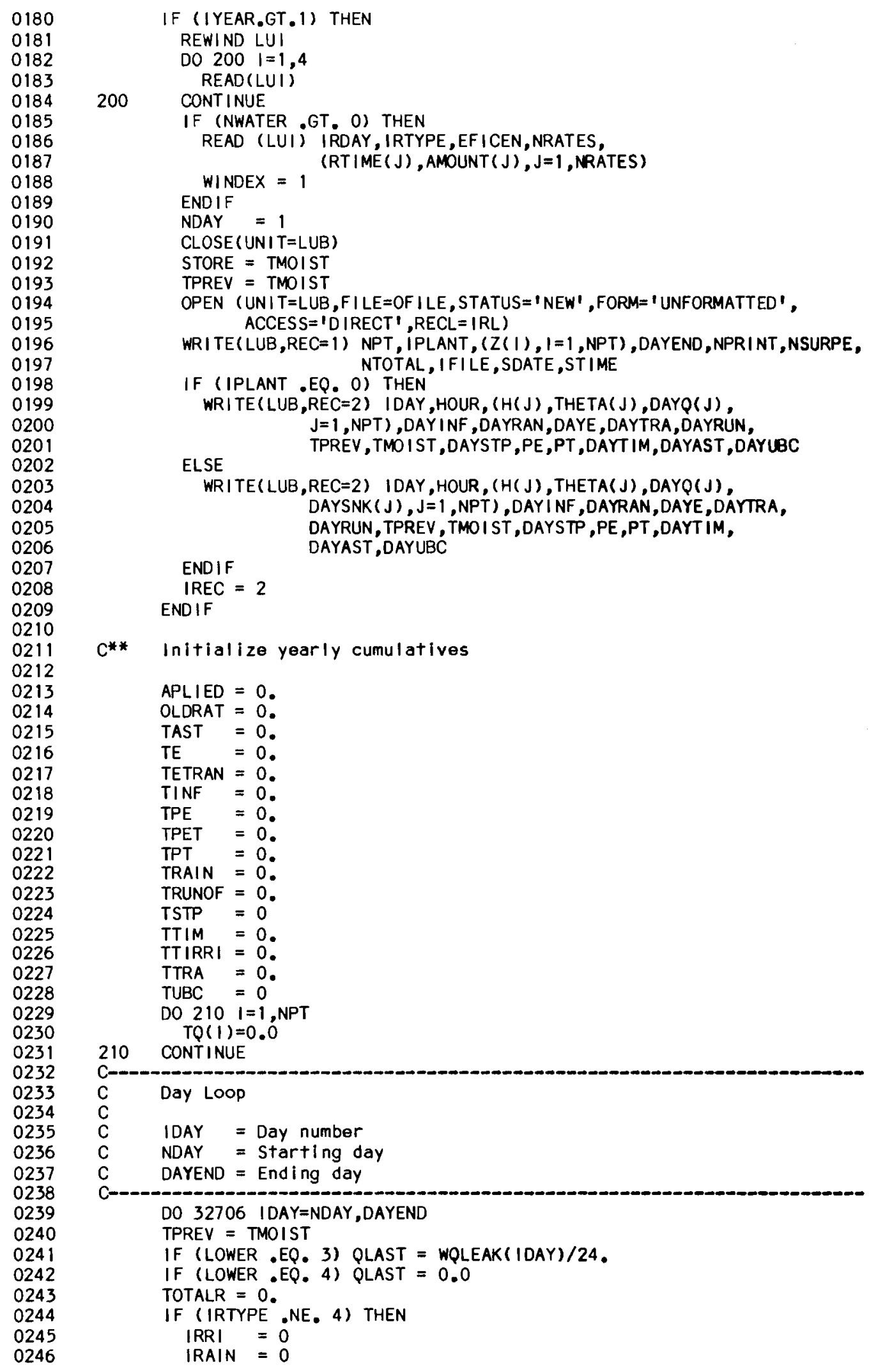




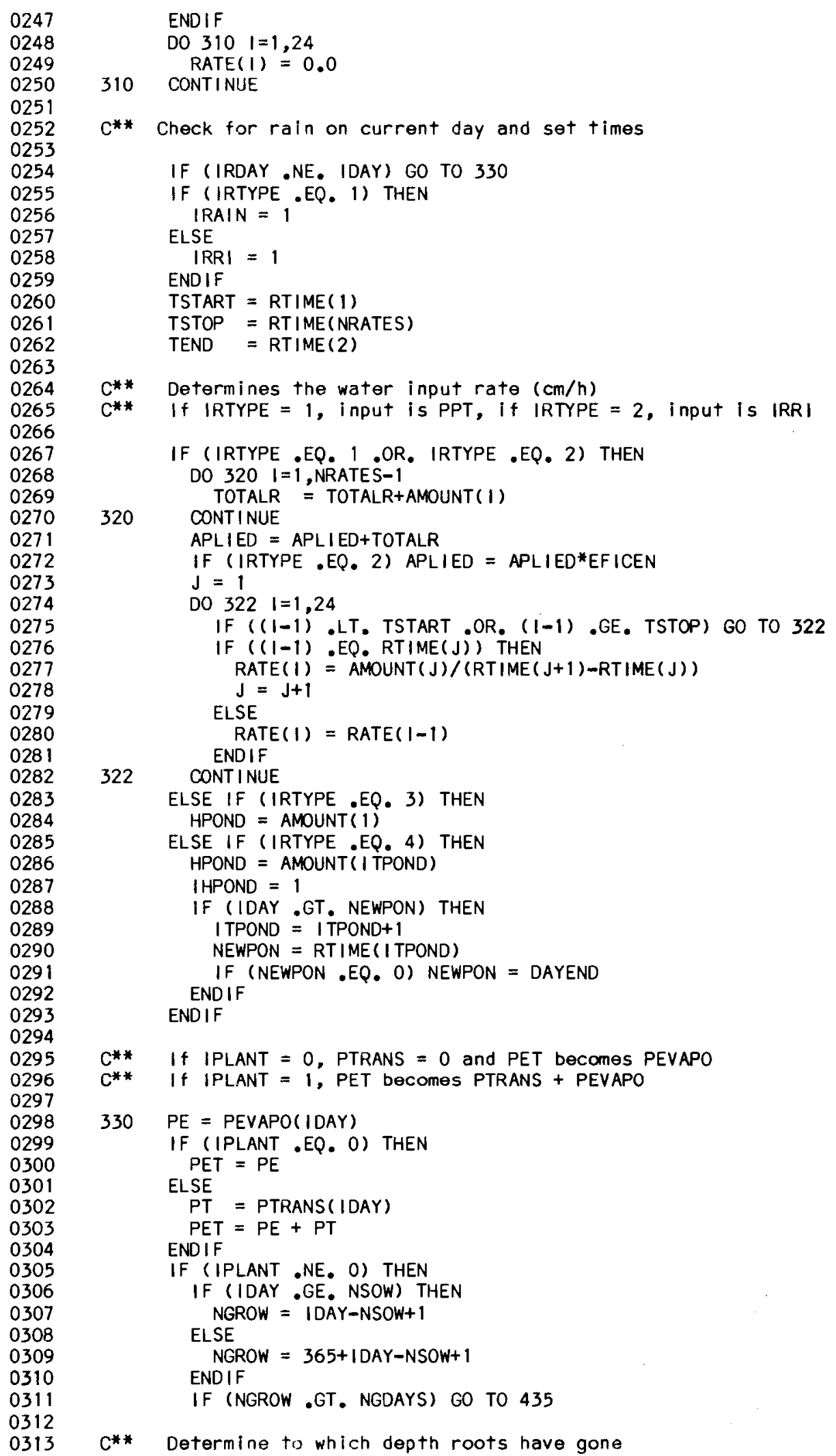




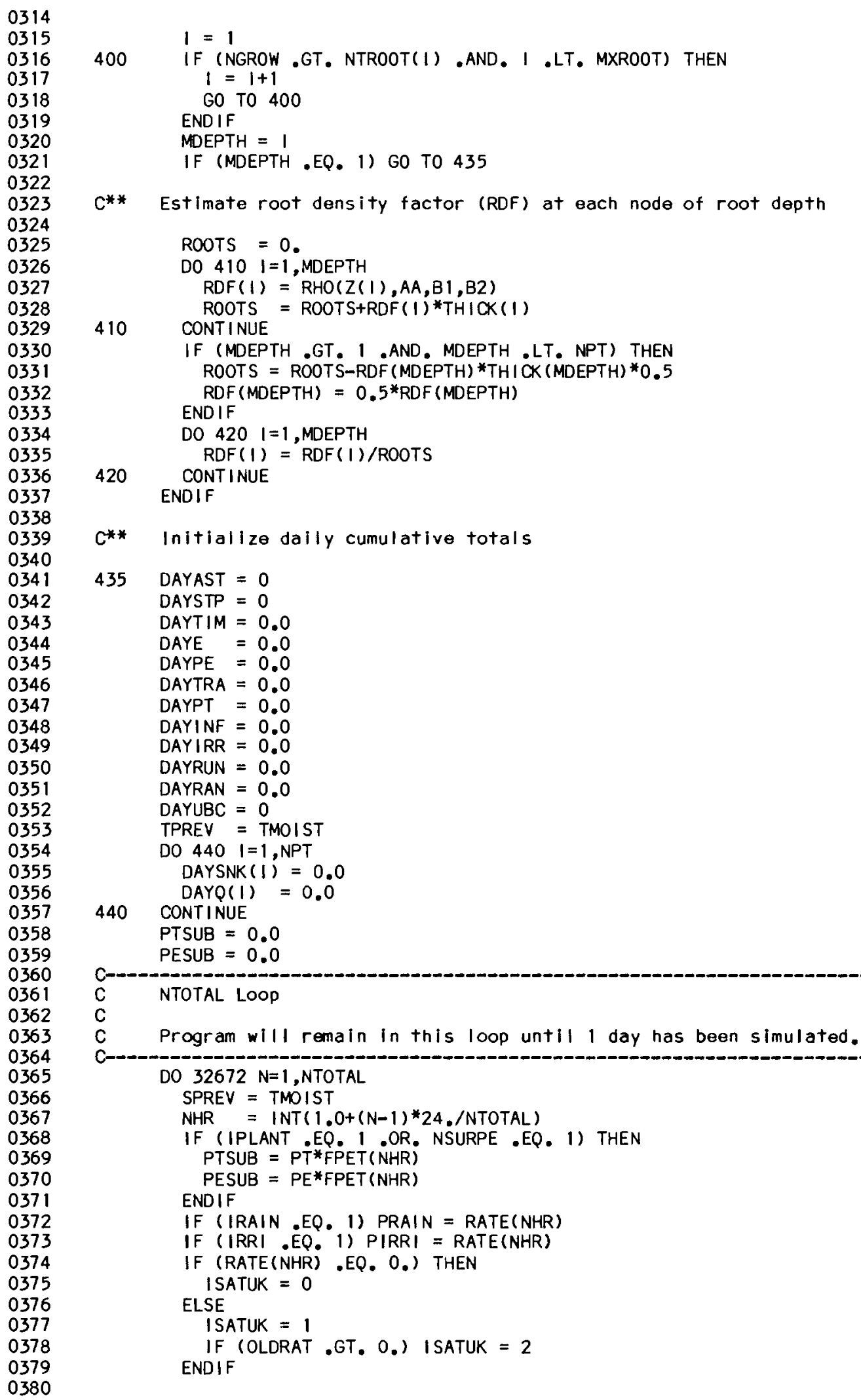




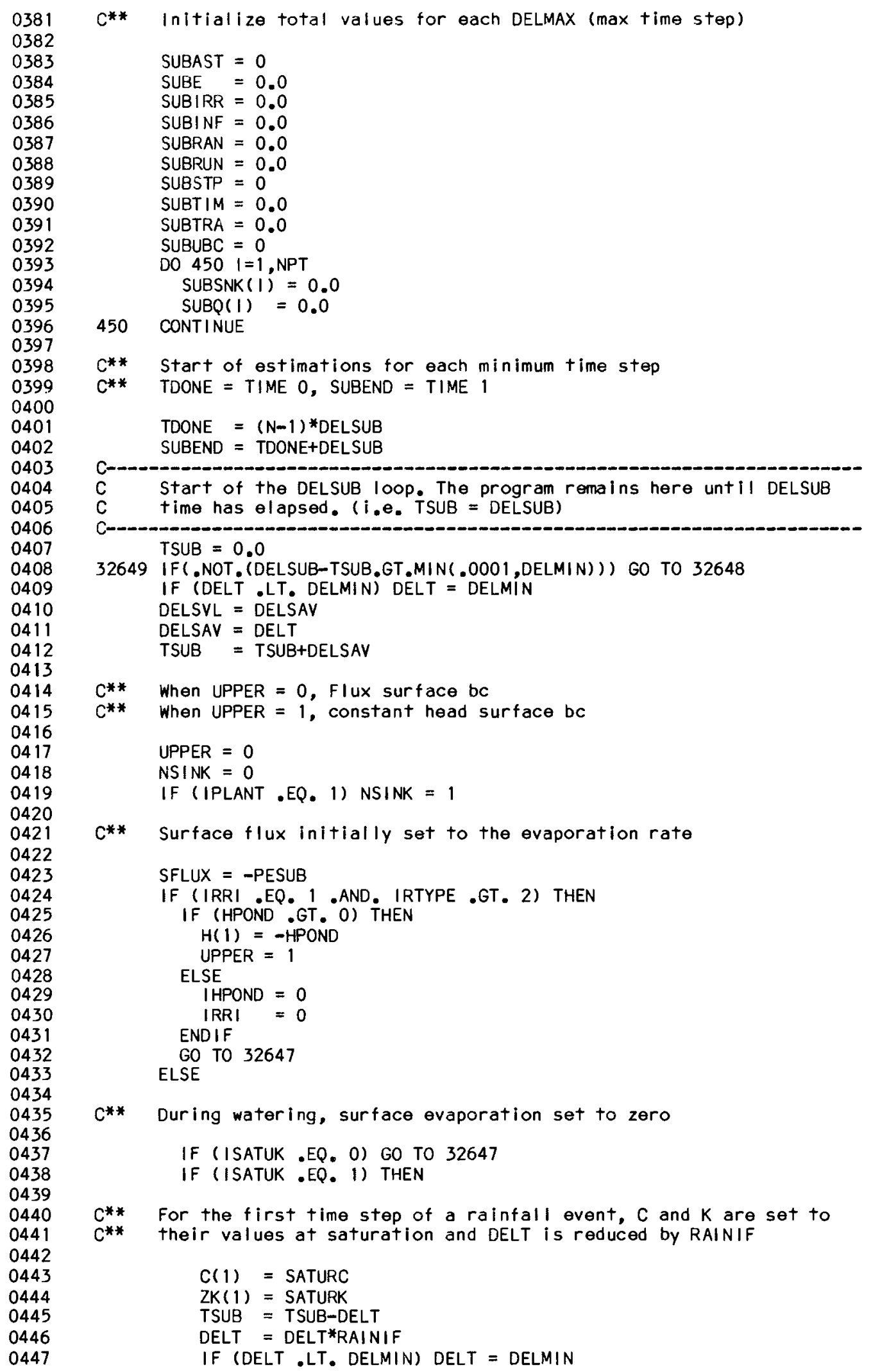




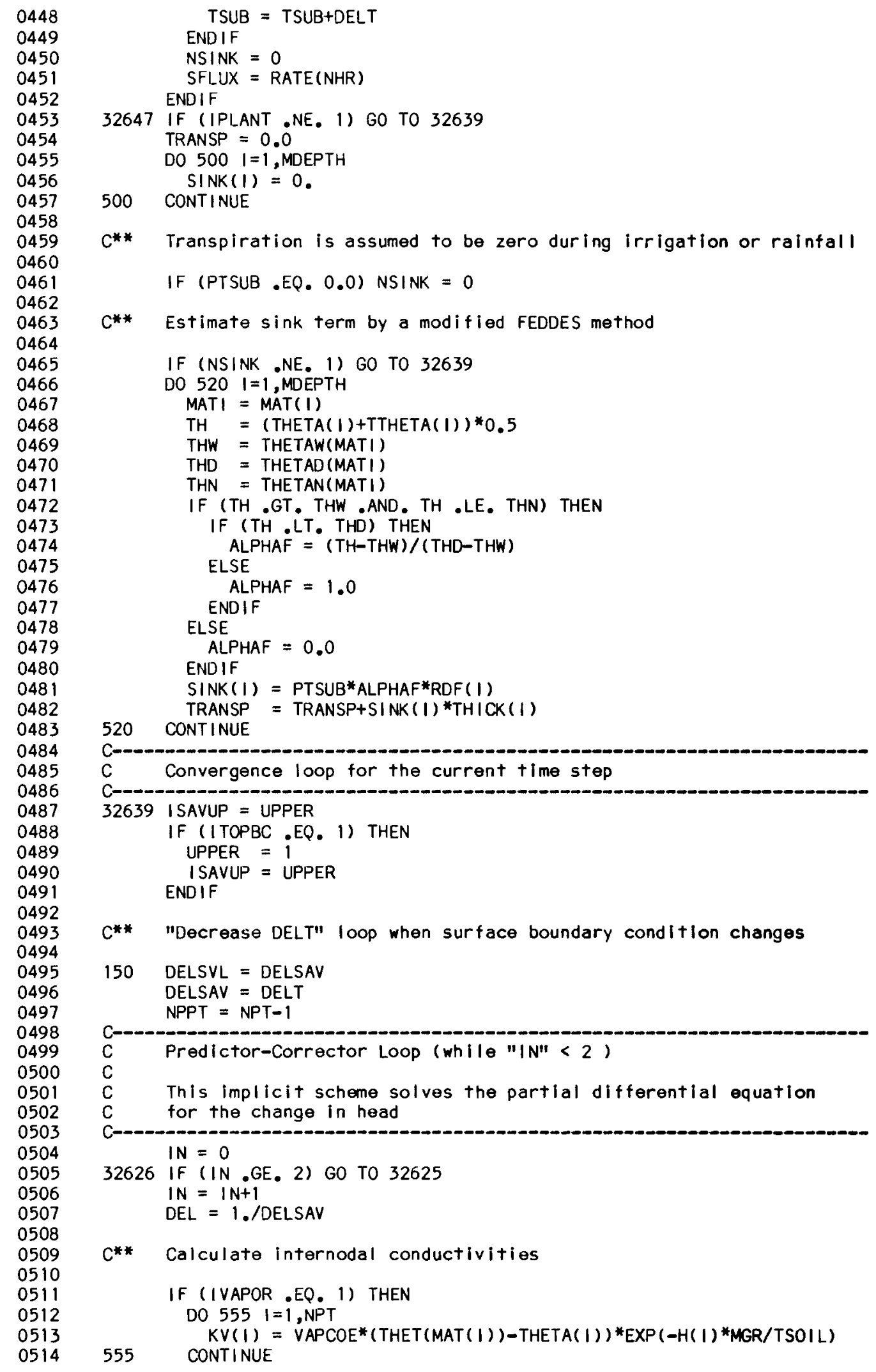




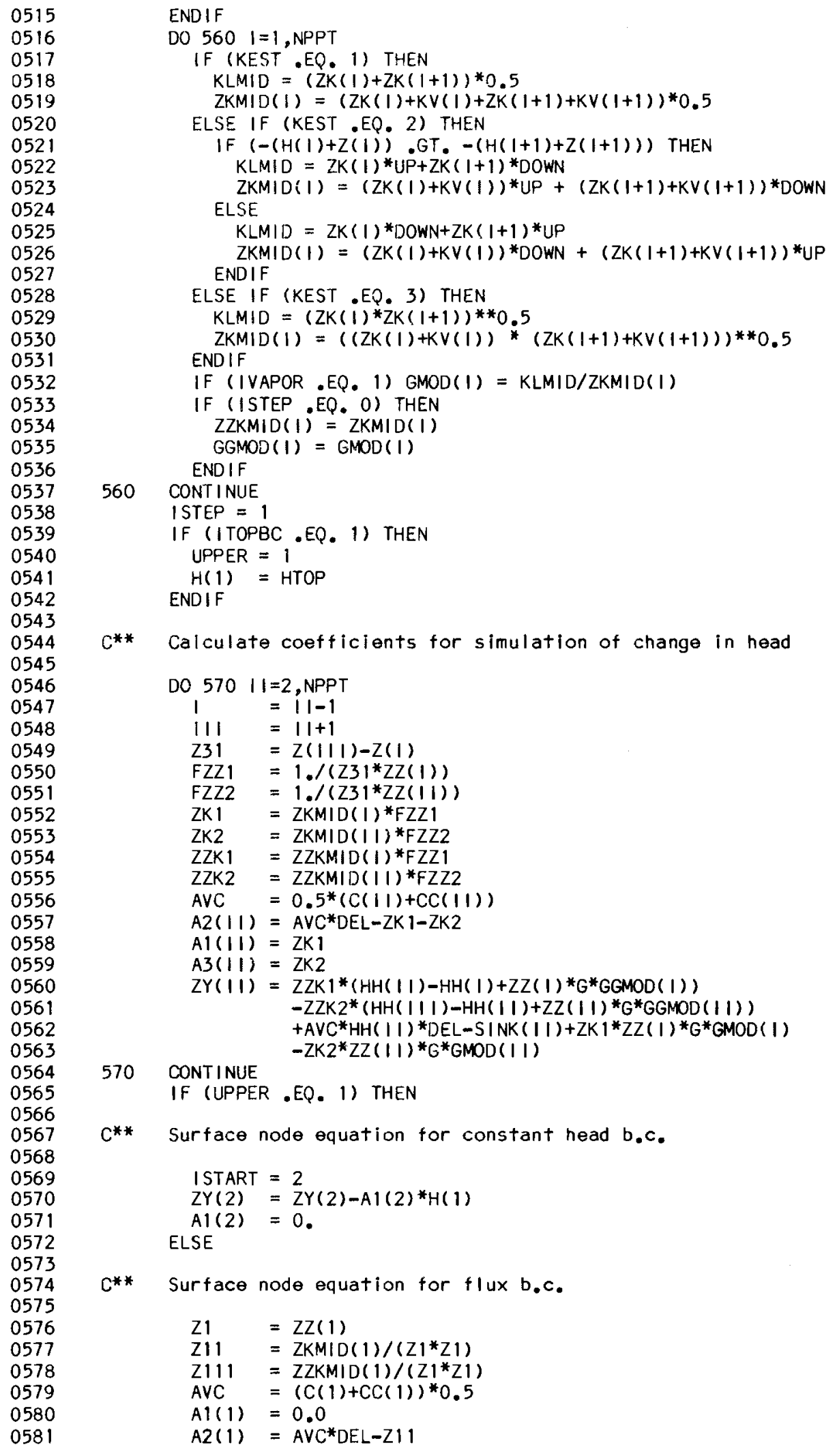




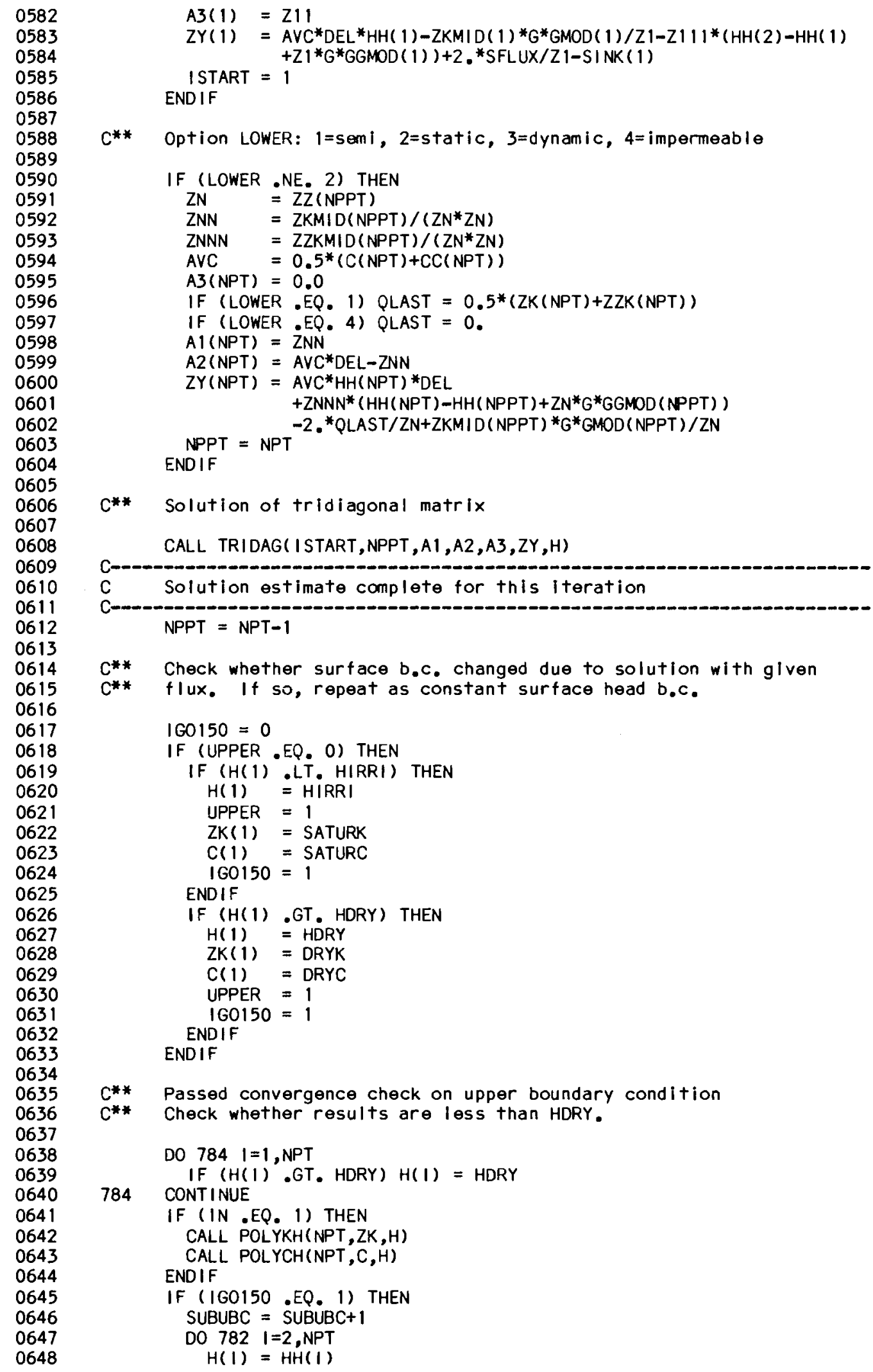




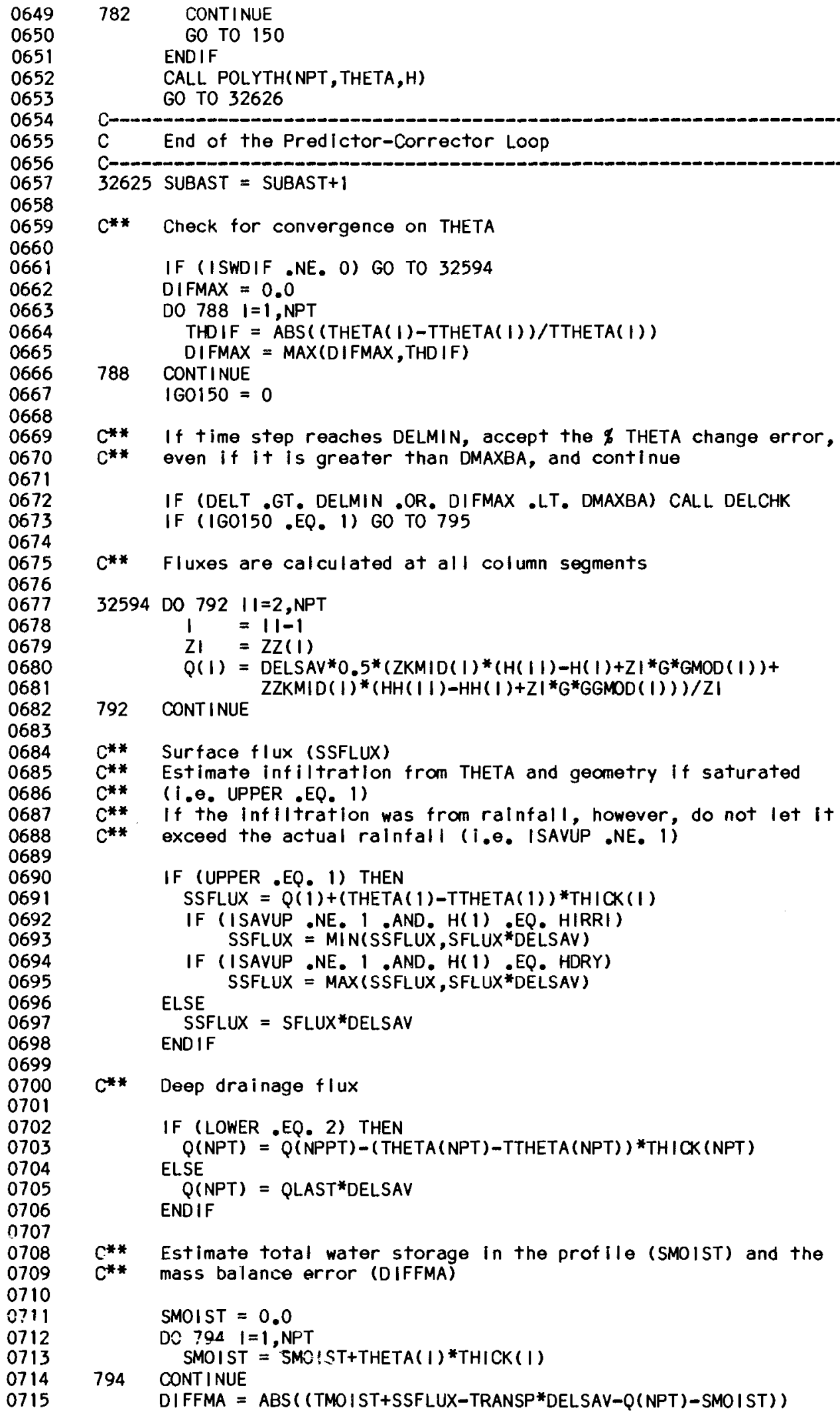

C** If time step reaches DELMIN, accept the \& THETA change error,

$C^{* *}$ even if it is greater than DMAXBA, and continue

IF (DELT .GT. DELMIN .OR, DIFMAX .LT. DMAXBA) CALL. DELCHK

IF (IG0150.EQ. I) 60 TO 795

$C^{* *}$ Fluxes are calculated at all column segments 


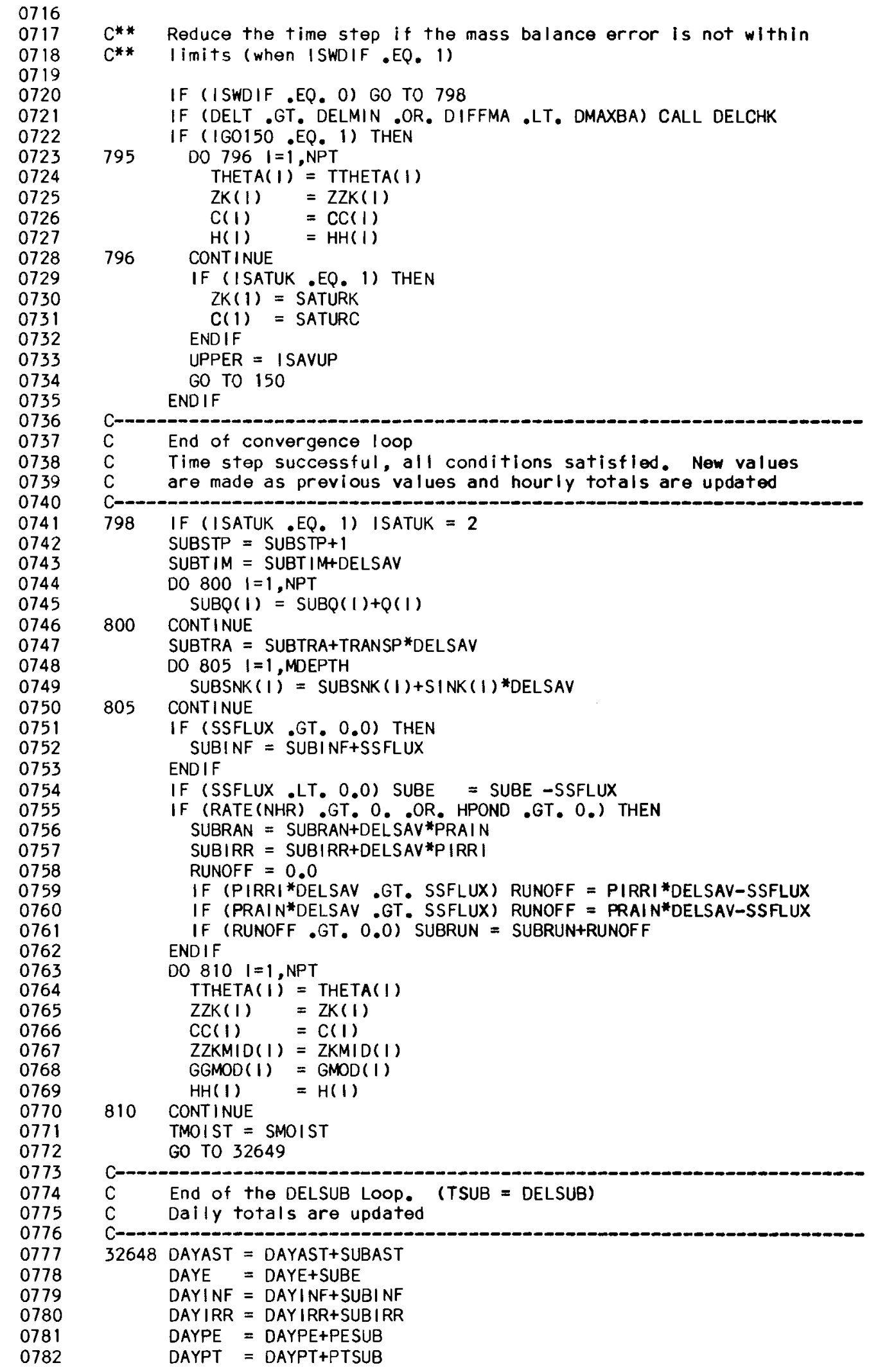




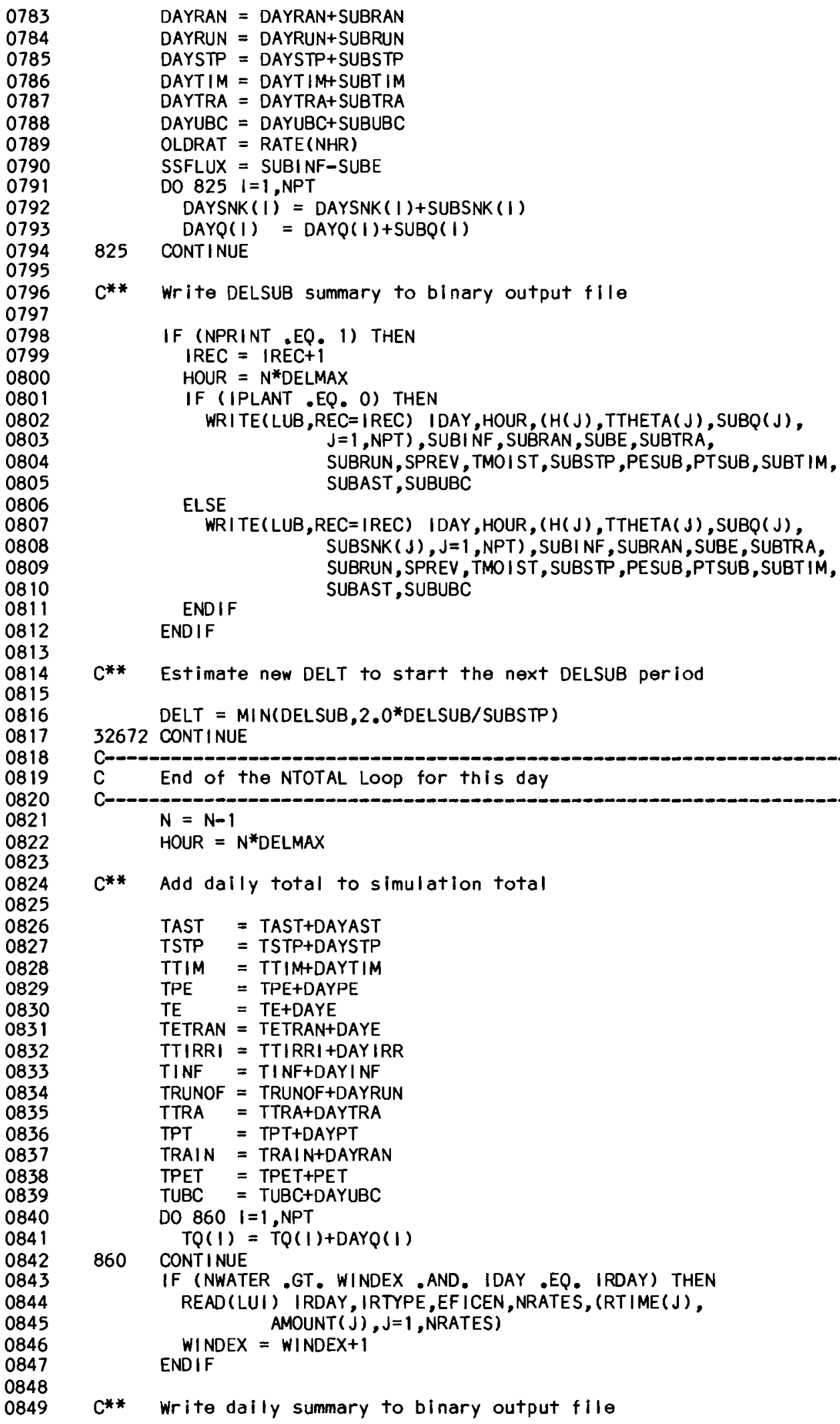


0850

0851

0852

0853

0854

0855

0856

0857

0858

0859

0860

0861

0862

0863

0864

0865

0866

0867

0868

0869

0870

0871

0872

0873

0874

0875

0876

0877

0878

$I R E C=\mid R E C+1$

IF (IPLANT EQ, O) THEN

WRITE (LUB, REC=IREC) IDAY,HOUR, $(H(J), \operatorname{THETA}(J), \operatorname{DAYQ}(\mathrm{J})$, $\mathrm{J}=1, N P T$ ), DAY I NF, DAYRAN, DAYE, DAYTRA, DAYRUN, TPREV , TMOIST, DAYSTP, PE, PT, DAYTIM, DAYAST,DAYUBC

ELSE

WRITE (LUB, REC=IREC) IDAY, HOUR, ( H(J), THETA (J), DAYQ (J), DAYSNK ( $J), J=1, N P T$ ), DAYINF, DAYRAN, DAYE, DAYTRA, DAYRUN, TPREV, TMOI ST, DAYSTP, PE, PT, DAYTIM,

ENDIF DAYAST, DAYUBC

32706 CONTINUE

C End of the Day Loop for this simulation

C

C

TERR = STORE+TINF-TE-TTRA-TQ (NPT) -TMOIST

IREC = IREC+1

$T T I M=T T I M / 24.0$

WR ITE(LUB, REC=IREC) IDAY, G, IPLANT, TPET, TPT, TTRA, TPE, TE, TETRAN , TRUNOF, TINF, TTIM, TRAIN, APLI ED, TTIRRI, TMO IST, TERR, TSTP, $(T Q(1), I=1, N P T), T A S T, T U B C$

32709 CONTINUE

CLOSE (UNIT $=$ LUB)

999 STOP

END 


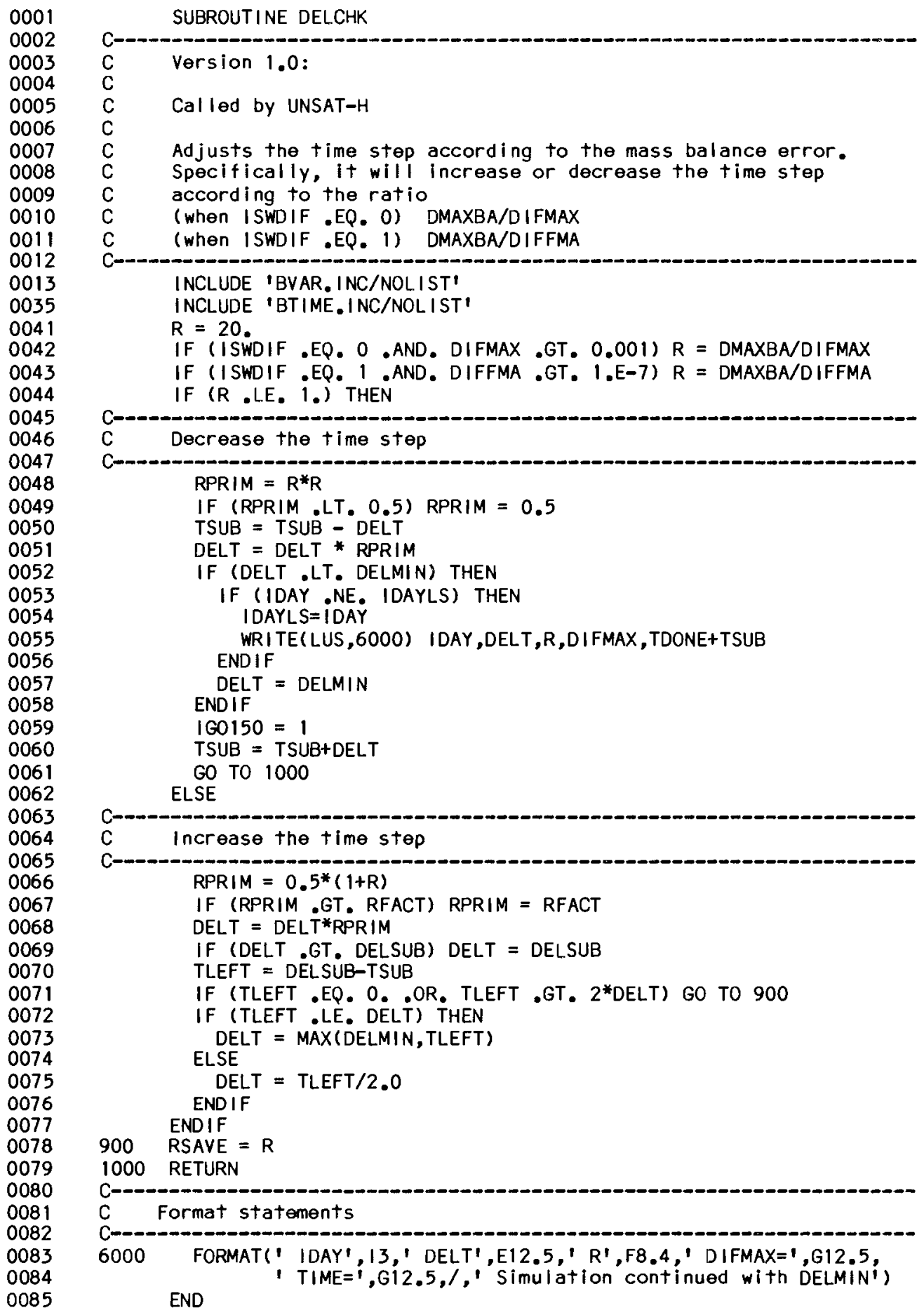




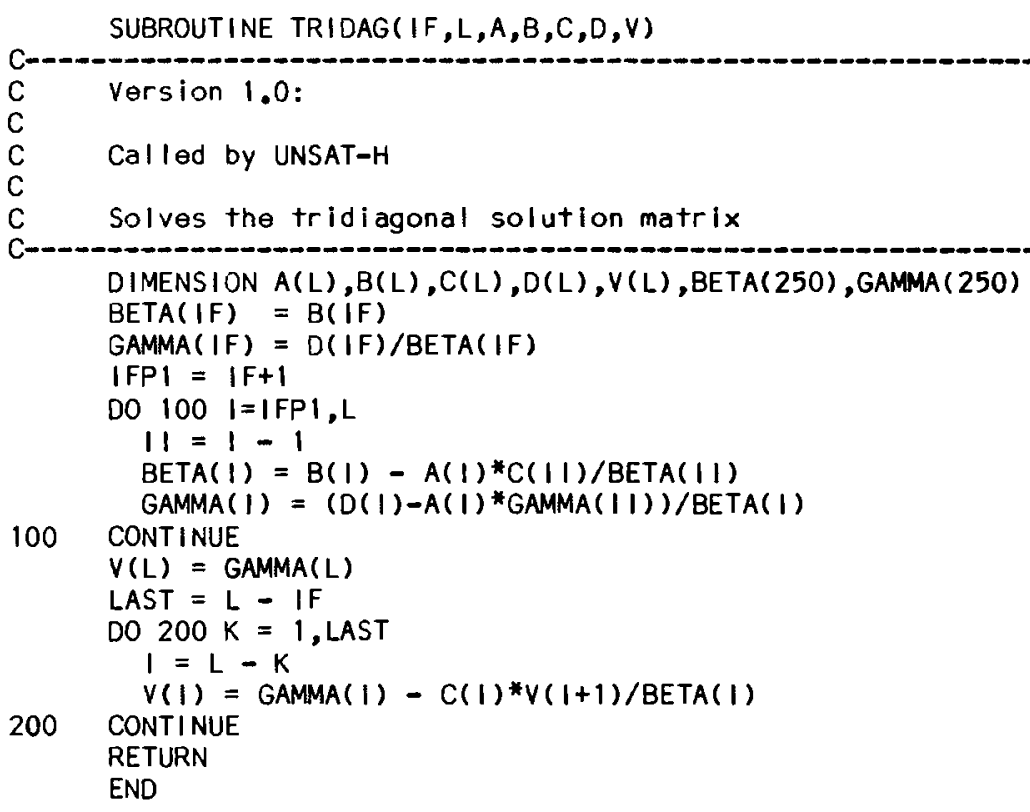




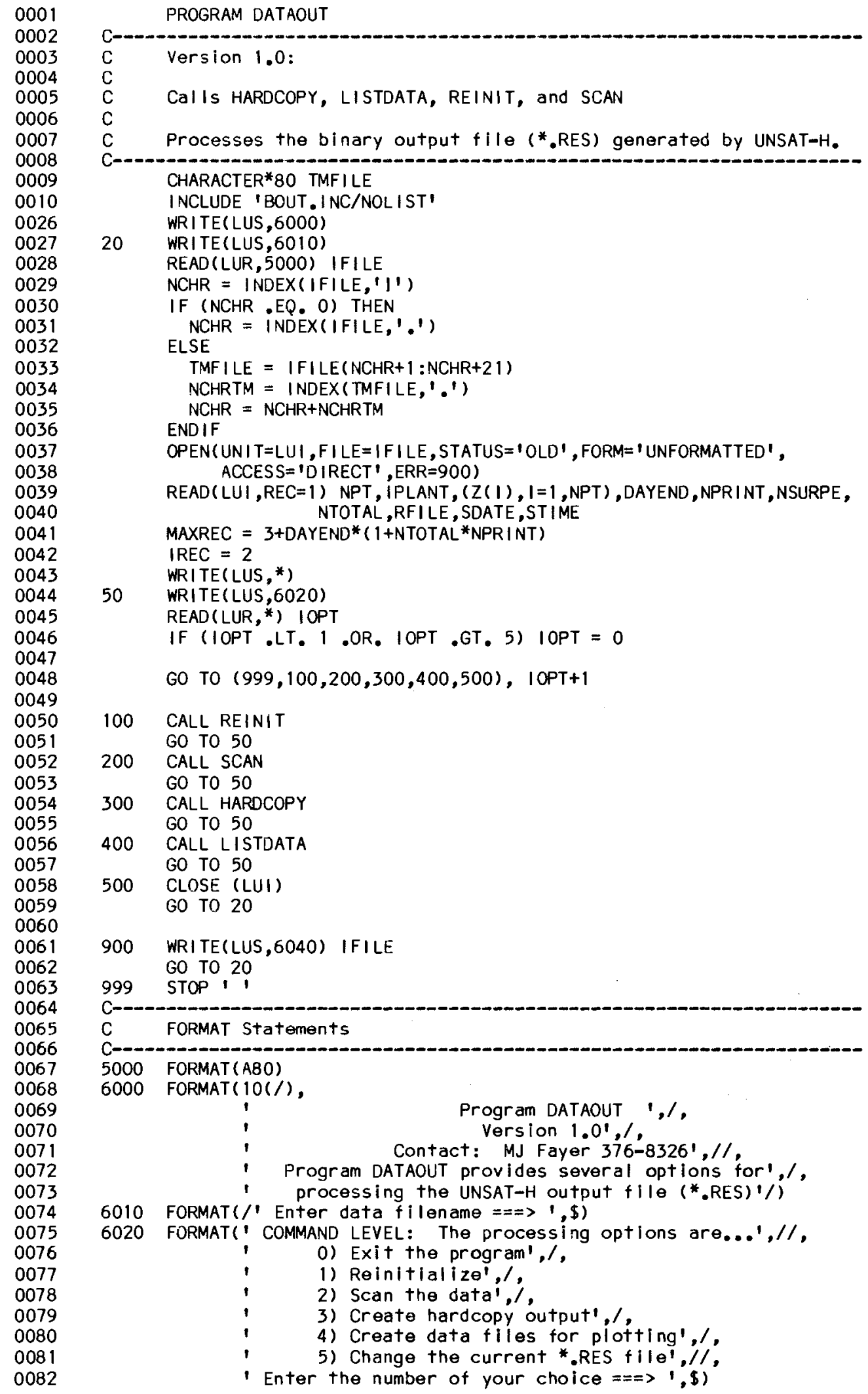


0083

0084

6040 FORMAT(/I No record of file ',A50,/,

0085

END

' Try again...'/) 


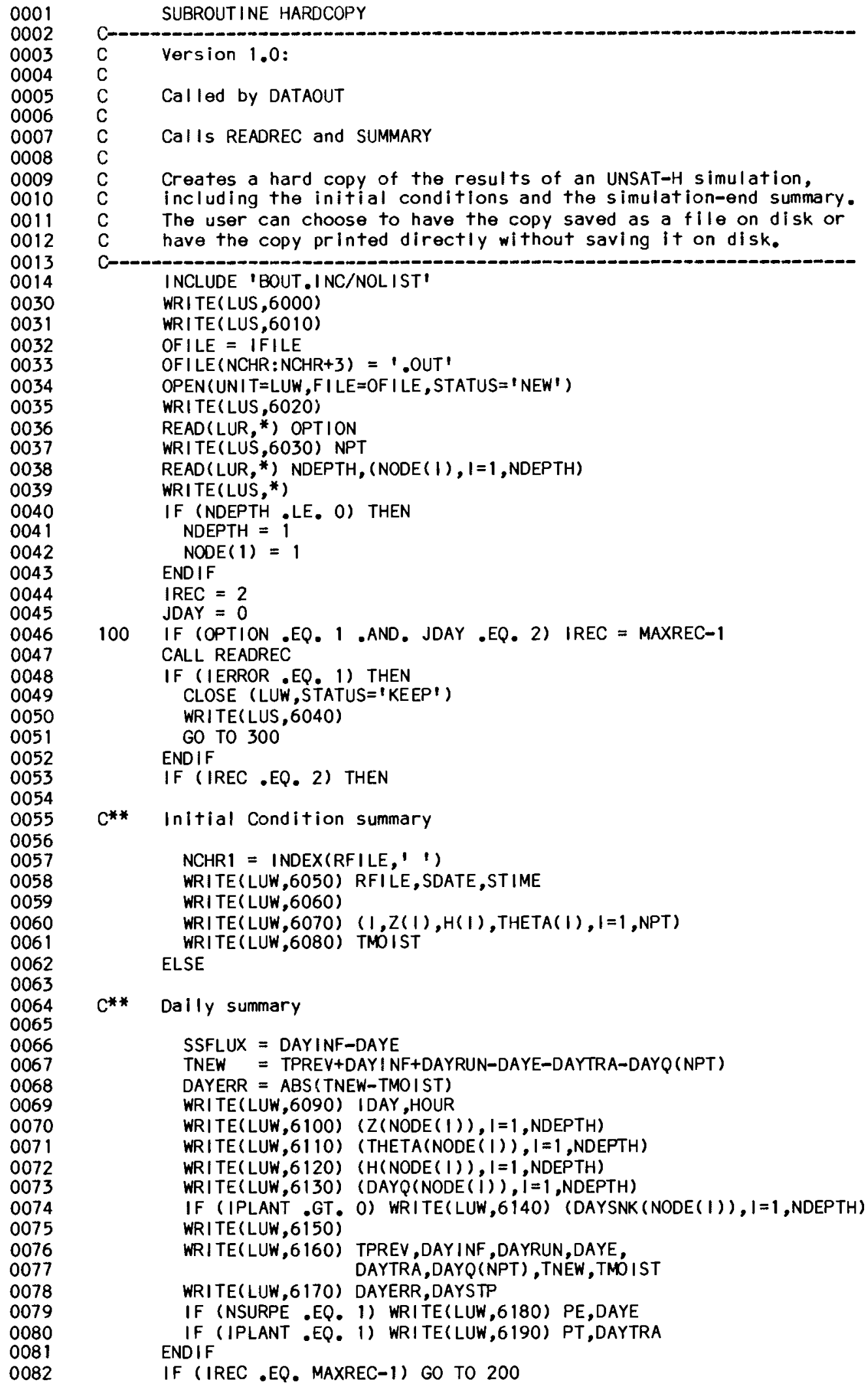




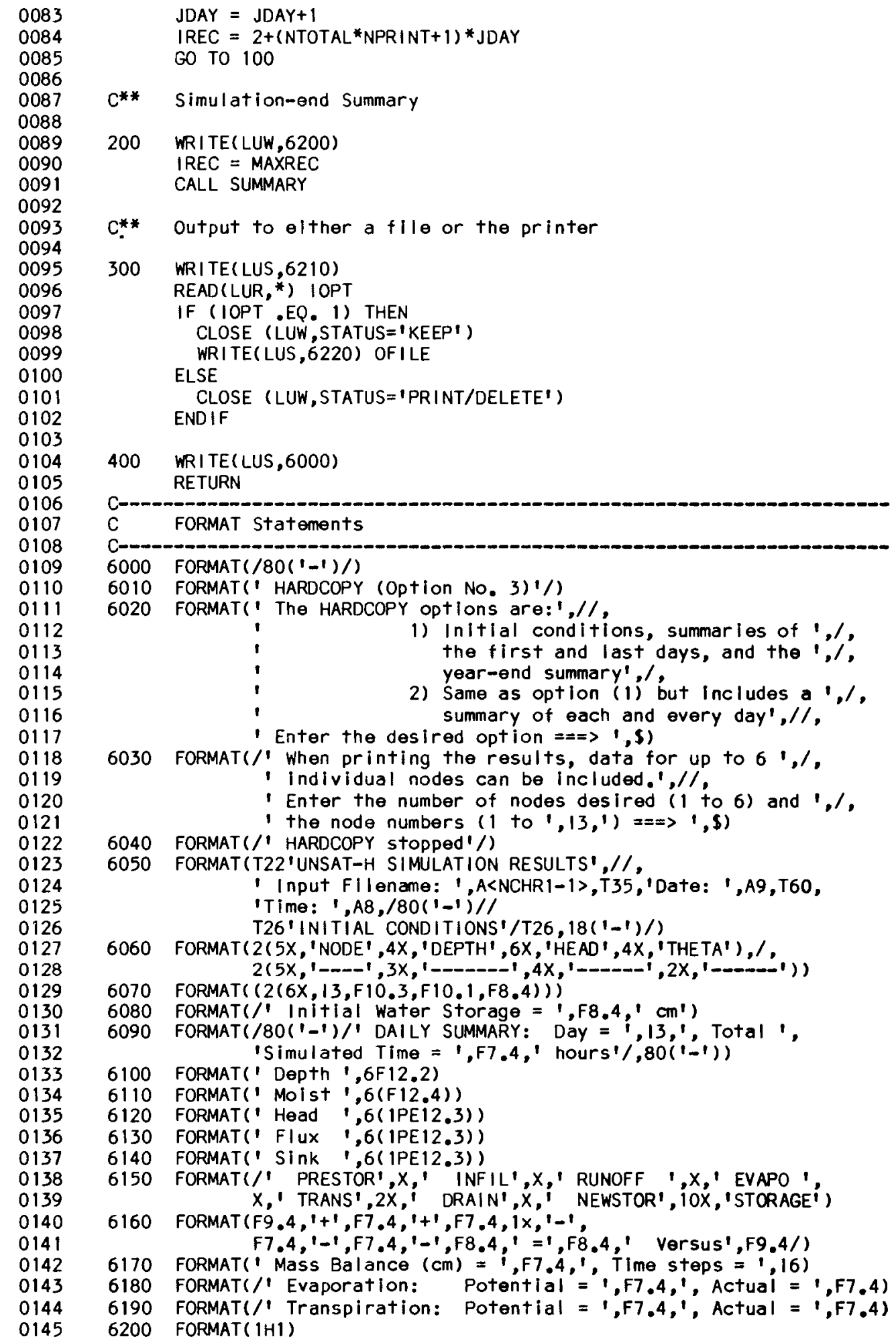


0146

0147

0148

0149

0150

0151
6210 FORMAT(/' Output specification: ',//,

1 1) to a file on disk', $/$,

2) directly to the printer', $/ /$,

- Enter the desired choice $===>1, \$$ )

6220 FORMAT( $/$ ' HARDCOPY output can be found in file ', A<NCHR+3>) END 


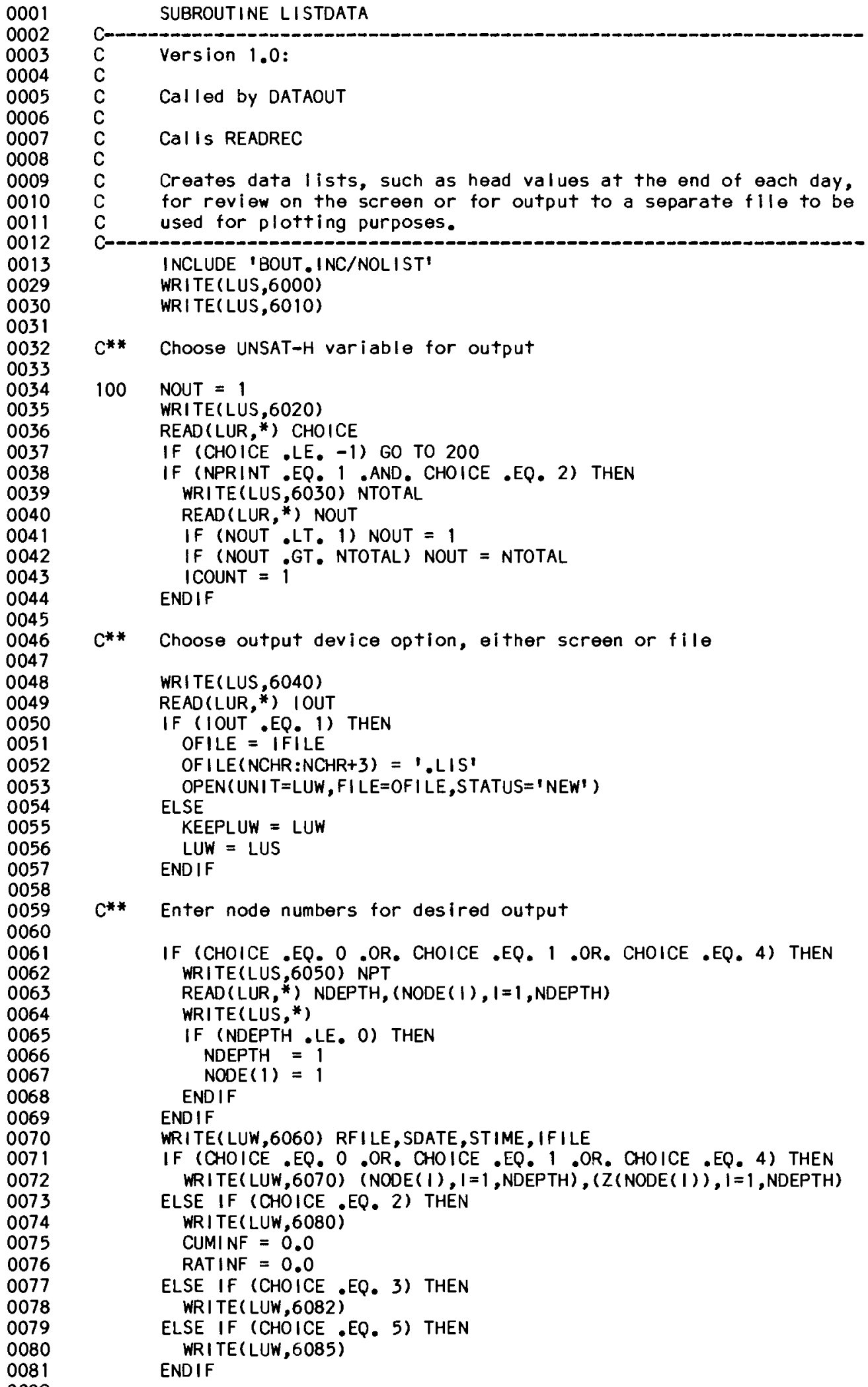

SUBROUTINE LISTDATA 


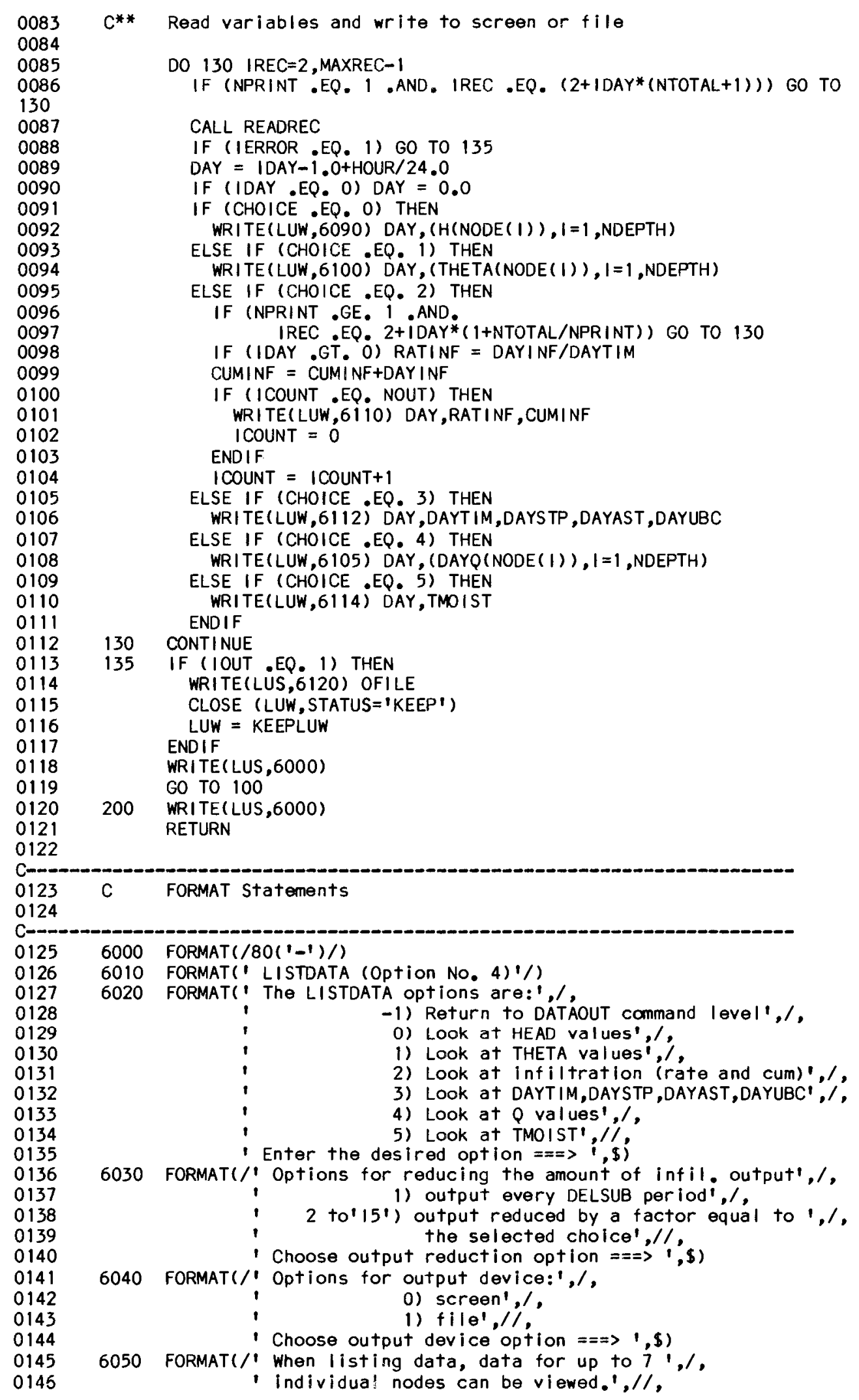




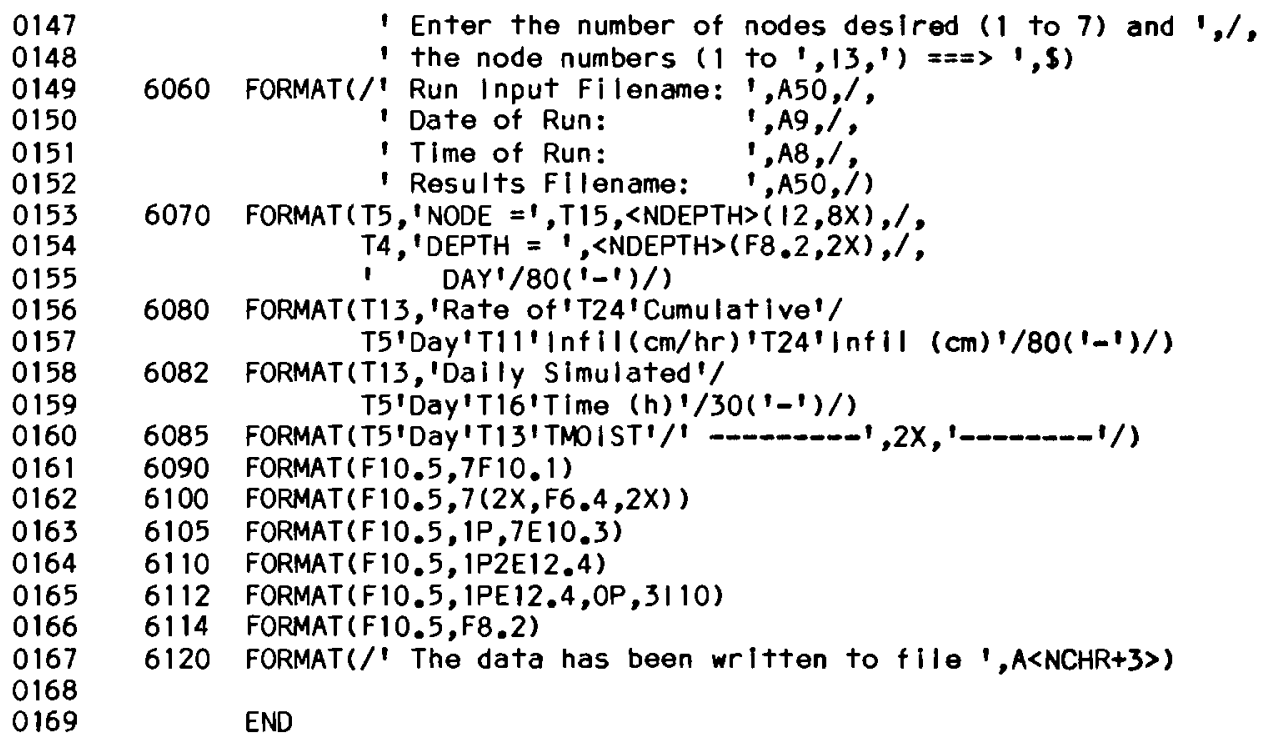




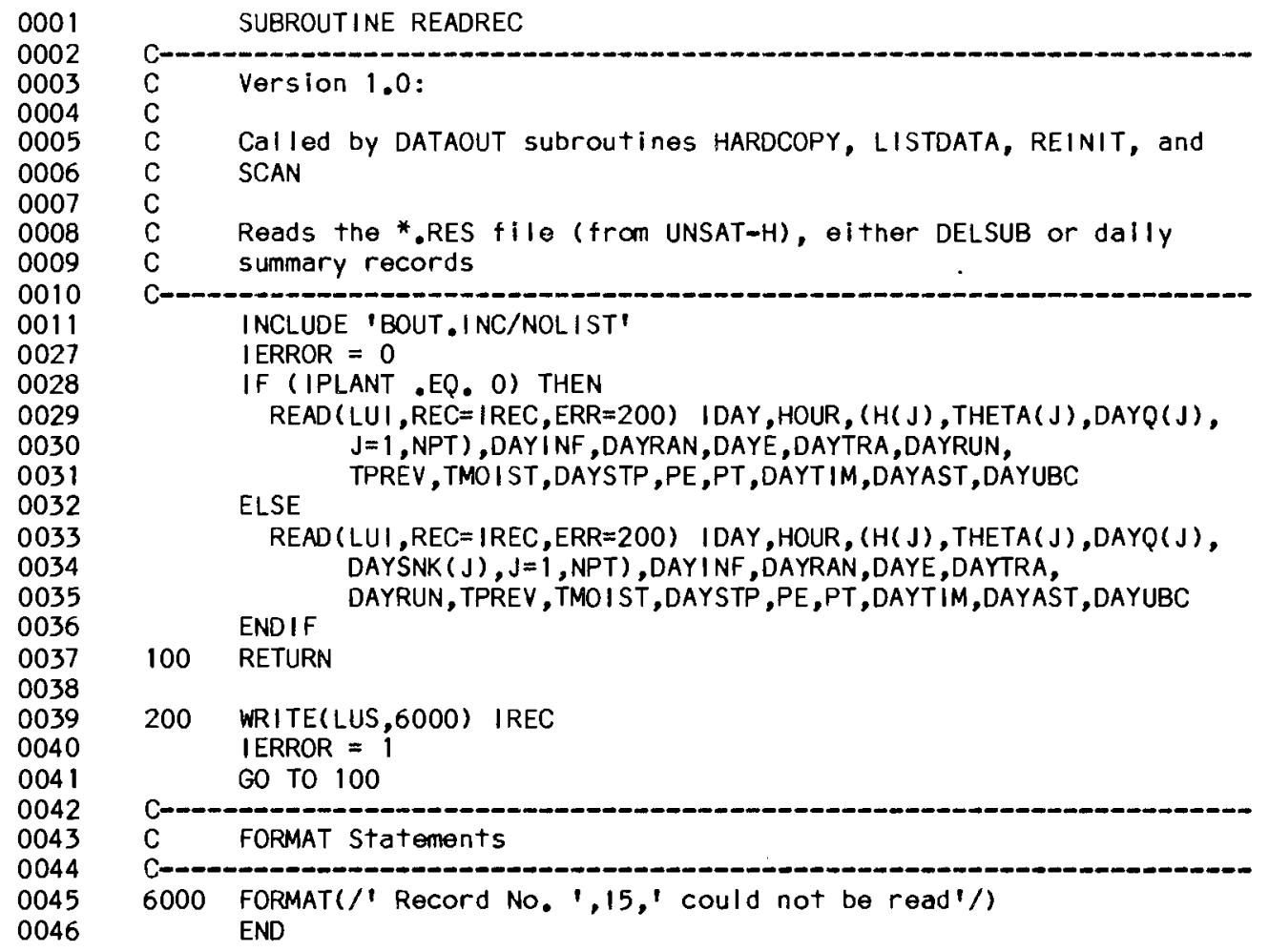




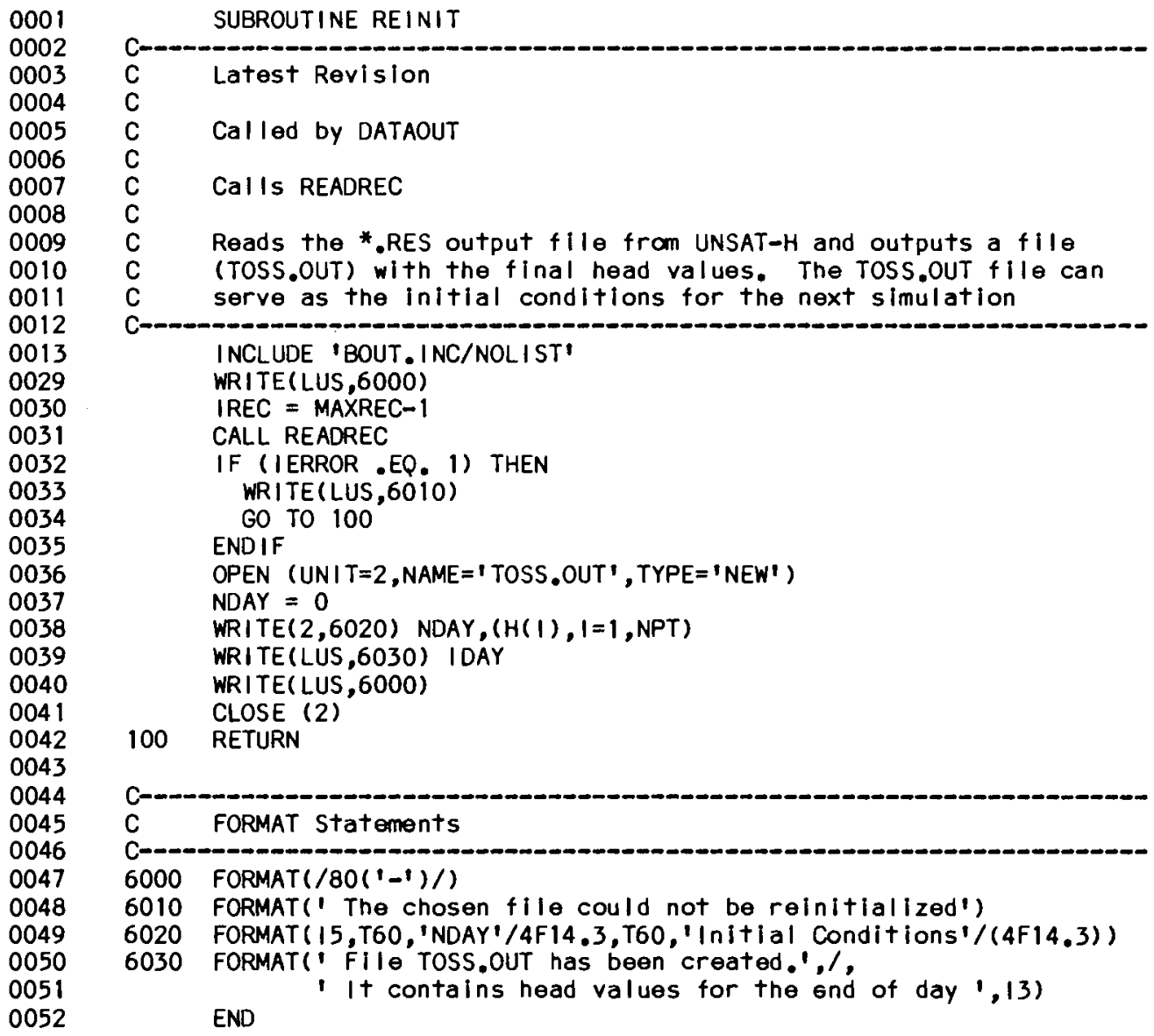




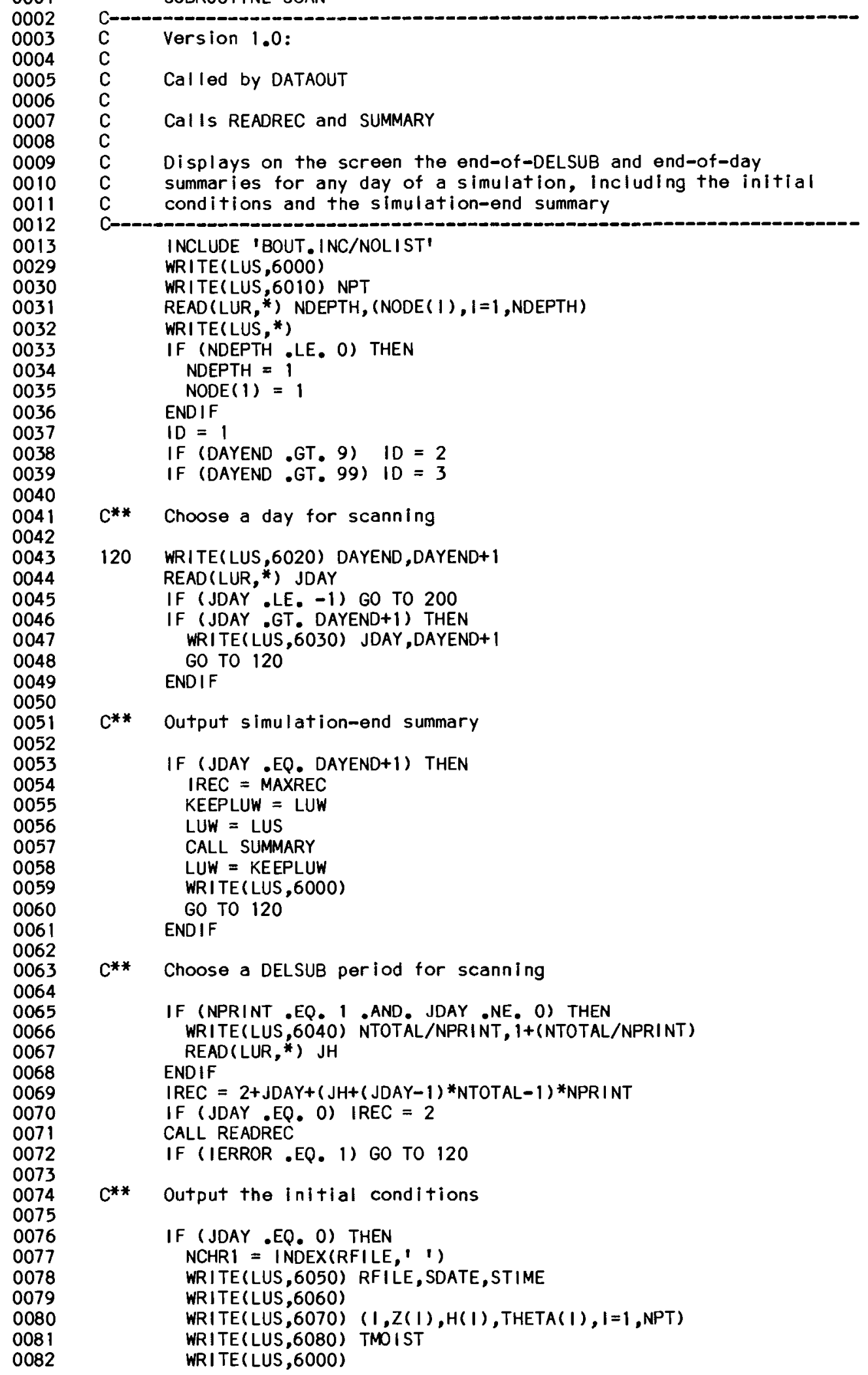




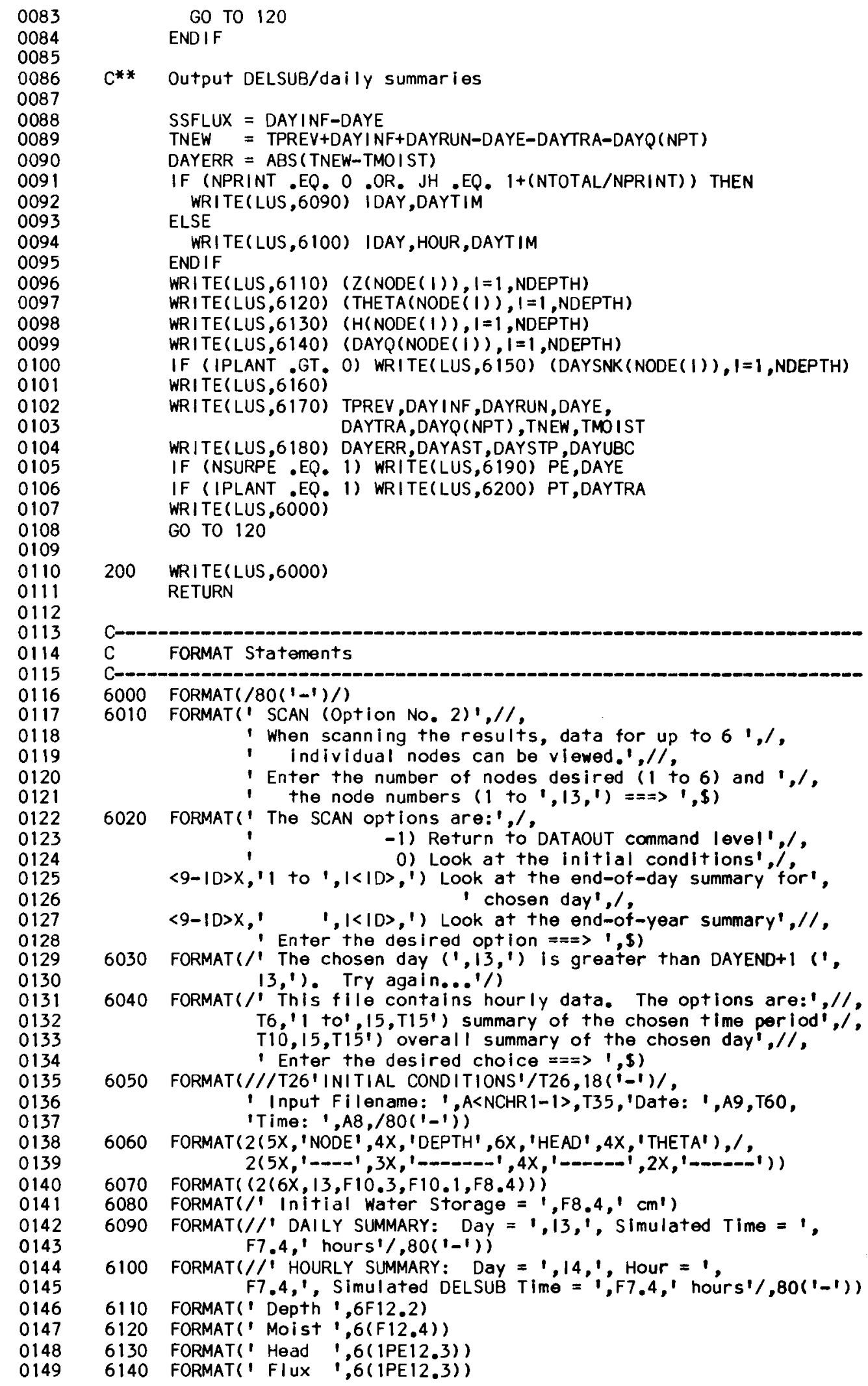




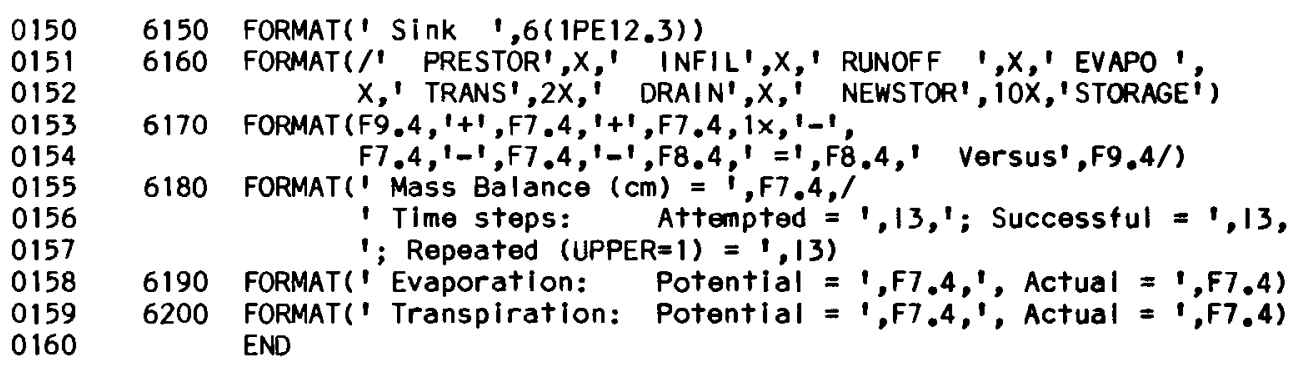




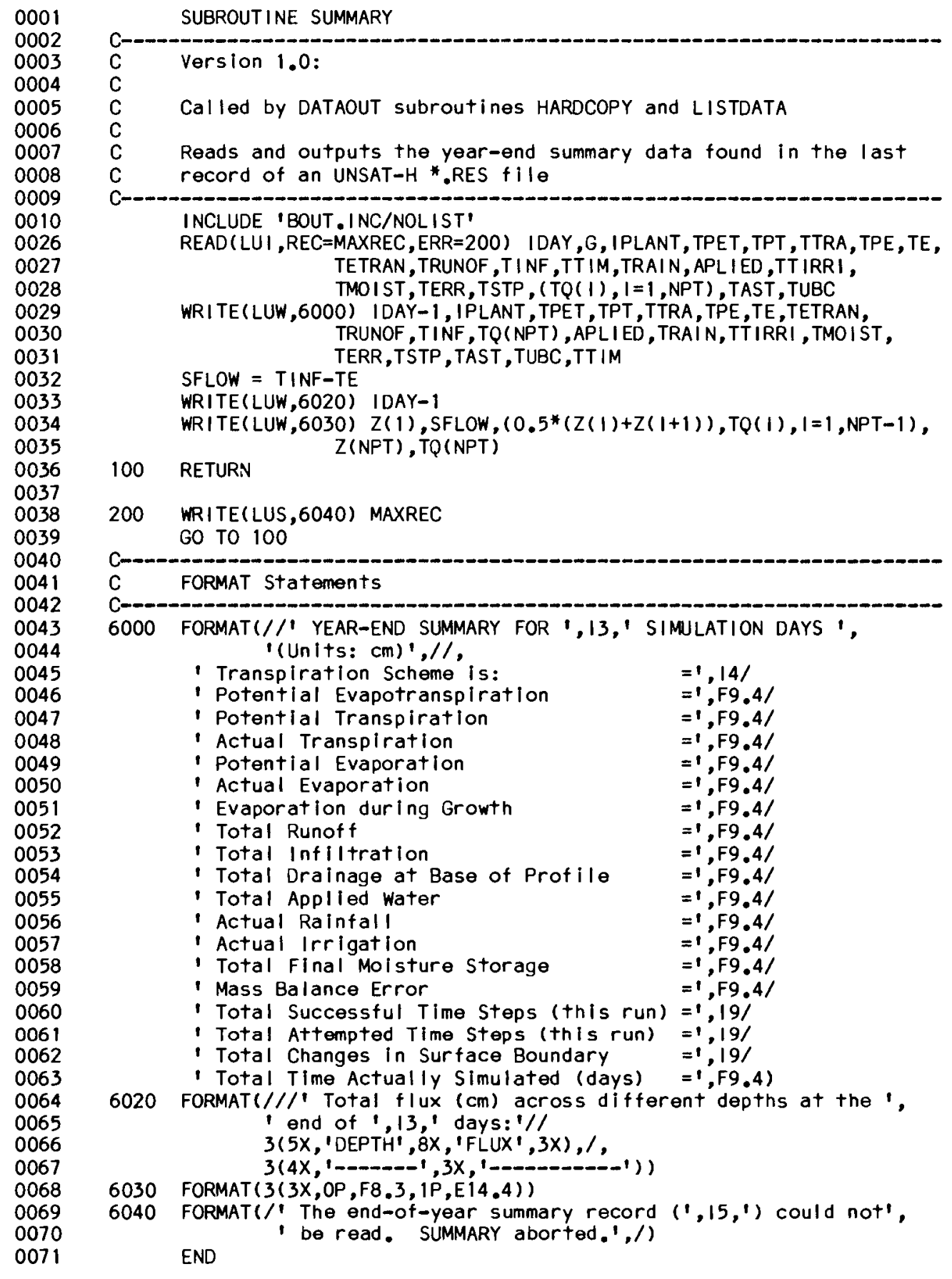




\subsection{GLOSSARY OF TERMS}

The following glossary defines the major terms used within the various codes. The glossary has been divided into sections defining variables, arrays, parameter constants, and functions and subroutines.

\subsubsection{Variables}

A Coefficient in Haverkamp conductivity function

AA Coefficient in the exponential root growth equation

ALPHA Coefficient in Haverkamp moisture characteristic description

ALPHAF Sink reduction factor, based on the moisture content of each node (Feddes method)

APLIED Running total of rainfall/irrigation amounts as they are input

AVC Average specific moisture capacity over a time step (units: 1/cm)

B Coefficient in Campbell functions and Haverkamp conductivity function BARE Fraction of soil surface that is bare of plants

BETA Coefficient in Haverkamp moisture characteristic description

BIOMAS Plant shoot biomass scaling factor used in adjusting transpiration (units: $\mathrm{g} / \mathrm{m}^{2}$ )

B1 Coefficient in the exponential root growth equation

B2 Coefficient in the exponential root growth equation

DAYE Running total of evaporation for a given day (units: $\mathrm{cm}$ )

DAYEND Ending simulation day

DAYINF Running total of infiltration for a given day (units: $\mathrm{cm}$ )

DAYIRR Running total of irrigation for a given day (units: $\mathrm{cm}$ )

DAYPE Total potential evaporation for a given day (units: $\mathrm{cm}$ )

DAYPT Total potential transpiration for a given day (units: $\mathrm{cm}$ )

DAYRAN Running total of rain for a given day (units: $\mathrm{cm}$ )

DAYRUN Running total of runoff for a given day (units: $\mathrm{cm}$ )

DAYSTP Running total of time steps taken during a given day

DAYTIM Actual number of hours simulated in a particular day (units: $h$ )

DAYTRA Running total of transpiration for a given day (units: $\mathrm{cm}$ )

DEL A shortened version of 1/DELSAV for use in calculating the coefficients for the solver (in the predictor-corrector loop) (units: $1 / \mathrm{h})$

DELMAX Maximum time step (normally $1 \mathrm{~h}$ ) (units: $\mathrm{h}$ )

DELMIN Minimum allowable time step (units: $h$ )

DELSAV The time step size of the current predictor-corrector loop (units: $h$ )

DELSUB Length of a time subdivision of a day, normally equal to DELMAX (units: $h$ )

DELSVL Value of the last successful time step (units: $h$ )

DELT The projected time step (units: h)

DIFFMA Mass balance error that is calculated at the end of each successful time step when ISWDIF $=1$ (units: $\mathrm{cm}$ )

DIFMAX Maximum observed fractional change in THETA for any node when ISWDIF $=0$ (units: $\mathrm{cm}^{3} / \mathrm{cm}^{3}$ ) 
DMAXBA Time-step control parameter. If ISWDIF $=0$, DMAXBA is the maximum allowable fractional change in the water content of any node. If ISWDIF = 1, DMAXBA is the maximum allowable difference between predicted and calculated soil profile water storage values (units: $\mathrm{cm}^{3} / \mathrm{cm}^{3}$ or $\mathrm{cm}$, respectively)

DOWN Downstream weighting factor for estimating conductivity at the midpoint between nodes; DOWN $=1.0$ - UP

DRYC Limit of specific moisture capacity when $H$ is set to HDRY

DRYK Limit of conductivity when $H$ is set to HDRY

DUMMY Dummy character variable used for input

EFICEN Efficiency of the irrigation scheme ( $i . e$. , how much of the water actually gets onto the soil surface)

FZZ1 Part of solution matrix

FZZ2 Part of solution matrix

G Option to orient the soil profile

(0) horizontally

(1) vertically

HD Head corresponding to moisture content below which plant transpiration starts to decrease below the potential (units: $\mathrm{cm}$ )

HDRY Maximum head to which the soil can dry out (units: $\mathrm{cm}$ )

HHPOND Initial ponding height when IRTYPE $=3$ or 4 (units: $\mathrm{cm}$ )

HIRRI Minimum head that can occur during rain or irrigation; a negative number indicates a positive pressure (units: $\mathrm{cm}$ )

HN Head corresponding to moisture content above which plants do not transpire because of anaerobic conditions (units: $\mathrm{cm}$ )

HOUR Running total of time simulated during the day (units: $h$ )

HPOND Current ponding height when IRTYPE $=3$ or 4 (units: $\mathrm{cm}$ )

HTMP Temporary storage location for head values during extrapolation of head values for property estimation (units: $\mathrm{cm}$ )

HTOP Head value of the surface node when ITOPBC = 1 for a constant head boundary condition (units: $\mathrm{cm}$ )

HW Head corresponding to moisture content below which plants wilt and stop transpiring (units: $\mathrm{cm}$ )

I Integer index

ID Index identifying a soil property polynomial in POLYCH, POLYKH, and POLYTH

IDAY Day number

IDAYLS Flag that indicates the last day that a detailed print was generated when DELT went below DELMIN. Occurs in the time-step control loops. Allows only 1 print per day, then is reset to IDAY

IERROR Sum of nodes for which the capacity was calculated in POLYCH as negative. If greater than zero, the program stops

IFILE Name of the input file (with *.BIN extension)

IG0150 Flag in the convergence loop

(0) indicates nothing

(1) indicates an iteration must be repeated because of a water-balance problem 
IHPOND Flag indicating that there will be ponding during that particular day

I I Integer index

II I Integer index

IN Indicates location within the predictor-corrector loop

(0) before the loop

(1) after the predictor but before the corrector

(2) after the corrector

INC Potential number of coefficients for completely describing any one soil hydraulic property, found in POLYCH, POLYKH, and POLYTH

IP Index of soil property coefficients, found in POLYCH, POLYKH, and POLYTH

IPLANT Option to include plants

(0) no plants

(1) plants

IR Index number of each rainfall event during a given day

IRAIN Flag indicating water application in the form of rain on day IRDAY = IDAY

IRDAY Day on which a rain/irrigation event occurs

IREC Record counter for control of binary output

IRL Binary record length that depends on the number of nodes

IRRI Flag indicating water application in the form of irrigation or ponding on day IRDAY=IDAY

IRTYPE Option for water application

(1) rain

(2) irrigation

(3) constant ponding depth less than 1 day

(4) constant ponding depth greater than 1 day

ISATUK Flag (normally 0 ) that is set to (1) to initiate a saturated surface condition at the start of a water application event and (2) once the event has been initiated

ISAVUP Saves the UPPER switch so it can be reset correctly if it is changed during the convergence loop

ISTART Array index passed to subroutine TRIDAG

(1) flux surface boundary condition

(2) constant head surface boundary condition

ISTEP Flag that is (0) on the first time step, thus allowing UNSAT-H to set ZKKMID and GGMOD equal to ZKMID and GMOD, respectively, on the first time. After the first time step, ISTEP is always (1) and ZKKMID and GGMOD are always equal to the ZKMID and GMOD values at the end of the previous time step

ISWDIF Option for time-step control

(0) maximum percent change in THETA

(1) mass balance

ITOPBC Option for the surface boundary condition

(0) flux

(1) constant head, for which the program will require a value for HTOP, the head at the surface

ITPOND Index of the next time for changing the ponding depth; used when IRTYPE $=4$

IVAPOR Option to include isothermal vapor flow; requires values for TORT, VAPDIF, and TSOIL

IYEAR Index of year being simulated 
J Integer index

KEST Options for estimating the conductivity between nodes

(1) arithmetic mean

(2) upstream weighting of arithmetic mean

(3) geometric mean

KLMID The liquid water conductivity at the midpoint between nodes (units: $\mathrm{cm} / \mathrm{h}$ )

KOPT Options available to describe soil hydraulic properties

(1) polynomials

(2) Haverkamp functions

(3) Campbel1. functions

(4) Haverkamp functions except that head in the moisture retention function is replaced by $\ln$ (head)

LEAF Option for entering leaf area index (LAI) (if IPLANT = 1)

(1) User supplies LAI values for the year

(2) User supplies a subroutine

LOGE Shortened version of $\log (\exp (1))$; used in POLYCH

LOWER Options to describe the lower boundary condition

(1) semi-infinite profile with a unit gradient

(2) constant head (e.g., static water table if initial head specified as zero)

(3) specified daily bottom flux

(4) impermeable boundary

MATI

MATN

Short version of MAT(I)

MAXPOL

MAXSUB

Number of different soil materials

Maximum degree of soil property polynomials +1

Maximum number of subdivisions of any given soil property

description. In other words, the maximum number of polynomials needed to completely describe the soil property

MDEPTH

Node to which roots have penetrated on a given day

MGR

Lumped parameter; molar weight of water times the gravity constant, divided by the universal gas constant (units: ${ }^{\circ} \mathrm{K} / \mathrm{cm}$ )

MXR00T Deepest node to which roots will penetrate during the year

$N \quad$ Index of present DELSUB period

NCHR Index of the '.' character position in a file name

NDAY Starting day

NDAYS Total number of days of available data

NEWPON Time (ITPOND) when the present ponding height should be changed (units: h)

NFHOUR Option for distributing the daily potential evapotranspiration (PET) value over the course of the day

(1) User supplies 24 hourly values that must sum to 1.0

(2) 24 hourly values are generated using a sine wave function from 0600 to 1800 and assuming the factors during the remaining hours are 0.01 ; all factors summing to 1.0 
NFPET Option for defining PET

(1) User supplies daily PET values and DATAINH partitions it into PE and PT based on LAI and equation by Ritchie and Burnett (1971)

(2) User supplies daily PET values and DATAINH partitions it into PE and PT based on the cheatgrass data of Hinds (1975)

NFROOT Option for defining root growth

(1) Exponential relationship

(2) User supplies a subroutine

NGRAV Orientation of the profile

(0) horizontal

(1) vertical

NGROW Growth day, starting from NSOW (units: day)

NHR Integer indicating the hour of the day

NHRVST Day of the year on which plants cease transpiring

NPOINT Number of changes in the LAI relationship when LEAF $=1$

NPPT NPT -1

NPRINT Option for level of output

(0) daily summaries with end-of-simulation summary

(1) hourly and daily summaries with end-of-simulation summary;

limited to 15 days total because of size of output file

NPT Number of nodes

NRATES Total number of changes in water-application rate on a given day

NSINK Flag indicating whether that plants are transpiring during the present time step

(0) no transpiration

(1) transpiration

NSOW Day of the year on which seeds are planted

NSTOP For output control

NSURPE Option for surface evaporation

(0) no evaporation

(1) evaporation

NTLEAK Number of times the flux lower boundary condition changes during the simulation period (if LOWER $=3$ )

NTOTAL Number of time subdivisions in a day. Normally equals 24 but can be more if DELMAX < 1

NUPTAK Option for plant water uptake

(1) Sink term approximation proposed by Feddes, Kowalik, and Zaradany (1978), requires HW, HD, and HN

(2) User supplies a subroutine

NWATER Total number of days on which rainfall or irrigation occurs

NYEARS Number of years that the simulation will be repeated

OFILE Output file name

PE Potential evaporation for the day, equivalent to PEVAPO(IDAY) (units: $\mathrm{cm} /$ day)

PESUB Hourly potential evaporation rate (units: $\mathrm{cm} / \mathrm{h}$ )

PET Daily potential evapotranspiration, the sum of PEVAPO and PTRANS (units: $\mathrm{cm}$ )

PIRRI Irrigation rate (units: $\mathrm{cm} / \mathrm{h}$ ) 


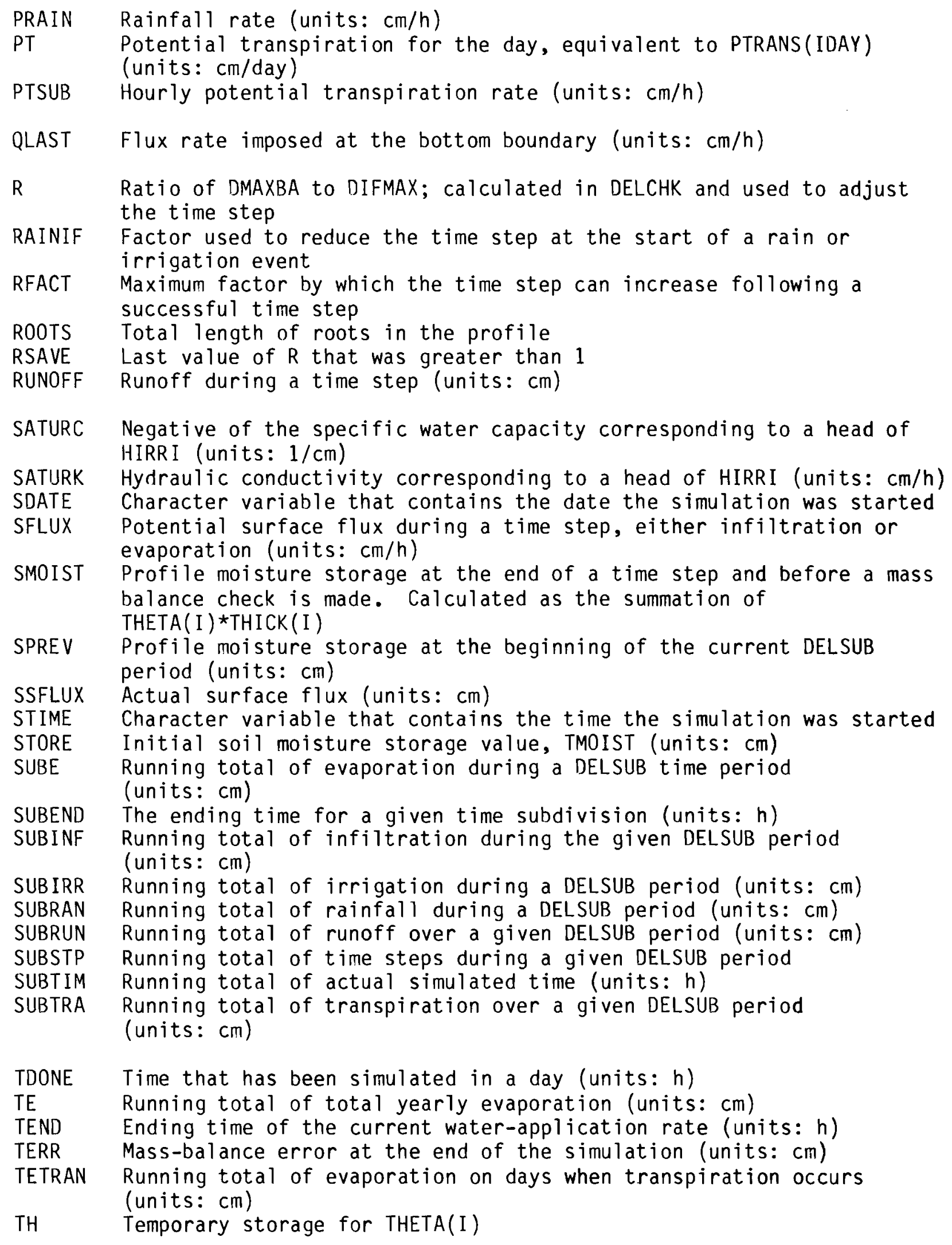


THD

THD Short version of THETAD(MAT(I))

THDIF

THMAX

THN

THTR

THW

TINF

TITLE

TLEFT

TMOIST

TORT

TOTALR

TPE

TPET

TPREV

TPT

TRAIN

TRANSP

TRUNOF

TSOIL

TSTART

TSTOP

TSTP

TSUB

TTIM

TTIRRI

TTRA

UP

UPPER

VAPCOE

VAPDEN

VAPDIF control the time step Short version of THETAN(MAT(I))

\section{Short version of THETAW(MAT(I))} (units: h)

Pore tortuosity, used when IVAPOR = 1

(units: $\mathrm{cm}$ ) periods (units: $\mathrm{cm}$ ) PRESTOR in the output (units: $\mathrm{cm}$ ) periods (units: $\mathrm{cm}$ ) Transpiration rate (units: $\mathrm{cm} / \mathrm{h}$ )

Average soil temperature (units: ${ }^{\circ} \mathrm{K}$ ) (units: $h$ ) (units: h)

(units: $\mathrm{cm}$ ) midpoints, used when KEST $=2$ while in the predictor-corrector loop

(0) flux

(1) constant head $\mathrm{cm} / \mathrm{h}$ )

Fractional change in THETA for a given node over a time step; used to

The maximum of THETA and TTHETA; used to calculate THDIF

Residual water content, used in Haverkamp moistyre çaracteristic description (Haverkamp et al. 1977) (units: $\mathrm{cm}^{3} / \mathrm{cm}^{3}$ )

Running total of yearly infiltration (units: $\mathrm{cm}$ )

Character variable containing the problem title from the input file Time left until the end of the next time period or flow-rate change

Profile moisture storage at the end of a successful time step and the end of the day, referred to as STORAGE in the output (units: $\mathrm{cm}$ )

Total water application amount (as it is input) for the day

Running total of yearly potential evaporation during non-infiltration

Running total of daily PET values (units: $\mathrm{cm}$ )

Profile moisture storage (TMOIST) of the previous day, referred to as

Running total of potential transpiration during non-infiltration

Running total of daily rainfall as applied to the surface (units: $\mathrm{cm}$ )

Running total of daily runoff amounts (units: $\mathrm{cm}$ )

Starting time of the first rainfall/irrigation event for that day

Stopping time of the last rainfall/irrigation event for that day

Running total of time steps taken since the beginning of the

simulation, obtained by summing NTSTEP values at the end of each day

Running total of time completed in a given DELSUB loop (units: $h$ )

Running total of actual time simulated (units: $h$ )

Running total of daily irrigation as applied to the surface

Running total of daily transpiration (units: $\mathrm{cm}$ )

Upstream weighting factor for estimating the conductivity at nodal

Flag that indicates the surface boundary condition; it can change

Combination of variables used in vapor flow calculations (units:

Saturated vapor density at the soil temperature TSOIL (units: $\mathbf{g} / \mathrm{cm}^{3}$ )

Diffusion coefficient of water vapor in air (units: $\mathrm{cm}^{2} / \mathrm{s}$ ) 


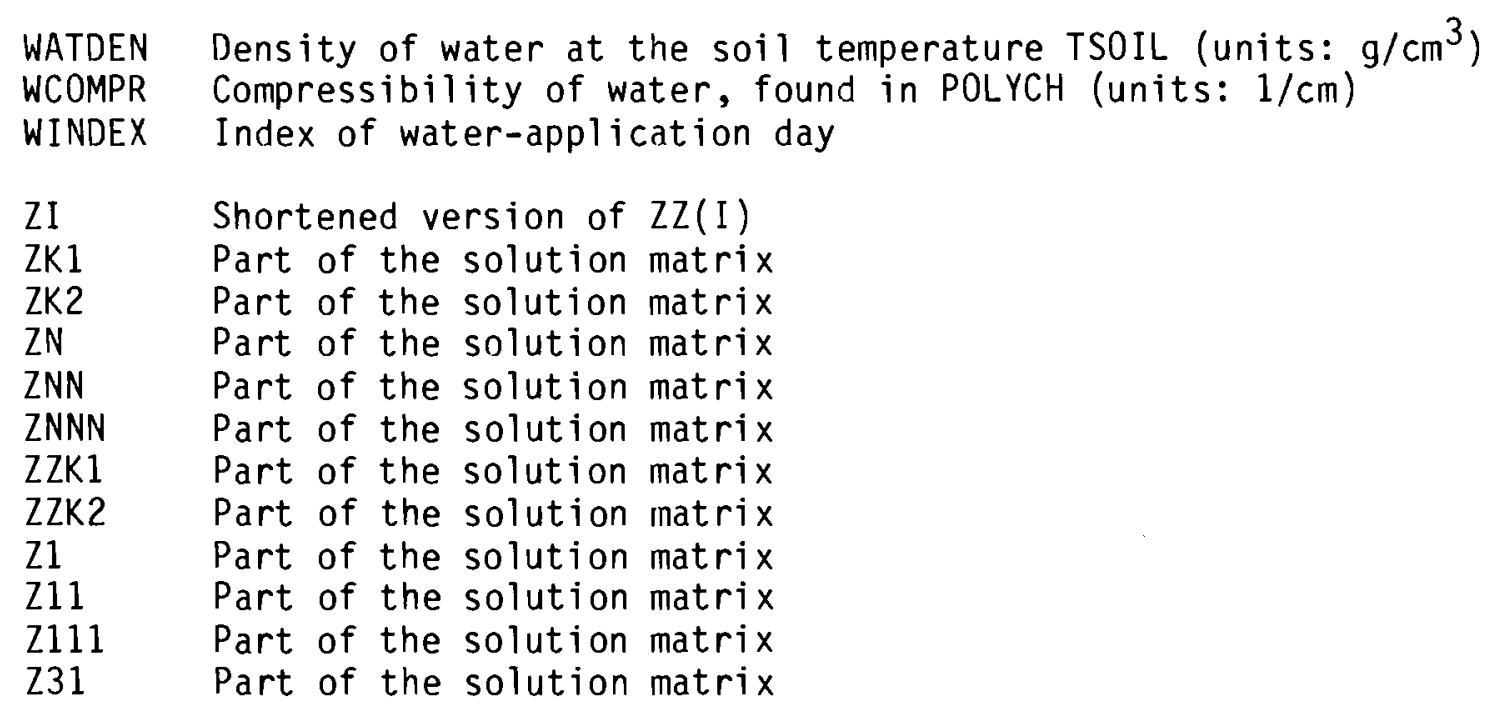

\subsubsection{Arrays}

AIRINK Air entry pressure of the conductivity function (units: $\mathrm{cm}$ ) AIRINT Air entry pressure of the soil moisture characteristic (units: $\mathrm{cm}$ ) AMOUNT Water-application amount (units: $\mathrm{cm}$ )

A1 Part of the solution matrix

A2 Part of the solution matrix

A3 Part of the solution matrix

C Negative of the present specific water capacity (units: $1 / \mathrm{cm}$ )

CC Negative of the specific water capacity at the end of the previous time step (units: $1 / \mathrm{cm}$ )

CREGKH Regression coefficients for polynomials used to describe the hydraulic conductivity, KEST = 1

CREGTH Regression coefficients for polynomials used to describe the soil moisture characteristic, KEST $=1$

DAYQ Running total of flux amounts between nodes during the day (units: $\mathrm{cm}$ )

DAYSNK Running total of the sink terms for each node during the day (units: dimensionless)

FLAI Leaf area index on the corresponding NGROW day

FPET Hourly PET distribution factors

GGMOD Value of GMOD at the end of the last successful time step

GMOD Ratio of liquid conductivity to total conductivity when IVAPOR = 1

$\mathrm{H} \quad$ Present soil moisture pressure head value (units: $\mathrm{cm}$ )

$\mathrm{HH} \quad$ Soil moisture pressure head value at the end of the previous time step (units: $\mathrm{cm}$ )

IHY Array containing all of the soil hydraulic property data 
KV Vapor conductivity when IVAPOR $=1$ (units: $\mathrm{cm} / \mathrm{h}$ )

MAT Identifies the soil material of the specified node

NDEGKH Number of polynomial coefficients for describing hydraulic conductivity in POLYKH

NDEGTH Number of polynomial coefficients for describing the moisture characterisitic in POLYCH and POLYTH

NGROW Day of the year on which the LAI is changed to the corresponding FLAI value (units: day)

NQLEAK Day on which the bottom boundary flux is changed to the corresponding QLEAK value (units: day)

NSUBKH Number of polynomials used to describe hydraulic conductivity in POLYKH

NSUBTH Number of polynomials used to describe the soil moisture characteristic curve in POLYCH and POLYTH

NTR00T Growth day on which roots reach the given node

PEVAPO Potential evaporation rate for the day (units: $\mathrm{cm} / \mathrm{day}$ )

PTRANS Potential transpiration rate for the day (units: $\mathrm{cm} /$ day)

Q Flux amounts between nodes for each DELSUB period (units: $\mathrm{cm}$ )

QLEAK Bottom boundary flux on the corresponding NQLEAK day (units: $\mathrm{cm} /$ day)

RATE Rate of rainfall for rainfall event IR (units: $\mathrm{cm} / \mathrm{h}$ )

RDF Root-density function (units: $1 / \mathrm{cm}$ )

RTIME Time of day when the water-application rate changes (units: $h$ )

SINK Rate of water removal by plants from a given node (units: $1 / \mathrm{h}$ )

SK Saturated hydraulic conductivity (units: $\mathrm{cm} / \mathrm{h}$ )

SLOPKH Linear slope between the conductivity values at heads of zero and airentry; used in POLYKH (units: $1 / \mathrm{h}$ )

SLOPTH Linear slope between the water content at heads of zero and airentry; used in POLYCH and POLYTH (units: $1 / \mathrm{cm}$ )

SUBQ Running total of flux amounts between nodes during the present DELSUB period (units: $\mathrm{cm}$ )

SUBSNK Hourly summary of sink term for each node (units: dimensionless)

THET Saturated water content (units: $\mathrm{cm}^{3} / \mathrm{cm}^{3}$ )

THETA Water content (units: $\mathrm{cm}^{3} / \mathrm{cm}^{3}$ )

THETAD Water content below which roots will remove water at less than the optimum rate (if NUPTAK = 1) (units: $\mathrm{cm}^{3} / \mathrm{cm}^{3}$ )

THETAN Water content above which anaerobic conditions exist and no water will be withdrawn by plants (if NUPTAK = 1) (units: $\mathrm{cm}^{3} / \mathrm{cm}^{3}$ )

THETAW Water content below which roots will not withdraw water (if NUPTAK = 1) (units: $\mathrm{cm}^{3} / \mathrm{cm}^{3}$ )

THICK Node thickness (units: $\mathrm{cm}$ )

TQ Yearly summary of flux amounts (DAYQ) between nodes (units: $\mathrm{cm}$ )

TTHETA Sojl moisture content at the end of the previous time step (units: $\mathrm{cm}^{3} / \mathrm{cm}^{3}$ ) 
WQLEAK Specified bottom boundary flux when LOWER $=3$ (units: $\mathrm{cm} /$ day)

XDIVKH Upper head limit to range of head values where the given hydraulic conductivity polynomial is valid (units: $\mathrm{cm}$ )

XDIVTH Upper head limit to range of head values where the given moisture retention polynomial is valid (units: $\mathrm{cm}$ )

$z$ Depth of node below the surface (units: $\mathrm{cm}$ )

ZK Hydraulic conductivity (units: $\mathrm{cm} / \mathrm{h}$ )

ZKMID Hydraulic conductivity at the midpoint between nodes (units: $\mathrm{cm} / \mathrm{h}$ )

$Z Y \quad$ Part of the solution matrix

ZZ Distance from node I to node I+1 (units: $\mathrm{cm}$ )

ZZK Hydraulic conductivity at the end of the previous time step (units: $\mathrm{cm} / \mathrm{h}$ )

ZZKMID Hydraulic conductivity at the midpoint between nodes at the end of the previous time step (units: $\mathrm{cm} / \mathrm{h}$ )

\subsubsection{Parameter Constants}

LUB Logical unit for binary output

LUI Logical unit for binary input

LUR Logical unit for interactive input

LUS Logical unit for interactive output

M1 Dimension of node arrays

\subsubsection{Functions and Subroutines}

DATE Function that returns the date (specific to VAX FORTRAN)

DELCHK Subroutine to adjust the time step

FUNED Function that returns the saturated vapor pressure $\left(\mathrm{g} / \mathrm{cm}^{3}\right)$ at the given temperature $\left({ }^{\circ} \mathrm{K}\right)$

MYHRY Subroutine to calculate 24 hourly values (which sum to 1.0 ) for partitioning daily PET into hourly PET values

POLYCH Subroutine to calculate specific water capacities

POLYKH Subroutine to calculate hydraulic conductivities

POLYTH Subroutine to calculate water contents

RHO Function to calculate the root density

TIME Function that returns the time (specific to VAX FORTRAN)

TRIDAG Subroutine containing the matrix solver 
Ritchie, J. T., and E. Burnett. 1971. "Dryland Evaporative Flux in a Subhumid Climate, 2, Plant Influences." Agron. J. 63:56-6?.

Ritchie, J. T. 1972. "Model for Predicting Evaporation from a Row Crop with Incomplete Cover." Water Resour. Res. 8(5):1204-1212.

Simmons, C. S., and C. R. Cole. 1985. Guidelines for Selecting Codes for Ground-Water Transport Modeling of Low-Level Waste Burial Sites. PNL-4890 Vo1. 1, Pacific Northwest Laboratory, Richland, Washington.

Simmons, C. S., and G. W. Gee. 1981. Simulation of Water Flow and Retention in Earthen Cover Materials Overlying Uranium Mill Tailings. PNL-3877, Pacific Northwest Laboratory, Richland, Washington.

Stone, W. A., J. M. Thorp, 0. P. Gifford, and D. J. Hoitink. 1983. Climatological Summary for the Hanford Area. PNL-4622, Pacific Northwest Laboratory, Richland, Washington. 

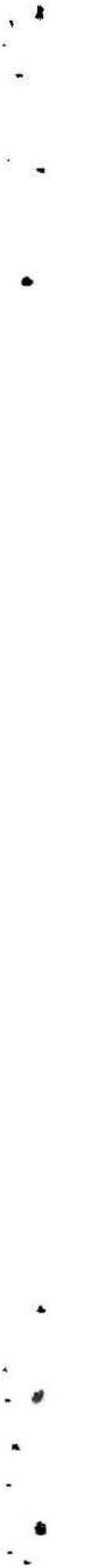

$\because$ 


\subsection{REFERENCES}

Bond, F. W., C. R. Cole, and P. J. Gutknecht. 1984. IJnsaturated Groundwater Flow Model (UNSAT1D) Computer Code Manual. CS-2434-CCM, Electric Power Research Institute, Palo Alto, California.

Campbe11, G. S. 1974. "A Simple Method for Determining Unsaturated Conductivity from Moisture Retention Data." Soil Sci. 177:311-314.

Campbe11, G. S. 1985. Soil Physics with BASIC. Elsevier, New York, New York.

Cline, J. F., D.W. Uresk, and W. H. Rickard. 1977. "Comparison of Soil Water Used by a Sagebrush-Bunchgrass and a Cheatgrass Community." J. Range Manage. 30:199-201.

Doorenbos, J., and W. 0. Pruitt. 1977. Guidelines for Predicting Crop Water Requirements. FAO Irrigation Paper No. 24, 2nd ed., Food and Agricultural Organization of the United Nations, Rome, Italy.

Fayer, M. J., W. Conbere, P. R. Heller, and G. W. Gee. 1985. Model Assessment of Protective Barrier Designs. PNL-5604, Pacific Northwest Laboratory, Richland, Washington.

Fayer, M. J., and G. W. Gee. 1985. UNSAT-H, An Unsaturated Soil Water Flow Code for Use at the Hanford Site: Code Documentation. PNL-5585, Pacific Northwest Laboratory, Richland, Washington.

Feddes, R. A., P. J. Kowalik, and H. Zaradny. 1978. Simulation of Field Water Use and Crop Yield. John Wiley and Sons, Inc., New York, New York.

Finlayson, B. A., R. W. Nelson, and R. G. Baca. 1978. A Preliminary Investigation into the Theory and Techniques of Modeling the Natural Moisture Movement in Unsaturated Sediments. RHO-LD-47, Rockwell Hanford Operations, Richland, Washington.

Gee, G. W., and P. R. Heller. 1985. Unsaturated Water Flow at the Hanford Site: A Review of Literature and Annotated Bibliography. PNL-5428, Pacific Northwest Laboratory, Richland, Washington.

Gee, G. W., and R. R. Kirkham. 1984. Arid Site Water Balance: Evapotranspiration Modeling and Measurements. PNL-5177, Pacific Northwest Laboratory, Richland, Washington.

Gee, G. W., and C. S. Simmons. 1979. Characterization of the Hanford 300 Area Burial Grounds. Task III - Fluid Transport and Modeling. PNL-2921, Pacific Northwest Laboratory, Richland, Washington. 
Gupta, S. K., K. K. Tanji, D. R. Nielsen, J. W. Biggar, C. S. Simmons, and J. L. Macintyre. 1978. Field Simulation of Soil-Water Movement with Crop Water Extraction. Water Science and Engineering Paper No. 4013, Department of Land, Air, and Water Resource, University of California, Davis, California.

Hamme 1, J. E., R. I. Papendick, and G. S. Campbell. 1981. "Fallow Tillage Effects on Evaporation and Seedzone Water Content in a Dry Summer Climate." Soil Sci. Soc. Am. J. 45:1016-1022.

Haverkamp, R., M. Vauclin, J. Touma, P. J. Wierenga, and G. Vachaud. 1977. "A Comparison of Numerical Simulation Models for One-Dimensional Infiltration." Soil Sci. Soc. Am. J. 41:285-294.

Hillel, D. 1980. Fundamentals of Soil Physics. Academic Press, New York, New York.

Hinds, W. T. 1975. "Energy and Carbon Balances in Cheatgrass: An Essay in Autecology." Ecological Monogr. 45:367-388.

Jones, T. L. 1978. Sediment Moisture Relations: Lysimeter Project 1967-1977 Water Year. RHO-ST-15, Rockwell International, Rockwell Hanford Operations, Richland, Washington.

Jones, T. L., G. S. Campbel1, and G. W. Gee. 1984. Water Balance at an Arid Site: A Model Validation Study of Bare Soil Evaporation. PNL-4896, Pacific Northwest Laboratory, Richland, Washington.

Klemmedson, J. 0., and J. G. Smith. 1964. "Cheatgrass (Bromus Tectorum L.)." The Botanical Review 30:226-262.

McKeon, T. J., S. W. Tyler, D. W. Mayer, and A. E. Reisenauer. 1983. TRUST-II Utility Package: Partially Saturated Soil Characterization, Grid Generation, and Advective Transport Analysis. NUREG/CR-3443, U.S. Nuclear Regulatory Commission, Washington, D.C.

Philip, J.R. 1969. "Theory of Infiltration." Adv. Hydrosci. 5:215-296.

Reisenauer, A. E. 1963. "Methods for Solving Problems of Multidimensional Partially Saturated Steady Flow in Soils." J. of Geophysical Research $68(20: 5725-5733$.

Reisenauer, A. E., E. B. Cearlock, C. A. Bryan, and G. S. Campbell. 1975. Partially Saturated Transient Groundwater Flow Model Theory and Numerical Implementation. BNWL-1713, Battel1e, Pacific Northwest Laboratory, Richland, Washington.

Richards, L. A. 1931. "Capillary Conduction of Liquids in Porous Mediums." Physics $1: 318-333$. 
APPENDIX A

MODEL DEVELOPMENT AT THE HANFORD SITE 

APPENDIX A

MODEL DEVELOPMENT AT THE HANFORD SITE

The development of unsaturated flow models at the Hanford Site has been driven by both changes in the applications (i.e., different flow problems) and the need for more detailed solutions to complex flow problems. There is currently a need at the Hanford Site for models that can predict rates of natural, precipitation-induced recharge.

The amount of precipitation that eventually becomes recharge is determined largely by the soil hydraulic properties and the surface-evapotranspiration condition. A wide spectrum of surface-evapotranspiration conditions exists at the Hanford Site, ranging from the free-water surfaces on evaporation ponds, to the unvegetated gravel surfaces at many waste-storage sites (e.g., tank farms), to well-vegetated soil surfaces (e.g., shrub-grass communities). As shown in Figure A.1, for the average soil type at the Hanford Site, annual water-balance considerations indicate that the amount of recharge to be expected at these sites varies widely. At evaporation pond sites, recharge to the water table can occur at rates exceeding several meters per day. In contrast, natural recharge occurs at rates measured in centimeters per year. In addition, natural recharge rates at various sites are strikingly different, ranging from $12 \mathrm{~cm} / \mathrm{y}$ or more for the gravel-covered soil sites under normal precipitation conditions, to near zero for the shrub-grass community sites.

Clearly, there is a wide range of surface conditions at the Hanford Site that must be carefully documented to allow us to describe recharge, and thus the potential for ground-water contamination, at any given site. Therefore, to assess present or predict future natural recharge rates, the models that are developed must be able to simulate the dynamic flow processes that are operating at the soil surface, specifically the transient processes of precipitation, evaporation, and transpiration. This is particularly true for arid-site recharge such as occurs at the Hanford Site where small changes in surface characteristics can have a pronounced effect on the recharge rate. 


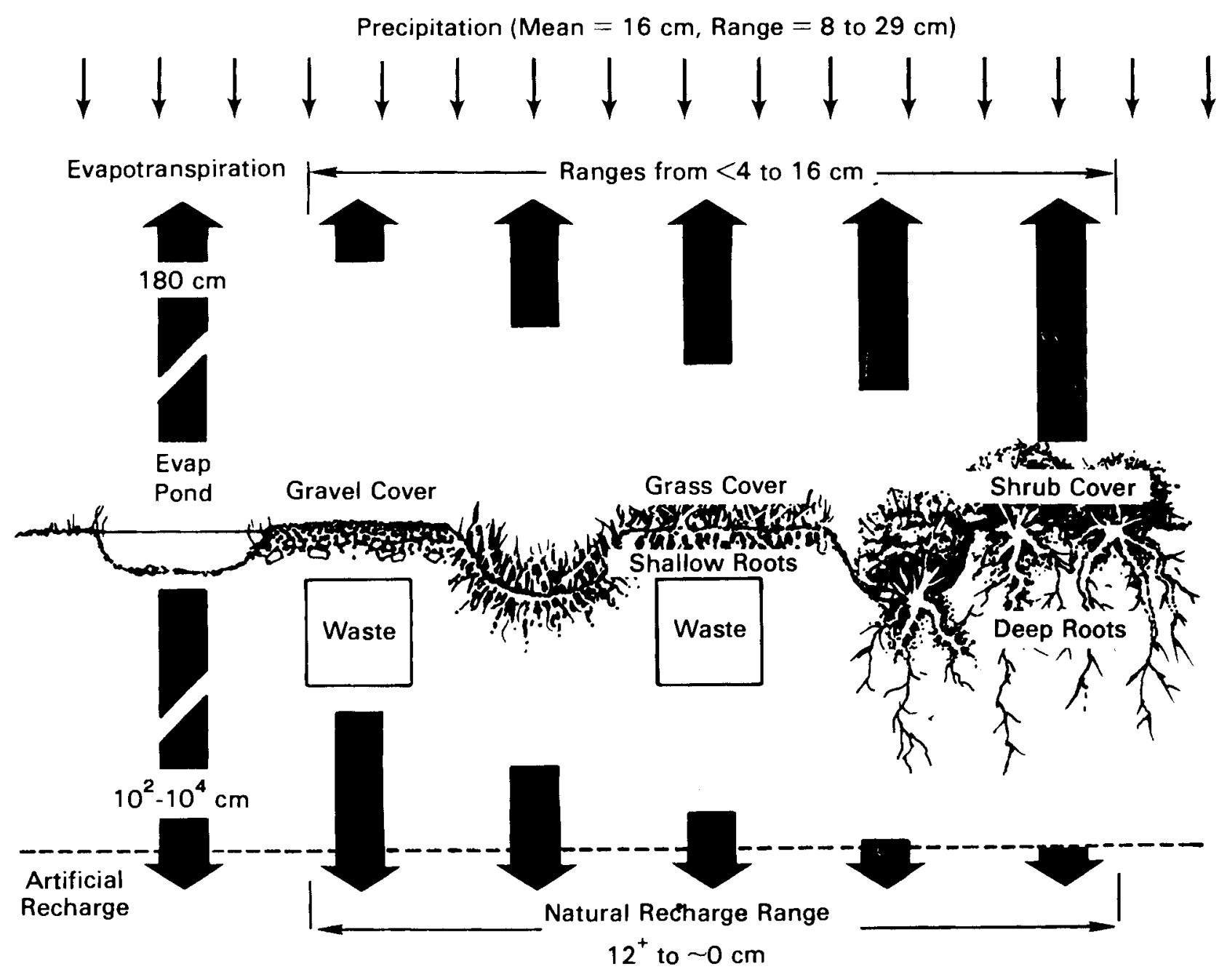

FIGURE A.1. Effect of Surface Conditions on Recharge at Hanford

\section{A.1 EVOLUTION OF MODELING}

The development of unsaturated flow models for assessing water flow pathways and rates at the Hanford Site started in the 1960s. The first applications of such models were to describe flow beneath storage ponds, cribs, and canals, and leaks from tanks used to store high-level waste. These applications required a multidimensional analysis of flow deep within the soil profile. Therefore, the emphasis in model development was on properly accounting for soil water redistribution and multidimensional flow patterns. Models developed during this period were recognized as being very advanced for their day by the scientific community. Necessary simplifications in the conceptual 
model of the system were justified because of the specific applications being examined at the time. For example, the models did not include surface processes such as precipitation, evaporation, and transpiration because water flow associated with these processed was judged to be of little consequence compared to the amount of water flowing from the ponds, cribs, or tanks.

In the development of these early models, virtually no attention was given to modeling natural, precipitation-induced recharge because it was assumed to be zero. Controversy over the issue of natural recharge dominated model development in the 1970s and early 1980s. As a result, the emphasis in model development shifted to understanding the flow of water entering the soil from natural precipitation rather than from the disposal of liquid wastes.

In the $1970 \mathrm{~s}$, the models developed to describe natural recharge were new models, not just modifications of models developed in the 1960s. Natural recharge was generally viewed as a one-dimensional process, so these new models were actually less sophisticated than earlier ones in that respect. Attempts were made, however, to include more detailed analyses of the physical processes involved in natural recharge. Models from the 1970 s emphasized such processes as two-phase flow of air and water and water-vapor flow, as well as included the effect of temperature gradients on the flow of water. Nevertheless, these models still neglected the importance of an adequate description of surface processes, such as evaporation and transpiration. Models developed during the 1970 s are inadequately documented and have not played a significant role in current model-development efforts.

In the late 1970s and early 1980s, model development ceased to involve the generation of new codes. Instead, emphasis was placed on adapting existing codes that were already documented and accepted in the literature. A great deal of emphasis was also placed on field experiments designed to illustrate the important processes that a model should include, and field experiments able to generate experimental data that could be compared to model predictions to test the effectiveness of the models used.

Table A.1 is a list of models that have been used to model unsaturated flow at the Hanford Site. In the following sections, each model is discussed relative to its intended purpose, its credibility, and its availability. 
TABLE A.1. Unsaturated Flow Models Used at the Hanford Site to Assess Recharge

\begin{tabular}{|c|c|c|c|}
\hline Models & Dimensions & Use/Features & Reference $(s)$ \\
\hline STEADY & 2 & $\begin{array}{l}\text { Recharge from Ponds and } \\
\text { Canals (steady-state } \\
\text { moisture profiles) }\end{array}$ & $\begin{array}{l}\text { Nelson and Reisenauer, } \\
1961 \text {; Nelson 1962; } \\
\text { Reisenauer 1963; Nelson } \\
\text { and Reisenauer 1963; } \\
\text { Reisenauer and Nelson } \\
\text { 1963; Reisenauer, Nelson, } \\
\text { and Knudsen 1963; Nelson } \\
1964 \text {. }\end{array}$ \\
\hline PST & 2 & $\begin{array}{l}\text { Recharge from a Tank Leak } \\
\text { (redistribution, drainage) }\end{array}$ & Reisenauer et al. 1975. \\
\hline MPHASE & 1 & $\begin{array}{l}\text { Natural Recharge (evapo- } \\
\text { ration, redistribution, } \\
\text { drainage) }\end{array}$ & $\begin{array}{l}\text { Finlayson, Nelson, and } \\
\text { Baca 1978. }\end{array}$ \\
\hline SEMTRA & 1,2 & $\begin{array}{l}\text { Natural Recharge (evapo- } \\
\text { ration, redistribution, } \\
\text { drainage) }\end{array}$ & $\begin{array}{l}\text { Baca, King, and Norton } \\
1978 \text {; Jones et a } 1981 .\end{array}$ \\
\hline FEMTRA & 2,3 & $\begin{array}{l}\text { Recharge from Water } \\
\text { Injection (redistribution, } \\
\text { drainage) }\end{array}$ & Sisson and Lu 1984 \\
\hline UNSAT & 1 & $\begin{array}{l}\text { Natural Recharge (evapo- } \\
\text { ration, transpiration, } \\
\text { redistribution, drainage) }\end{array}$ & $\begin{array}{l}\text { Gupta et a } 1 \text { 1978; Gee and } \\
\text { Kirkham } 1984 \text {; Jones, } \\
\text { Campbe } 11 \text {, and Gee } 1984\end{array}$ \\
\hline UNSAT-H & 1 & $\begin{array}{l}\text { Natural Recharge (evapo- } \\
\text { ration, transpiration, } \\
\text { redistribution, drainage) }\end{array}$ & $\begin{array}{l}\text { Fayer and Gee 1985; Fayer } \\
\text { et al. } 1985 .\end{array}$ \\
\hline UNSAT2 & 2 & $\begin{array}{l}\text { Natural Recharge (evapo- } \\
\text { ration, transpiration, } \\
\text { redistribution, drainage) }\end{array}$ & $\begin{array}{l}\text { Neuman, Feddes, and } \\
\text { Bresler 1974; Davis and } \\
\text { Neuman 1983; Fayer et al. } \\
\text { 1985. }\end{array}$ \\
\hline
\end{tabular}

\section{A.1.1 STEADY}

In the early 1960s, the need at the Hanford Site was to assess water flow from canals or ponds to the water table. The tool developed for that purpose was STEADY, described by Reisenauer (1963) as a combined saturated-unsaturated, steady-state, multidimensional model of water flow. Reisenauer's 1963 paper, in which he presented the model and methodology developed at the Hanford Site, 
won the Robert $E$. Horton Award for the outstanding contribution to the advancement of the science of hydrology during 1963. The theory and documentation for STEADY are found in Nelson (1962) and Reisenauer, Nelson, and Knudsen (1963).

Steady-state flow analysis assumes a constant source input, which means that convergence and stability are almost always guaranteed. Examples of steady flow from a ponded surface through both homogeneous and layered soils to the water table are presented by Reisenauer (1963). Other examples using STEADY to simulate the flow of water from trenches to the ground water and later to the river are presented in subsequent papers (e.g., Reisenauer and Nelson 1963; Nelson 1964). In all of these cases, evaporation, transpiration, and precipitation were considered to be zero. Although it was a major advance in hydrology at the time, the STEADY model has not been used since the $1960 \mathrm{~s}$ because it cannot solve transient flow problems.

\section{A.1.2 PST}

Tank leaks and pipeline ruptures result in pulse applications of liquid to the soil. The Partially-Saturated Transient flow model (PST) was developed to assess the redistribution and drainage in the unsaturated zone that result from these finite pulses. The theory and numerical implementation of PST are described by Reisenauer et al. (1975), but there is no formal documentation of the mode1. Initial attempts to use PST to evaluate a specific tank leak problem required such excessively long computational times that the use of PST for modeling tank leaks was abandoned. Attempts to use the model for other purposes met with mixed success. The major problems centered on the infiltration of water into dry soils and the resultant computational difficulties [an excellent discussion of this problem is presented by Finlayson, Nelson, and Baca (1978)]. The PST code was never formally verified nor was there ever any success at matching model results with field data. For these reasons, the use of the PST model was soon discontinued.

\section{A.1.3 MPHASE}

The first investigation into the theory and techniques of modeling natural recharge under Hanford Site conditions was reported by Finlayson, Nelson, and Baca (1978). Although not found in the final document, the name MPHASE 
appeared in preliminary drafts and was intended to indicate that the model could simulate nonisothermal, multiphase flow. MPHASE was developed as an experimental code to investigate the complexities of unsaturated flow in arid soils. Based on numerical experiments, the authors selected a finitedifference scheme with upstream weighting to handle the extreme nonlinearities that are associated with such processes such as infiltration into dry soil.

Model results were compared with field data from the open-bottomed lysimeter located in the 200 Area and, according to Finlayson, Nelson, and Baca only qualitative agreement was obtained. In fact, the match was quite poor. The model underpredicted total water storage by more than $10 \mathrm{~cm}$ at two times (February and April 1974) and over-predicted, by a similar amount, a profile monitored just a few months later (June 1974). Finlayson, Nelson, and Baca indicate that the code could produce stable results for only a few of the test cases. These results, together with the lack of a plant water uptake algorithm and, most importantly, the lack of published documentation, are reasons why the MPHASE code is not currently used for predicting recharge rates for Hanford Site conditions.

\section{A.1.4 SEMTRA}

Realizing the need to analyze natural recharge on the Hanford Site, Baca, King, and Norton (1978) developed the Simultaneous Energy and Moisture TRansport Analysis model, SEMTRA, which provides nonisothermal flow capabilities similar to MPHASE. The theory and governing equations are discussed by Baca, King, and Norton, but the model has never been formally documented. Two model verification tests were conducted by Baca, King, and Norton. In the first test, analytical solutions from Gibbs and Baca (1978) for both temperature and water-content profiles were compared with model results and showed apparent agreement. In the second test, isothermal infiltration data from van Genuchten (1978) were successfully simulated.

Baca, King and Norton (1978) conducted simulations of the 200-Area openbottom lysimeter for the period from November 1974 through March 1975. Although most of the simulated moisture profile matches the data on several dates, this result is of little value because the time period simulated was too short. During the 5 -month period that was simulated, most of the moisture 
profile changes were occurring in the top meter of soil, and it is in this zone that Baca, King, and Norton acknowledge "significant discrepancies" between simulated and measured moisture contents. As they point out, the lack of agreement for the top meter of the lysimeter could be the result of an inappropriate surface boundary condition (the evaporation algorithm was not described in their report). Baca, King, and Norton also simulated the heat balance of the lysimeter, but no temperature data were available for comparison.

The SEMTRA model should be applicable to sites that are bare of vegetation. However, it is expected that plants will cover all waste sites eventually. The SEMTRA model was not designed to handle plant water uptake, an important mechanism for water loss from desert soils. Because it lacks a plant water uptake capability, and because it lacks formal documentation, the SEMTRA model is not currently in use.

\section{A.1.5 FEMTRA}

According to Sisson and Lu (1984), the Finite El lement Model for TRAnsport (FEMTRA) was developed to analyze buried liquid discharges such as tank leaks. Although there is no formal documentation of the model, Sisson and Lu report that FEMTRA is a multidimensional version of the SEMTRA model. One verification test has been made by comparing two- and three-dimensional model solutions with an analytical solution for a buried point source (Warrick 1974). For short times (up to $3.84 \mathrm{~h}$ ) after injection, the match of moisture contents between analytical and numerical solutions was reported by Sisson and Lu (1984) to be satisfactory.

In a validation exercise, the liquid-flow portion of the model was tested with field data obtained from an injection test performed in the 200 Area at the Hanford Site. Because no onsite soil characterization data were available, soil data were selected from samples taken about $8 \mathrm{~km}$ away. Model-predicted moisture profiles at several depths for four injection tests were compared with measured data. Close to the injection point, the match between simulation and data was good, but further from the injection point, the match was less satisfactory. Sisson and Lu noted that the lack of important site characterization data on both soil properties and layering sequences yielded results that may 
have been fortuitous. Therefore, it is unclear whether simulating their experiment was a good test of the FEMTRA model. For the model to be tested further for use in analyzing deep unsaturated-flow problems, FEMTRA will have to be documented.

For tank leaks and similar transient-flow problems deep within the unsaturated zone, the FEMTRA model may provide adequate solutions. However, the injection test did not demonstrate FEMTRA's ability to simulate the important process of evaporation, necessary in simulating natural recharge. Also, the model does not have the ability to simulate plant water uptake. For these reasons and because of the lack of model documentation, FEMTRA is not currently in use for modeling natural recharge.

\section{A.1.6 UNSAT and UNSAT1D}

Gupta et al. (1978) developed the one-dimensional, isothermal, unsaturated flow model UNSAT for agricultural applications, specifically to simulate water and nitrogen transport under irrigated conditions. This model is applicable to a wide variety of unsaturated flow situations and has several options for describing plant water uptake and evaporation processes. Gupta et al. (1978) documented UNSAT and presented a number of applications of it to various drainage and crop growth experiments. The UNSAT1D model, which was documented by Bond, Cole, and Gutknecht (1984), is conceptually the same as UNSAT. The major differences between the two models are the input formats and the fact that Bond, Cole, and Gutknecht (1984) included a number of auxiliary programs to process input and output data. Verification tests of UNSAT1D were performed by Simmons and Cole (1985) in which comparisons of infiltration, evaporation, drainage, and redistribution processes were made between numerical simulations reported by Hillel (1977) and simulation results using UNSAT1D. The results of these comparisons indicated agreement between the models, suggesting that the mathematical equations describing flow in the unsaturated zone are adequately coded in UNSAT1D (and by inference, in UNSAT). The UNSAT model was first used at the Hanford Site in the late 1970s to evaluate water flow in the 300-Area low-level waste sites (Gee and Simmons 1979). Since that time, the UNSATID 
version has been used to assess natural recharge under bare and grass-covered sites (Jones, Campbe11, and Gee 1984; Gee and Kirkham 1984). Appendix B contains a discussion of these efforts.

\section{A.1.7 UNSAT $-\mathrm{H}$}

Predicting recharge at the Hanford Site required an unsaturated flow model more attuned to arid sites than UNSAT. Therefore, the UNSAT-H model was created by modifying UNSAT to include both isothermal vapor flow and a function representing plant water uptake (i.e., cheatgrass transpiration) specific to the Hanford Site. These and other changes to UNSAT were documented by Fayer and Gee (1985). Sections 3.0 and 4.0 of this report detail the water-flow theory and finite-difference equations used in UNSAT-H. Section 6.0 describes the input parameters required for the model.

Because the models are closely related, UNSAT $-H$ benefits from the UNSAT and UNSATID verification tests that were performed to look at infiltration, redistribution, and drainage processes. A verification test of UNSAT-H was reported by Fayer and Gee (1985) and is reproduced in Section 7.1, demonstrating that UNSAT-H simulations of infiltration are comparable to both numerical (Haverkamp et al. 1977) and analytical (Philip 1969) results from the literature.

The UNSAT-H model has been used to analyze recharge beneath the protective barriers for the Hanford Defense Waste Technology Development Program (Fayer et a1. 1985). An example application of UNSAT-H to measured field data from the 200-Area closed-bottom lysimeter is presented in Appendix B of this report. The UNSAT-H model is currently the only fully documented model in use at the Hanford Site for analyzing natural recharge. Although tailored to the Hanford Site, this model has enough general features to be useful for application at other arid sites (e.g., Idaho, Nevada) where the plant cover effects on evapotranspiration have been estimated or measured.

\section{A.1.8 UNSAT2}

For some situations deep beneath the soil surface, soil flow paths may not be strictly vertical because of either layering sequences or the presence of a protective barrier overhead. The UNSAT2 model, which is not related to UNSAT, 
UNSAT10, or UNSAT-H, is a two-dimensiona1, isotherma1, saturated-unsaturated flow model (Neuman, Feddes, and Bresler 1974) that can be used to analyze flow in such situations. In addition, UNSAT2 can simulate the important surface processes of evaporation and transpiration. Davis and Neuman (1983) documented the model and presented two comparisons with laboratory data. In these tests, the authors demonstrated that laboratory data for infiltration and redistribution could be successfully simulated with UNSAT2. However, these applications concerned very wet soil systems. How well the code operates for dry soil conditions remains to be tested.

The UNSAT2 model has been used to evaluate water flow as it occurred in two dimensions around a protective barrier (Fayer et a1. 1985). In that exercise, the evaporation and transpiration algorithms were not utilized. Instead, constant upper-boundary fluxes (i.e., recharge rates) were assumed. Fayer et al. found that the UNSAT2 model was able to describe flow when the soil had uniform properties but could not be used for layered soil conditions. That inability to model the barrier under the conditions at the Hanford Site (i.e., layered soil) resulted from two specific problems. First, the number of nodes that can be simulated is limited to about 1000 because of the amount of output per output cycle and the limitations of the machine (VAX 11/780). This reduces the level of detail that can be used to analyze a particular flow region. The second problem is related to changes in the time step, which can only be done by stopping and restarting the program. Simulations of long periods of time can require many time-step changes and thus frequent interruptions by the code operator. Because of the these problems and others, this code would require modification to make it more useful for solving unsaturated flow problems for the Hanford Site.

\section{A.2 PRESENT MODELING STATUS}

A variety of models have been used at the Hanford Site during the past 25 years to evaluate water movement in the unsaturated zone. Of the models deve1oped to predict natural recharge, some have focused on phenomena deep within the soil, such as two-phase flow and geothermal gradients, while others have focused on surface processes. The current consensus on model development at 
the Hanford Site is that a correct description of the surface processes of evaporation and transpiration is the first priority in the development of water-balance models for the Hanford Site. These processes dominate the various factors that determine the amount of recharge at a given site. Next in importance after a description of evaporation and transpiration is the description of such processes as vapor flow and coupled heat and water flow. Analyses of these processes can proceed concurrently with development of evaporation and transpiration models.

In assessing waste-management practices at the Hanford Site, only credible, fully documented models should be used. Such full documentation establishes the current state of modeling, enables outside researchers to easily review the work, and gives us a base from which to proceed with further model development. Currently, the only models that meet the documentation criterion are UNSAT-H and UNSAT2. Not only are both models fully documented, they also simulate the major processes that affect the water balance, and they have al ready been used for Hanford Site analyses.

The UNSAT-H model, which is strictly one-dimensional, is suitable for evaluating the effects of evaporation and plant water uptake on annual recharge rates. The UNSAT-H model and its precursors have a long history of verification and use that gives us some assurance that UNSAT-H is correctly coded in the computer.

The UNSAT2 mode1, which is two-dimensional, can be used to evaluate the effects of evaporation, plant water uptake, and water flow in complex geometries, but its operation has not been completely satisfactory. An enhanced capability for modeling multidimensional water flow under Hanford Site conditions is needed.

To simulate the flow regime within complex geometries requires a large number of nodes. To expect one model (e.g., UNSAT2) to handle both the surface processes and the subsurface flow field complexities may be an overextension of modeling capabilities. A preferred method is to use models such as UNSAT-H to calculate recharge rates, which then serve as input to multidimensional models that are designed to analyze subsurface unsaturated flow in complex geometries. Thus the surface and subsurface processes would both be modeled well. 
Nevertheless, UNSAT-H must undergo validation testing (as described in Appendix $B$ ) to establish its level of credibility for predicting recharge rates at the Hanford Site. In addition, if UNSAT-H is to be used for predicting long-term recharge rates, the conceptual model underlying UNSAT-H may need further revision (as discussed in Section 3.0). Therefore, the present form of the UNSAT-H model should be viewed not as a final product but as a good base from which further model development can occur.

\section{A.3 REFERENCES}

Baca, R. G., I. P. King, and W. R. Norton. 1978. Finite Element Models for Simultaneous Heat and Moisture Transport in Unsaturated Soils. RHO-SA-31, Rockwell Hanford Operations, Richland, Washington.

Bond, F. W., C. R. Cole, and P. J. Gutknecht. 1984. Unsaturated Groundwater Fl ow Model (UNSAT1D) Computer Code Manual. CS-2434-CCM, Electric Power Research Institute, Palo Alto, California.

Davis, L. A., and S. P. Neuman. 1983. Documentation and User's Guide: UNSAT2 - Variably Saturated Flow Model. NUREG/CR-3390, Nuclear Regulatory Commission, Washington, D.C.

Fayer, M. J., and G. W. Gee. 1985. UNSAT-H, An Unsaturated Soil Water Flow Code for Use at the Hanford Site: Code Documentation. PNL-5585, Pacific Northwest Laboratory, Richland, Washington.

Fayer, M. J., W. Conbere, P. R. Heller, and G. W. Gee. 1985. Model Assessment of Protective Barrier Designs. PNL-5604, Pacific Northwest Laboratory, Richland, Washington.

Finlayson, B. A., R. W. Nelson, and R. G. Baca. 1978. A Preliminary Investigation into the Theory and Techniques of Modeling the Natural Moisture Movement in Unsaturated Sediments. RHO-LD-47, Rockwell Hanford Operations, Richland, Washington.

Gee, G. W., and R. R. Kirkham. 1984. Arid Site Water Balance: Evapotranspiration Modeling and Measurements. PNL-5177, Pacific Northwest Laboratory, Richland, Washington.

Gee, G. W., and C. S. Simmons. 1979. Characterization of the Hanford 300 Area Burial Grounds. Task III - Fluid Transport and Modeling. PNL-2921, Pacific Northwest Laboratory, Richland, Washington.

Gibbs, A. G., and R. G. Baca. 1981. Analytical Models for Simultaneous Heat and Moisture Transport in Soils. RHO-LD-49, Rockwe11 Hanford Operations, Richland, Washington. 
Gupta, S. K., K. K. Tanji, D. R. Nielsen, J. W. Biggar, C. S. Simmons, and J. L. MacIntyre. 1978. Field Simulation of Soil-Water Movement with Crop Water Extraction. Water Science and Engineering Paper No. 4013, Dept. of Land, Air, and Water Resour., Univ. of Calif., Davis, California.

Haverkamp, R., M. Vauclin, J. Touma, P. J. Wierenga, and G. Vachaud. 1977. "A Comparison of Numerical Simulation Models for One-Dimensional Infiltration." Soil Sci. Soc. Am. J. 41:285-294.

Hillel, D. 1977. Computer Simulation of Soil-Water Dynamics: A Compendium of Recent Work. International Development Research Centre, Ottawa, Canada.

Jones, T. L., G. S. Campbe11, and G. W. Gee. 1984. Water Balance at a Arid Site: A Model Validation Study of Bare Soil Evaporation. PNL-4896, Pacific Northwest Laboratory, Richland, Washington.

Jones, T. L., W. A. Jordan, A. H. Lu, and J. B. Sisson. 1981. Predictions of Infiltration and Drainage Using Field and Laboratory Measured Hydraulic Parameters. RH0-SA-164, Rockwell Hanford Operations, Richland, Washington.

Nelson, R. W. 1962. Darcian Transport of Fluids in Heterogeneous Partially Saturated Porous Media 1. Mathematical and Numerical Formulation. HW-72335 (Part 1), Hanford Atomic Products Operation, Richland, Washington.

Nelson, R. W. 1964. Analysis of Waste Released by Seepage to the Columbia River from the 1301-N Crib. HW-81306, Hanford Atomic Products Operation, Richland, Washington.

Nelson, R. W., and A. E. Reisenauer. 1961. Analysis of 100-N Disposal Crib Influence on the Sanitary Tile Field. HW-70058, Hanford Atomic Products Operation, Richland, Washington.

Nelson, R. W., and A. E. Reisenauer. 1963. "Application of Radioactive Tracers in Scientific Groundwater Hydrology." In Radioisotopes in Hydrology, Proceedings Series IAEA SM-38/17, International Atomic Energy Agency, Vienna, Austria.

Neuman, S. P., R. A. Feddes, and E. Bresler. 1974. "Finite Element Simulation of Flow in Saturated-Unsaturated Soils Considering Water Uptake by Plants." Development of Methods, Tools and Solutions for Unsaturated Flow. Third Annual Report (Part 1), Technion, Israel Institute of Technology, Haifa, Israel.

Philip, J. R. 1969. "Theory of Infiltration." Adv. Hydrosci. 5:215-296.

Reisenauer, A. E. 1963. "Methods for Solving Problems of Multidimensional Partially Saturated Steady Flow in Soils." J. of Geophysical Research $68(20): 5725-5733$. 
Reisenauer, A. E., and R. W. Nelson. 1963. "Some Influences of Soils and Water Table Depths on Seepage from Lined and Unlined Canals." In Proceedings of the Seepage Symposium, pp. 68-75, ARS 41-90, Agricultural Research Service, U.S. Department of Agriculture, Beltsville, Maryland.

Reisenauer, A. E., R. W. Nelson, and C. N. Knudsen. 1963. Steady Darcian Transport of Fluids in Heterogeneous Partially Saturated Porous Media, 2, The Computer Program. HW-72335 (Part 2), Hanford Atomic Products Operation, Richland, Washington.

Reisenauer, A. E., D. B. Cearlock, C. A. Bryan, and G. S. Campbe11. 1975. Partially-Saturated Transient Groundwater Flow Model Theory and Numerical Implementation. BNWL-1713, Battelle, Pacific Northwest Laboratory, Richland, Washington.

Simmons, C. S., and C. R. Cole. 1985. Guidelines for Selecting Codes for Ground-Water Transport Modeling of Low-Level Waste Burial Sites. PNL-4980 VoT. 1, Pacific Northwest Laboratory, Richland, Washington.

Sisson, J. B., and A. H. Lu. 1984. Field Calibration of Computer Models for Application to Buried Liquid Discharges: A Status Report. RHO-ST-46P, Rockwell Hanford Operations, Richland, Washington.

van Genuchten, M. T. 1978. Mass Transport in Saturated-Unsaturated Systems, One-Dimensional Solutions. 78-WR-06, Water Resources Program, Department of Civil Engineering, Princeton University, Princeton, New Jersey.

Warrick, A. W. 1974. "Time-Dependent Linearized Infiltration, 1 Point Sources." Soil Sci. Soc. Am. Proc. 38:383-386. 
APPENDIX B

MODEL VALIDATION: AN ASSESSMENT OF CREDIBILITY 


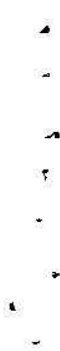


APPENDIX B

\section{MODEL VALIDATION: AN ASSESSMENT OF CREDIBILITY}

Computer models that describe the flow of water in unsaturated soils are under development as part of the Hanford Site Performance Assessment program. These models constitute some of the tools that will be used at the Hanford Site to evaluate waste disposal options, demonstrate disposal system safety, and demonstrate compliance with applicable regulations. Therefore, it is important to show that these models are valid representations of the real world, and that they can be used successfully to give some indication of future behavior. Regulators, decision makers, and the public must have some assurance that the models are correct (on some level) in their predictions. For example, the Nuclear Regulatory Commission (NRC), in the rule governing the siting of lowlevel waste sites (Radiation Protection Programs 1982), requires that models used in performance assessments give a "reasonable assurance" that their predictions are correct. Therefore, in the model development effort, there should be a strong commitment to demonstrating model credibility.

Establishing the credibility of a model is accomplished in two stages. In the first stage, called "verification," the model is checked for implementation errors (e.g., wrong units, improper coding). This checking is usually accomplished by comparing model predictions with analytical solutions to a known problem or with solutions predicted by another model that has already been verified. Verification is a necessary process that should be performed before a model is used for any purpose. The second stage in establishing model credibility is "validation," in which model predictions and experimental data are compared. In this manner, the validity of the conceptual model (which includes site characterization) of the system being simulated is tested.

In a recent report on code selection guidelines, Simmons and Cole (1985, p. 2.28) state that "A validation should be performed to test a code's ability to simulate specific processes, as observed in an actual system under controlled experimental conditions." They note that validation is not an attempt 
to test fundamental laws and equations of water flow. Furthermore, Simmons and Cole (1985, p. 2.29) state that "...a model can only project the possible future system behavior, provided all dominant factors are accounted for and actual system attributes (processes and parameters) are not modified in time (i.e., geologic and geochemical permanency)."

Construction of a modeling tool for performance assessment requires a number of steps. As conceived by Simmons and Cole (1985), these steps can be arranged in the manner illustrated in Figure B.1. Steps 8 and 9 represent model validation. In practice, model validation may include the process

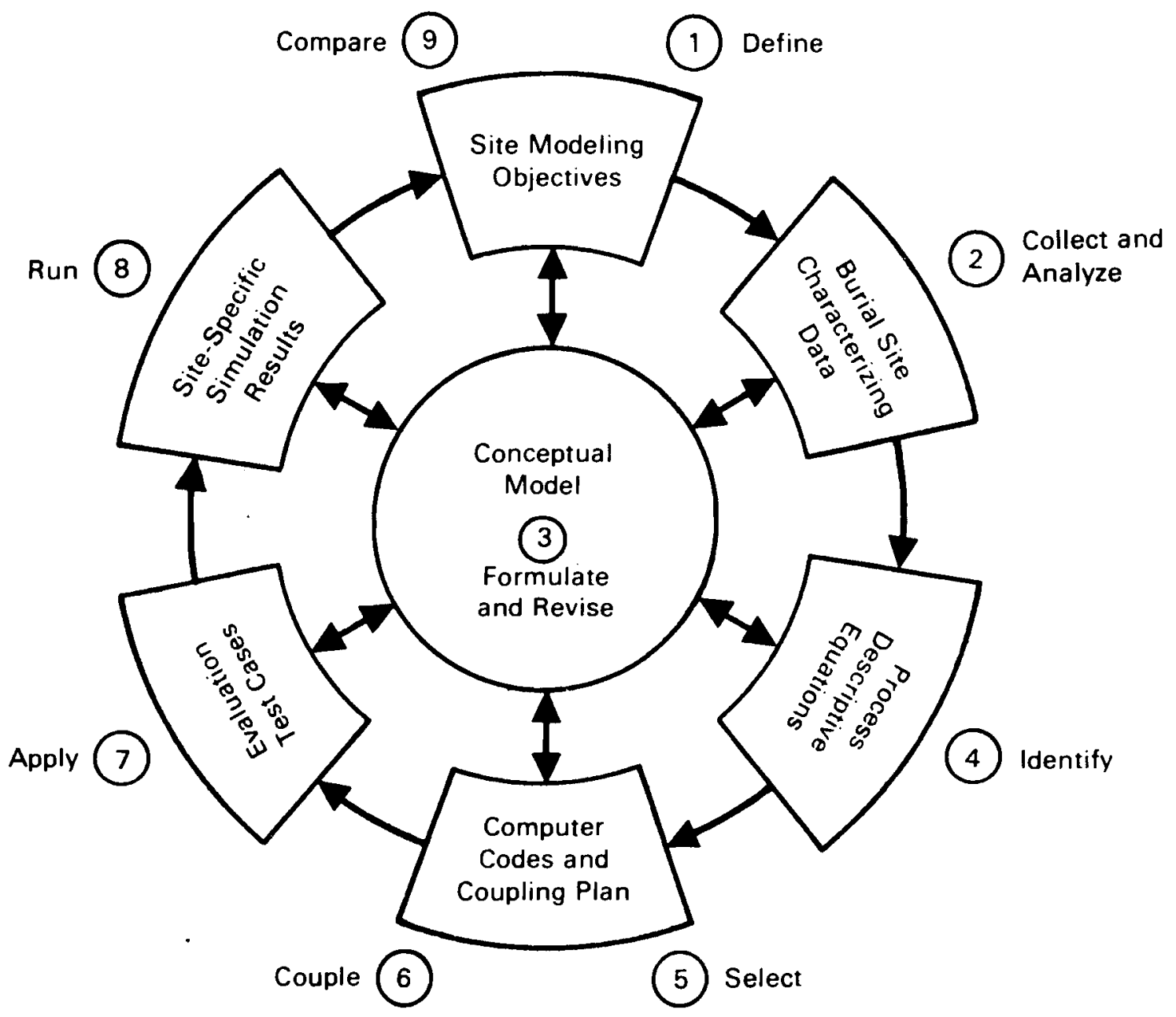

FIGURE B.1. Steps in Constructing and Validating a Model for Performance Assessment (after Simmons and Cole 1985) 
of "calibration" in which some input parameters are adjusted until the match between model predictions and measured data meets the modeling objectives. The rationale behind calibration is that there is a level of uncertainty in some of the input parameters, such as that caused by heterogeneity in soil hydraulic properties. If the match between predictions and measured data does not meet the modeling objectives specified in step 1, the input parameters are adjusted (the model is calibrated) until agreement is reached (i.e., the match meets the objectives). If agreement cannot be reached, or if agreement can be reached but the parameters as adjusted are outside the range of acceptance, then the model user must return to the conceptualization stage to revise the model or the site characterization (input data). If, after repeated passes through the calibration loop, the model user is unsuccessful at satisfying the modeling objectives, the model user should return to step 1 and reassess the overall objectives. If agreement can be reached and the parameters are within an acceptable range, then the model can be said to be validated for that system or application. When validation occurs, the model attains a higher degree of credibility than models that have not been validated for a similar system.

Enhancement of model credibility is certainly possible. A model that has been validated with three different data sets has a greater level of credibility than a model validated for only one data set. In a sense, therefore, model validation is a process rather than a single event; it is the process of establishing and building trust in the ability of a model to predict the behavior of a system. As a model is used and refined, it becomes more credible in making predictions. When the time comes to apply the model to a situation similar to one(s) for which the model has been validated, the model user has the assurance that the model will perform with some degree of reliability. It is up to the model user to decide what level of model reliability is needed for a particular task.

Historically, unsaturated flow modeling at the Hanford Site has focused on steps 3 through 7 of Figure B.1, which run from model conceptualization to computer coding and verification. Less attention has so far been focused on modeling objectives (step 1), characterization data (step 2), and model 
validation (steps 8 and 9); yet it is these steps which will ultimately be used to establish the level of model credibility. A discussion of steps $1,2,8$, and 9 in relation to modeling natural recharge at the Hanford Site follows.

\section{B.1 OBJECTIVES}

At the Hanford Site, the major objectives of the unsaturated-flow modeling effort are 1) to estimate present recharge rates, 2) to estimate future recharge rates given different conditions, and 3 ) to assist in design of wastedisposal structures intended to limit recharge (e.g., protective barriers). Recharge is considered to be the net downward flux of water at some depth below which evapotranspiration cannot cause upward migration of the water. Estimates of present recharge rates will be used to assess the transport of contaminants from waste sites to the ground water (which eventually reaches the Columbia River). Estimates of future recharge rates under different conditions, such as climatic change, plant community succession, or changing surface conditions, will aid in assessing future risk. Knowing the future risk will aid in determining when and where mitigating procedures can be practiced today to lower that future risk. Finally, model estimates of recharge will be used to help select a preferred barrier design.

Having established recharge rate estimation as the principal objective of unsaturated zone modeling (step 1 of Figure B.1), the next step in the validation process is to establish the criterion by which this objective will be met. The criterion should be a chosen level of accuracy in the recharge estimate. That level will depend on the use to which the recharge rates will be put. The most stringent requirement for accuracy will probably be for transport analyses. The accuracy requirement for design analysis, in which relative recharge rates are used, should be less stringent.

The accuracy required of the model can be estimated using relationships, such as those shown in Figure B.2, in which travel times have been plotted for various soils and recharge rates. In this example, travel time is the time it would take for water to travel from the vicinity of a waste form in the unsaturated zone to a water table located $64 \mathrm{~m}$ below. 


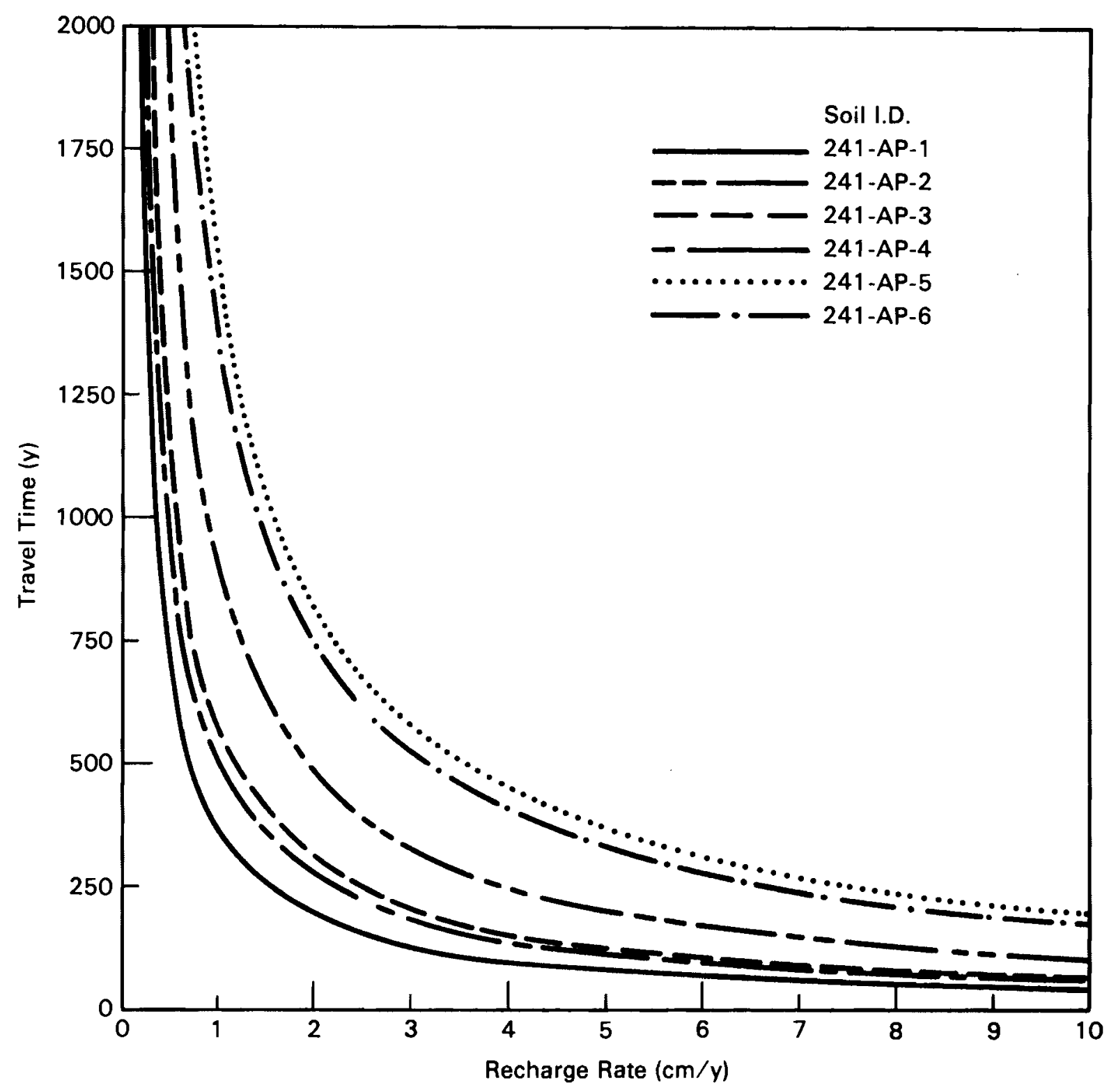

FIGURE B.2. Estimated Travel Time Through the Unsaturated Zone Beneath the 241-AP Tank Farm

Another example useful for setting an accuracy criterion is the transport analysis work done for the U.S. Department of Energy (1986). In that work, recharge through the protective barrier was assumed to be zero. Therefore, beneath the barrier, transport of waste was modeled strictly as a diffusion process, a process with extremely long travel times. However, recharge rates through the barrier as 1 ow as $0.1 \mathrm{~cm} / \mathrm{y}$ are sufficiently large that advective 
transport would be significant; hence travel times would be much shorter. To answer the question of whether advection can be neglected in the analysis may require that the model prediction of recharge through the barrier be accurate to within $0.1 \mathrm{~cm} / \mathrm{y}$.

One factor that may determine the accuracy criterion of the modeling objective a priori is the data source. If model validation must be conducted with data collected previously, the accuracy of that data will set the model's accuracy limits. If validation is to be conducted with data to be gathered in the future, the data collection effort can be designed with the desired modelaccuracy goal in mind.

\section{B.2 DATA CRITERIA}

When designing data collection and analysis efforts for model validation purposes (step 2 of Figure B.1), a set of accuracy criteria for the measured data must be established consistent with the model objectives. In other words, the water balance components ( $\Delta W, P, E, T$, and D) of Equation (3.1) and the state of the system (e.g., the moisture distribution in the profile) must be known and simulated with equal accuracy. For some cases, Equation (3.1) can be simplified to focus on a particular water-balance component. For example, bare-surface weighing lysimeters that are not drained can be used to study the evaporation process. In this situation, Equation (3.1) reduces to $E=P-\Delta W$; $T$ and $D$ are zero. Lysimeter data thus provide an opportunity to test evaporation subroutines and assure ourselves that we can model evaporation with some level of credibility. This same process can also be used to study each water balance component.

For the model to simulate the water balance components, additional data must be provided; these include precipitation data as well as the meteorological data necessary to calculate evaporation. When plants are part of the system, the model must be provided with data on the type of plants, area covered, rooting depth, and mechanisms for plant response to the environment. These additional data must also be sufficiently accurate to satisfy the accuracy criteria. 
The data collection effort will necessarily involve spatial and temporal discretizations. For some parameters, the correct discretization may not be known in advance. For instance, how often should storage in deep lysimeters be measured in a year? This is where model-validation efforts can guide data collection. As validation proceeds, the model may be shown to be sensitive to how often certain parameters are measured. In the case of deep lysimeter storage, the data-collection schedule can be adjusted to provide the needed level of temporal detail.

\section{B.3 COMPARISONS OF MODEL PREDICTIONS AND FIELD DATA}

Simulations using UNSAT1D, a code which is related to UNSAT-H (see Appendix A), have been compared with Hanford Site data. Until 1986, there had been no formal comparisons of UNSAT-H simulations and Hanford Site data (steps 8 and 9 of Figure B.1). In this section, we will briefly review two simulation

efforts using UNSATID and present an example comparing UNSAT-H simulations with the 200-Area data set. In all three cases, no quantitative criteria were established with which to judge the comparison.

\section{B.3.1 BWTF South Caisson}

Jones, Campbel1 and Gee (1984) used UNSAT1D to simulate a 1-year data set from the south caisson at the BWTF. That caisson is $7.6 \mathrm{~m}$ deep and $2.7 \mathrm{~m}$ in diameter. The measured water balance components [see Equation (3.1)] were precipitation and change in storage. They estimated drainage to be between 0 and $3 \mathrm{~cm}$ based on drainage data collected after the period simulated. Evaporation was unknown (there were no plants and thus no transpiration). Because of the uncertainty in drainage amount, Jones, Campbell and Gee could make only qualitative comparisons between model and data. They simulated $1 \mathrm{~cm}$ of drainage compared to their estimate of between 0 and $3 \mathrm{~cm}$. Of equal importance, however, was their study of rainfall distribution variations between the HMS and the BWTF. When they used the HMS precipitation data, the model simulated $1.4 \mathrm{~cm}$ more evaporation than when they used the BWTF data (15.8 versus $14.4 \mathrm{~cm}$, respectively), even though the HMS had only $0.5 \mathrm{~cm}$ more precipitation. This result illustrates the potential for loss in accuracy for just a 1-year period when offsite precipitation data are used. 


\section{B.3.2 300-Area Grass Site}

The other previous attempt to simulate Hanford Site data was by Gee and Kirkham (1984). They simulated both a 9-month and an 18-month set of data collected from the 300-Area grass site. The measured water-balance components were precipitation and change in storage. By assuming there was no net upward flux of water at the $1-m$ depth, they estimated that drainage at the site was $8.5 \mathrm{~cm}$ during a 9-month period (March to December 1983). Evaporation and transpiration were unknown. For the time period from January to October 1983, the model simulated $5 \mathrm{~cm}$ of drainage when a simplified soil description was used and only $3.5 \mathrm{~cm}$ of drainage (January to December 1983) when a more detailed soil description was used. The differences in model predictions emphasize the effects of soil layering on the final results. The underprediction of drainage may have been the result of both incomplete characterization of the soil hydraulic properties and use of an uncalibrated transpiration function.

\section{B.3.3 200-Area Closed-Bottom Lysimeter}

As an example of how previously collected data sets can still be useful, we used UNSAT-H to simulate the 200-Area closed-bottom lysimeter. A summary description of this facility is provided by Hsieh, Brownell, and Reisenauer (1973). Data from the closed-bottom lysimeter consist of a 14-year (1972 to $1985)$ record of the moisture dynamics under a specific set of conditions. As discussed in Section B.2, the paucity of plant data from this site precludes our performing a rigorous validation. In total, however, the data set does offer a qualitative record of what has occurred naturally at the site. Given that, we can model the 14-year period and compare our results with the measured data for insight into measurement needs.

For this example, we conducted two simulations, one with and one without plants, to show the effect of the presence of plants. Most of the details of the simulations (e.g., node spacing, soil properties) are identical to those given in Section 7.2. The remaining details to be provided below include initial conditions and year-to-year variations in plant activity, precipitation, and PET. The measured water-balance components are precipitation and 
change in storage. Drainage is known to be zero because the bottom of the lysimeter is sealed. The unknown components are evaporation and transpiration.

Initial gravimetric water contents were measured as a function of depth sometime around January 1972, and the values are listed by Hsieh, Brownell and Reisenauer (1973). Assuming a bulk density value of $1.6 \mathrm{~g} / \mathrm{cm}^{3}$, we converted the moisture contents to volume fractions. Using the Campbell function for soil water retention, we calculated the corresponding suction head values for use as initial conditions for UNSAT-H. Gravimetric water contents were also measured on October 7, 1985. Again using a bulk density value of $1.6 \mathrm{~g} / \mathrm{cm}^{3}$, we converted the data to volumetric fractions.

The only plant data we used that are not provided in Section 7.3 are the yearly fractions of soil surface that are bare. The bare soil fraction as a function of year is listed in Table B.1. Because there were no plants in the years 1972 and 1973, the bare soil fraction is 1.0. All other plant data remain constant from year to year.

As described in Section 7.3, hourly precipitation and meteorological data for each year of the simulation were obtained from the HMS, which is located $6.5 \mathrm{~km}$ northwest of the lysimeter site.

Year-end summaries of the simulations are provided in Tables B.2 and B.3 for the cases without and with plants, respectively. In Figure B.3, we have

TABLE B.1. Annual Bare Soil Fraction Assumed in the Simulation of the 200-Area Closed-Bottom Lysimeter

$\begin{array}{llll}\frac{\text { Year }}{1972} & \frac{\text { BARE }}{1.00} & \frac{\text { Year }}{1979} & \frac{\text { BARE }}{0.70} \\ 1973 & 1.00 & 1980 & 0.70 \\ 1974 & 0.94 & 1981 & 0.70 \\ 1975 & 0.88 & 1982 & 0.70 \\ 1976 & 0.82 & 1983 & 0.70 \\ 1977 & 0.76 & 1984 & 0.70 \\ 1978 & 0.70 & 1985 & 0.70\end{array}$


TABLE B.2. Summary of Simulations of the 200-Area Closed-Bottom Lysimeter Without Plants on the Surface (initial storage $=85.6 \mathrm{~cm}$ ).

(The mass-balance error did not exceed $0.2 \mathrm{~cm} / \mathrm{y}_{\bullet}$ )

\begin{tabular}{|c|c|c|c|c|c|c|}
\hline Year & Precip. & Drain & Evap. & $\begin{array}{c}\text { Final } \\
\text { Storage } \\
\end{array}$ & $\begin{array}{c}\text { Net } \\
\text { Storage } \\
\end{array}$ & $\begin{array}{c}\text { Net Storage } \\
\text { Since } \\
\text { Jan 1, } 1972 \\
\end{array}$ \\
\hline 1972 & 16.2 & 0.0 & 15.2 & 86.5 & 0.9 & 0.9 \\
\hline 1973 & 21.0 & 0.0 & 13.6 & 93.9 & 7.4 & 8.3 \\
\hline 1974 & 13.5 & 0.0 & 16.9 & 90.3 & -3.6 & 4.7 \\
\hline 1975 & 18.9 & 0.0 & 18.0 & 91.1 & 0.8 & 5.5 \\
\hline 1976 & 7.6 & 0.0 & 9.3 & 89.2 & -1.9 & 3.6 \\
\hline 1977 & 16.3 & 0.0 & 13.0 & 92.4 & 3.2 & 6.8 \\
\hline 1978 & 16.6 & 0.0 & 15.3 & 93.5 & 1.1 & 7.9 \\
\hline 1979 & 14.0 & 0.0 & 11.8 & 95.7 & 2.2 & 10.1 \\
\hline 1980 & 24.6 & 0.0 & 21.2 & 98.9 & 3.2 & 13.3 \\
\hline 1981 & 17.9 & 0.0 & 16.8 & 99.9 & 1.0 & 14.3 \\
\hline 1982 & 20.3 & 0.0 & 18.6 & 101.4 & 1.5 & 15.8 \\
\hline 1983 & 28.1 & 0.0 & 23.3 & 106.0 & 4.6 & 20.4 \\
\hline 1984 & 18.4 & 0.0 & 19.8 & 104.5 & -1.5 & 18.9 \\
\hline 1985 & 12.9 & 0.0 & 11.2 & 106.2 & 1.7 & 20.6 \\
\hline Total & 246.3 & 224.0 & & & & \\
\hline
\end{tabular}

Note: Simulated storage on 0ctober 7, 1985, was $103.1 \mathrm{~cm}$.

plotted simulated storage in the lysimeter for the 14-year period. Annual variations aside, note that storage in the lysimeter under the bare surface continually increases while storage under the partially vegetated surface remains essentially constant. This points out the enormous effect that vegetation has on the water balance. When the soil surface is vegetated, the available water is utilized and recharge rates can approach zero. In the absence of vegetation, storage of water in the profile increases, a condition which is conducive to increased recharge rates. Thus, any waste-management practice that entails the suppression or removal of vegetation (e.g., gravel surface cover, herbicide application) enhances the recharge rate. 
TABLE B.3. Summary of Simulations of the 200-Area Closed-Bottom Lysimeter With Plants on the Surface (initial storage $=85.6 \mathrm{~cm}$ ).

(The mass-balance error did not exceed $0.2 \mathrm{~cm} / \mathrm{y}_{.}$)

\begin{tabular}{|c|c|c|c|c|c|c|}
\hline Year & Precip. & Transp. & Evap. & $\begin{array}{c}\text { Final } \\
\text { Storage } \\
\end{array}$ & $\begin{array}{c}\text { Net } \\
\text { Storage } \\
\end{array}$ & $\begin{array}{l}\text { Net Storage } \\
\text { Since } \\
\text { Jan 1, } 1972 \\
\end{array}$ \\
\hline 1972 & 16.2 & 0.0 & 15.2 & 86.5 & 0.9 & 0.9 \\
\hline 1973 & 21.0 & 0.0 & 13.6 & 93.9 & 7.4 & 8.3 \\
\hline 1974 & 13.5 & 2.3 & 16.0 & 88.8 & -5.1 & 3.2 \\
\hline 1975 & 18.9 & 4.0 & 16.6 & 87.0 & -1.8 & 1.4 \\
\hline 1976 & 7.6 & 3.3 & 8.2 & 83.0 & -4.0 & -2.6 \\
\hline 1977 & 16.3 & 1.7 & 11.8 & 85.6 & 2.6 & 0.0 \\
\hline 1978 & 16.6 & 5.2 & 13.6 & 83.3 & 2.3 & -2.3 \\
\hline 1979 & 14.0 & 2.0 & 10.5 & 84.8 & 1.5 & -0.8 \\
\hline 1980 & 24.6 & 6.4 & 18.3 & 84.6 & -0.2 & -1.0 \\
\hline 1981 & 17.9 & 3.5 & 14.3 & 84.6 & 0.0 & -1.0 \\
\hline 1982 & 20.3 & 3.1 & 16.5 & 85.0 & 0.4 & -0.6 \\
\hline 1983 & 28.1 & 4.9 & 21.2 & 86.9 & 1.9 & 1.3 \\
\hline 1984 & 18.4 & 5.0 & 17.4 & 82.8 & -4.1 & -2.8 \\
\hline 1985 & 12.9 & 2.1 & 9.8 & 83.8 & 1.0 & -1.8 \\
\hline Total & 246.3 & 43.5 & 203.0 & & & \\
\hline
\end{tabular}

Note: Simulated storage on October 7,1985 , was $80.6 \mathrm{~cm}$.

Both the simulated and measured moisture content profiles for 0ctober 7 , 1985, are illustrated in Figure B.4. Notice that all depths of the simulated profile without plants have become wetter than the measured initial conditions. This simulated increase in water content throughout the profile represents an increase in storage of $17.5 \mathrm{~cm}$ over the 14 -year period, which, if it continued, could result in a potential recharge rate of $1.3 \mathrm{~cm} / \mathrm{y}$. The measured data, however, show that storage actually decreased by $2.8 \mathrm{~cm}$ over the same period, indicating a net loss of water from the lysimeter. The simulation with plants indicates that storage decreased by $5 \mathrm{~cm}$ for the 14 -year period, which is comparable to the $2.8-\mathrm{cm}$ decrease measured. Like the storage changes 


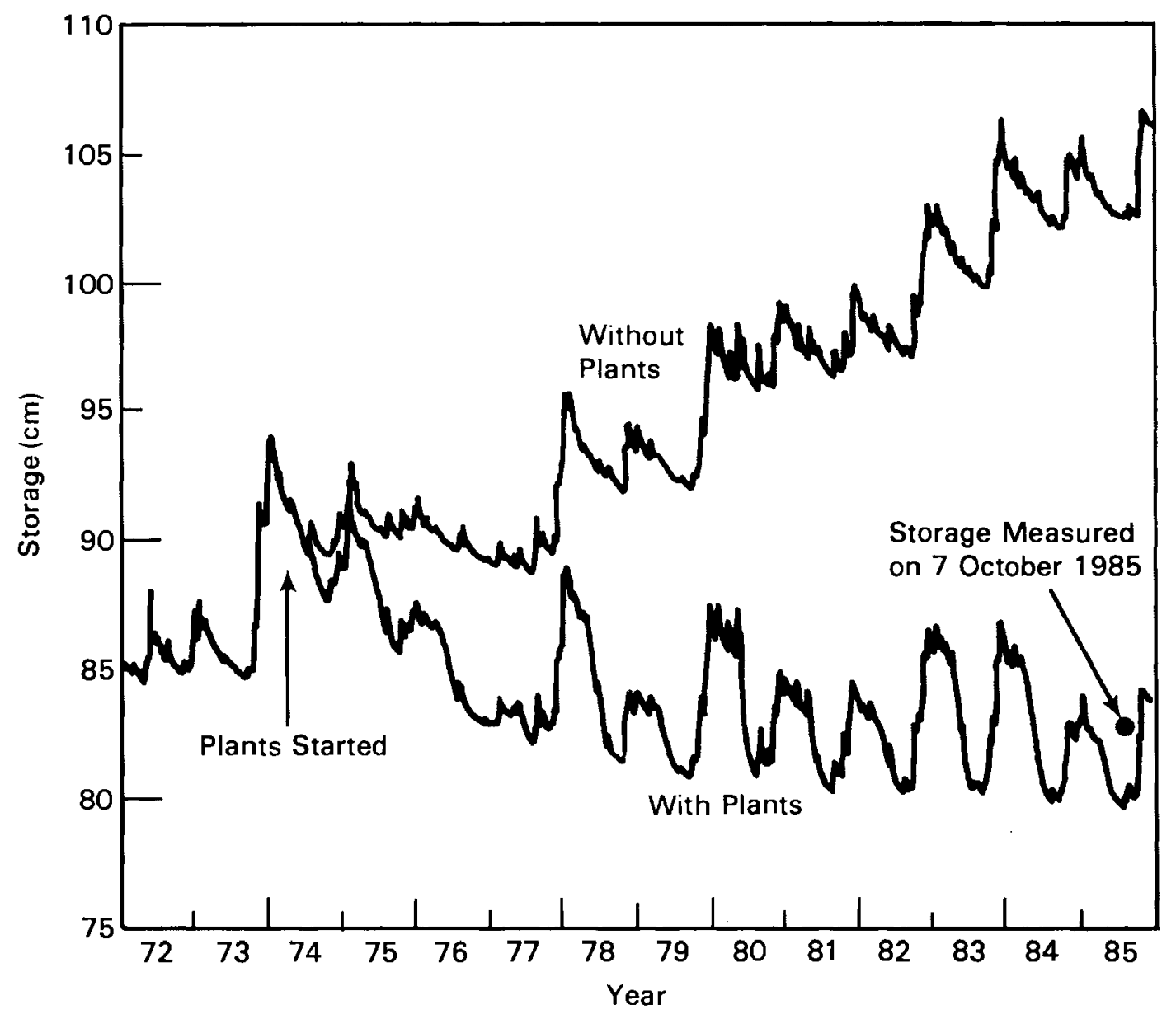

FIGURE B.3. Simulated Storage Variations in the 200-Area Closed-Bottom Lysimeter, Both With and Without Plants

in Figure B.3, the simulated moisture profile (Figure B.4) under the plant scenario more nearly coincides with the measured data than the simulated profile under the bare surface scenario.

We must stress that these results are qualitative because our representation of plants is hypothetical. The results are sufficient, however, to indicate the importance of plants in the water balance of the Hanford Site. In this particular case, plants reduced the potential recharge rate from $1.3 \mathrm{~cm} / \mathrm{y}$ to near zero by reducing the storage of water within the profile. Therefore, to quantify recharge at vegetated sites, water-balance models must include the process of plant transpiration. 


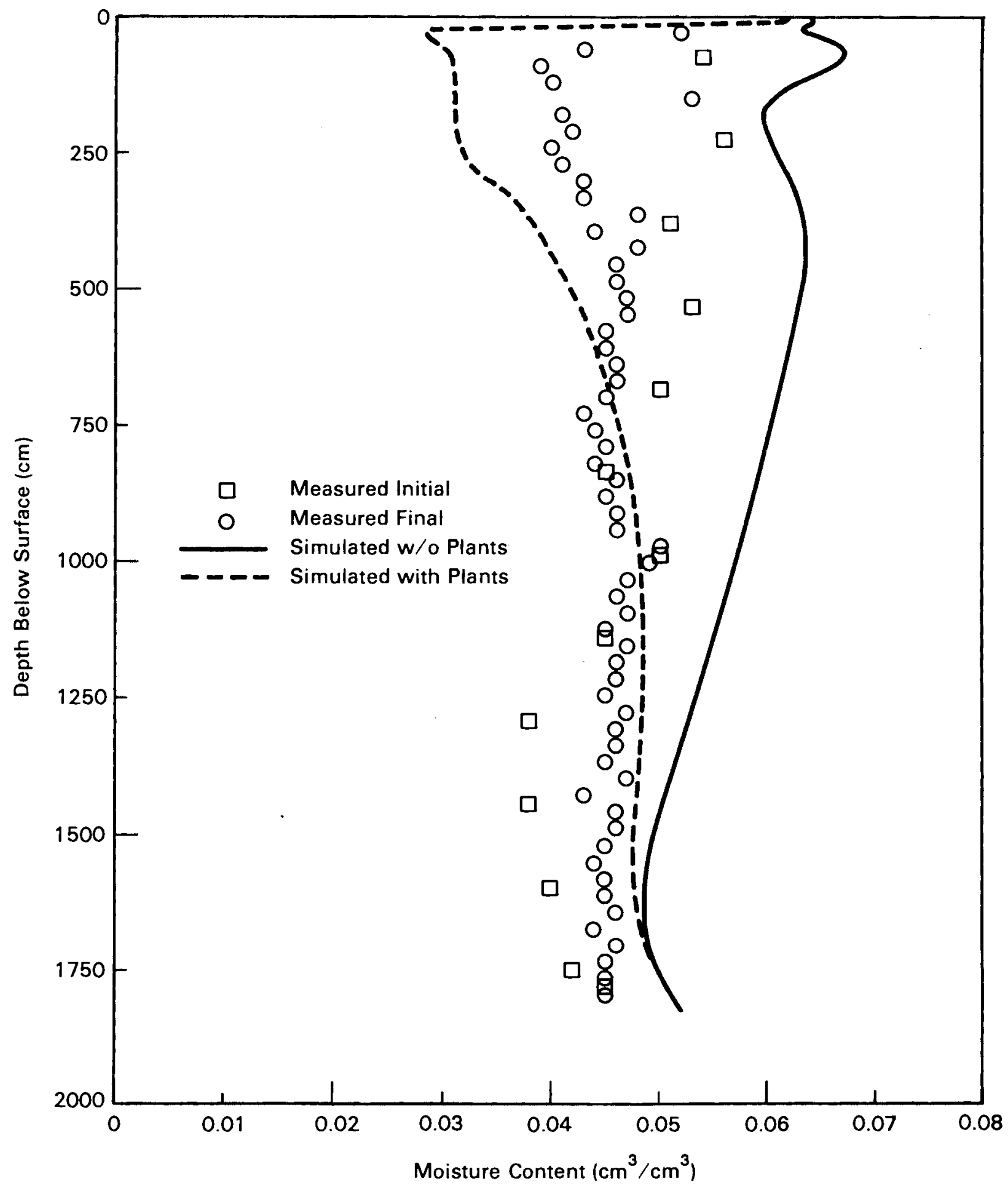

FIGURE B.4. Simulated and Measured Moisture Profiles for the 200 Area Closed-Bottom Lysimeter 


\section{B.4 REFERENCE}

Campbe11, G. S. 1977. An Introduction to Environmental Biophysics. SpringerVerlag, New York, New York.

Gee, G. W., and P. R. Heller. 1985. Unsaturated Water Flow at the Hanford Site: A Review of Literature and Annotated Bibliography. PNL-5428, Pacific Northwest Laboratory, Richland, Washington.

Gee, G. W., and R. R. Kirkham. 1984. Arid Site Water Balance: Evapotranspiration Modeling and Measurements. PNL-5177, Pacific Northwest Laboratory, Richland, Washington.

Hillel, D. 1980. Fundamentals of Soil Physics. Academic Press, New York, New York.

Hsieh, J. J. C., L. E. Browne11, and A. E. Reisenauer. 1973. Lysimeter Experiment Description and Progress Report on Neutron Measurements, BNWL-1711, Pacific Northwest Laboratory, Richland, Washington.

Jones, T. L., G. S. Campbe11, and G. W. Gee. 1984. Water Balance at an Arid Site: A Model Validation Study of Bare Soil Evaporation. PNL-4896, Pacific Northwest Laboratory, Richland, Washington.

Radiation Protection Programs, 47 Fed. Reg. 57446-57482 (December 1982).

Simmons, C. S., and C. R. Cole. 1985. Guidelines for Selecting Codes for Ground-Water Transport Modeling of Low-Level Waste Burial Sites. PNL-4980 Vol. 1, Pacific Northwest Laboratory, Richland, Washington.

Stone, W. A., J. M. Thorp, 0. P. Gifford, and D. J. Hoitink. 1983. Climatological Summary for the Hanford Area. PNL-4622, Pacific Northwest Laboratory, Richland, Washington.

U.S. Department of Energy. 1986. Draft Environmental Impact Statement, Disposal of Hanford Defense High-Level, Transuranic and Tank Wastes, Hanford Site, Richland, Washington. DOE/EIS-0113 (Vol. 3), U.S. Department of Energy, Washington, D.C. 
No. of

Copies

J. C. Corey

Savannah River National

Laboratory

P.0. Box A

Aiken, SC 29801

T. R. Thomas

Westinghouse Idaho Nuclear

Co., Inc.

P.0. Box 4000

Idaho Falls, ID 83403

Technical Library

Savannah River National

Laboratory

P.0. Box A

Aiken, SC 29081

E. M. Romney

Laboratory of Biomedical and

Environmental Sciences

University of California

at Los Angeles

Los Angeles, CA 90024

W. A. Jury

Department of Soils

University of California

at Riverside

Riverside, CA 92502

Jonathan Herrmann

Office of Solid Waste

U.S. Environmental Protection Agency

Municipal Environmental Research Laboratory

Cincinnati, $\mathrm{OH} \quad 45268$

Jack Fischer

Low-Level Radioactive Waste Program

U.S. Geological Survey

Water Resources Division

12201 Sunrise Valley Drive

Reston, VA 22092
No. of

Copies

G. A. Dinwiddie

U.S. Geological Survey

12201 Sunrise Valley Drive

Reston, VA 22092

I. J. Winograd

U.S. Geological Survey

National Center - Mail Stop 432

Reston, VA 22092

E. P. Weeks

U.S. Geological Survey

Federal Center Mail Stop 413

Denver, C0 80225

E. 0'Donnell

Earth Sciences Branch

Division of Health, Siting and Waste Management Research

U.S. Nuclear Regulatory Commission

Washington, DC 20555

T. J. Nicholson

U.S. Nuclear Regulatory

Commission

Div. of Engineering Safety

MS NL-005

Washington, DC 20555

Jeanne Rensel

High-Level Waste Management

Washington State Department

of Ecology

Mail Stop Pu II

0lympia, WA 98504

W. Brewer

Office of High-Level Nuclear Waste Management

Washington State Department of Ecology

Mail Stop PV-11

Olympia, WA 98504 
No. of

Copies

G. S. Campbell

Agronomy Department

Washington State University

Pulliman, WA 99164

Lynn Frank

Department of Energy

625 Marion Street, N.E.

Salem, OR 97310

D. Hillel

Department of Plant and Soil Science

12A Stockbridge Hall

University of Massachusetts

Amherst, MA 01003

Hanford Engineering Development

Laboratory

R. E. Lerch

4 Richland Operations Office

E. A. Bracken

C. E. Collantes

M. W. Shupe

J. D. White

26 Rockwell Hanford Operations

M. R. Adams

R. G. Baca

C. DeFigh-Price (2)

C. J. Geier (2)

W. F. Heine

H. E. McGuire

C. C. Meinhardt

K. W. Owens

S. J. Phillips

R. D. Prosser

J. F. Relyea

R. C. Routson

W. W. Schulz

J. C. Sonnichsen

J. A. Thies
No. of

Copies

D. A. Turner

T. B. Veneziano

W. J. Waugh

R. T. Wilde

G. F. Williamson

N. R. Wing

D. D. Wodrich

R. D. Wojtasek

D. E. Wood

Pacific Northwest Laboratory

P. A. Beedlow

P. E. Bramson

L. L. Cadwell

J. W. Cary

D. W. Dragnich

C. E. Elderkin

M. J. Fayer (10)

G. W. Gee (5)

M. J. Graham

L. K. Grove

H. A. Haerer

J. M. Hales

M. S. Hanson

J. N. Hartley

P. C. Hays

P. R. Heller

E. A. Jacobson

T. L. Jones

C. T. Kincaid

R. R. Kirkham

G. V. Last

J. F. McBride

I. C. Nelson

A. E. Reisenauer

L. E. Rogers

R. J. Serne

C. S. Simmons

R. L. Skaggs

J. A. Stottlemyre

G. P. Streile

M. B. Walter

R. E. Wildung

Technical Information (5)

Publishing Coordination (2) 
No. of

Copies

OFFSITE

ONSITE

M. J. Barainca, Program Manager

Low-Level Waste Management Program

Idaho Operations Office

U.S. Department of Energy

550 Second Street

Idaho Falls, ID 83401

R. Boland

Waste Management Project Office

Nevada Operations Office

U.S. Department of Energy

P.0. Box 14100

Las Vegas, NV 89114

T. C. Chee

Research and Management Division

Office of Defense Waste and

Transportation Management

DP-123, A237

19901 Germantown Road

Germantown, MD 20545

B. W. Church, Director

Health Physics Division

Nevada Operations Office

U.S. Department of Energy

P.0. Box 14100

Las Vegas, NV 89114

G. H. Daly, Acting Director

Waste and Research Development

Division

Office of Defense Waste and

Transportation Management

DP-123, A237

19901 Germantown Road

Germantown, MD 20545
No. of

Copies

F. Gorup, Program Manager

Nuclear Waste Management Group

Chicago Operations Office

U.S. Department of Energy

9800 South Cass Avenue

Argonne, IL 60439

E. A. Jordan

Low-Level Waste Program

Manager

Division of Storage and Treatment Projects

NE-25 (GTN)

U.S. Department of Energy

Washington, DC 20545

J. W. Healy

51 Grand Canyon Drive

Los Alamos, NM 87544

0. D. Markham

U.S. Department of Energy

Idaho Operations Office

Radiological and Environmental Sciences Laboratory

Idaho Falls, ID 83401

R. L. Walters

Ecological Research Division ER-75

Office of Health and Environmental Research, OER

U.S. Department of Energy

Washington, DC 20545

30 DOE Technical Information Center

Technical Library

Argonne National Laboratory

Argonne, IL 60439

F. L. Parker

4400 Iroquois

Nashville, TN 37205 
No. of

Copies

Scott Tyler

Desert Research Institute

P.0. Box 60220

Reno, NV 89506

E. A. Jennrich

Low-Level Management

Program

EG\&G Idaho, Inc.

P.0. Box 1625

Idaho Falls, Idaho 83415

Environmental Protection Agency

Technology Assessment Division

Office of Radiation Programs

Washington, D.C. 20460

Technical Library

Idaho National Engineering

Laboratory

Idaho Falls, Idaho 83401

T. E. Hakonson

Los Alamos National Laboratory

P.0. Box 1663

Los Alamos, NM 87545

J. W. Nyhan

Los Alamos National Laboratory

P. 0. Box 1663

Los Alamos, NM 87545

J. G. Steger

Los Alamos National Laboratory

P. 0. Box 1663

Los Alamos, NM 87545

Technical Library

Los Alamos National Laboratory

P.0. Box 1663

Los Alamos, New Mexico 87545

National Academy of Sciences

National Research Council

2101 Constitution Avenue

Washington, DC 20418
No. of

Copies

\author{
Dan Stephens \\ Dept. of Geosciences \\ New Mexico Institute of Mining \\ and Technology \\ Socorro, NM 87801 \\ P. J. Wierenga \\ Dept. of Soil Science \\ New Mexico State University \\ Las Cruces, NM 88004 \\ J. S. Baldwin \\ Low-Level Waste Management \\ Program \\ Oak Ridge National Laboratory \\ P.0. Box X \\ Oak Ridge, TN 37830 \\ L. J. Mezga, Program Manager \\ Low-Level Waste Management \\ Program \\ Oak Ridge National Laboratory \\ P.0. Box X \\ Oak Ridge, TN 37830 \\ Technical Library \\ Oak Ridge National Laboratory \\ P.0. Box $X$ \\ Oak Ridge, Tennessee 37830 \\ E. W. Kendall \\ Waste Management Project Manager \\ REECO \\ P.0. Box 642 \\ Mercury, NV 89023 \\ J. J. Blakeslee, Program Manager \\ Nuclear Waste Processing \\ Rockwell International \\ P.0. Box 464 \\ Golden, CO 80401 \\ C. E. Wickland \\ Manager, Waste Operations \\ Rockwell International \\ Rocky Flats Plant \\ P.0. Box 464 \\ Golden, C0 80401
}

